\title{
Lori Blondeau:
}

\section{High-Tech Storytelling for Social Change}

\author{
by \\ Carla Taunton \\ School for Studies in Art and Culture
}

Thesis submitted to the Faculty of Graduate Studies and Research, in partial fulfillment of the requirement for the Degree of Master of Arts

Faculty of Arts and Social Sciences

\author{
Carleton University \\ Ottawa, Canada
}

September, 2006

(C) Carla Taunton 


$\begin{array}{ll}\begin{array}{l}\text { Library and } \\ \text { Archives Canada }\end{array} & \begin{array}{l}\text { Bibliothèque et } \\ \text { Archives Canada }\end{array} \\ \begin{array}{l}\text { Published Heritage } \\ \text { Branch }\end{array} & \begin{array}{l}\text { Direction du } \\ \text { Patrimoine de l'édition }\end{array} \\ \begin{array}{l}\text { 395 Wellington Street } \\ \text { Ottawa ON K1A ON4 }\end{array} & \begin{array}{l}\text { 395, rue Wellington } \\ \text { Ottawa ON K1A ON4 } \\ \text { Canada }\end{array}\end{array}$

Your file Votre référence ISBN: 978-0-494-26932-9 Our file Notre référence ISBN: 978-0-494-26932-9

NOTICE:

The author has granted a nonexclusive license allowing Library and Archives Canada to reproduce, publish, archive, preserve, conserve, communicate to the public by telecommunication or on the Internet, loan, distribute and sell theses worldwide, for commercial or noncommercial purposes, in microform, paper, electronic and/or any other formats.

The author retains copyright ownership and moral rights in this thesis. Neither the thesis nor substantial extracts from it may be printed or otherwise reproduced without the author's permission.
AVIS:

L'auteur a accordé une licence non exclusive permettant à la Bibliothèque et Archives Canada de reproduire, publier, archiver, sauvegarder, conserver, transmettre au public par télécommunication ou par l'Internet, prêter, distribuer et vendre des thèses partout dans le monde, à des fins commerciales ou autres, sur support microforme, papier, électronique et/ou autres formats.

L'auteur conserve la propriété du droit d'auteur et des droits moraux qui protège cette thèse. $\mathrm{Ni}$ la thèse ni des extraits substantiels de celle-ci ne doivent être imprimés ou autrement reproduits sans son autorisation.
In compliance with the Canadian

Privacy Act some supporting forms may have been removed from this thesis.

While these forms may be included in the document page count, their removal does not represent any loss of content from the thesis.
Conformément à la loi canadienne sur la protection de la vie privée, quelques formulaires secondaires ont été enlevés de cette thèse.

Bien que ces formulaires aient inclus dans la pagination, il n'y aura aucun contenu manquant.

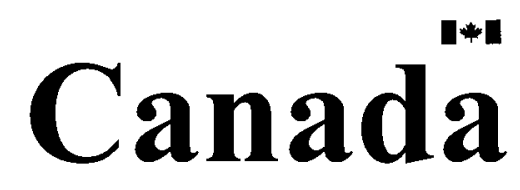




\begin{abstract}
This thesis explores the artistic practice of Cree/Saulteaux performance artist Lori Blondeau. The performance art of Lori Blondeau contributes to the discourse of Aboriginal sovereignty, reclaiming Aboriginal women's identities from Eurocentric colonial representations and popular culture's stereotypes. Her performances share Aboriginal stories and colonial histories to negotiate an indigenized space for discussion of Aboriginal perspectives. Through the lens of indigenous self-determination and empowerment, Blondeau shares her family's stories, which can be situated within the larger context of Canadian Aboriginal history. I examine Lori Blondeau's high-tech storytelling performance practice, illustrating her fusion of Aboriginal storytelling with performance art. Her work is explored as a decolonizing artistic practice, staging sites for cultural resistance.
\end{abstract}




\section{Acknowledgements}

I would like to thank my co-thesis supervisors, Dr. Allan J. Ryan and Dr. Ming Tiampo for their encouragement and suggestions in the development of this work and in the process of writing this thesis. I would also like to thank Lynda Muir for her valued input. I acknowledge Lori Blondeau and her work as inspiration for this thesis.

Many people have supported me during the research, writing, and preparation process. First, I would like to thank my family, my parents Jack and Cheryl Taunton, my sister Kristen Taunton, and my Nana Catherine Rankine Purdy for their unconditional support and encouragement. I would also like to acknowledge Kellie Davidson, Nicole Perry, and Geny Hicks for being there for me throughout this process. I acknowledge my fellow graduate students, Catherine Hale, Anne De Stetcher, Heather Igloliorte and Michelle McGeough as ever present advisors and for sharing their wisdom with me. 


\section{Table of Contents}

$\begin{array}{ll}\text { Abstract } & \text { ii }\end{array}$

$\begin{array}{ll}\text { Acknowledgments } & \text { iii }\end{array}$

Table of Contents iv

List of Illustrations $\quad \mathrm{v}$

Preface $x$

$\begin{array}{lll}\text { Chapter One } & \text { Introduction } & 1\end{array}$

Chapter Two Setting the Stage: Historical Continuum of 23 Aboriginal Performance Art

Chapter Three $\quad$ Reclaiming the Story: Lori Blondeau's 58

High-Tech Storytelling Practice

Chapter Four Lori Blondeau's High-Tech Storytelling for the 98

Decolonization of Aboriginal Women's Identities

$\begin{array}{ll}\text { Conclusion } & 132\end{array}$

$\begin{array}{ll}\text { Endnotes } & 137\end{array}$

Bibliography 156

$\begin{array}{ll}\text { Illustrations } & 172\end{array}$ 


\section{List of Illustrations}

Figure 1: Lori Blondeau, Are You My Mother? Performance still, 2000; rpt. in Lynne Bell, "Scandalous Personas, Difficult Knowledge, Restless Images," Canadian Art vol. 21 no. 4(Winter 2004): 51.

Figure 2: Lori Blondeau, Sisters. Performance still, 2000; rpt. in Lynne Bell, "Scandalous Personas, Difficult Knowledge, Restless Images." Canadian Art vol.21 no. 4 (Winter 2004): 52.

Figure 3: Lori Blondeau, CosmoSquaw,1996; rpt. in Lynne Bell, "Scandalous Personas, Difficult Knowledge, Restless Images." Canadian Art vol.21 no. 4 (Winter 2004): 50 .

Figure 4: Lori Blondeau, Lonely Surfer Squaw. Colour tinted photograph, 1996; rpt. in Lynne Bell, "Scandalous Personas, Difficult Knowledge, Restless Images." Canadian Art. vol.21 no. 4 (Winter 2004):53.

Figure 5: Lori Blondeau, Betty Daybird. Performance still. 2000. in Amy Sara Carroll, Performing Body-Politics: Belle Rogue's Collection's Runway Interventions. (Regina: Neutral Ground Gallery, 2000) 44.

Figure 6: Lori Blondeau, Belle Sauvage, Performance still, 2002. in Gordon Shelgrove Gallery Archive, University of Saskatchewan: http://www.usask.ca/snelgrove/mfa/02 LB/08.html

Figure 7: Pauline Johnson (1861-1913), "Mohawk poet and performer" photograph c. 1904; Provincial Archives of British A-09684.

Figure 8: Amelia Productions, 100 Aboriginal Women at DIA Vancouver, Video still, 1981; rpt. in Tagny Duff, "FFWD, RWD, and PLAY: Performance Art, Video, and Reflections on Second-Wave Feminism in Vancouver 1973-1983," in Caught in the Act: An Anthology of Performance art by Canadian Women, eds., Tanya Mars and Johanna Householder (Toronto: YYZ Books, 2004) 51.

Figure 9: Rebecca Belmore Fountain, video still, 2005. in Jann LM Bailey and Scott Watson, Rebecca Belmore: Fountain [exhibition catalogue] (Kamloops Art Gallery and The Morris and Helen Belkin Art Gallery), cover page.

Figure 10: "Rebecca Belmore's Fountain" Cover of Canadian Art vol. 22 no. 2 (Summer 2005).

Figure 11: "Lori Blondeau as Belle Sauvage" Cover of Canadian Art vol. 21 no. 4 (Winter 2004).

Figure 12: Rebecca Belmore Exhibit 671b, Performance still (January 12, 1988), 
Thunder Bay Art Gallery; rpt. in Charlotte Townsend-Gault, "Having Voices and Using Them: First Nations Artists and 'Native Art'," Arts Magazine vol. 65 (February 1991):65.

Figure 13: James Luna, Emandatio, Performance still, Venice Biennale Performance, 2005; rpt. in http://www.artnet.com/magazine/reviews/walrobinson/robinson6-10-05.asp

Figure 14: Coco Fusco and Guillermo Gomez-Pena, Two Amerindians, Performance still, 1992; rpt. in Marvin Carlson, Performance: A Critical Introduction (London and New York: Routledge, 2004) 201.

Figure 15: James Luna, Shameman, Performance still, 2000. rpt. in www.collections.ic.gc.ca/artists/luna img.html

Figure 16: Rebecca Belmore, Fountain, Performance still, 2005; rpt. in Jann L.M. Bailey and Scott Watson, Rebecca Belmore: Fountain [exhibition catalogue] (Kamloops Art Gallery and The Morris and Helen Belkin Art Gallery, 2005).

Figure 17: Rebecca Belmore, Fountain, Performance still, 2005; rpt. in Jann L.M. Bailey and Scott Watson, Rebecca Belmore: Fountain [exhibition catalogue] (Kamloops Art Gallery and The Morris and Helen Belkin Art Gallery, 2005).

Figure 18: Rebecca Belmore, Fountain, Performance still, 2005; rpt. in Jann LM Bailey and Scott Watson, Rebecca Belmore: Fountain [exhibition catalogue] (Kamloops Art Gallery and The Morris and Helen Belkin Art Gallery, 2005).

Figure 19: Rebecca Belmore, Fountain, Performance still, 2005; rpt. in Jann LM Bailey and Scott Watson, Rebecca Belmore: Fountain [exhibition catalogue] (Kamloops Art Gallery and The Morris and Helen Belkin Art Gallery, 2005).

Figure 20: Rebecca Belmore, Fountain, Performance still, 2005; rpt. in Jann LM Bailey and Scott Watson, Rebecca Belmore: Fountain [exhibition catalogue] (Kamloops Art Gallery and The Morris and Helen Belkin Art Gallery, 2005).

Figure 21: Rebecca Belmore, Ayumee-aawach Oomama-mowan: Speaking to Their Mother, Performance still, 1991. rpt. in Lee- Ann Martin, "The Waters of Venice: Rebecca Belmore at the 51 ${ }^{\text {st }} \quad$ Biennale," Canadian Art vol. 22 no. 2 (Summer 2005):53.

Figure 22: Rebecca Belmore, Mawa-che-hitoowin: A Gathering of People for Any Purpose, installation, mixed media, 1992; rpt. in Janet Berlo and Ruth Phillips, Native North American Art (Oxford: Oxford University Press, 1998) 237.

Figure 23: Rebecca Belmore, Named and UnNamed: Vigil Performance, performance still; in Charlotte Townsend-Gault, The Named and the UnNamed [exhibition catalogue] (Vancouver: Morris and Helen Belkin Art Gallery, 2002): 20.

Figure 24: Lori Blondeau, SurferSquaw Catch, Photograph,1996; in 
http://www.mawa.ca/archives/postcards/lorib/lb5.html

Figure 25: Lori Blondeau, Surfer Squaw Surf-Up, Photograph, 1996; in http://www.mawa.ca/archives/postcards/lorib/lb5.html

Figure 26: Lori Blondeau, Surfer Squaw Grease, Photograph, 1996; in http://www.mawa.ca/archives/postcards/lorib/lb5.html

Figure 27: Lori Blondeau and $7^{\text {th }}$ Generation of Image Makers, Streetwise Poster Campaign, Poster Reproduction, 2004; in http://www.photobasedart.ca/html/publications/essays/ESY0406.html

Figure 28: Lori Blondeau and $7^{\text {th }}$ Generation of Image Makers, Streetwise Poster Campaign, Toronto part of Planet Indigenous Festival, 2004; in http://www.photobasedart.ca/html/publications/essays/ESY0406.html

Figure 29: Thomas Moore, before and after his entrance into the Regina Indian Residential School in Saskatchewan, photograph, 1874; Library and Archives Canada NL-022474

Figure 30: Lori Blondeau, Sisters, Performance still, 26 September, 2002. America Remixed Exhibition, Milan Italy; in City of Milan Archive La Fabbrica del Vapora www.fabbricadelvapore.org/it/foto.show.php2?k=75

Figure 31: Lori Blondeau, Sisters. Performance still, 2002; in Gordon Shelgrove Gallery Archive, University of Saskatchewan: http://www.usask.ca/snelgrove/mfa/02 LB/08.html

Figure 32: Lori Blondeau, Sisters. Performance still, 2002; in Gordon Shelgrove Gallery Archive, University of Saskatchewan: http://www.usask.ca/snelgrove/mfa/02 LB/08.html

Figure 33: Lori Blondeau, Sisters, Performance still, 2002; in Gordon Shelgrove Gallery Archive, University of Saskatchewan: http://www.usask.ca/snelgrove/mfa/02_LB/08.html

Figure 34: Lori Blondeau, Materials used in Sisters, Digital photograph, March 22, 2002 at Gallery One One One: Wintercount walkabout Winnipeg. http://www.umanitoba.ca/schools/art/galleryoneoneone/winter.html

Figure 35: Lori Blondeau, Sisters, Performance still, November 29, 2002.Grunt Gallery, Vancouver: First Nations Performance Archive. www.grunt.bc.ca/fnp/ or www.grunt.bc.ca/IndianAct//

Figure 36: Lori Blondeau, Sisters, Performance still, November 29, 2002. Grunt Gallery, Vancouver: First Nations Performance Archive. www.grunt.bc.ca/fnp/ or 
www.grunt.bc.ca/IndianAct/

Figure 37: Lori Blondeau, Sisters, Performance still, November 29, 2002. Grunt Gallery, Vancouver: First Nations Performance Archive. www.grunt.bc.ca/fnp/ or www.grunt.bc.ca/IndianAct/

Figure 38: Lori Blondeau, Sisters, Performance still, November 29, 2002. Grunt Gallery, Vancouver: First Nations Performance Archive. www.grunt.bc.ca/fnp/ or www.grunt.bc.ca/IndianAct/

Figure 39: Lori Blondeau, Sisters, Performance still, November 29, 2002. Grunt Gallery, Vancouver: First Nations Performance Archive. www.grunt.bc.ca/fnp/ or www.grunt.bc.ca/IndianAct/

Figure 40: Nanoochee, colour print. rpt. in Gail Guthrie Valaskakis, Indian Princesses and Cowgirls: Stereotypes from the Frontier (Montreal: Oboro, 1992),13.

Figure 41: Daughters of the Incas, Printed by Bwon and Bigelow, St. Paul, Minnesota, 1929. rpt. in Gail Guthrie Valaskakis, Indian Princesses and Cowgirls:

Stereotypes from the Frontier (Montreal: Oboro, 1992), 24.

Figure 42: Shelley Niro, Mohawks in Beehives 1,1991. black and white hand tinted photograph, $20 \times 25 \mathrm{~cm}$. in Allan J. Ryan, The Trickster Shift: Humour and Irony in Contemporary Native Art (Vancouver: UBC Press, 1999), 70.

Figure 43: Jim Logan, Venus Myth, multi-media, 1993; rpt. in Allan J. Ryan, The Trickster Shift: Humour and Irony in Contemporary Native Art (Vancouver: UBC Press, 1999),81.

Figure 44: Lori Blondeau, Some Kinda Princess. Photograph,1999. rpt. in Lynne Bell, "Scandalous Personas, Difficult Knowledge, Restless Images." Canadian Art. vol.21 no. 4 (Winter 2004): 48 .

Figure 45: Images of Walt Disney's 1995 Pocahontas

Figure 46: Lori Blondeau, Betty Daybird: Belle Rogue's Collection's Runway Interventions, Performance still, 2000. Regina: Neutral Ground Gallery; in http://www.neutralground.sk.ca//assets $2004 /$ movies/br excerpt 4.mov

Figure 47: Lori Blondeau, Betty Daybird, 2000. in Carroll, Amy Sara. Performing Body Politics: Belle Rogue's Collection's Runway Interventions. (Regina: Neutral Ground Gallery, 2000), 45.

Figure 48: Lori Blondeau, Betty Daybird: Belle Rogue's Collection's Runway Interventions, Performance still, 2000. Regina: Neutral Ground Gallery; in http://www.neutralground.sk.ca//assets2004/movies/br excerpt 4.mov 
Figure 48: Lori Blondeau, Betty Daybird: Belle Rogue's Collection's Runway Interventions, Performance still, 2000. Regina: Neutral Ground Gallery; in http://www.neutralground.sk.ca//assets2004/movies/br excerpt 4.mov

Figure 49: Lori Blondeau, Betty Daybird: Belle Rogue's Collection's Runway Interventions, Performance still, 2000. Regina: Neutral Ground Gallery; in http://www.neutralground.sk.ca//assets2004/movies/br excerpt 4.mov

Figure 50: Lori Blondeau, Betty Daybird: Belle Rogue's Collection's Runway Interventions, Performance still, 2000. Regina: Neutral Ground Gallery; in http://www.neutralground.sk.ca//assets2004/movies/br excerpt 4.mov

Figure 51: Lori Blondeau, Betty Daybird: Belle Rogue's Collection's Runway Interventions, Performance still, 2000. Regina: Neutral Ground Gallery; in http://www.neutralground.sk.ca//assets $2004 /$ movies/br excerpt 4.mov

Figure 52: Lori Blondeau, Betty Daybird: Belle Rogue's Collection's Runway Interventions, Performance still, 2000. Regina: Neutral Ground Gallery; in http://www.neutralground.sk.ca//assets2004/movies/br excerpt 4.mov

Figure 53: Lori Blondeau, Betty Daybird: Belle Rogue's Collection's Runway Interventions, Performance still, 2000. Regina: Neutral Ground Gallery; in http://www.neutralground.sk.ca//assets2004/movies/br excerpt 4.mov

Figure 54: Lori Blondeau, Betty Daybird: Belle Rogue's Collection's Runway Interventions, Performance still, 2000. Regina: Neutral Ground Gallery; in http://www.neutralground.sk.ca//assets2004/movies/br excerpt 4.mov

Figure 55: Lori Blondeau, Betty Daybird. Photograph. In Belle Rogue Fashion Show performance. rpt. in Amy Sảra Carroll, Performing Body Politics: Bell Rogue's Collection's Runway Interventions, (Regina: Neutral Ground Gallery, 2000),44.

Figure 56: Lori Blondeau, Belle Sauvage, Six Colour Silkscreen print. 22" x 30", 2002 http://www.banffcentre.ca/va/art editions/blondeau l.asp

Figure 57: Lori Blondeau. Belle Sauvage. Performance still. rpt. in Lynne Bell, "Scandalous Personas, Difficult Knowledge,Restless Images," Canadian Art vol. 21. no. 4 (Winter 2004):51.

Figure 58: Lori Blondeau, Belle Sauvage, Photograph, 1999. rpt in Lynne Bell, "Scandalous Personas, Difficult Knowledge, Restless Images." Canadian Art vol.21 no. 4 (Winter 2004): 48.

Figure 59: Doris Day, Calamity Jane, 1953 Warner Brothers Film Production. rpt. in http://www.dorisdaytribute.com/movies-calamityjane.htm 


\section{Preface}

\section{Jeanette C. Armstrong, I am Indian Woman ${ }^{1}$ (Okanagan)}

I am a squaw

A heathen

A savage

basically a mammal

I am a female

only in the ability

to breed

and bear papooses

to be carried

quaintly

on a board

or lost

to welfare

I have no feelings

The sinuous plains of my

brown body

Carry no hint

Of the need

To be caressed

Desired

Loved

Its only use

To be raped

Beaten and bludgeoned

in some

B-grade western

I have no beauty

The lines

cut deep

into my aged face

are not from bitterness

or despair

at seeing my clan destroyed one by one

they are here

to be painted or

photographed

sold

and hung on lawyers walls

I have no emotions

The husky laughter

A brush of wings

Behind eyes

soft and searching

lightly touching others

is not from caring

but from the ravaged

beat of black wings

rattling against the bars

of an insanity

that tells me

something is wrong here

Some one is lying.

I am Indian Woman

Where I walk

beauty surrounds me

grasses bend and blossom

over valleys and hills

vast and mulitcolored

in starquilt glory

I am the keeper of generations

I caress the lover gently croon as I wrap the baby with quietness I talk

to the old ones and carefully

lay to rest

loved ones

I am the strength

of nations

I sing to the whispering autumn winds

in the snow

I dance

slowly

filling my body

with power

feeling it

knowing it

I am the giver of life to

whole tribes

I carry the seeds

Carefully through dangerous

wastelands

give then life

scattered

among cold and towering

concrete

watch them grow

battered and crippled

under all the lies

I teach them the songs

I help them to hear

I give them truth

I am a sacred trust

I am Indian woman 
This poem by Okanagan storyteller Jeanette Armstrong positions my thesis within the larger discourse of Aboriginal ${ }^{2}$ storytelling and sheds light on the powerful role the story can play for contemporary indigenous communities. This poem reveals the impact of colonial histories and dominant representations on Aboriginal peoples, while at the same time sharing Aboriginal cultural knowledge. It also emphasizes the purpose of my thesis, which is to explore the role of the Aboriginal artist in a postcolonial society. Armstrong's powerful words reveal the impact of colonial representations on Aboriginal peoples' identities, and they illustrate how storytelling can be used for staging resistance and interventions, while also sharing self-understanding and empowerment. This thesis explores the work of Cree/Saulteaux performance artist Lori Blondeau. Her high-tech storytelling performance practice will be discussed as contributing to the discourse of Aboriginal sovereignty, reclaiming Aboriginal women's identities from Eurocentric representations and popular culture's stereotypes of the Indian princess ${ }^{3}$ and squaw. Her work generates questions in relation to the legacies of colonial impact on contemporary socio-cultural realities. Similar to Armstrong's words which engage her reader by contradicting the dominant society's definitions of the 'Indian woman', Blondeau's performances reclaim, in order to re-position, the role and image of Aboriginal women from an indigenous perspective.

I was drawn to this topic by my interest in the relationship between art and politics. Fundamentally, I am interested in exploring art as a vehicle for voicing political resistance and one that offers possibilities for social change. As Edward Said notes, one of the significant roles of the intellectual is to provide a counterpoint, by means of storytelling, to inform society of the atrocious nature of domination and marginalization 
and to remind everyone that the subjects discussed and interpreted are people. ${ }^{4}$

My interpretations of Blondeau's performances attempt to show her participation in the processes of decolonization. These analyses are generated with an awareness that her practice is based in a cultural tradition that is not my own. The purpose of this thesis is to contribute to the discussion of Aboriginal performance art, as a well-established artistic medium that continues to gain national recognition. However, the body of critical writing that discusses and analyses Aboriginal performance art is a developing academic discourse. This thesis intends to contribute to the discussion of Aboriginal art, while acknowledging the larger discourse of the postcolonial Canadian context. 


\section{Chapter 1 Introduction}

Weaving the lessons, values, and oratory of her grannies, utilizing the natural prose inherent in oral history and the tradition of teaching through the use of story, combined with her own poetic visions, has given rise to unique and significant contributions to [the] collective search for a path to re-gain our humanity. ${ }^{5}$

He whakatauiki: He toi whakairo, he mana tangata. Where there is artistic excellence, there is human dignity. ${ }^{6}$

The purpose of my thesis is to discuss the high-tech storytelling of Aboriginal performance artist Lori Blondeau (Cree-Saulteaux). Her performances will be discussed as acts of cultural resistance. I argue that Blondeau's performance art negotiates decolonized spaces for the continuation of indigenous stories. The act of performance, which removes aesthetic expressions from a static frame and brings them 'alive,' has enabled Aboriginal artists such as Lori Blondeau to vocalize the Aboriginal experience. Aboriginal performance art is a medium that some indigenous artists have adopted for political activism. I will argue that her performances are a decolonizing tool used to challenge pre-existing stereotypes and negotiate new identities. I will explore the possible outcomes of Blondeau's high-tech storytelling for social change. The focus of my thesis is to present Blondeau as a social activist who employs performance art and storytelling to reclaim and re-envision silenced histories and the identities of indigenous women.

Lori Blondeau was raised as an urban Aboriginal in Regina, and maintained a close relationship with her family on the Gordon Reserve in northern Saskatchewan. In the 1970s she discovered her interest in art while visiting the studio of her brother, Edward Poitras. Blondeau was awarded an honorary Bachelor of Fine Arts from the University of Saskatchewan on the merit of her extensive artistic portfolio, including her apprenticeship with renowned Aboriginal performance artist James Luna. In 2002 she 
completed her Master of Fine Arts at the University of Saskatchewan, where she currently works as a sessional instructor and is a PhD candidate. Blondeau is the cofounder and director of TRIBE, an arts organization for Aboriginal media, visual, and performing arts. In 2000 she organized the 'High-Tech Storytellers' conference, which explored the theme of Aboriginal storytelling in contemporary society. Rebecca Belmore was one of her invited performers. ${ }^{7}$ Blondeau performs at a variety of venues including artist-run centres and university galleries, and Aboriginal and local arts festivals. Her audiences are diverse in cultural background, educational levels, and age. They are artists, academics, students, family members, and other members of the general public. In her artist statement Lori Blondeau articulates the issues that are presented in her work:

My work explores the influence of popular media and culture (contemporary and historical) on Aboriginal self-identity, self-image, and self-definition. I am currently exploring the impact of colonization on traditional and contemporary roles and lifestyles of aboriginal women. I deconstruct the images of the Indian Princess and the Squaw and reconstruct an image of absurdity and insert these hybrids into the mainstream. The performance personas I have created refer to the damage of colonialism and to the ironic pleasures of displacement and resistance. ${ }^{8}$

Here Blondeau's intentions as a performance artist become clear: she is attempting to voice the multiple impacts of colonization.

Many Aboriginal performance artists, including James Luna and Lori Blondeau, consider themselves to be 'high-tech storytellers'. ${ }^{9}$ My use of the term 'high-tech' does not mean to associate the practice with the 'high tech industry,' but to show the impact contemporary society has had on the storytelling practice of Blondeau. High-tech storytelling incorporates additional props, such as audio recordings and visual projections, that are not used in traditional storytelling practices. Blondeau's high-tech storytelling affirms the significance of Aboriginal oral traditions, while challenging the absence of recognition of storytelling as a legitimate [his]story. 
In "Our (Inter) Related History", Gerald McMaster discusses the significance of the interrelated Aboriginal and non-Aboriginal histories. He believes this interrelated history is fundamental to Canadian identity, and these histories can be intertwined through the visual arts. ${ }^{10}$ McMaster uses the double helix DNA molecule as a metaphorical model. In this model, the two strands of the double helix spiral upwards and are connected by rungs, like a ladder. McMaster argues, "In this model there is continuous dialogue, debate, and struggle. Like the DNA molecule this is the constituent part of who we are. This is how I see our interrelatedness." ${ }^{\text {"11 }}$ McMaster's metaphor can be used to support my discussion of Blondeau's artistic practice, which I argue combines both Aboriginal storytelling and 'mainstream' performance art.

In my discussion of Blondeau's fusion of Aboriginal storytelling and performance art, I will give an overview of traditions of indigenous oratory to support my argument that storytelling is a method of cultural resistance. My intention is not to homogenize Aboriginal peoples' storytelling practices but to disclose a cohesive purpose, namely the sharing of knowledge for cultural survival. The heterogeneity of indigenous communities in Canada is reflected in the stories told. However, stories sharing the Aboriginal experience of colonial histories reveal similarities between communities, such as the confrontation with hegemonic legislative policies.

I also recognize the importance of avoiding the generalization and homogenization of Aboriginal artistic practices. Steven Loft remarks that storytelling is all too often the umbrella under which Aboriginal art is placed, and while the story is a significant part of oral-based cultures, "it cannot be used as 'catch-all' categorization."12 Lori Blondeau acknowledges the act of sharing stories as a fundamental facet of her 
performance art. She employs storytelling in visual, verbal, and physical ways, by means of voice, memory, body, and technology. Although Loft's cautionary note is important in terms of the discussion of Aboriginal art, and warns of a danger akin to grouping all Aboriginal artists under the rubric of the 'trickster,' Blondeau is a storyteller nonetheless. In the following chapters, I will explore the tradition of storytelling as a method for cultural resistance and survival, suggesting that the contemporary use of the story in Blondeau's performances is a continuum of this process. Jean Fisher argues that the act of positioning art work within a tradition is not a form of silent protest but rather a form of intervention. ${ }^{13}$ Blondeau's performances will be situated and explored as utilizing traditions of storytelling to provoke destabilization of colonial discourses. Blondeau's performances will also be discussed in relation to Aboriginal empowerment and sovereignty. Art historian Lynne Bell describes Blondeau's work as witty, decolonizing performance art, that not only "talks back to historical colonial representations of indigenous peoples but it also addresses the continuing imperialism of present-day commodity culture, seen in films, fashion, magazines, mainstream TV shows, and children's books." 14 I will focus on how Blondeau uses these representations to raise significant questions about Aboriginal women's identities.

In Chapter 2 I lay the foundation and provide the contextual background to critically examine the politically vocal high-tech storytelling performance practice of Lori Blondeau. I will argue that the work of Pauline Johnson contributed to the development of Aboriginal performative storytelling. Aboriginal storytelling and performance art will be explored as methods of resistance to support my argument, discussed in Chapters 3 and 4, that Blondeau's high-tech storytelling participates in the decolonizing process. I 
will also include a brief exploration of the work of Aboriginal performance artists James Luna and Rebecca Belmore in order to contextualize Aboriginal performance art and high-tech storytelling.

Chapter 3 will examine Blondeau's performances as interventions to reclaim Aboriginal histories from the colonial text. The performances, Are You My Mother? and Sisters, will be explored as sites of public memory, 'gifting' knowledge in order to negotiate indigenized spaces. I use the metaphor of the palimpsest to discuss how Blondeau's performances function to uncover the traces of Aboriginal histories and stories.

In Chapter 4 the performances CosmoSquaw, Lonely Surfer Squaw, Betty Daybird and Belle Sauvage will be explored as negotiating interventions within the discourse of colonial representation of Aboriginal women. The politics of the body and dress and the construction of identities will be explored as they relate to Blondeau's performance personas. The stereotypes of the Indian princess and squaw are discussed, as they are continually re-negotiated by Blondeau's performances. Her performances and the process of storytelling will be argued as acts of decolonization, supported by the metaphor of the palimpsest.

I have limited this study to the discussion of Lori Blondeau as a high-tech storyteller. Her performances presented from 1996-2005 will be examined. The performances, Are You My Mother? (Figure 1), Sisters (Figure 2), CosmoSquaw (Figure 3), Lonely Surfer Squaw (Figure 4), Betty Daybird (Figure 5), and A Moment in the Life of Belle Sauvage (Figure 6) will be explored. 


\section{Aboriginal Performance Art}

A brief discussion of Aboriginal performance art allows me to situate Blondeau within this artistic practice. This overview supports my argument that Lori Blondeau incorporates traditions of storytelling into her performance practice. From the early 1970 s onward, performance art experienced a shift in focus with the introduction of new participants from minority cultural ancestry, such as African, Chinese, Aboriginal and Latin-American, also known as 'the others.' Women also fall into this category of 'otherness.' Aboriginal performance art did not emerge as an artistic medium until the mid-1980s, as contemporary Aboriginal art evolved in new directions. It was at this time that the politics of identity arose as a common theme in all mediums of contemporary Aboriginal art. Della Pollack argues that the field of performance art exploded in the mideighties due, in part to the 'performative turn' across disciplines. ${ }^{15}$ The border confining performance expanded to include previously considered 'low' forms of oral performance, such as personal and life narratives and rites of resistance. Concurrently, performance studies saw the rise of performances that explored the processes of identity formation and social change. In her article "Oral Traditions in Performance" Della Pollack observes that the "literary met the anthropological; the text collapsed into context-and a fury of debates over the nature, status, and value of performance ensued." ${ }^{\text {16 }}$ Pollack argues that the performance is a co-creative production that embodies and makes change. From this perspective, performance art can be viewed as an instrument for social change.

In her article "Performance Art and The Native Artist: a rEvolutionary Mix?" Aiyyana Maracle was compelled to ask, "why are so many Native artists embracing performance as the vehicle for their stories and imagery?" "She left her reader without 
specific answers; however, I would argue that this increase in performance art is due to its radical possibilities, enabling Aboriginal artists to reclaim not only their voice but also their visual language. This means that they have more control over the reception of their art, and also, are witness to this engagement as their body is the focal point of the experience. Maracle comments on the possibilities performance offers to Aboriginal artists. She recognizes performance art as a revolutionary artistic medium for the Aboriginal artist. ${ }^{18}$ Unpacking Maracle's discussion further, I would argue that performance art offers Aboriginal artists a vehicle to physically make space for themselves and their stories in places once segregated, and controlled by, Euro-Canadian society. This intervention in gallery/museum spaces and/or academic conferences ${ }^{19}$ is arguably a decolonizing act.

Aboriginal performance art is an artistic practice that is deeply resonant with the tradition of storytelling. However, the storyteller now has access to high-tech tools to create new and innovative forms of oral and visual expression. ${ }^{20}$ Blondeau affirms this with the following statement:

It's really important for me to tell my own stories in my work. A lot of Aboriginal artists are telling our ancestor's stories. I think that is scary because we have to start telling our stories in order to have an accurate history a hundred years from now. In telling my own stories I am leaving something for my own children. My stories are being recorded in slides, video, and photographs, and maybe my kids will pass them on. That's why it's important to tell your own stories. ${ }^{21}$

In the 1980s when individuals such as Rebecca Belmore and James Luna emerged onto the art scene, equipped with a performance practice defined in many cases by its potential to generate conversations around social and political change, Canadian art witnessed a revolutionary transformation of performance art. However, Maracle suggests that the primary elements remain the same. ${ }^{22}$ In other words, Maracle is alluding to the existence 
of a similar element in both performance art and Aboriginal storytelling, the presentation of a story as a performance or the performance as a story. The presentation of both traditions, consequently, remains fundamentally linked to the following: the storyteller/artist, the audience, the purpose for telling the story, and the story itself. From her observations, Maracle concludes that:

It is understood within the contemporary literature on Aboriginal theatre that the premise of contemporary Native theatre is an evolution of traditional performance forms, where music/sound, text/oratory, and dance/movement all integrally contribute to creating the story, then its evolved form [performance art] should likewise embody that sensibility. ${ }^{23}$

In other words, Maracle argues that performance art is a contemporary form of traditional storytelling. The act of storytelling was, and continues to be, a performative experience. James Luna calls Aboriginal artists who include indigenous knowledge of cultural traditions in their contemporary art practice 'Contemporary Traditionalists'. Lori Blondeau agrees with the idea that tradition is part of her performances. She states:

I believe every culture has traditions, but they evolve. Although, my ancestors have always done performance, I do it differently because this is the time I live in... I'm carrying on the tradition of performance but I don't have to wear feathers or beads to be authentic. ${ }^{24}$

\section{Politics of Identity, Stereotypes, and Recognition}

This brief summary of the politics of identity is included to support my discussion of Blondeau's confrontations with stereotypes. I argue that this is a method to reclaim the image of Aboriginal women. In her article "Independent Identities," Lucy Lippard contextualizes the necessity for contemporary Aboriginal women artists to reclaim and play with stereotypical images:

The historical identity of Indian women, as seen through the eyes of the paternalistic culture that has represented them for some 150 years, both resembles and differs from the image of western women. Indigenous women, like their male counterparts, were seen as amoral savages and children of nature; they were idealized as 'Indian 
princesses' and tragic 'maidens' paddling their canoes bravely over waterfalls, sending their men off to battle, stoically enduring terrible hardships...At the same time, even in today's somewhat cleaned-up media, these Pocahontas images continue to conflict with the other image of the mute and submissive squaw... Stereotypes of the Indian woman as either 'spiritual warrior/ goddess' or 'squaw' are western created counterparts of the Madonna-or-whore syndrome. They neatly bypass most realistic modern female identities. ${ }^{25}$

This discussion gives significance to Blondeau's artistic practice, which attempts to subvert the Indian princess and squaw stereotypes. Aboriginal women have been depicted through the lens of western popular culture since the time of contact. These depictions of indigenous women are always one-dimensional, with no attempt to show the subject's personality or history. These invented images erased the presence of Aboriginal peoples from the Canadian landscape, and attempted to legitimize the processes of colonization. ${ }^{26}$ In "Four Skin" Gerald Vizenor illuminates the construction or the invention of the Indian:

We were invented by missionaries and theologians and social scientists subsidized by the federal government, and now, in the cities, we are rewarded, praised, and programmed, for validating the invention of the Indian. In that dialectic we are impressed to assume ownership of stranger experiences: imitate data, live out theories, pretend our lives in beads and feathers, hold their mirrors for portraits and photographs, and serve as models, wilderness brothers and sisters to campers and hunters and ecologists. We have even been taught to resist questions about ourselves, about the Indian invention, because the white world has invested too much in this invention. ${ }^{27}$

Current scholarly research in Cultural Studies suggests that the construction of self occurs through a process involving 'individual identification' with the cultural signs, images, and narratives dominant in the ways of seeing and representing the world. ${ }^{28}$ In his article "The Spectacle of the Other," Stuart Hall discusses the relationship between media representation, identity, and political struggle. This provides a framework in which to explore the construction of Aboriginal women's stereotypes and a basis for navigating the political and theoretical methods Blondeau incorporates into her performances for a re-visioning of Aboriginal women. He suggests that identity is not formed through 
internal conceptions of the self, but through the influences and adoptions of the evertransforming narratives and representations. Consequently, identity is always being reconstructed and contested. ${ }^{29}$ Gail Guthrie Valaskakis employs Stuart Hall's discussion of identity politics in her exploration of Aboriginal identities. She writes that identity is a composition of social subjects, constructed through representations and narratives presented not only by the dominant society, but also from within the Aboriginal community. ${ }^{30}$ This means that Aboriginal identity is influenced by the powerful force of the indigenous narrative, the story.

James Clifford discusses the political nature of identity, which he posits is embedded within systems of power based on race, class, and gender. The systems of control have regulated identity, resulting in significant ramifications on the understanding of the contemporary and historical collective experience. ${ }^{31}$ Concurrently, Bonita Lawrence's "Gender, Race, and Regulation of Native Identity in Canada and the United States" situates the politics of Aboriginal identities, as specifically discussed in relation to social, cultural, and political history. Lawrence reveals the processes of colonization as a fundamental player in the regulation of Canadian indigenous identity. She identifies systems of classification and control and how they play a central role, enabling the colonizer to define who and what is 'Indian.' In this respect, Lawrence includes Foucault's understanding of regulatory regimes as a discourse in which "a way of seeing life is produced and reproduced by various rules, systems, and procedures-forming an entire conceptual territory on which knowledge is produced and shaped." ${ }^{, 32} \mathrm{My}$ exploration of the ways in which Blondeau destabilizes stereotypes will embody Lawrence's conclusion: 
Understanding how colonial governments have regulated Native identity is essential for Native people, in attempting to step away from the colonizing frameworks that have enmeshed our lives, and as we struggle to revive the identities and way of living that preceded colonization. ${ }^{33}$

Aboriginal stereotypes situate within colonial discourse as the 'others.' Homi K. Bhabha argues that stereotypes are a central facet in colonial discourses. They are characterized by a fixity and a clarity that are closely associated with processes of visualization, meaning that the objective of colonial discourse is to produce "the colonized as a social reality which is at once an 'other' and yet entirely knowable and visible." ${ }^{34}$ Bhabha's discussion of the stereotype in The Location of Culture is useful to keep in mind when exploring the colonial discourse's relationship to the stereotype. As Bhabha argues,

The stereotype is a complex, ambivalent, contradictory mode of representation, as anxious as it is assertive, and demands not only that we extend our critical and political objective but that we change the objects of analysis itself. The difference of other cultures is other than the excess of signification or the trajectory of desire. These are theoretical strategies that are necessary to combat 'ethnocentricism' but they cannot, of themselves, unreconstructed, represent that otherness. ${ }^{35}$

From Bhabha's discussion, I will explore Blondeau's performances as a negotiation that attempts to dislodge stereotypical representations of the 'Indian.' Bhabha's theoretical trope of mimicry will be used in relation to Blondeau's performance personas. Bhabha writes, "Mimicry is, thus, the sign of a double articulation; a complex strategy of reform." ${ }^{36}$ From this point of view, I argue that one of Blondeau's methods for the subversion of the stereotypes of Aboriginal women is mimicry. Charles Taylor's "The Politics of Recognition" acknowledges the serious negative implications of stereotypes and marginalization. His conclusions support the significance of Blondeau's challenge of stereotypes.

This discussion of stereotypes provides an explanation of the ways in which 
representations are constructed, in contrast to Blondeau's performance practice of stripping the Indian princess and squaw from the Aboriginal woman's body. It will be argued that her act of removing layers of Eurocentric representations makes her body the site of cultural intervention and resistance.

\section{Theoretical and Methodological Approaches}

Blondeau's performances will be explored as a crucial artistic practice creating new sites for 'aesthetic unsettlement, ${ }^{37}$ and a potent site for the establishment of a decolonizing pedagogy. ${ }^{38}$ Aboriginal artists such as Blondeau are voicing their intentions to intervene and assist in the decolonization of discourse, space, and knowledge. Marie Battiste discusses the significant impact indigenous scholars have had on the processes of decolonization. I argue that the contemporary work of many indigenous artists participates in the same process, which Battiste claims urges their communities to exercise their inherent rights in order to determine political status and pursue their cultural identity. ${ }^{39}$ Hawaiian scholar, Poka Laenui's definition of decolonization will be used to substantiate Blondeau's participation within the larger process of indigenous decolonization. Laenui observes:

\footnotetext{
True decolonization is more than simply placing Indigenous or previously colonized people into the positions held by colonizers. Decolonization includes the reevaluation of the political, social, economic, and judicial structures themselves and the development, if appropriate, of new structures that can hold and house the values and aspiration of the colonized people. ${ }^{40}$
}

Laenui's article "Processes of Decolonization" asserts that colonization and therefore decolonization are less politically based and are more social processes. Laenui offers great insight into the potential of decolonized spaces and challenges the definitions instituted by the colonial process. He argues that the process of decolonization can be 
organized into five distinct phases: rediscovery/recovery, mourning, dreaming, commitment, and action. Rediscovery and Recovery "sets the foundation for the eventual decolonization of the society." and for discussing the trauma of colonization; it is an occasion to remember community histories and familial stories in order to move on. ${ }^{42}$ Dreaming is the most crucial phase for decolonization, as it is within this space that the 'full panorama of possibilities' are expressed through exploration of culture, knowledge, and identities. ${ }^{43}$ Perhaps this is a time for empowerment. As Buffy Saint Marie phrases it, "We'll sing our historical truth songs so never again will anyone be able to sweep it under the rug. But we will not be victims of it anymore. We'll sing out songs of joy in being Indian. ${ }^{, 44}$ Commitment is connected to the process of dreaming, and offers a time and space for the sharing of voices previously silenced. Commitment is a communallymade decision towards community rediscovery and recovery. This process calls for constant questioning to maintain self-determined decision making and enable movement towards sovereignty. In other words, it is a plan of where to go next. The last phase is Action. This phase is proactive not reactive to the processes of colonization. The weapons of choice are contemporary society's communication vehicles, such as the internet, television, radio, newspaper, and, I would argue, the arts. ${ }^{45}$ This process of decolonization based on strategic phases is a theoretical framework that in reality may not be possible. It offers potential methods for movement towards decolonized, and therefore indigenized, bodies, stories, histories, identities, and spaces.

I will use the tradition of oratory to contextualize the high-tech storytelling of Blondeau. Storytelling can be seen as the theory by which one can navigate Aboriginal 
performance art. Barbara Godard argues that performative storytelling can negotiate a neutral space for Aboriginal culture and create a space for critical reflection. ${ }^{46}$ In my discussion of Blondeau, I will draw on Lee Maracle's concept of 'oratory,' which introduces a theoretical framework wherein Aboriginal scholars, writers, and artists could follow through their processes of decolonization. ${ }^{47}$ She advocates the use of storytelling to reclaim the voice of Aboriginal peoples. To address the significance of Blondeau's incorporation of storytelling in her performances, I draw on Thomas King's powerful statement, "the truth about stories is that's all we are."48 This is in agreement with Gerald Vizenor's assertion, “You can't understand the world without telling a story. There isn't any center to the world but story. ${ }^{, 49}$ Leroy Little Bear discusses the traditional role of storyteller, as experienced in contemporary Aboriginal communities. He views storytelling as an integral part of the educational process, sharing stories of real-life experiences, creation, and values. ${ }^{50} \mathrm{I}$ argue that the use of storytelling in performance is a way to educate and transfer understanding in order to foster a new post-colonial discourse. Blondeau's performance art/storytelling acts will be explored as potential sites for a post-colonial history lesson.

The story and theoretical methods of the story will be woven throughout the body of this thesis. In a discussion of storytelling it is significant to see the story as an agent of reclamation and decolonization. The story participates on multiple levels and generates numerous meanings. Steven Loft argues that "the strength lies not in the telling of the story, but in its power to assert meaning." ${ }^{, 51}$ This concept is shared by Chippewa storyteller Lenore Keeshig-Tobias, who discusses the significance of stories in Aboriginal knowledge. Keeshig-Tobias asserts, "Stories are not just entertainment. 
Stories are power. They reflect the deepest, the most intimate perceptions, relationships and attitudes of a people. Stories show how a people, a culture thinks." ${ }^{, 52}$ I draw on this concept of storytelling as a powerful method for generating meaning to argue Blondeau's effective use of the story for the purpose of sharing knowledge in order to empower and educate. In this sense, the story is a process that can be employed to re-establish control of representation and the empowerment of community. In her essay "Says Who: Colonialism, Identity and Defining Indigenous Literature," Anishnaabe writer Kateri Damm emphasizes the power of telling stories:

When we express ourselves and we listen to the creative and cultural expressions of others, we must do so from an informed position so that we do not contribute to the confusion and oppression but instead bring into sharper focus who we are. By freeing ourselves of the constricting bounds of stereotypes and imposed labels of identity we empower ourselves and our communities. 53

The story offers an indigenous world view, which I employ as a theoretical trope to elucidate the significance of Lori Blondeau's high-tech storytelling practice.

Post-colonial theoretical methods allow for critical negotiations of histories saturated in colonial subordination, domination, and control. The palimpsest embodies the historiography of the post-colonial condition. Palimpsests are sheets of writing that have been erased and overwritten with new text. ${ }^{54}$ Over the course of the past centuries, the palimpsest has surfaced within post-colonial theoretical discourse. ${ }^{55}$ In post-colonial discourse the metaphor of the palimpsest is synonymous with colonial history and its series of writings, overwritings, and erasures. The palimpsest implies that colonial trauma is an all-encompassing pattern of writings and erasures resulting in a colonial discourse. I will use the palimpsest metaphor in my discussion of Blondeau's decolonizing performance practice. The palimpsest implies not just a resistance to current oppression 
and violence but also a remembrance of the past, while informing the present, even though there may be only traces, in effect buried silences, of 'official' historiography. ${ }^{56}$

I draw on this metaphor to elucidate the notion that the 'overwritings' of colonial discourse onto the histories of the colonized do not completely erase indigenous stories. The term is valuable due to the fact that it illustrates the ways in which pre-colonial culture and the processes of colonization are facets that continue to contribute to a postcolonial society's developing cultural identity. If we understand that the pre-colonial landscape was named by colonial place, then the imperial naming process of lands ignores the previously established landscape. Paul Carter's The Road to Botany Bay is among the most substantial discussions of the construction of place with relation to identity. Carter examines place as a palimpsest, a surface on which traces of successive writings and inscriptions generate the experience of place, which according to Carter is itself historical. His use of the palimpsest illustrates how 'empty' uncolonized spaces become place, and through the colonial processes of textuality (mapping, naming, fictional and non-fictional narratives) contribute to the creation of claimed place and dominant cultural identity. ${ }^{57}$ In the Canadian context, colonial discourse attempted to erase indigenous constructions of land and place, allowing them to appear empty and ready to receive inscriptions. In this post-colonial setting, Aboriginal peoples are scraping off the layers of colonization, metaphorically speaking. Through this act of removing the prejudiced histories, indigenous knowledge systems surface; however, they are never completely erased. In the post-colonial sense, this action amounts to an attempt to decolonize rather than to find a pure form of authentic Aboriginal history, as this does not exist. This act locates stories, and therefore images and identities, that reflect Aboriginal 
subjectivity rather than the stereotypes of colonial discourse. The outcome is a combined history with a new perspective: the colonized now decolonized through the action of erasing colonial discourse from Aboriginal stories.

The metaphor of the palimpsest is a valuable way to understand the complexities of post-colonial cultures and the methods used by colonial powers to control the histories and stories of the colonized. Gillian Cowlishaw, in her book Rednecks Eggheads and Blackfellas, makes effective use of the palimpsest to draw conclusions in her study of racial power in Australia. In her view, the palimpsest metaphor emphasizes the "active layering of cultural meanings," whereby the colonizer's socio-cultural meanings are privileged and dominant, contorting those of the colonized indigenous peoples. ${ }^{58}$ In the case of Canada's Aboriginal peoples, who did not have written texts, the oral histories were then 'written' or textually overlayed with colonial writings and the documentation of anthropologists and linguists, who frequently misunderstood and mistranslated oral stories due to cultural differences. My inclusion of the palimpsest metaphor implies that colonial trauma is not a singular event, but an encompassing and long-lasting pattern of writings and erasures on colonial and colonized land, bodies, and minds. Lori Blondeau's performance practice will be shown to be an attempt to remove the layers of colonial history to reveal traces of Aboriginal stories/histories.

In addition to my use of the palimpsest as a theoretical approach, I will draw on the act of 'gifting' as a metaphor for bearing witness. I use the concept of 'bearing witness' to address Blondeau's performance spaces as possible sites for social change. Traditionally during storytelling, gifts were given as symbols of a mutual understanding. The act of gifting acknowledges the purpose of the meeting and the reason for this 
sharing. ${ }^{59}$ In North American indigenous culture, the relationship between performer and audience is a component of ceremonial dance, storytelling, and the other events that ensue from the act of gifting. The 'gift institution' involves a social expectation of reciprocity, and in some cases, such as seen in the Potlatch tradition of the First Nations of the Northwest Coast, a return in the form of status, prestige, and power. ${ }^{60}$ In many cultures throughout the world, the act of mutually exchanging gifts contributes to ongoing social cohesion. Similarly, the relationship between artist and viewer is always a significant aspect of art's reception and recognition. However, in the case of the performance artist and her audience, this exchange is intensified. Blondeau's performances will be argued as sites of public memory, enabling the recollection of callous colonial histories, while also negotiating a space to re-vision what has been camouflaged and ignored in Canadian society. She entices her audience to remember and look for traces of histories. Blondeau's audience acts as witness to the possibility of a decolonized image of Aboriginal women. ${ }^{61}$ Bearing witness will be explored as a powerful historical practice. ${ }^{62}$ In Aboriginal cultures, the gift should be understood as being property, ranging from material objects to dances and stories. ${ }^{63}$ In contemporary gifting practice, a member of the collective audience is given a gift for being witness to the story, dance, or naming that was performed. Both giver and recipient are aware of the meaning of the gift in this exchange.

The gift can symbolize the sharing of knowledge through storytelling. Bearing witness means to write on or present the body as the written document of proof. In Lori Blondeau's performances both the audience and her body will be argued as bearing witness to acts of re-membrance. In Performing the Body: Performing the Text, Amelia 
Jones and Andrew Stephenson discuss the performative element in art, and how the

audience's reception never creates universal meaning. ${ }^{64}$ This places significant stress on the effective communication skills of a performance artist, who must convey certain meanings to generate dialogue with her audience. The argument that the sharing of stories can create a space for reciprocal relationships depends on the intentions of the audience. However, for the most part, those attending performance art come with the intention to engage with, or at least criticize it. Integral to this tightly woven, interdependent relationship between viewer and artist is the necessity for new lines of communication, and for an activation of the tradition of bearing witness. Blondeau's performativity will therefore be explored as the gift; this gift is new knowledge or the recognition of old and new stories.

\section{Literature Review}

The specific literature that explores the methods and interpretations of Aboriginal performance art is limited to performance reviews, articles, and exhibition catalogues. There are no texts that offer a focused discussion of Aboriginal performance art and its major players. My discussion of Lori Blondeau will contribute to this emerging discourse, while also offering new perspectives and arguments in relation to the interpretation, impact, and reception of her performance art. This thesis will also contribute to the discussion of high-tech storytelling, including an analysis of traditions of indigenous oratory while intervening within the colonial body of literature, which assigns an inferior place to traditions of oratory, in comparison to written traditions.

From 1998 to 2005 three major and several minor publications examined the work of Lori Blondeau. Blondeau's article "Some Kinda Princess" is a personal account of her 
performances, including some of her performance narratives. Lynne Bell's "Scandalous Personas, Difficult Knowledge, and Restless Images" and "High-Tech Storyteller," jointly written with Janice Williamson, provide interpretations of Blondeau's performances, discuss her high-tech storytelling practice, and include interviews with the artist. Jayne Wark's article "Dressed to Thrill: Costume, Body, and Dress in Canadian Performative Art" looks at Blondeau's use of costume for the creation of her subversive personas. Amy Sara Carroll's brief discussion of Blondeau's work in her exhibition catalogue Belle Rogue Fashion Show focuses on Blondeau's personas' employment of subversion as a tactic to re-fashion identity. The use of performance and photography by Blondeau to reclaim colonial spaces was explored by Bell's "Artists Pages: Decolonizing Tactics in 'Writing Space'." These are the primary sources that introduced me to Lori Blondeau's performance practice and provided the foundation for this thesis.

Aboriginal performance art is an established artistic practice with an emerging academic discourse. A small amount of literature has been published on Aboriginal performance art; however, this artistic practice is situated within the larger discourse on contemporary Aboriginal art. There is a wealth of literature exploring contemporary Aboriginal art, from major anthologies to exhibition catalogues. A recent contribution to the discussion of contemporary Aboriginal art is Transference, Tradition and Technology, a collection of articles written by Aboriginal scholars, artists, and curators that examines new media arts through the indigenous lens. This publication offers great insight into current socio-political and cultural issues surrounding Aboriginal art. The writers, including Steven Loft and Dana Claxton, explore contemporary Aboriginal art from an empowered perspective, deconstructing the victimization of indigenous cultures. 
Jackson Rushing's Native American Art in the Twentieth Century is a collection of articles by some of the academic leaders in the field, among them Lucy Lippard, Ruth Phillips, and Gerald McMaster. This publication explores diverse issues in contemporary Aboriginal art, such as the interplay between Aboriginal identities and politics. The development of Aboriginal art and how space was generated for the discussion of Aboriginal history, identities, and stories is also addressed. Jackson Rushing remarks that,

One of the defining characteristics of Aboriginal American art since the 1960s has been the investigation of stories, narratives, and histories - both verbal and visual. Sometimes Native (hi)story has been the subject of scrutiny, celebration, or revitalization...Elsewhere, Euro-American (hi)stories, including those 'told' by museums, about Native art and culture have been the subject of indigenous artists: Gerald McMaster's exhibition 'Savage Graces' (1992) and Robert Houle's Kanata (1992). ${ }^{65}$

Allan J. Ryan's The Trickster Shift contributes to the discussion of contemporary Aboriginal art, with his inclusion of Trickster theory. Ryan explores Aboriginal aesthetic expressions, arguing that the use of parody and irony recalls the trickster. He examines the use of parody as a postmodern tool of 'serious play' for radical questioning.

In her article "If Art is the Answer, What is the Question?" Charlotte TownsendGault presents a compelling argument of the need for greater awareness of the politics of indigenous material culture. She argues that the politics of the object is a significant consideration when discussing Aboriginal visual culture. Townsend-Gault suggests that objects can be understood as the counterpoint for identity politics, cultural debates, and confrontations, based on their contested status as property, art, ethnographical symbols, and treasures. ${ }^{66}$ Furthermore, she asserts, "a large part of their present significance lies in a challenge to colonialist authority, the assertion of survival, the demand for response, and the provocation to action." In other words, there is a relationship between the visual 
manifestations of Aboriginal cultures and contemporary socio-political relations. ${ }^{67}$

In Native North American Art, Janet Berlo and Ruth Phillips raise many 'questions of definition,' such as labelling, that complicate the discussion of contemporary Aboriginal art. The term 'art' raises issues such as: centuries of access to the canon of art history being limited to the white European male masters; the inferior 'craft' label bequeathed to the majority of 'traditional' or 'historic' Aboriginal arts; the limitation of accurate interpretations of indigenous visual culture due to closed and narrow definitions; and questions of representation and discussion of indigenous arts from a Eurocentric world view. These categorizations assign an inferior status to Aboriginal aesthetic expressions, relative to their Euro-Canadian counterparts. Since the postmodern movement, such exclusionary definitions have been challenged and rendered obsolete by critics, art historians, and artists. ${ }^{68}$ I will draw upon these diverse perspectives to analyze and contextualize the work of Lori Blondeau within the larger discourse of contemporary Aboriginal art. 


\section{Chapter 2 Setting the Stage: Historical Continuum of Aboriginal Performance Art}

\section{Introduction}

The purpose of this chapter is to discuss the complexities of Aboriginal performance art, and to establish a foundation for this multifaceted artistic medium and its relationship to high-tech storytelling. The story has long been a vehicle for resistance, employed as a strategy for cultural survival; storytelling is a method of intervention. The relationships between storytelling and performance art will be discussed to create a foundation for navigation of the performance practice of Lori Blondeau. Pauline Johnson, James Luna, and Rebecca Belmore, who use the story for intervention and political protest, are introduced as significant players in the practice of performative storytelling. Their storytelling practices and Blondeau's participate in a larger discourse of traditions of Aboriginal oratory.

The traditions of indigenous storytelling and the multiple roles the story has played throughout Aboriginal history will also be explored. In addition, a foundation of understanding of storytelling will be established in order to recognize the interconnectivity of performance art and storytelling. I will discuss the story as a teaching tool, as a method of cultural resistance and survival, and also as a performative aesthetic connected to the creation of identity and community. The work of Aboriginal poet Pauline Johnson, one of the original Modern Aboriginal storyteller/performance artists, will be discussed in order to demonstrate her relationship to contemporary performance art. By establishing the link between Johnson, Lori Blondeau, and current Aboriginal artists who are exploring performance art (i.e., Rebecca Belmore), I can illustrate the continuum of Aboriginal acts of intervention against colonial expansion, domination and 
subordination. However, the subtle political voices of individuals like Pauline Johnson differ greatly from the overt and explicit vocal and visual expressions of many contemporary Aboriginal artists. This exploration of storytelling will weave together several threads to create an understanding of its significance for Aboriginal communities.

This chapter does not attempt to create a linear history of Aboriginal performance art or to show a progression, but to illustrate the multiple threads that have been woven together to create an intricate fabric of the Aboriginal experience in colonial and, theoretically, post-colonial Canada. Leroy Little Bear, a member of the Blood nation of the Blackfoot Confederacy, describes Aboriginal philosophy as a concept of all things being interconnected and in constant motion, resulting in a necessity to look at the whole to begin to unravel a pattern or answer. ${ }^{1}$ Although Little Bear is referring specifically to a Plains Aboriginal philosophical system, he claims that all North American indigenous belief systems are holistic, cyclical, repetitive, process-oriented, and firmly grounded in a specific place. ${ }^{2}$ I do not mean to suggest that this research is an example of Aboriginal philosophy. Rather, I am attempting to adopt and incorporate a holistic approach to contemporary Aboriginal art, specifically performance art, in contrast to Eurocentric methods of investigation, which seem more static, linear, singular, and objective.

The role of the story as a tool for intervention is important to the discourse on indigenous decolonization and sovereignty. Jolene Rickard writes, "The work of indigenous artists needs to be understood through the clarifying lens of sovereignty and self-determination, not just in terms of assimilation, colonization, and identity politics... Sovereignty is the border that shifts indigenous experience from victimized stance to a strategic one."3 Aboriginal performance art continues the tradition of self- 
determined voicing and expressing of political statements by means of the story.

Aboriginal artist Jimmie Durham notes the political significance of the Aboriginal artist's position as meaning maker and storyteller:

Traditions exist and are guarded by Indian communities. One of the most important of our traditions is...constant change-adaptability, the inclusion of new ways and new material-it is a tradition that our artists have particularly celebrated and have used to strengthen our societies. ${ }^{4}$

Similarly, Blondeau incorporates traditions of oratory into her performance practice, while also participating in her contemporary urban environment. She pushes the boundaries of the definitions of both performance art and Aboriginal storytelling. The result of generations of impact on Aboriginal oral traditions by contemporary technology, art, and society, high-tech storytelling is the binding thread of this thesis. I will begin my examination of the concept of high-tech storytelling used by Blondeau and her mentors, James Luna and Rebecca Belmore, with a look at one of its earliest proponents, Pauline Johnson.

\section{Pauline Johnson: The Performance of Storytelling}

During the modernist century that lasted from the 1860 s to the 1960 s, performance, not graphic or plastic art, was the available space for Native artistic production, and further, that performance offered the most favourable site for Native negotiations of the dominant culture's images of Indiannes as pre-modern, degenerate and vanishing. ${ }^{5}$

Pauline E. Johnson (1861-1913), Mohawk poet and performer, personifies this negotiation. She was the first woman of Aboriginal descent to publicly perform her stories for mainstream Canada during the late nineteenth and early twentieth centuries. Johnson adopted her grandfather's name, Tekahionwake, and travelled across Canada and to Europe performing her stories. Her narratives examined the complicated issues surrounding race and gender, and her voice illuminated Aboriginal histories and their relationship to the colonial discourse. Reading Johnson's poems, essays, and stories 
substantiates her role as an advocate for Aboriginal and women's rights, ${ }^{6}$ as well as one who offered acts of resistance. In "The Re-interment of Red Jacket" she celebrated her Mohawk ancestry, and in "The Cattle Thief" she accused British settlers of participating in the genocide of Aboriginal peoples. In her day, the discussion of history from an Aboriginal perspective was not common practice. Johnson communicated an indigenous point of view with the general public. "The Cattle Thief" validates my claim that her works were acts of resistance and intervention. ${ }^{7}$

Pauline Johnson's poems played into the legacy of exoticism and romanticism that was attached to Aboriginal representation; at the same time, they subtly and overtly criticized assimilation and land loss, and challenged the audience's understanding of what an 'Indian' woman is. However, she also offered her audiences verses capturing the beauty of the Canadian landscape and Aboriginal culture. Carole Gerson and Veronica Strong-Boag see Johnson's collection of poems and prose as widely overlooked and believe she should be reconsidered as one of Canada's most significant writers. They write, "Johnson's verse, fiction, and non-fiction tested the boundaries of what it meant to be mixed-race and female in the imperial and patriarchal world of Europe and North America during the decade after the creation of the new Dominion of Canada.,"8 Furthermore, her oratory participated in creating a 'Canadian' consciousness and identity, one that appropriated Aboriginal iconography. This is exemplified in "The Song My Paddle Sings," where Johnson describes paddling a canoe_a stereotypical and iconic image given back to her non-Aboriginal audience. Johnson writes:

West wind, blow from your prairie nest, Blow from the mountains, blow from the west. The sail is idle, the sailor too; $\mathrm{O}$ ! wind of the west, we wait for you. Blow, blow! 


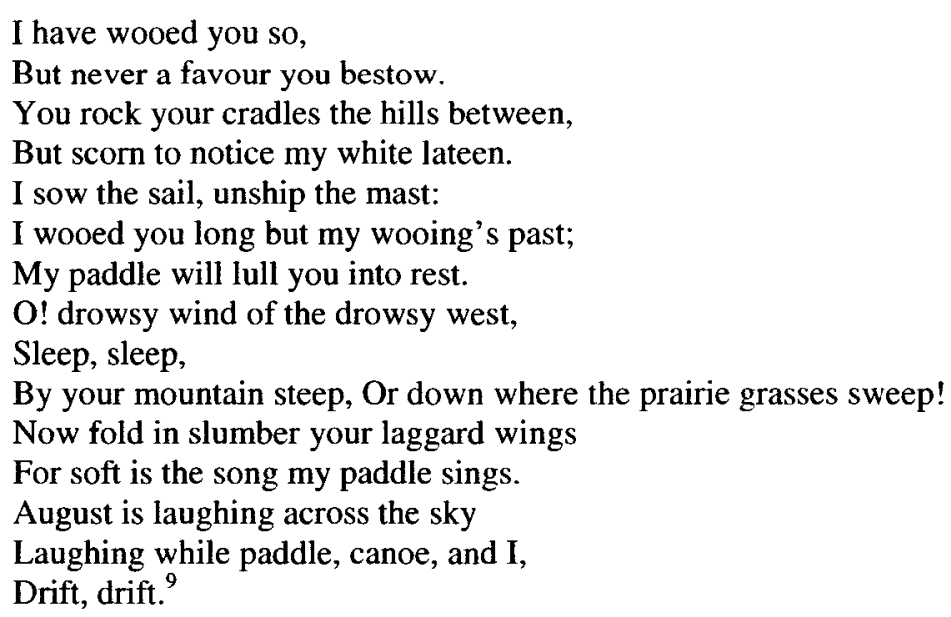

Her oratory presented resistance to the colonial discourse, while captivating her audiences with her powerful verses saturated in 'Indianness.' A contradiction lay at the heart of Johnson's performances, for from one poem or story to the next, she alternated words of resistance with words saturated in the romanticism of the 'Indian.'

The inclusion of images of Aboriginal culture from the lens of the 'mainstream' enabled her to negotiate a space for her acts of socio-political intervention. Arguably, the result of her performances can be seen to have reaffirmed notions of romanticism. However, I would argue that it was Johnson's understanding of the social climate she was situated in that enabled her to play with images such as the romantic 'Indian Princess' in order to subvert them and intervene within the discourse of colonial representation. In this sense, the storytelling practice incorporated into the performance art of Lori Blondeau, Rebecca Belmore, and others, participates in a continuum of performative resistance, dating from Pauline Johnson's 1892 appearance in the Gallery of Art at Toronto's Academy of Music. ${ }^{10}$ At this evening of Canadian poetry, Johnson made a bold decision to recite a poem unlike others of its time. Her "A Cry From an Indian Wife" did not celebrate the glamour of war; it was written in a woman's voice and unequivocally presented an Aboriginal perspective to a non-Aboriginal audience. ${ }^{11}$ This poem shared 
the story of an Aboriginal woman whose husband was going off to fight on the side of the

Metis in the 1885 Northwest Rebellion:

They but forget we Indians owned the land From ocean to ocean; that they stand

Upon a soil that centuries agone

Was our sole kingdom and our right alone

They never think how they would feel to-day

If some great nation came from far away

Wresting their country from their hapless braves

Giving what they gave-but wars and graves ${ }^{12}$

This was the first time Johnson performed for a large audience at such a prestigious venue. The new tone and new perspective of her performance captured her audience, who, according to Frank Yeigh's ${ }^{13}$ personal account, went 'wild with applause' at the end.

Johnson was a provocative performer, incorporating contrasting personas and captivating audiences with her theatrics. Her dual performance personas from 1894 arguably represented both her First Nations and British ancestry, each recognizable to her audiences by their distinct dress. She wore her buckskin 'Indian' dress with bear tooth necklace for the first half of the concert and an evening gown for the second. Johnson's 'Indian Princess' attire was an asymmetrical buckskin dress, revealing her ankles chastely wrapped in leggings, with embellishments of Aboriginal culture, such as fur pelts, silver medallions, wampum belts, and her father's hunting knife (Figure 7). ${ }^{14}$ The change of costume reminded her audience that although she was Aboriginal playing into their understanding of 'Indian' culture ('exotic,' 'romantic,' 'primitive'), she was also a EuroCanadian middle-class woman, connected to 'them' by her mother's lineage. Gerson and Strong-Boag discuss Johnson's dual persona as a representation of her 'dual loyalty' to both her Aboriginal and Euro-Canadian heritages. Charlotte Gray, author of the recent 
biography on Johnson, Flint and Feather (2002), remarks in an interview that this celebration of both sides of her heritage was not common in Victorian Canada and marked her as a woman ahead of her time. ${ }^{15}$ My interpretation of the inclusion of an evening dress after her 'Indian Princess' dress was Johnson's attempt to legitimize her performances and to facilitate acceptance of her work. This manipulation reminded the audience of her European ancestry. She negotiated dominant Euro-Canadian society's acceptance of her by prompting the audience's mystification of her 'Indianness' while also impressing them with her European poise, middle-class respectability, and most importantly her inherent talent. As Ruth Phillips argues, Johnson "exploited popular stereotypes of Indianness through dress and stage props as a strategy for affirming a positive Native identity." 16 Johnson's performances are linked as much to the tradition of oratory as to the tradition of spectacle. Aboriginal performers utilized stereotypes and "fed their audience's desire to see a real Indian." 17 Through her 'dressing up' strategy, she was able to share her provocative stories, voicing the political issues of Aboriginal reality, and offering an Aboriginal perspective. Johnson wrote poems and prose that provoked a re-evaluation of the 'norms' (today seen as prejudices) of dominant society, while also asserting interventions in the colonial discourse. These objectives are reflected in her poem, "Cattle Thief":

Raved of the wrong she had suffered since her earliest babyhood:

"Stand back, stand back, you white-skins, touch that dead man to your shame;

You have stolen my father's spirit, but his body I only claim.

You have killed him, but you shall not dare to touch him now he's dead.

You have cursed, and called him a Cattle Thief, though you robbed him first of bread-

Robbed him and robbed my people-look there, at that shrunken face,

Starved with a hollow hunger, we owe to you and your race.

What have you left to us of land, what have you left of game

What have you brought but evil, and curses since you came?

How have you paid us for our game? How paid us for our land?

By a book, to save our souls from the sins you brought in your other hand.

Go back with your new religion, we never have understood

Robbing an Indian's body, and mocking his soul with food. 
Go back with your new religion, and find-if you can-

The honest man you have ever made from out a starving man.

You say your cattle was not ours, your meat is not our meat;

When you pay for the land you live in, we'll pay for the meat we eat.

Give back our land and our country, give back our herds of game;

Give back the furs and the forests that were ours before you came;

Give back the peace and plenty. Then come with your new belief,

And blame, if you dare, the hunger that drove him to be a thief."18

This powerful poem not only describes the effects of colonial expansion on the lives of

Plains Aboriginal peoples, such as starvation and loss of traditional lands, but also

acknowledges the genocide of the North American indigenous population. Johnson

clearly gave voice to stories of colonial atrocities, many of which were contemporary to

her and would have otherwise been silenced.

Pauline Johnson was an advocate for Aboriginal peoples and a social activist. In

her article "A Strong Race Opinion on the Indian Girl in Modern Fiction," published 22

May 1892 in The Toronto Star, Johnson wrote:

The term 'Indian' signifies about as much as the term 'European' but I cannot recall ever having read a story where the heroine was described as a 'European'. The Indian girl we meet in cold type, however, is rarely distressed by having to belong to any tribe, or to reflect any tribal characteristics. She is merely a wholesale sort of admixture of any band existing between the MicMacs of Gaspé and the KwawKwlith of British Columbia. ${ }^{19}$

Clearly, Johnson was critical of the homogeneous representation of Aboriginal women in popular culture. She also criticized Euro-Canadian authors who wrote about Aboriginal culture without knowledge of it, who have "never been on an Indian reserve in their lives, have never met a 'real live' redman... what wonder that their conception of a people they are ignorant of, save by hearsay, is dwarfed, erroneous, and delusive."20

From Pauline Johnson's prose and dramatic performances of her poetry, we can ascertain an intention for intervention. She is arguably one of the first modern storyteller/activist/performance artists. Her dynamic acts of performativity can be understood as a historical precedent for contemporary Aboriginal performance art as 
political intervention. Johnson's practice can be situated within the discussion of pushing boundaries and provoking fundamental changes for Aboriginal peoples. In this sense, Pauline Johnson and Lori Blondeau can be jointly placed under the umbrella of Aboriginal performance art-their methods and tools of engagement reflecting the sociopolitical climates of their time. They are linked by their practice of oratory utilized for political intervention and indigenous empowerment. They are both storytellers, performing stories to re-dress, re-write, re-view, and re-voice Aboriginal histories and identities.

\section{The Story: The Tradition of Aboriginal Oratory}

"Indian stories are teachings, prayers, songs." 21 This statement by Ojibway Elder and storyteller Art Solomon acknowledges the fundamental principles of the story within the context of the Aboriginal community. Canadian indigenous stories are teachings, and indigenous peoples understand stories as being rooted in the common experience of oral tradition. As Guthrie Valaskakis affirms: "It is the power of narrative as teaching, prayer, song experienced through collective heritage which makes stories so valued and so important in Indian Country. $" 22$ The tradition of orality can be linked to the fundamental principles of communication. Thomas A. McKean, a Communications scholar who studies song and story traditions, argues that tradition, which can be defined as the passing on of socio-cultural knowledge through shared actions and teachings, is communication. Noting the significant relationship between performer, source, and audience, McKean states that the tradition of communication is "by extension, the cultural manifestations of that relationship at the intersections of memory, orality, and literacy." ${ }^{23}$ Channels of communicating are mutable and are susceptible to change and 
new readings; however, the purpose of communication remains intrinsically connected to methods of sharing knowledge. The nature of communication is subjective, and reflects specific periods in cultural history. Aboriginal storytellers have told stories that in turn have been passed on by their listeners, enabling generation after generation to hear the same narratives with few changes. In "Man Made of Words," Kiowa storyteller/writer/scholar N. Scott Momaday asserts that within the discourse of Aboriginal storytelling, fundamental practices occur. For example, historical events, community norms, cultural practices, knowledge, and views of life are passed on, thereby disclosing the heterogeneous nature of storytelling in Aboriginal communities. ${ }^{24}$ In this sense, Aboriginal oral tradition is the body of unwritten principles and teachings that make up the socio-cultural fabric of community. Arguably, then, oral tradition not only plays a prominent role within Aboriginal culture; 'it is the culture itself., ${ }^{25}$ This suggests and affirms the belief of many Aboriginal peoples, that the word is a living, breathing, and dynamic being.

There are many different kinds of stories; some share how the world was created, and the gifts of power and medicines, while others recount war, conflict, and other traumatic events. Some stories tell of family ancestral lineage and recount the lives of great leaders. ${ }^{26}$ Storytelling continues as a method to teach new generations. Acoma Pueblo storyteller Simon Ortiz considers storytelling to be a process that illuminates and presents truths lived by North American indigenous peoples:

There were always stories. And they weren't just stories, they were the truth. They were views on the truth of life. And the truth of this life was that it was a way of life, the way we-the community of Acoma Pueblo, the larger Native American world, the world in general-lived. And it was the stories which opened my eyes, my mind...upon the way of life of that world in which I lived. And because the world continued and I continued with it, the stories went on, constantly in the making, changing, reaffirming the belief that there would always be the stories. ${ }^{27}$ 
This being said, the concept of 'truth' is a problematic term in relation to Western discourse, and while Aboriginal storytelling is understood as sharing factual events, such as namings, the passage of rights, and historical events, there is also an acceptance of the relationship between storytelling and subjectivity. Bo Scholer's statement, 'By nature, storytelling is subjective,' suggests the story does not claim to present objective facts but rather shares a reality of subjectivity in the retelling from generation to generation. ${ }^{28}$ Boundaries shift, as do stories, however these shiftings do not make the stories fictional, as they are narratives considered to be factual truths. For example, Lori Blondeau's hightech storytelling is evidence of such shiftings in the definition of storytelling. Although her stories are shared in a new way and offer new insights, they remain narratives sharing life experiences and factual 'truths.' The story is a history of life lived, a mapping of sorts, which charts the course of history. ${ }^{29}$

Aboriginal histories offer insights into indigenous knowledge systems, but also negotiate hard stories endured throughout the colonial processes. These stories from Canada's colonial period of domination, subordination, and oppression suggest reasons for current realities and problems plaguing Aboriginal communities. There are numerous significant consequences of this colonial domination over Aboriginal peoples; among the most heinous are alcohol and drug abuse and high suicide rates. The sharing of past histories of relocations and land loss, residential schools, and ceremonial bans offers insights into current situations in both reserve and urban communities. Through sharing these hard histories, Aboriginal storytelling can also be looked upon through the lens of self-determination, empowerment, and sovereignty. Storytelling has been utilized by multiple generations of Aboriginal peoples, sharing perspectives, giving voice, and 
creating resistance. In this respect, a new generation of storytellers has emerged; today they perform their artistic narratives in the form of hip hop music, graffiti art, dance, poetry, textual writing, and visual art. Many of these new storytellers are First Nations women. Emerance Baker, a First Nation writer, remarks:

The power to tell our stories and to share them so widely is not new to Native women. We have been telling stories for generations. And as the medium for telling our stories changes somewhat over time, so too does the form, shaping and telling of our stories reflect the differences of the spaces we now occupy. ${ }^{30}$

Lori Blondeau is one of these innovative artists, pushing the boundaries of the practice of storytelling, using new methods of conveying individual, familial, and communal stories. This generation is sharing the hard truths of Canada's Aboriginal communities, voicing the necessity of continued dialogue among indigenous peoples and drawing together generations and diverse cultural communities. Stories act as a process of bridging; they weave past, present, and future histories into one fabric. In other words, old memories and stories exist alongside current realities and tomorrow's possibilities in contemporary Aboriginal narratives. ${ }^{31}$ In the practice of contemporary storytelling, memory plays a significant role in the telling and reception of the story. Memory in this sense is history. Gerald Vizenor suggests that the storyteller rekindles, or re-illuminates narrative histories:

The teller of stories is an artist, a person of wit and imagination, who relumes the diverse memories of the visual past into the experiences and metaphors of the present... The tribal creation takes place at the time of the telling in the oral tradition; the variations in mythic stories are the imaginative desires of tribal artists. ${ }^{32}$

It is from this perspective that Blondeau's performances will be analyzed in the following chapters. The sharing of stories acts as a common thread linking contemporary Aboriginal artists to past and present histories, offering these narratives as teachings. Some stories present factual events, while others offer imagined spaces and times, 
dream worlds to extend empowerment and possibilities for the future. Renowned Muskoke-Creek poet-storyteller Joy Harjo writes, "I mostly rely on contemporary stories. Even though the older ones are like shadows or are there dancing right behind them, I know that the contemporary stories, what goes on now, will be those incorporated into those older stories or become a part of that." ${ }^{33}$ In this sense, the divisions between old and new stories are not clear, as they are a part of each other. For example, Blondeau's performances fuse her life stories with those of her grandparents, simultaneously sharing pre-colonial stories, colonial histories, and post-colonial possibilities. In Are You My Mother? Blondeau includes her experiences of head lice with her grandmother's stories, revealing layers of meaning and lessons. She shares traditions of Aboriginal women picking head lice from their children's hair, which is a lesson on mothering and nurturing affection. This is in contrast to the story of washing young children's hair at residential school with 'disinfectant,' because the Aboriginal children were considered to be 'savagely dirty,' which summons memories of colonial trauma and dislocation from Aboriginal ways of mothering. While the manifestation of Blondeau's process is new, arguably the structure and cultural foundations are not. As formulated by Thomas McKean, "If tradition is process rather than content, as I believe it is, the mechanics are essentially the same today."34 Although the current generation of storytellers utilizes new methods and materials, new songs and dances, they remain fundamentally linked to their storytelling ancestors. The foundation on which these artists express their cultural and contemporary identities remains tightly bound to a basic principle, the tradition of orality. Ortiz states that Native "oral tradition is inclusive - it is the actions, behaviours, relationships, practices, throughout the whole social, economic, and spiritual life process 
of people. In this respect, the oral tradition is the consciousness of the people." ${ }^{\text {35 }}$ Stories are passed from generation to generation, linking grandparents to grandchildren, and are the documents of histories. In this sense, stories are the threads of old memories that are woven into the consciousness, connecting through knowledge the members of communities. In the Aboriginal story, identity and connection to community are expressed together. Okanagan storyteller Jeanette Armstrong articulates this interconnectivity of stories and the creation of community identity in her poem "Threads of Old Memory." The following passage captures the essence of the role of the storyteller:

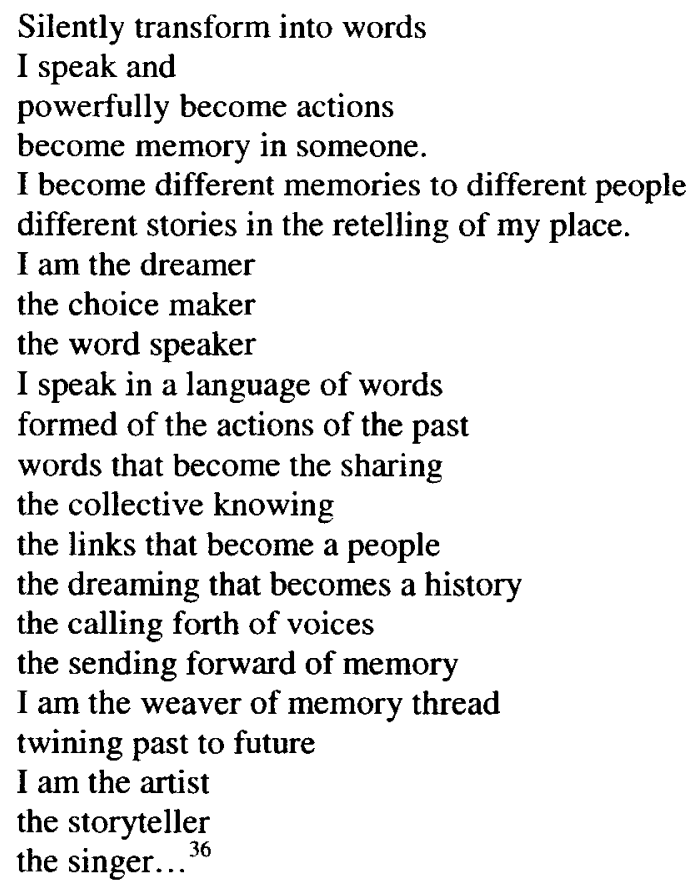

Stories in Aboriginal communities are the lifeline of knowledge, linking the generations by sharing spiritual, historical, and cultural knowledge. The multiple roles the contemporary storyteller assumes are significant in terms of cultural survival and empowerment. Armstrong is a self-determined educator, entertainer, and dreamer. She 
offers the possibilities for post-colonial re-voicing of Aboriginal knowledge and autonomy.

\section{Acts of Resistance: Performance Art and Storytelling}

Culture becomes as much an uncomfortable, disturbing practice of survival and supplementaritybetween art and politics, past and present, the public and the private--as its resplendent being is a moment of pleasure, enlightenment or liberation. It is from such narrative positions that the postcolonial prerogative seeks to affirm and extend a new collaborative dimension, within the margins of the nation-space and across boundaries. ${ }^{37}$

Intrinsic to the history of contemporary performance art in Canada is the concept of resistance. Lori Blondeau utilizes the practice of performance to resist and to protest. The concept of performative storytelling as an act of resistance and intervention is fundamental to my argument, which proposes that Blondeau's high-tech storytelling practice re-constitutes representations of Aboriginal women in particular, in order to decolonize the colonial discourse. Consequently, space for testimony is negotiated, giving voice to otherwise silenced communities. Art historian Jessica Bradley substantiates Peggy Phelan's claim that the significance of performance art lies in "representation without reproduction," a one-time event that locates "a subject in what cannot be reproduced within the ideology of the visible. ${ }^{, 38}$ In other words, as Bradley suggests, performance art's significance is its potential to excavate and bring to life the issues and images that "are systematically marginalized by the dominant culture." 39 At the heart of Aboriginal performance art as exemplified by Lori Blondeau and her contemporaries is the idea of the visible and its ability to maintain the invisibility of other voices and representations. ${ }^{40}$ What this means is that Blondeau, Rebecca Belmore, and James Luna re-negotiate spaces in order to take control over their representation, while also giving vision to their once 'invisible' position as Aboriginal people in Euro- 
American society. Peggy Phelan proposed this concept in Unmarked: The Politics of Performance, where she investigates subjectivity and identity which are not visibly represented. ${ }^{41}$ Lori Blondeau's performances destabilize multiple images of 'Indianness,' incorporating the story of the ways in which these stereotypes have been created as well as resisted.

Native resistance is cultural persistence; its strategies are stories. The story not only expresses power of the past but offers empowerment for the future. Gerald Vizenor (Anishinabe) argues, in Manifest Manners: Post-Indian Warriors of Survivance, that Native stories bear witness and give presence to 'survivance.' Vizenor says this "is a state in which we are moving beyond our basic survival in the face of overwhelming cultural genocide to created spaces of synthesis and renewal., ${ }^{, 42}$ Re-expression of old stories plays a significant role in the generation of new stories and the possibilities of social change. The reception of performances can instigate new ways of understanding, making the gallery a site for social activism. In The Native American Oral Tradition: Voices of the Spirit and Soul, Lois Einhorn recognizes the importance of the oral tradition in Aboriginal cultures, claiming that the stories encourage the imagination. She also acknowledges the importance of repetition, stating that through hearing stories repeatedly, the listener gains a deeper understanding of them. ${ }^{43}$ From this point of view, the telling and re-telling of stories creates a space for the continual reception of indigenous world views, thus connecting communities by means of cultural knowledge. Craig Womack remarks that stories not only preserve Aboriginal communities, but "acknowledge that our cultures are largely intact because our stories tell us how we are adapting to the challenges we are continually encountering in our communities." ${ }^{, 44}$ In this 
sense, the act of telling stories contributes not only to the process of resistance and survivance, but in the post-colonial context, the story offers sovereignty and empowerment.

Furthermore, storytelling is a communal act of resistance, representing the ongoing creation of world views. Kim Anderson, in A Recognition of Being: Reconstructing Native Womanhood, discusses how the act of storytelling preserves language and the power of the spoken word. She observes that "indigenous stories are significant because they are anchors of resistance."45 Prior to contact with Europeans, Aboriginal peoples relied on stories to connect communities and maintain strong tribal cohesion. The story was a means for cultural continuance, and can account for its survival. ${ }^{46}$ This system of inter-tribal communication continued throughout the period of colonial expansion, and persists today. What makes the story so significant is the fact that despite great efforts made by both the Canadian government and Christian religious organizations to eradicate 'Indian' culture, indigenous knowledge prevailed. In Talking Indian: Reflections on Survival and Writing, Anna Lee Walters, a Pawnee/Otoe writer, credits cultural continuance and survival over generations to the power of oral traditions. $^{47}$

The creation of Aboriginal identities is connected to the stories told. However, these identities are now interwoven with Eurocentric representations of Aboriginal peoples. From the beginnings of contact, through the processes of colonial subordination, the 'Indian' emerged saturated in Euro-Canadian concepts of cultural superiority. The 'Indian' is a representation of the European imagination, a created myth based on Eurocentric perspectives. The othering of indigenous peoples and the fixed sign of Indian 
warrior, Indian princess, and squaw, all reflected in travellers' journals, literature, photography, and later Hollywood westerns, have resulted in stereotypes that prevail today. These stereotypes not only penetrate the mainstream consciousness of the nonAboriginal, but more significantly, inform Aboriginal peoples of themselves. For generations, Aboriginal peoples have been witness to the marginalized and subordinated image of the Native, resulting in a detrimental self-understanding. ${ }^{48}$ However, the act of Aboriginal storytelling is a counterforce to these negative images. Homi K. Bhabha suggests the theory that post-colonial projects seek to explore scattered historical contingencies for:

Elaborating empowering strategies of emancipation, staging other social antagonisms. To reconstitute the discourse of cultural difference demands not simply a change of cultural contents and symbols; a replacement within the same time-frame of representation is never adequate. It requires a radical revision of the social temporarily in which emergent histories may be written, the rearticulation of the 'sign' which cultural identities may be inscribed. ${ }^{49}$

Lori Blondeau's performance practice can be located within Bhabha's concept of postcolonial projects, for she acts as a storyteller to reclaim Aboriginal stories from the colonial discourse. The storyteller, therefore, gives voice to silenced histories and subsequently re-envisions cultural identities. Armstrong states in "Threads of Old Memory":

I search for the sacred words spoken serenely in the gaps between memory the lost places of history pieces mislaid forgotten or stolen muffled by violence splintered by evil... When I speak I choose the words gently asking the whys dangerous words in the language of the newcomers words releasing unspeakable grief for all that is lost dispelling lies in the retelling I choose threads of truth that in its telling cannot be hidden 
and brings forward

old words that heal

moving to a place

where a new song begins

a new ceremony. ${ }^{50}$

In this respect, Emerance Baker's recent article, “Loving Indianness: Native Women's

Storytelling as Survivance" argues that Aboriginal stories about being Aboriginal may

have begun as responses to the damaging constructions of the 'female native' by

European discourses. Paula Gunn Allen, a Laguna/Sioux professor and writer, comments:

Since the coming of the Anglo-Europeans beginning in the fifteenth century, the fragile web of identity that long held tribal people secure has gradually been weakened and torn. But the oral tradition has prevented the complete destruction of the web, the ultimate disruption of tribal ways. The oral tradition is vital; it heals itself and the tribal web by adapting to the flow of the present while never relinquishing its connection to the past. ${ }^{51}$

The relationships between identity and story, aesthetic expressions and identity, community and stories are all interconnected.

Performance art comes to the forefront for reclaiming identity and resisting stereotypes. Elin Diamond argues that performance art can affirm or deny, create or deconstruct identity. ${ }^{52}$ Performance art, characterized as a 'radical form of art making,' has its roots in the experimental and interdisciplinary dimensions of twentieth-century art movements. ${ }^{53}$ From the 1970 s onward, performance art emerged as the genre of choice for many artists from marginalized groups and cultures who "found the strategy of radical critique necessary to articulate issues surrounding ethnicity, sexual orientation, gender, race and class distinctions. ${ }^{, 54}$ Nonetheless, Aboriginal performance art did not surface until the mid-1980s, along with other new indigenous aesthetic expressions. In Performance and Cultural Politics, Elin Diamond states that performance can facilitate a discussion for the terminology of 're,' meaning, that performance can reconfigure, resignify, reinscribe, recreate and reclaim existing discourses. ${ }^{55}$ Within this context of 
acknowledging the role of performance in the postmodern and post-colonial era, the position of identity is heightened.

Charles Garoian, in Towards an Art of Politics, notes that the methods of intellectual exploration and expression, grounded in postmodern thought, have enabled artists to critique traditional aesthetics to challenge and blur the established boundaries. Furthermore, with regard to cultural identity, postmodern performance art has provided artists with a position from which to engage historical ideologies and stereotypes, to question the politics of art, and to challenge the complexities and contradictions of cultural domination in the modern, postmodern, and post-colonial worlds. ${ }^{56}$ An authoritative voice in performance art, Allan Kaprow, argues that performance art can provide laboratory conditions for basic research in art and life. ${ }^{57}$ Consequently, for Kaprow, the production of art involves a dedication to close observation, engagement, and interpretation of the process of living, as well as the incorporation of strategies of appropriation. From this point of view, Aboriginal performance artists like Blondeau appropriate stereotypical identities to critique perceptions of indigenous peoples, bringing to life the absurdity and erroneous representations and stereotypes held by Euro-Canadian society. Performance art enables the blurring of art and life, and allows for art to come alive, stepping out of the frame and into a living medium. Blondeau removes the stereotypes of the 'Indian Princess' and 'Squaw' from the static printed page and brings them to life, incorporating her own lived experiences into the creation of subversive performance personas such as CosmoSquaw (Figure 4) and Belle Sauvage (Figure 6). Goldberg says, "Live gestures have constantly been used as a weapon against the conventions of established art, the radical stance has made performance a catalyst in the 
history of twentieth century art." 58 The decision made by Aboriginal artists such as Blondeau, Belmore, and Luna to adopt performance as a medium for artistic expression is a method for protest, enabling their voices and visions to be reclaimed, recreated, and redirected. The combining of performance art with Aboriginal storytelling allows Blondeau to draw from two discourses whose central purpose is to engage in order to resist. Therefore, performance art in the post-colonial context enables art and stories to come alive, protesting cultural inaccuracies and voicing change.

Henry Giroux argues for the incorporation of artistic and aesthetic expression for an expansion of knowledge and understanding. ${ }^{59}$ In essence, Giroux recognizes the power of art to educate. I argue that performance art is similar to the process of storytelling, as they both offer an occasion to generate discussion and cohesion within a group of people, while also expressing acts of social and cultural resistance. Giroux's concept of 'rupturing practice' theorizes performance art as an arena for cultural activism. It introduces into this arena new modes of representation and voices that have previously been ignored by the 'mainstream. ${ }^{60}$ This concept gives performance the means for epistemological rupture, causing a shift in relations of power, and is exemplified in Lori Blondeau's A Moment in the Life of Belle Sauvage and Are You My Mother? These performances will be discussed in depth in the following chapters. Blondeau's artistic practice is story-bound, telling numerous stories at once and enabling interplay between performance art and storytelling. Through performance, the artist controls the story she wishes to tell. In other words, Blondeau's act of performing the story is a means for disruption. It is also an intervention utilized as a strategy of cultural survival. Culture, as discussed by Bhabha, is a strategy of survival rooted in cultural displacement. Bhabha 
writes, "Culture reaches out to create a symbolic textuality, to give the alienating everyday an aura of selfhood, a promise of pleasure."61 Following Bhabha's argument, Aboriginal performance artists who are high-tech storytellers relocate indigenous stories, and participate within the long history of Aboriginal cultural resistance.

Due to the current political climate in Aboriginal communities, performance art can act as a platform for artists to discuss socio-cultural and political issues with both indigenous and non-indigenous audiences. ${ }^{62}$ Blondeau transforms spaces such as the gallery, once entrenched in colonial discourse, into places that encourage discussion and contemplation. The performance practice of Blondeau compellingly fuses the methods of performance art and Aboriginal storytelling to generate acts of socio-political and cultural resistance.

\section{Contemporary Aboriginal Performance Art: The Rise of High-Tech Storytellers as Political Activists}

In 1981, one hundred Aboriginal women from across Canada invaded the Department of Indian Affairs (now DIAND) in Vancouver, British Columbia. They occupied the government office for eight daysं, after which time they were forcibly removed by the police, charged, and then jailed. During their eight-day occupation, the organizers of the protest invited the media to record particular moments, such as the sharing of stories and the singing of songs (Figure 8). Tagny Duff writes:

\footnotetext{
Amelia Productions, a collective of video artists and feminists, were also invited to document the event, and produced the documentary video Concerned Aboriginal Women. The organizers employed video, TV, and print media (in particular Kinesis, a feminist magazine) and worked with Amelia Productions to declare their manifesto calling for better living conditions for indigenous people living on reserves, and for the provincial and federal governments to acknowledge corruption in the DIA office. ${ }^{63}$
}

As Duff states, this political action of documenting and recording the occupation of the DIA offices is in line with the parameters of what she calls performance intervention for 
the camera. Duff argues that this protest reflects parallel strategic tactics to "performative media infiltration' employed by earlier feminist activists. The protest staged by the Aboriginal women reflects the long history of indigenous political interventions, protests, and political resistance. ${ }^{64}$ Perhaps this collective protest by one hundred Aboriginal women is among the first performances of high-tech storytelling for political activism.

An introduction to Aboriginal performance art as an artistic medium locates parallels and connections between Lori Blondeau's performance practice and the larger discourse on the subject. Within this discussion of Aboriginal performance art, the practice of high-tech storytelling will be explored, linking the work of Blondeau with that of Luna and Belmore. All three incorporate Aboriginal traditions of storytelling with contemporary artistic practice and technology, such as, video, photography, and music. These artists draw on traditions of oratory, sharing stories to entertain and educate. The practice of Aboriginal performance art has been nurtured and supported through artist-run centres such as the Grunt Gallery in Vancouver, and its projects, for example, the First Nations Performance Series, 1989-2004. ${ }^{65}$ Through the initiatives of galleries like Grunt, the Walter Phillips Gallery in Banff, Alberta, and funding projects from the Canada Council for the Arts, contemporary Aboriginal performance art has moved into a realm of its own, and onto the international stage. In 2005, Anishinabe performance/installation artist Rebecca Belmore became the first Aboriginal woman to be selected as Canada's representative at the venerable international art exhibition, the Venice Biennale. ${ }^{66}$ Concurrently, James Luna represented the Smithsonian's National Museum of the American Indian at the same event. Belmore's presence as Canada's representative is a significant event in the history of Canadian and Aboriginal art. Could this selection be a 
catalyst for more development and change within the climate of Aboriginal political, artistic, and art historical discourse? This event raises many questions about the sociopolitical history of Aboriginal culture in the Canadian context. Does this event symbolize the current or future relationship between indigenous peoples and the Canadian government? Does it reflect institutional shiftings whereby contemporary Aboriginal art is no longer marginalized? Or is it the result of a successful and well-written grant proposal? Then again, perhaps we are witnessing yet another token gesture whereby Belmore represents nothing more than a public relations triumph, showing the global artistic and political communities Canada's 'commitment' to the 'improvement' of its relationship to its indigenous peoples. Whether this event in Canadian art history is a catalyst for change or political tokenism, Rebecca Belmore's performance serves as evidence of her place on the international art scene, and makes a bold statement in regard to her abilities as an artist.

In the future, Belmore's video-based performance, Fountain (Figure 9), at the Venice Biennale, will undoubtedly be considered a pivotal moment in Canadian Aboriginal art. In 2004-05, both Belmore (Figure 10) and Blondeau (Figure 11) were the subjects of cover stories in Canadian Art Magazine. These events may lend the necessary momentum for galleries and cultural institutions across Canada to step up and recognize contemporary Aboriginal art as a significant body of work. Blake Gopnik critically discusses Luna's and Belmore's selection to attend the Biennale:

\footnotetext{
When artists have been chosen for the Biennale, you know they've truly arrived. This year, two native North Americans had prominent spots in the exhibition. Does this mean that native art in general has reached a new level of art-world recognition? Or is it a fluke, or even the kind of tokenism that could disappear again $?^{67}$
}

Gopnik's statement asks critical questions with reference to contemporary Aboriginal art. 
It also acknowledges the significant place Aboriginal performance art has within the larger global discourse of contemporary art.

Rebecca Belmore was one of the first Canadian Aboriginal performance artists to receive extensive attention in the late 1980s. Lee-Ann Martin writes:

Early national attention came to her in 1987 in Thunder Bay, Ontario, where she lived at the time. Rising to the Occasion, now in the collection of the Art Gallery of Ontario, was a dress that simulated a beaver house and which figured prominently in the parade and video performance Twelve Angry Crinolines, staged on the occasion of a royal visit to the city by Prince Andrew and his new wife. 68

The following year, Belmore received national attention once again, for her Exhibit $671 B$ (Figure 12), which was a critical response to issues surrounding the exhibition, The Spirit Sings: Artistic Traditions of Canada's First People, organized by the Glenbow Museum in conjunction with the 1988 Calgary Winter Olympic Games. Exhibit $671 B$ was performed outside the Thunder Bay Art Gallery. ${ }^{69}$ It was as much a performance as a political protest foreshadowing the beginnings of contemporary Canadian Aboriginal

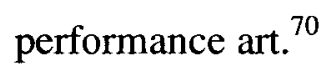

Aboriginal performance art must acknowledge its association and interconnection with the indigenous visual arts. ${ }^{71}$ Contemporary Canadian indigenous artists are exploring the multiple stereotypes and identities ascribed to Aboriginal peoples as a result of colonial history. Their work fits within the broader discourse on identity and cultural performance. However, the categorization of 'mainstream, 72 performance can be problematic due to differing socio-political experiences and realities. For instance, performance artist Coco Fusco discusses the current backlash against art produced by artists from the non-dominant society and/or minority groups, which negotiates and presents issues of colonial domination and its effects on identity and culture. According to Fusco: 
Since the backlash against early 1980s identity-based art exploded in the early 1990s, the art world has grown increasingly hostile to the deployment of personal experience as aesthetic or political gesture. In the 1980s, multiculturalism enjoyed a brief period of positive attention and autobiographical confessions were the order of the day. ${ }^{73}$

Fusco discusses how issues of representation, history, and identity differ for subaltern

artists when compared to mainstream artists. She acknowledges the necessity of

continued political negotiations and protest through artistic practice. She writes:

The backlash against socially engaged art practice has spread from the popular media and the far right into everyday life and art scholarship. The political demands for inclusion and institutional critique that characterized subaltern art practice of earlier periods are regularly described by critics as a prior evolutionary stage, implying that truly human art needs to surpass such concerns. It is as if we are being encouraged to believe that institutional racism never existed, as if art history had never been Eurocentric, as if the current wave of 'multicultural normalization' had always been in place. To focus on the imbalances of power and institutionalized racism has deemed anathema to beauty, championed once again as the essence of art. Cultural production that addresses the ways that the colonial legacy of racism shapes the arts institutions, arts reception, and art scholarship has been lumped together with the tales of woe confessed on television talk-shows. ${ }^{74}$

In relation to its development as an artistic practice, Aboriginal performance art's history is situated within a narrative parallel to that of mainstream performance. Marvin Carlson writes that from the 1970 s onward the performance of identity, usually based in the autobiographical, became a common form of performance art. He notes that,

Its frequent concern with providing a voice to previously silenced individuals or groups often involved such work in social and cultural issues as well. Other sorts of politically engaged performance, however, were also developing at the same time...less concerned with the exploration and expression of the identity of the individual and more with the social and cultural context within which that individual must operate. ${ }^{75}$

Aboriginal performance art may be seen as a combination of performances of

personal identity and culture. In terms of the aesthetics, the productions are

heterogeneous reflections and manifestations of the diverse cultural communities across

Canada and their relationship with Euro-American society. Aiyyana Maracle writes:

From my observations and conversations, Native practitioners of performance draw their influences from a variety of sources, not the least of which is their personal understanding of Native culture and spirit, and/or their search for it. Overlaid on this are one, some, or all of the following: the traditions of historical and contemporary performance art, European theatre traditions, dance, and music of varying genres. ${ }^{76}$

Inasmuch as they are situated within contemporary society Aboriginal artists possess a 
relationship to the 'mainstream' development of artistic practices. However, I agree with Fusco's criticism of the mainstream's negative analysis of identity-based art made by the 'subaltern' artists. As we recognize connections between 'mainstream' and Aboriginal performance art, as a discourse, we must also highlight the diverse issues experienced by Canada's Aboriginal community to avoid assimilating indigenous histories into the socalled 'mosaic' of multiculturalism. As Phillip Zarilli observes, performance art "as a mode of cultural action is not a simple reflection of some essentialized, fixed attributes of a static, monolith in culture but an arena for the constant process of renegotiating experiences and meanings that constitute culture."77 From Zarilli's point of view, performance can be recognized as a central apparatus contributing to the ongoing construction of culture. Aboriginal performance artists utilize cultural signs for their commentaries that criticize the Eurocentric position in relation to non-Aboriginal 'understanding' of Aboriginal cultures. They explore through performance their cultural and political histories. Archer Pechawis suggests that contemporary Aboriginal performance art allows for a claiming of space:

In that space the stories are re-told, re-interpreting what was assumed understood. The performance space becomes part of the moccasin telegraph: a gathering place, a communal council fire. Grievances are aired. Relations are shown. News of the community is examined, the larger community of Indianess considered. ${ }^{78}$

James Luna is a high-tech storyteller, incorporating his lived experiences into his performance narratives and installation spaces. Blondeau relates a story about him:

He [Luna] told me a story about being at an Indian Studies Conference. He was sitting at a table with an old lady who was about to receive an award for being a storyteller and she asked him what he did and he told her: I'm a high tech storyteller-I use all these props. And after he did his presentation, he came back to the table and she goes: Oh, you are a high tech storyteller! ${ }^{79}$

Luna shares his stories using new technology, material culture, and humorous inventions such as a 'high-tech peace pipe,' 'wet-dream catcher,' and '2worlds War Dance 
technology' ${ }^{80}$ He says, "In my work, I'm not just criticizing a condition, I am in the condition. ${ }^{, 81} \mathrm{He}$ is a Luiseno Native American and lives on the La Jolla Indian Reservation, in California. He believes that installation/performance art offers "an opportunity like no other for First Nations people to express themselves without compromise in traditional art forms of ceremony, dance, oral traditions, and contemporary thought. ${ }^{, 82}$ His installations and performances transform gallery spaces into what Luna describes as 'battlefields,' where the audience is confronted with the nature of cultural identity, the tensions generated by cultural isolation, and the dangers of cultural misinterpretation. ${ }^{83} \mathrm{He}$ is aware of the biased space of galleries and museums. He confronts the coded colonial space, with the intention of generating conflict and opposition against colonial systems of control, with the understanding that a neutral space will almost certainly never exist. His purpose is clearly to make a difference through education. His work addresses ignorance and the dangers of typecasting and stereotyping while creating ways of understanding. ${ }^{84}$ Luna's created environments function "as both aesthetic and political statements, addressing the mythology of what it means to be 'Indian' in contemporary North American society and exposing the hypocrisy of the dominant society, which trivializes First Nations people as romantic stereotypes." Luna's work challenges viewers to examine their own prejudices, as it is provocative, often dealing with difficult issues, such as poverty and alcohol abuse.

Luna's Biennale performance, Emandatio 2005 (Figure 13), was composed of one performance and two installations. The Chapel for Pablo Tac is one of his installation spaces. This was a new work created for the Biennale. Emandatio is a Latin word that translates as 'emendation,' and is defined as "the act of altering for the better, or 
correcting what is erroneous or faulty; improvement; removal of errors or corruption."86 Similar in form to other works in his extensive performance/installation portfolio, Emandatio was a multifaceted presentation of video projections, audio recordings, photographs, layered screens, found objects, and dance and audience participation. ${ }^{87}$ The exhibition honoured a Roman Catholic Luiseno, Pablo Tac, who in 1832 set sail to join the priesthood and learn missionary skills in Rome. The installation chapel was dedicated to him. Luna's performance stage was a pseudo-ceremonial stone circle. He dressed in a series of costumes representing the clichés of Indianness. He incorporated objects that interplay with the sign of the 'Indian', such as, moccasins, a loincloth, an eagle feather, a war shirt, and a Winchester rifle. However, these objects challenge notions of authentic Aboriginal culture. Firstly, most of the material culture incorporated into Luna's performance was not from his own cultural heritage. In addition, his loincloth was a blue thong with leopard print spots, and his war shirt had sports webbing up the sides. Blake Gopnik's observation from witnessing Luna's performance was that it seemed that Luna was "trying to inhabit everything an Indian is supposed to be, has been, or could be." an interview with Gopnik, Luna acknowledges the misunderstandings his performances generate. Luna's account reflects similar unfortunate and frustrating misinterpretations of Coco Fusco's and Gomez-Pena's Couple in A Cage (Two Undiscovered Amerindians)

(Figure 14). ${ }^{89}$ Gopnik asks, "Did anyone read your performance as a traditional folk form of Indian Culture?" Luna replies:

They always do. Because even though it's tongue in cheek, part of the attraction is that I take my structure from a ceremony. But [my work] is not a ceremony, it's a performance. There are moments when I catch the audience out of the corner of my eye, and see them tear up: "Oh my God, it's an Indian," [they say]. And I kind of chuckle to myself. But after all the Indian hoopla, [I hope] they'll just talk about the piece as a piece...We weren't at the [Biennale] by fluke, or just because we're Indian, but because we've earned this. [The work] isn't just about native identity...it's about being human and being perceived as different, or being different, in this world. ${ }^{90}$ 
This discussion brings up a critical question: At what point does this strategy become predictable, and perhaps therefore, less effective? I would argue that as long as the majority of the audience members perceive the subversions as 'authentic' representations of Aboriginal culture, Luna's, Fusco's and Pena's strategies of 'playing Indian' will be politically effective and necessary. Perhaps for the 'expert' members of the audience these strategies may seem predictable, as they have been incorporated by artists such as Luna since the late 1980s. It is important not to overlook the fact that the wider audience may be unaware of the issues of Aboriginal representation in popular culture. Regardless, until global society experiences major shifts in awareness of indigenous socio-cultural contexts, the issues discussed by these artists will remain relevant in the struggle for Aboriginal decolonization and sovereignty.

The performance of satirical pseudo ceremony is also characteristic of Luna's Shameman (Figure 15). This performance satirizes the non-Aboriginal's concept of 'going native' while criticizing Aboriginal people who exploit sacred ceremony for the gazing eyes of non-Aboriginals and for economic profit. Luna opens his performance with a series of pseudo rituals including the spiritual offering of an air-freshener can, rather than a smudge of sweet grass and tobacco. He includes elements of ritual, but, he says, "these are more about protocol or oral history than spirituality. They're... a way of remembering."91 This method of remembering through the ritual act of storytelling will be explored in the work of Lori Blondeau. Both artists share common methods of storytelling, and both include 'hard stories' in their performances, which Luna argues makes 'battlefields' of gallery spaces, in order to communicate silenced historical events endured by Aboriginal peoples. In many cases, Luna and Blondeau's politicized 
performances are effectively delivered to their audiences through their use of the powerful trope of humour.

Ellen Fernandez-Sacco discusses Luna's political negotiations, which confront his presumably detached and passive viewers, consequently highlighting the instability of individual and collective identity and the consequences of the romanticization of Aboriginal culture. ${ }^{92}$ This is what makes performance art so powerful; the artist and his actions confront the prejudices people hold towards others. Luna's performance art tackles contemporary and historical issues by employing humour and parody to take, as he describes, "the first step to recovery." ${ }^{93}$ What is being recovered? Identity, voice, stories and histories of indigenous peoples are being recovered by Aboriginal artists. Luna utilizes humour as a strategy to "win over audiences and lure them into listening to more challenging material." 94 Laughter allows for the confrontation of painful truths and attitudes, which in turn enables a rejuvenation of relationships and perspectives. ${ }^{95}$ Furthermore, the relationship between Aboriginal and non-Aboriginal people can be renegotiated by generating a greater cross-cultural understanding and communication. James Luna has successfully negotiated high-tech storytelling, which has been influential in the development of Aboriginal performance art.

Rebecca Belmore is one of Canada's leading installation/performance artists. Like Luna, she is a high-tech storyteller who utilizes technology and other props to tell her story. From her Exhibit $671 B$ (1988) (Figure 12) to her Biennial video-performance Fountain (2005) (Figure 9), Belmore includes personal, familial, community, and national stories to share Aboriginal histories. Jann L.M. Bailey and Scott Watson introduce Belmore in her Biennale catalogue with the following passage:

Belmore's art, whether it is installation, video or photograph, has its basis in performance, 
which she, in turn, sees as a medium shared by old traditions and modern expression-a medium both indigenous and international. As a vehicle for polemics, Belmore's performance art almost always features her body. Her physical presence in the work calls forth a sense of loss for something absent, while creating an energy of resistance... The sense of loss in Belmore's work has been explicit and specific. In addition to lost battles and the scourge of racism, there is a loss of cosmology and nature, a remapping and reimagination of the inhabited world... 96

This is evident in Fountain (Figure 9) which was conceived for the Canada Pavilion in Venice. The video-performance is projected through falling water. Lee-Ann Martin writes that "Fountain is quintessential Belmore. Her reputation, across Canada and internationally, has been earned with performances and installations that reveal sensitivities to history and place, memory and absence. ${ }^{977}$ Martin commends Belmore's "ability to manipulate materials and concepts into innovative special environments," 98 which I would argue ultimately generates commentary and testimony to colonial history. Fountain is set on Iona Beach, south of Vancouver, where the city's sewage is dumped into the ocean, only kilometres from the Vancouver International Airport. The performance is presented in five scenes and is videotaped on a typical, cold January day. It starts with a panoramic view of the grey ocean and sky, moves quickly along a sandy beach littered with logs from the forest industry salvaged by the ocean's tide. Suddenly, fire explodes on the beach. The next scene shows Belmore in the ocean, struggling to fill a bucket with water (Figure 16). She continues to struggle, but repeatedly falls (Figure 17). This cycle of struggle then shifts, showing Belmore walking towards the camera (Figure 18), holding a bucket, struggling forward with 'great resolve.' Belmore 'heaves' the bucket, imagined as water, at the viewer. The water has transformed into blood, flowing down the screen (Figure 19), leaving the viewer with an image of Belmore staring through the bloodied screen (Figure 20). As Martin suggests, she "confronts the camera with a somber, resilient look. It is the expression of someone ready to move 
forward, with nothing but fear and, sadly, nothing more to lose."99 Belmore's performance offers multiple meanings specific to Vancouver, the Pacific Northwest, and Canada, but also to Europe and Venice. She intricately weaves layers of meaning into her performance offering multiple stories for her viewer to unravel and reflect upon. For example, fountains are common to European cities as large and opulent civic installations, arguably representing the Renaissance of European culture and the birth place of imperialism. For an aboriginal viewer, fountains could represent the colonization of indigenous culture by European invasion. Water is the common thread which is woven through each scene of this performance. Perhaps commenting on the Pacific ocean and the reliance of the people on this resource, or does it represent the waters European settlers travelled across to arrive in North America.

Ayumee-aawach Oomama-mowan: Speaking to Their Mother (1991) (Figure 21) is a performance that demonstrates Belmore's use of indigenous oratory in her artistic practice for political activism. This performance employs a beautiful and enormous wooden megaphone; it has moved to various locations across Canada addressing Mother Earth, acting in continuum as a collective story. ${ }^{100}$ Belmore reclaims indigenous voice, and claims a decolonized space for the sharing of multiple Aboriginal voices. I perceive this performance to be a method of talking back to the land, which offers the opportunity to share stories contributing to the movement towards sovereignty and also to the process of decolonization. Ayumee-aawach Oomama-mowan offered a platform for personal voices to be vocalized, which throughout the processes of colonization had been marginalized and muted ${ }^{101}$ Townsend-Gault discusses how in Ayumee-aawach Oomamamowan, the lyrical and political negotiate equal roles in giving voice to others, while also 
enabling Belmore to find hers. ${ }^{102}$ Belmore's work creates a new space for contemporary Aboriginal stories and voices to be heard.

\section{Belmore's installation Mawa-che-hitoowin: A Gathering of People for Any} Purpose (1992) (Figure 22) created for the National Gallery of Canada's exhibition Land, Spirit, Power, consists of a circle of chairs taken from her own kitchen and from those of her women friends and family. Earphones are placed on each chair, enabling the viewer to participate in the circle, to listen to the stories being shared. Sitting on these women's chairs and listening to their stories, the viewer listens to life experiences of Aboriginal women. The women's circle introduces the viewer to Belmore's female communitylearning the sources of their struggles, joys, and strength. ${ }^{103}$ These voices and stories have been neglected, ignored, and discarded. Janet Berlo and Ruth Phillips note that this piece creates a space for listening, talking, and for reaching understanding. ${ }^{104}$ It also recognizes oral tradition and storytelling, while evoking Belmore's more personal influences:

I have with me the influence of my Kokum (grandmother) and my mother... I see their hands in my work...I can see their hands touching hide, cloth, and bead, creating colour, beauty: working hands. I look at my hands and I am aware of their hands. That is how I wish to work. ${ }^{105}$

Like Ayumee-aawach Oomama-mowan, Belmore's The Named and the Unnamed (2002) (Figure 23) gives voice to the silenced. Here, she is telling a contemporary story, expressing the harsh urban realities of Aboriginal women. Exhibited at the Morris and Helen Belkin Art Gallery in Vancouver, her Named and Unnamed project honours the women who have disappeared from downtown Vancouver, a large number of whom were Aboriginal sex trade workers. ${ }^{106}$ During her performance, which was videotaped on the streets of east Vancouver and incorporated into the gallery exhibition, Belmore yelled out the names of the missing women. She created a vigil-like scene. Her inclusion of oratory 
reinforces her intention to give voice to the silenced and to give recognition to oral stories_-in doing so she created a record of this contemporary history. In this work, Belmore is vocalizing a 'public secret,' forcing recognition of the missing women. ${ }^{107}$ The record is in the memories of all who witnessed her performance and installation. Belmore's contemporary art production articulates an aspect of the urban Aboriginal women's experience, re-asserting their identities and voices. Lori Blondeau considers both Belmore and Luna as artistic mentors, and their performance and installation practices as significant influences of her work.

\section{Conclusion}

The performances briefly discussed are part of a larger discourse of Aboriginal performance art. Pauline Johnson set the stage for this discussion of Aboriginal performance art, as her performative personas articulated some of the first story-based indigenous interventions in Canadian history. Utilizing storytelling for social change, the performance practice of Luna and Belmore participates in the decolonization of Aboriginal histories, identities, and lands. Lori Blondeau's performance practice reflects both Luna's and Belmore's high-tech approach to storytelling, as she incorporates 'hard histories,' personas, humour, music, video-installations, and photographic projections into her performances. With Belmore and Luna, Lori Blondeau participates in a collective of Aboriginal performance artists who continue to push boundaries through their practice. ${ }^{108}$ These high-tech storytellers use the practice of performance to engage their audiences to bear witness to colonial histories; their oratory is a testimony to indigenous resistance. 


\section{Chapter 3 Reclaiming the Story: Lori Blondeau's High-Tech Storytelling Practice \\ Introduction}

The story never stops beginning or ending. It appears headless and bottomless for it is built on differences...The story circulates like a gift; an empty gift that anybody can lay claim to by filling it to taste, yet can never truly possess. A gift built on multiplicities. One that stays inexhaustible within its own limits. Its departures and arrivals. Its quietness.' Trinh T. Minh-ha

In this chapter, the multiple roles the story plays in the performance art of Lori Blondeau will be explored. The discussion of the story and the act of storytelling in the previous chapter set the stage for a discussion of Blondeau's work as storyteller and political activist, while also highlighting the socio-cultural role stories play in the Aboriginal community. Blondeau's work will be explored as a continuum of performative storytelling, which incorporates a hybrid language to incite political activism for the reclamation of Aboriginal identity. Her performance art will be examined as a tool to discuss and to negotiate colonial histories and Aboriginal stories. This chapter will first explore Blondeau's high-tech storytelling, discussing the methods and implications of her performance practice. Then the performances Are You My Mother? (Figure 1) and Sisters (Figure 2) will be critically analyzed. My analyses of these performances is based on a critical engagement with video and photographic recordings, Blondeau's descriptions of the performance space, scenes and narratives, critics' reviews, and interviews with the artist. The relationship of the performances to the story and the act of storytelling will be examined. In the post-colonial sense, Blondeau re-claims and re-envisions stories of Aboriginal people. The colonial histories presented by Blondeau will be discussed. I argue that Blondeau's performance art can be seen as a post-colonial history lesson, as a method to teach her audiences silenced histories. Blondeau's practice will be explored and argued as resistance, as an act of interpellation to mainstream 
representations of Aboriginal stories.

\section{Gifting the Story}

According to Susan Brill de Ramirez, "There is a certain power that is compelling in the oral narrative as spoken by a storyteller simply because the spoken word is so immediate and intimate." ${ }^{, 2}$ Within the 'ritual' of the storytelling practice, the audience, or rather the listener, participates in a reciprocal relationship, as "the storyteller and listener interact throughout the process in a conversation that reflects the inherent interrelationality of storytelling." 3 The listener is an "active participant whose presence is necessary to the telling-creation of the story." audience is an integral part of the performance." Audience politics play a significant role in performance art's reception. Blondeau's performances are not offering exact truths to her audience; meaning is negotiated between the subjects and across language. This is exemplified by Blondeau's remarks about her performance practice, "This work has taught me that when I am working in this medium, my performance is never the same twice, the venue, the audience, and my own state of mind inform the outcome of the

piece." ${ }^{6}$ The interpretations made by audience members differ based on the individual, and the nature of performance art as an ephemeral artistic practice. In Blondeau's performance, she shares and makes connections with colonial histories such as the residential school system. Some of her audience members could be survivors of this traumatic history, while others, such as academics, may have studied it. Certain members of the audience will be unaware of the episode and may recognize the gaps in their understanding of Aboriginal history. The individual experiences and knowledge of each member of the audience will affect the ways in which Blondeau's performances are 
received and interpreted. Amelia Jones and Andrew Stephenson argue from these perspectives that "meaning comes to be understood as a negotiated domain, in flux and contingent on social and personal investment and contexts."7 By emphasizing the shiftings that occur through interpretation and result in meaning, Jones and Stephenson argue "that interpretation itself is worked out as performance between artists and spectators (whether professional or non-specialist). ${ }^{, 8}$ Blondeau acknowledges that the interpretation of her performances depends on the 'type' of audience in her performative space. She writes in relation to performing Sisters:

I've had different responses while performing this work to Native and non-Native audiences. I've come to realize that when the audience is mixed, the reaction from the Native people is different from that of the White people. Native viewers appear to use humour as a relief for the seriousness of the piece, and having Native people in the room seems to give White audience members - permission to laugh. If I have no Native people in the room, my audience takes the pieces very seriously and rarely laughs. ${ }^{9}$

Furthermore, focusing on interpretation as an exchange or negotiation between performer and her audience, she emphasizes the reciprocal relationship present in both performance art and Aboriginal acts of storytelling. In this way, Blondeau's gallery spaces become public sites of learning, creating interactive and reciprocal learning environments. Her performances create sites of public memory while also participating in a site of public memory.

In Blondeau's performance practice, the audience bears witness, participating in the decolonization of Aboriginal identities and stories. They witness her stripping of histories from the colonial texts, while also revealing traces of indigenous knowledge. The work of bearing witness, noted by Edward Said, is a powerful historical practice. ${ }^{10}$ Bearing witness is an act of acknowledgement and recognition, which engenders understanding and, potentially, intervention. It is a 'powerful historical practice' because 
it offers the potential for social change and preventing the repetition of past atrocities. As Homi Bhabha states, "Remembering is never a quiet act of introspection. It is a painful re-membering, a putting together of disembodied past to make sense of the trauma of the present."11 Blondeau's performances gift the knowledge of the story, engendering recognition of Aboriginal cultural history. Her stories act in her performance spaces as the agent in the storyteller-listener relationship. The audience reciprocates by accepting the knowledge and stories gifted to them by Blondeau. Drawing on the concept of the palimpsest, from a post-colonial point of view, the histories re-voiced by Blondeau instigate a decolonization of indigenous oral texts through the act of bearing witness.

\section{Performance Art and Storytelling: Lori Blondeau as High-Tech Storyteller}

James Luna...calls himself a high-tech storyteller, which hits the nail on the head, because that's what Aboriginal artists are. ${ }^{12}$

Lori Blondeau is a high-tech storyteller whose artistic practice illustrates the fusions of oratory traditions, contemporary technologies, and performance art. It is significant to note that Blondeau also participates in Cyber Powwow, ${ }^{13}$ which utilizes cyberspace as a vehicle for sharing Aboriginal artists' voices and artistic visions. Her role as high-tech storyteller pushes the boundaries of oratory traditions, not only the content of her narratives, but in the use of multiple props to articulate her story. Technology is incorporated into her performance spaces, bringing the tradition of Aboriginal storytelling into the realm of high-tech.

Lori Blondeau's high-tech performance practice, photography, video-projections, and music are among the many technological materials brought into the performance space. For example, when Sisters (Figure 2) was presented at the Gordon Snelgrove Gallery of the University of Saskatchewan in 2002, the first part of the performance was 
projected onto a large screen or wall behind Blondeau during the second part of the performance. The specifics of the performances will be discussed later in the chapter. In some of the Betty Daybird (Figure 5) performances, a slide show is projected behind her with images of Daybird's adventures. During her performance at Neutral Space Gallery's Belle Rogue Fashion Show, for instance, images of Daybird posing in various venues, such as a pool hall, are incorporated into her storytelling practice. Music also plays a significant role in Blondeau's practice. It is incorporated into Belle Sauvage's performances, usually at her entrance and exit, to enhance audience reception. The music choices generate further meaning not only in relation to Blondeau's performance personas, but also for the audience members. The music incorporated by Blondeau from Tom Petty to Frank Sinatra can trigger memories in her audience.

Storytelling and performance art share a fundamental element, ephemeral space. Phelan proposes that the significance of performance art lies in its role as 'representation without reproduction,' which is a one-time event that locates a subject that cannot be 'reproduced within the ideology of the visible. ${ }^{14}$ However, in most cases, performances are recorded on video or photographs and are often incorporated into an installation by the artist. In the case of Rebecca Belmore's Venice Biennale performance, Fountain (Figure 9), her performance was a video-based production. Performance art in the age of video recordings and cyberspace is a paradoxical artistic medium that has allowed a larger audience to view and experience performances. This concept of performances transcending into the production of objects is seen in the performance and performative photography of Blondeau. The taking of a series of digital photographs, similar to a series of video scenes, constitutes participation within the realm of performance art, as it 
'records' and 'documents' the artist's series of events and actions. This is exemplified in Blondeau's images Surfer Squaw Catch (Figure 24), Surfer Squaw Surf-Up (Figure 25), Surfer Squaw Grease (Figure 26). The image of Lonely Surfer Squaw (Figure 4) photographed by Bradlee Larocque will be discussed in detail later. In this series of images, the performance of Blondeau transcends the concept of a 'one-time event' and illustrates how performance is a process-oriented artistic practice. Her stories are not only shared through her performance, but are also shared through her 'recordings,' illustrating the pluralities performance offers. For the 2004 Planet IndigenUs festival (13-22 August) in Toronto, in partnership with Gallery TPW, Lori Blondeau and the $7^{\text {th }}$ Generation of Image Makers (7GIM, an Aboriginal youth mural program) participated in the Streetwise public postering project (Figure 27). On this occasion, Lonely Surfer Squaw took to the streets. She was showcased all over the city on the poster collaboratively created with 7GIM, provoking public discussion and contemplation, and perhaps laughter (Figure 28). By removing Blondeau's Lonely Surfer Squaw from the gallery and placing her acts of performativity on the street, The Streetwise project challenged the public to question their views on the representation of Aboriginal women in popular culture. This poster would have been seen repeatedly by the public. I would argue that each repeat viewing of the Lonely Surfer Squaw offered a possibility for critical engagement, perhaps raising questions such as why is this here, or why is this woman standing in the snow with a surfboard, along a river?

It is important to address the fact that Blondeau's performances are repetitively performed at various venues. Even with a scripted narrative, each performance is a onetime event with numerous variables, such as the artist's current mood, audience 
reception, and even venue parameters that affect the course of the performance.

Blondeau's photographs, videos, and installations act as testimony to the process of their own formation, and paradoxically, to performance art as a form that is essentially process oriented, ephemeral. Her work operates within the revolutionary realm of 'representation without reproduction' that Phelan claims for performance, and simultaneously, in the realm of images as permanent works that continue to challenge the omissions and silences within the representation of indigenous peoples.

The incorporation of storytelling into the practice of performance art by contemporary artist Lori Blondeau creates an effective hybrid aesthetic expression. Blondeau's employment of performative storytelling is successfully unsettling, and is a politicized force that clearly articulates her intentions as an Aboriginal performance artist. "For me being Aboriginal," says Blondeau, "dealing with political issues, performance art gives me a forum that I don't think I would be able to have in painting or printing. It gives me the choice of being able to use my voice and do texts. For the Aboriginal people, it's a great medium." "15 Blondeau hopes "to create a whole new set of images which show us as contemporary people living in contemporary society."16 She employs the practice of performance art to articulate her concerns and desires for Aboriginal people, using her family's story to present the larger issues, such as loss of identity, stereotyping, urbanization, gambling, alcoholism, and cultural displacement. Blondeau concludes:

I use my mother and her sisters and their stories a lot in my work, as well as my own history. The really great thing about performance art is that I' $m$ able to create this living history at the moment in time. I'm trying to juxtapose a fictional history against the history that has been created for us by Canadian history. I guess it's playing with history. ${ }^{17}$

Playing with history and Aboriginal knowledge is a strategic practice utilized by 
Blondeau, offering new representations for her Aboriginal audiences, and new understandings for the non-Aboriginal viewer. Blondeau's performance incorporates post-colonial instruments for refashioning voice and vision, elements from mainstream performance art, and storytelling, a fundamental tradition of Aboriginal culture. Drawing upon Luna's understanding of body politics, we can see the human body as a 'social instrument' to articulate critical discourse. She intertwines her stories with colonial histories and their legacies to create a narrative. Blondeau's incorporation of her cultural knowledge acts symbolically as currency gifted in the form of a story within the open parameters of performance art. The act of gifting in the form of new knowledge and representations can result in a political shifting of power and is arguably a method for empowering subjected peoples. Her method recalls Pierre Bourdieu's theory that knowledge is interconnected to political theory due to the fact that the symbolic power imposed to construct and control social frameworks "is a major dimension of political power." ${ }^{18}$ Blondeau empowers herself by reclaiming the voice and the stories of her community, thereby shifting colonial dimensions of domination and power.

Performance art has a long history of radical activism. ${ }^{19}$ Within this specific realm, performance art is an artistic practice employed in many cases to attempt to dislodge and/or rupture fixed systems of knowledge. Blondeau's practice fits within the discourse of art activism, and she uses her stories as the focus of her political protest. This concept of storytelling for social action is discussed by Edward Said in Culture and Resistance, where he talks about the significance of using storytelling as a vehicle in which to navigate a counterpoint to official public memory. Said argues, "One has to keep telling the story in as many new ways as possible, as insistently as possible, and in 
as compelling a way as possible, to keep attention on it." ${ }^{20}$ Blondeau practices this strategy of continued and repetitive telling and re-telling of stories by presenting her performances numerous times in multiple venues.

With respect to performance art theory, the essence of Blondeau's performativity lies in the re-naming of bodies, spaces, landscapes, and histories through an act of hightech storytelling. She claims colonized spaces, such as the gallery, in order to negotiate and instigate the process of decolonization. In this sense, her performance practice removes the overwritings of colonial discourse layered upon the indigenous body, landscape, and space. Her body and voice act as the traces left on the palimpsest. Performance utilizes lived experience for the process of resignifying languages, bodies, and texts. As Judith Butler observes:

We do things with language, produce effects with language, but language is also the thing that we do. Language is the name for our doing: both 'what' we do (the name for the action that we characteristically perform) and that which we effect, the act and its consequences. ${ }^{21}$

Furthermore, just as the 'name' plays a significant role in the process of language in performance art, the act of naming has contributed to the colonization process of Canada. Naming is a colonial agency employed to declare ownership and authority over lands, bodies, and culture. The process of naming also contributes to the construction of national identities. In the Canadian context, the overlaying of colonial names, such as Regina (where Blondeau grew up), and appropriating indigenous names, such as Saskatchewan, formed part of a systematic colonial strategy. The naming of Canada and her lands was part of a strategic process of generating Canadian identity.

Blondeau is aware of these processes and incorporates her own voice as a method for retelling and rewriting, while also re-naming spaces coded in colonial discourse. For 
example, the gallery space has a long history and in many cases remains encoded by Euro-centric perspectives and attitudes of Aboriginal culture. Aboriginal culture has long been the object of Western fascination, a curiosity that led to the development of academic fields and museums. Annie Coombes notes that during the late nineteenth century, the museum housed Aboriginal cultural material that was collected and categorized for the purpose of study by enthnologists and anthropologists. Coombes writes that the collections were used as visual 'evidence' of racial inferiority in comparative studies with European 'civilization,' to justify colonial expansion and domination of Aboriginal lands and peoples. These collections are also objects of aesthetic and exotic pleasure, and spectacle. ${ }^{22}$ In this discourse of the dominant and the 'other,' the museum acts as a visual metaphor of imperial histories and colonialism's conquests. In Making Representations: Museum in the Post-colonial Era, Moira G. Simpson, a respected scholar of museum studies writes:
In Europe, the tradition of museums as institutions both reflecting and serving a cultural elite has been long established and, in many, is still maintained. The museum, the 'cabinet of curiosities', is the storeroom of a nation's treasures, providing a mirror in which are reflected the views and attitudes of dominant cultures, and the material evidence of the colonial achievements of the European cultures in which museums are rooted. $^{23}$

Although the museum can act as a visual manifestation of the colonial process, it now also mirrors the current post-colonial era, illustrated by collaborative projects with source communities ${ }^{24}$ In Canadian institutions, progressive and inclusive practices have emerged, reflecting the socio-political shift towards more positive Aboriginal relations in the country's politics. The museum is undergoing radical shifts, fostering rewritings, and re-evaluating its relationships with the cultures represented in their collections. Simpson notes that these changes reflect, "shifts in the relationship between dominant Western 
cultures and those of indigenous, minority, and suppressed cultures everywhere." 25 However, alongside the theoretical shiftings and re-writings of museological practice remain the atrocious histories of unauthorized removals of material culture and sacred material of Indigenous communities throughout North America.

The nature of Lori Blondeau's performance art as an act of intervention within the gallery and museum space is reinforced by the fact that it is not collectable. Recordings made of her performances are controlled by her and are not for sale. ${ }^{26}$ At this point in her artistic career, Blondeau's work does not directly comment on the museum. Her choice of performance art, a medium that cannot be collected, is arguably an act of resistance to museological acquisition practices. In addition, she participates in the decolonization of Aboriginal representation in the gallery by means of TRIBE, an arts organization for evolving Aboriginal media, visual, and performing arts. Blondeau is the co-founder and the current director of TRIBE. ${ }^{27}$ TRIBE's mandate is to foster and support Aboriginal contemporary arts; however, it is a gallery without walls, without a permanent space, and it crosses boundaries while exploring the limitations offered by traditional gallery spaces. $^{28}$

As a gallery without borders, TRIBE negotiates and promotes the inclusion of Aboriginal arts in the 'mainstream.' It is establishing platforms on which contemporary indigenous arts can be situated, providing a political voice camouflaged in the costume of an arts organization. The relationship between the museum and/or gallery with Aboriginal cultural material is predicated on the histories of colonial hegemony, but is also a reflection of the current political shiftings that signal a new era of Aboriginal autonomy. 
Lori Blondeau's performances are situated within the process of storytelling as an act of survivance ${ }^{29}$ and resistance. Moreover, her artistic practice clearly tells the "hard stories' in order to decolonize the histories/stories of Aboriginal peoples, specifically women. She participates in a conversation whose content is social activism, and partakes in the arena of socially conscious artists such as Coco Fusco and James Luna. What these two have in common with Lori Blondeau is their use of artistic practice as political agency to challenge, re-write, and confront the dominant society's version of their culture, story, and identity. Augosta Boal, founder of The Theatre of the Oppressed in Brazil in the late 1970 s, explains how artists can actively challenge the dominant arts, culture, and writings through sharing and placing authority in their story. Interventions through the arts can therefore stimulate new perspectives and negotiate new spaces for interaction. ${ }^{30}$

\section{Are You My Mother?: Re-writing and Resistance}

I see memory as not just associated with past history, past events, past stories, but nonlinear, as in future and ongoing history, events, and stories. ${ }^{31}$ Joy Harjo

To set the stage, the gallery space is completely transformed for the performance of Are You My Mother? (Figure1). Lori Blondeau sits on a large rock, skinning logs. The audience walks in during her action. There is an enclosed pen made of wood posts and sheep wire near the back of the gallery, and a large rock (or chair) off to one side of it. Chairs are placed both inside and outside of the pen for audience members. In front of the rock are two logs. Sod covers the floor of the gallery space, and projected on the wall is an image of Queen Victoria. Blondeau is wearing red pants, black cowboy boots, and a traditional ribbon shirt. When the pen is full, she stops skinning logs and hammers the fence shut. She sits down on the rock (or chair) and continues skinning logs. Throughout 
this act, she tells numerous stories about the impact of the residential school experience on her family. At times she digresses from her storytelling, giving out commands such as, 'Sit up straight.' At one point in her performance, she invites the audience to join her in skinning logs. After audience participation, she returns to her storytelling. At the end of her performance, she asks an audience member to assist her, and Blondeau braids the woman's hair—then they switch places. Next, the 'planted' audience member braids the artist's hair. In the closing scene of her interactive performance, Blondeau's braid is cut off. She then stands and walks in silence out of the gallery.

Her narratives illuminate the reasons for the fence, the skinning of logs, and the picture of Queen Victoria, while also giving meaning to the title of her performance. The title Are You My Mother? recalls the loss of nurturing mothering that Aboriginal children underwent due to the residential school environment. In many cases, children became disconnected from their mothers. Also it evokes Blondeau's learning of her mother and grandmother's experiences, making her see them in a new light. The title invokes a vision of an Aboriginal child looking up at the photograph of Queen Victoria and asking, 'Are you my mother?' This question recalls the displacement the children could have felt, when left with only memories of home. These are Blondeau's family's stories.

Lori Blondeau has established her position as a high-tech storyteller incorporating personal and family stories as the bases of her performance narratives. She relates, "My family is my first and most important community. My mother and grandmother taught me how to tell stories and they taught me the significance of telling my own stories...their stories are a part of my history." ${ }^{, 32}$ Blondeau's point of departure in Are You My Mother? is her family's stories of the residential school experience in Saskatchewan. ${ }^{33}$ It is a story 
of survival and of resistance. Lynne Bell suggests, and I would agree with her, that Blondeau utilizes the medium of performance art to clear a new space for 'the enunciation of difficult knowledge.' These new spaces that Blondeau generates from her thoughtful, introspective, and generous performances enable negotiation of colonial histories and offer resistance to silenced stories. In this respect, Walter Benjamin's account of memory and stories can be employed to illustrate Blondeau's process-oriented performance practice. Benjamin notes, "memory creates the chain of tradition which passes a happening on from generation to generation," ${ }^{, 34}$ and the storyteller shares her own experiences or those which have been reported to her. Through the act of sharing, she makes it the experience of those who are listening. ${ }^{35}$ When the audience members become witnesses, they take on the role of active listeners publicly giving recognition to her stories.

Jean Fisher discusses Coco Fusco's storytelling practice as a site where the act of witness may enable audiences to "rediscover [their] potential as agents of change."36 Although Fusco and Blondeau's performance practices differ, they possess parallels in their use of storytelling to re-negotiate colonial histories and gendered spaces. In this regard, they both occupy, through narrative, symbolic spaces. ${ }^{37}$ Fisher argues that storytelling "has special poignancy for those peoples for whom the trauma of racial violence has yet to be healed and adequately narrativized." 38 Blondeau's storytelling contributes to the ongoing processes of Aboriginal empowerment and healing.

Blondeau's family's stories of the trauma endured in residential schools, as presented in Are You My Mother?, mirror the lived experiences of Aboriginals across Canada. These experiences are arguably a major contributor to many socio-cultural issues 
in Aboriginal urban and reserve communities. ${ }^{39}$ Blondeau remarks:

It wasn't until 1988, when she [my mother] and my grandmother came to visit me in Montreal, that she started to talk about these experiences. There was a program on television-a drama series called Where the Spirit Lives - about a residential school on the prairies at the turn of the century. It was a young Cree girl who was taken from her family and put into a residential school: it was her story. ${ }^{40}$

After viewing the film Where the Spirit Lives, Blondeau asked her mother and grandmother what residential schools were really like. Blondeau recalls, "It was the first time that I found out that my grandmother's first language was Cree. They both told me that the television show we watched was very similar to their own experiences." 41 Thus, it was as an adult that Blondeau was made aware of the tragedies endured by the generations of Aboriginal people sent to the jointly administered, government and church controlled boarding schools. ${ }^{42}$ This system of removing and relocating children from their families, communities, and cultural context was one of the Canadian government's most intensive legislative policies to eradicate Aboriginal language and culture, to naturalize and Europeanize the 'Indian.' Although the fallout from this colonial system of education has been significant, cultural resistance and survivance continued, undermining these aggressive assimilation policies.

The residential school system was officially established in 1892 and was in effect until 1969. Although the Canadian government withdrew from official responsibility, several schools continued operation through the 1970 s into the 1980s. However, the last federally run residential school, the Gordon Residential School, closed in Saskatchewan in 1996 (Blondeau is a member of Gordon First Nations and her grandparents lived on Gordon Reserve). It is imperative to note the complexities of this history, and my intention is not to generate a simplistic, one-dimensional narrative or digress from Blondeau's performance, but to discuss the specific histories she shares. For the purposes 
of this discussion, the issues raised are strictly in relation to Blondeau's performance. The purpose behind the institution of the residential school system, according to the 1897 Sessional Report from the Indian Commissioner, was clearly established. The following statement by A.E. Forget, Indian Commissioner, is taken from the 1897 Sessional Report:

This branch of the Indian service has ever been recognized as one of the most, if not perhaps the most, important features of the extensive system which is operating towards the civilization of our native races, having its beginning in small things- the first step being the establishment of reserve day-schools of limited scope and influence, the first forward step was the founding of boarding schools both on and off the reserves. The beneficent effect of these becoming at once apparent, an impetus was thus given to the movement in the direction of Industrial training, which was at once entered upon the establishment of our earlier industrial institutions... until to-day the Dominion has had at its command a system which provides for its Indian wards a practical course of industrial training, fitting for useful citizenship of the youth of a people who one generation past were practically unrestrained savages. ${ }^{43}$

What is evident from this report is that the Aboriginal children entering the residential school system were to be re-educated to fit the Euro-Canadian model, in an attempt to strip them of their indigenous knowledge, which through ignorance, was considered to be traditions of 'savagery.' This was the experience of Blondeau's grandmother, whose first language was Cree. Onondaga artist and curator Jeff Thomas remarks in his catalogue Where are the Children: Healing the Legacy of the Residential Schools, how the residential school system, a program of social engineering established by the Canadian government, can be characterized as an aggressive system of ethnocide. ${ }^{44}$

From our position in history, we can now look back and recognize the truth of Thomas's claim. The residential school system was a forceful attempt to break down the foundation of communities, the family. The relocation of children was a means to solve the 'Indian problem,' which could be defined as the existence of Aboriginal peoples who were living on lands Euro-Canadian settlers wanted to farm. A famous pronouncement by Duncan Campbell Scott, Deputy Superintendent General of Indian Affairs, in 1920, 
encapsulates the prevailing attitude of this period towards the Aboriginal population:

"Our object is to continue until there is not a single Indian in Canada that has not been absorbed into the body politic, and there is no Indian question, and no Indian department." ${ }^{, 45}$ It was during this period of early 'development' that the government officially adopted a policy of assimilation, which was originally established during the pre-Confederation period. ${ }^{46}$ This policy was designed to "move communities, and eventually all Aboriginal peoples, from their helpless 'savage' state to one of self-reliant 'civilization' and thus to make Canada but one community-a non-Aboriginal, Christian one." ${ }^{, 47}$ The report of the Royal Commission on Aboriginal Peoples remarks that education was evidently a significant method for 'civilizing' and assimilating Natives. Today, in our democratic nation, the treatment of children in such brutal and cruel fashions seems unfathomable, and indeed disgraceful. Unfortunately, residential schools maintain a strong relationship to today's reality: the physical, mental, spiritual, and sexual abuses endured by some children who attended these jail-like 'educational' institutions constitute a legacy of trauma for new generations of Aboriginal children and their families. From this perspective, continued unpacking of this history is essential, and fundamentally linked to the possibilities of community healing. The Aboriginal Healing Foundation (AHF) suggests in their 'program handbook' that:

Intergenerational or multi-generational trauma happens when the effects of trauma are not resolved in one generation. When trauma is ignored and there is no support for dealing with it, the trauma will be passed from one generation to the next. What we learn to see as "normal" when we are children, we pass on to our own children. Children who learn that... or [sic] sexual abuse is "normal", and who have never dealt with the feelings that come from this, may inflict physical and sexual abuse on their own children. The unhealthy ways of behaving that people use to protect themselves can be passed on to children, without them even knowing they are doing so. This is the legacy of physical and sexual abuse in residential schools. ${ }^{48}$ 
Though there is a significant history of the degradation and abuse endured by the children, there is also a history of resistance and even stories of positive experiences. Many children challenged and resisted this colonial system of education, for example by continuing to use their Aboriginal language. ${ }^{49}$ These disturbing legacies have been recognized and brought out into the open. Organizations such as AHF support and encourage discussion of these experiences through storytelling and the visual arts. Perhaps, in this sense, a performance such as Are You My Mother? can act as catalyst for continued healing and empowerment. Lori Blondeau reveals why it was so important for her to tell these stories:

I wanted to talk about my mother's residential school story because, even though I am not part of my family's residential school generation, I realize that I am still strongly affected by the after-shocks of the system that was put in place to assimilate my people and exterminate their culture. We are still feeling the effects whether we went to residential schools or not. This was the drive behind wanting to make Are You My Mother? $?^{50}$

Lori Blondeau intricately weaves multi-generational stories into a politically vocal fabric. I suggest that this process of telling and re-telling not only sparks discussion but also acts as a memorial to all Aboriginal families touched by the reality and aftermath of residential schools. Thus, her performances can be seen as testimony; they acknowledge the travesties of assimilation policies while recognizing the power of the human spirit to prevail. In the following passage, which is included in the performance narrative, Blondeau remarks on the inhuman treatment of both the child and her relations, while at the same time noting the power of memories as a method of cultural survival:

One of the stories my mother told me was about her grandparents visiting her in residential school. Her own parents wouldn't go because it was too difficult for them. When her grandparents visited her, they weren't allowed to go into the grounds; they had to visit with a chain-link fence between them. My mother told me that she missed home, but what she missed most of all was the smell of home, because the residential school was a sterile environment. When her grandparents visited, my great-grandmother would throw a 
tablecloth over the fence for my mother and set one for herself and my great-grandfather. They would have a picnic of tea and bannock. My mom would always get her grandmother to throw her sweater over the fence, and then my mother would take the sweater and hold it up to her nose and just smell it. The smell evoked the memories that gave her the strength to be in this jail-like environment where physical contact with her family was not allowed. ${ }^{51}$

Blondeau's great-grandmother's presence, her smell, and her bannock served as reminders of the safe, nurturing home that Blondeau's mother grew up in prior to being forcibly removed from her family and relocated into residential school. This was the first story that Blondeau internalized and used as inspiration for her performance, and she notes, "When my mother told me about this story, I was taken aback because I could visualize it in my head as a performance piece." 52

In all of Blondeau's work, the audience plays an integral role, participating in post-colonial processes of recognition, reconciliation, re-writings, and restitution. Blondeau is actively engaged with Canada's colonial histories, and negotiates what renowned contemporary artist Isaac Julien calls "the undoing of the colonial archive." 53 In this respect, I would argue that a close engagement with the colonial archive 'with intention to un-do it' reflects a palimpsest aesthetic. In Are You My Mother?, by bearing witness to the violence and hardship of residential schools, the audience is thrust into a reciprocal relationship with Blondeau and her family's stories. What this means is that Blondeau's stories are certain to traumatize her audience as a method of provoking recognition. From this point of view, her deployment of narrative pulls into public circulation traces of memory, knowledge, and stories that have been discarded, camouflaged and or silenced by dominant discourses, and subsequently “contaminates them with a dissonant beat. ${ }^{, 54}$ Bearing witness means to write with the body, or present the body as the written document. Her body also bears witness to acts of re-membrance, and then shares these with her audience. In essence, Blondeau's process of calculated and 
fabricated storytelling is a witness's testimony. Shoshana Felman, a scholar of comparative literature who specializes in issues of trauma and testimony suggests that,

As a relation to events [witness's testimony] seems to be composed of bits and pieces of a memory that has been overwhelmed by occurrence that have to settle into understanding or remembrance, acts that cannot be constructed as knowledge nor assimilated into full cognition, events in excess of our frames of reference... Texts that testify do not simply report facts but, in different ways, encounter - and make us encounter-strangeness. ${ }^{55}$

Although Felman is talking about the impact that text can have in recounting trauma, her argument can be applied to the visual and the oral narratives of Blondeau's performance practice. From this perspective, Blondeau is gifting knowledge to her multi-generational, multicultural, and diversely educated audiences. The reception of art, similar to the reception of knowledge is highly subjective. The knowledge thus bequeathed will ultimately engender discoveries of both new and old histories/stories. Her 'gifting' of these stories creates an opportunity for viewers to take this knowledge, share it with others within their community, and reflect on their understanding of Aboriginal culture and history. In addition, her act of storytelling opens the door to cross-cultural exchanges while offering more narratives from an empowered and self-determined Aboriginal perspective. Are You My Mother? is a post-colonial history lesson which asks its listeners to actively participate in a reciprocal relationship, learning.

In addition to sharing Blondeau's familial stories of the residential school, Are You My Mother? (Figure 1) generates a commentary on power relations and systems of domination. Foucault suggests that strategies of power make an individual a subject. He argues that power applies itself to everyday life and categorizes the individual, therefore marking her by her own individuality; attaches her to her own identity, thereby imposing a law of truth on her that she must recognize, and by which others have to recognize her 
as well. Foucault defines the term 'subject' as one who is "subject to someone else by control and dependence, and tied to his own identity by a conscience or self-knowledge. Both meanings suggest a form of power that subjugates and makes subject to." 56 In the context of colonial domination of Aboriginal peoples, Are You My Mother? attempts to subvert colonial power structures by appropriating and disclosing them. This point is illustrated by the following description by Blondeau:

There is an image of Queen Victoria projected on the wall, making reference to the language of treaties, which refer to her as the Great White Mother. I imagine her picture would have hung on the walls of turn-of-the-century residential schools. Symbolically, she was the mother of all the Native children who were forced to go to residential schools. ${ }^{57}$

Furthermore, the projected image of Queen Victoria recognizes the British Empire's 'conquest' of lands throughout the world—and acknowledges colonial hegemony over indigenous peoples. While sitting in the pen, the audience is looked down upon by Queen Victoria, an analogy to the experience of the residential school student. The image of Queen Victoria is an emblem of the colonial discourse, which is saturated by attitudes of a hierarchy of culture, defined by superiority and entitlement. Colonial discourse is arguably an apparatus of power, which, as Homi Bhabha suggests, activates the recognition and disavowal of racial, cultural, and historical differences. Bhabha pursues the topic further:

Its predominant strategic function is the creation of a space for a 'subject peoples' through the production of knowledges in terms of which surveillance is exercised...it seeks authorization for its strategies by the production of knowledges of colonizer and colonized which are stereotypical... The objective of colonial discourse is to construe the colonized as a population of degenerate types on the basis of racial origin, in order to justify conquest and to establish systems of administration and instruction. ${ }^{58}$

From Bhabha's perspective, residential schools participate in the colonial discourse of surveillance and domination. Blondeau now articulates these histories in a space once 
controlled by the dominant society. In Blondeau's performance space, she subverts the systems of control once held by a colonial hegemonic government and illuminates the presence of surveillance. Surveillance is defined as,

[one of the] most powerful strategies of imperial dominance... because it implies a viewer with an elevated vantage point, it suggests the power to process and understand that which is seen, and it objectifies and interpellates the colonized subject in a way that fixes its identity in relation to the surveyor. ${ }^{59}$

Blondeau does this by placing and 'locking' some of her audience members in a confined pen, thereby controlling their movement. In the context of surveillance and control systems, the 'gaze' plays a fundamental role; and conversely, in the post-colonial sense, by recognizing the presence of a colonial gaze, the subaltern can mirror back colonial strategies of dominance.

Are You My Mother? elucidates the power structures of colonial Canada and the systemic incorporation of domination throughout societal spheres. During her performance, once the fenced in area is full of audience members, Blondeau closes the pen shut. This act of enclosure, I would argue, is intended to make her audience feel uncomfortable and force them to recognize their loss of control. In "Some Kinda Princess," Blondeau writes: "I get up when I see the pen is full, and I close it and hammer it shut with fence-post nails...I want people to feel that they can't leave, that they have no choice but to stay in the pen. This is a reference to my mother's experience in residential school: She had no choice; she had to stay. ${ }^{, 60}$ There are numerous possible readings of the fence, but I would suggest that it resonates with the same symbolism as the image of Queen Victoria: colonial control, domination, and superiority. The fence maps out a specific space. In this performance, however, it is a fluid space that moves through history, naming both colonial and post-colonial landscapes. Blondeau can be said to 
move though history by means of the stories she shares, back to those of her greatgrandmother, then forward to her own story. She negotiates a new space, one that she controls and claims for her family's stories. The fence in her performance evokes the experience of her parents and grandparents being forbidden to enter onto Residential school grounds. In theory, Blondeau thereby reclaims the fenced-in land of residential schools. As Blondeau tells the fence story, some audience members sit confined in this space, while others peer in. In this way, the enclosing fence makes reference to concepts of the spectacle. Each group is looking at the other side of the fence, while Blondeau controls both spaces.

In addition, the story of Blondeau's mother and grandmother visiting through the fence stirs the senses, where remembrance is stored. Among the senses, smell is particularly evocative and poignant. Blondeau affirms, "It is about how smell can trigger memories." This appeal to the senses, incorporated into the gallery space, will generate personal memories for the audience, perhaps of their own mothers and grandmothers. In her article "Some Kinda Princess," Blondeau refers to another sensory element of the performance, "I want to fill the entire gallery with the smell of freshly skinned logs. It is a way for me to evoke my mother's action of smelling her grandmother's sweater." And this is exactly what she does, by skinning logs herself. Blondeau states that "the smell of logs being skinned, triggers for her memories of being at her grandparents' house." In addition, this narrative asks the engaged listener to think of the smells that remind them of home. This can be seen as counterpart to asking the audience to imagine a child in a sterile space that smells of bleach and cleaner, longing for home. Blondeau tells her audience "My mother told me that she missed home, but what she missed most of all was 
the smell of home, because the residential school was a sterile environment." Perhaps in this sense, Blondeau's inclusion of the smell of fresh cut wood is gifted in the form of a memory.

Blondeau notes that the physicality of skinning logs also interested her. She writes, “As I skin the logs, I begin my narrative of my mother's experience in residential school and my own story of being affected by this colonial institution, even though I never went there." ${ }^{, 61}$ Here, we are reminded of Blondeau's position as a high-tech storyteller, using numerous props in order to capture the imaginations of her audience. Her voice is another essential performative tool. Blondeau comments, “Once I've enclosed all the people in the pen, I go back to my position of skinning the logs, and I continue my narrative in a monotone voice."62 There are numerous possible readings of the incorporation of the monotone narrative. Is it the voice of the sisters teaching the children? Is it making reference to the deficient recognition of this history? Is it reference to the life lived in residential schools? That is, the monotonous daily activities, of cleaning, chores, eating, praying, and then sleeping. Blondeau continues, "At one point, I look at the audience members in the pen and tell them to sit up straight. This is done in a moment of anger. Then I go back to my monotone voice and continue on with my own storytelling. ${ }^{\text {63 }}$ This radical shift in tone of voice giving aggressive direction to people who are 'locked in,' makes reference to both the physical and verbal violence directed towards the children. Blondeau's 'moment of anger' can also be understood as representing the residual anger within survivors of residential schools and their families. While memories of their own schooling may be triggered throughout this performance, the non-Aboriginal members of the audience may realize their inability to truly 
understand this colonial legacy.

Through recognizing the limitations of understanding a lived experience that you yourself have not had, one acknowledges the process of learning new knowledge through performance art. Live performance negotiates lived experience, therefore acting as a bridge between the narrative of memory and current reality. I suggest that through continued learning and sharing of stories, communities can cross cultural borders and continue conversations in order to foster an understanding based on respect. The notion of 'understanding' in relation to the politics of performance has been discussed by Peggy Phelan in Unmarked. Although I agree with Phelan concerning the limitations of fully understanding one another's differences, I disagree with her notion that we must not continue to strive for further cultural understanding and that the concept of understanding means that one must arrive on the other side. I suggest that cultural understanding means an attempt to recognize differences and to acknowledge a commitment to learning crossculturally in a respectful way. In Phelan's view, "Perhaps the best possibility for 'understanding' racial, sexual, and ethnic differences lies in the active acceptance of the inevitability of misunderstanding." ${ }^{, 64}$ Acknowledging the dangerous nature of her statement as a political and pedagogical telos inviting 'belligerent refusal to learn,' Phelan modifies her argument by saying, "It is an attempt to walk (and live) on the rackety bridge between self and other-and not the attempt to arrive at one side or the other-that we discover real hope." ${ }^{65}$ I would argue that this walking on the bridge between self and other is the key to understanding. We cannot ever truly arrive on the other side, but we can continue to negotiate our diversities in order to foster stronger relationships established by cross-cultural understanding. 
Following the command to 'sit up straight' —arguably a moment of violent rupture in the narrative-Blondeau asks the people in the pen if they will help her skin the logs. Bearing in mind that throughout Blondeau's action of skinning logs, she shares the stories of her mother's experiences at residential school, multiple readings of her request are possible. In Blondeau's writings she does not give specifics into the possible readings of the logs, just that the smell reminds her of her grandparents. It is at this moment in the performance that the roles of the audience and the performer shift. She asks them to participate in a reciprocal relationship, where they in turn perform for her. Blondeau acknowledges the politics of spectacle and the colonial gaze by noting, "I am now the audience gazing at them." ${ }^{66}$ Here, the artist blurs the boundaries and suggests empowerment through switching the dynamics of the colonial power system: the Aboriginal woman now sits in the seat of power as the observer. By laying claim to the gaze, Blondeau also invokes a connection to the history of physically exhibiting indigenous peoples for the European gaze. Within colonial history exists a tradition of exhibiting the 'other' for the enjoyment and pleasure of the dominant society. Aboriginal peoples were exhibited in numerous spaces throughout post-contact history, for example in nineteenth-century World Exhibitions. Arguably here, as in all her performances, Blondeau asserts a reciprocal gaze, once again resisting the colonial discourse and making space for indigenous voice and vision.

Several audience members now begin stripping logs with Blondeau. They contribute to the performative ephemera, as well as to the re-writing or stripping of colonial histories from the Canadian landscape. This generates a reciprocal exchange between discourses and performance art participants enabling multiple stories to be told 
simultaneously. Each individual brings his or her story into the performance space. Although participants may not verbally share these experiences, their interpretation of the performance witnessed will be based on their memories and experiences.

In this piece, Blondeau is playing with power. She comments on colonial domination and the power structures built to ensure the position of the colonizer over the colonized. She also acknowledges her own power through the sharing of her stories and through her authoritative gestures and commands. She reflects colonial systems of control back onto themselves, and reverses the image of the colonizer over the colonized, creating a new space for negotiations. Fundamentally, Blondeau's act of enclosing her multicultural audience in a pen and requesting their help to skin logs demonstrates the power held by the state over Aboriginal peoples during the late nineteenth and early twentieth centuries. This reading is re-enforced by her inclusion of the pen in the gallery space. An alternative reading can be found in the fact that Blondeau is not merely asking the audience to skin logs, but rather is demanding they do so. This section of the performance recalls the hard labour and chores expected of the children during their attendance at the schools. ${ }^{67}$ Blondeau transforms herself from the child doing the chores into the teacher or principal dictating the work loads. ${ }^{68}$

After the participation of the audience, Blondeau returns to her place on the rock and resumes her role as orator, shifting the gaze back to her. As previously suggested, the gaze and action can be reciprocal. Through this act of shifting the boundaries, from participating by listening to physical participation, the audience is made aware that they too are being watched. Blondeau utilizes aggressive acts of engagement, first by closing the audience in, next in her angry command 'to sit up straight' (as one could imagine the 
teachers at the schools saying), and then through asking them to assist in skinning logs.

As the audience looks at Blondeau, she looks back at them, watching their reactions to her stories, her commands, and her questions. Blondeau's performance space re-imagines colonial systems of power. The colonized are symbolically represented by those in the pen who are rendered powerless. As they look out they are, in turn, closely observed while their mobility remains controlled by Blondeau. Are You My Mother? transcends the borders between storyteller/performance artist and listener/audience, while also slipping through historical and cultural divisions.

The audience continues to participate in the performance. Blondeau recommences her oral narrative, moving this time to the thematic of hair:

\begin{abstract}
At this point, I get an audience member (someone planted) and sit her down on the rock on which I have been sitting and begin to brush her hair. As I am brushing her hair, I say, "I come from a long line of women who love to pick lice." Then I begin to tell stories that have been told to me by my grandmother and mother about picking lice. I also tell my own stories about lice. ${ }^{69}$
\end{abstract}

This is the concluding story of Are You My Mother? It is a multifaceted narrative, which places nurturing moments alongside moments of aggressive tensions. Blondeau's oral narrative can be unpacked in many ways, as there are many stories interconnected to the ones that she shares. This narrative of picking lice may come as a shock to some of her audience. Mothers may understand immediately one of Blondeau's meanings, residential school survivors may make very different associations.

The story of picking lice is a parable of the nature of mothering. Her story's meaning is illuminated by the nurturing actions of brushing hair. On the other hand, one of her personal stories is about the trauma of lice. When she was in grade one, at the age of six or seven, Blondeau was made to feel that if she had lice, it was due to cultural 
ancestry. Her teacher told her "that it was only Indian people who got lice because [they] were dirty." ${ }^{, 70}$ Unfortunately, this shared memory recognizes continual racial prejudice in the mainstream education system while also acknowledging the stereotype that Aboriginal people are dirty. The teacher's harsh comment was internalized by Blondeau and had a profound impact on her self-esteem. Later in life, as a mother, she notes:

While living in Montreal, I had an experience that brought back this memory. My oldest daughter was infested with lice and I took her to a clinic. We went into the doctor's office, and I explained to him that she had these bugs in her hair; at that point he asked us to leave his office and not touch anything. This incident triggered memories of the stereotype that had been ingrained in me as a child. ${ }^{71}$

This episode motivated Blondeau to ask her mother and grandmother about head lice.

Their stories caused her to wonder why they and her aunties claimed to 'love picking nits?' Their answers enabled Blondeau to see the link between 'picking nits' out of a child's hair and nurturing:

I came to realize that it wasn't about being dirty. And it wasn't about us being Indians, because everyone gets lice. It was about affection, grooming, catching up on community gossip. And making sure that we take care of the lice so that we don't keep getting infested with them. Witnessing my mother, grandmother, and my aunts telling about why they like to pick lice and listening to their humour totally empowered me. ${ }^{72}$

As the audience bears witness to this intimate story, they participate in the erasure and rewriting of the stereotype of the 'dirty Indian.' Blondeau goes on combing the woman's hair, and tells another story:

When I think of my mother's residential school story, I think about how difficult it was for my grandmother to have her children taken way from her for ten months of the year. As a mother myself, I think how hard it must have been to witness your children being taken away from you and not being able to have any physical contact with them. My grandmother told me that when the kids came home from residential school they had lice. She would spend her first week with them cleaning their heads. I saw this also as a way for her trying to get reacquainted physically, mentally and emotionally with her children. Picking head lice became a ritual for her. ${ }^{73}$

I suggest that the act of combing the woman's hair is a theoretical returning home of the child from the experience of residential school into the nurturing space of empowerment. 
From the very beginning, Are You My Mother? is overshadowed by the projected image of Queen Victoria as the symbolic 'mother' figure of colonial Canada, and the theme of mothering is marked by tensions and contradictions. A definition of 'mothering' is to give birth to, create, and produce; to watch over, nourish, and protect maternally. The obverse side of this definition held true in the residential schools, where the majority of children were neither nurtured nor protected. Instead they were punished and abused, and made to feel that their mothers were 'savages,' and unfit to watch over them.

Are You My Mother? is a performance full of complexities, moving from moments of mothering affection to violent narration. The story of hair and the residential school is a violent narrative, linked to the indoctrination process. Trauma was endured from the moment of arrival. Brothers and sisters were separated from each other; they were then scrubbed with disinfectant and had their hair cut. The action that marked the completion of their institutionalization process was their renaming and/or assignment of a number. These practices of separation served to systematically strip the children of their 'Indianness,' along with their dignity, making the acts just as violent as sexual or physical abuse. ${ }^{74}$ Arguably, this process of stripping the children of the scents of home reflects a colonial ritual, defined by Pierre Bourdieu as symbolic violence, which he says is "the gentle, hidden form which violence takes when overt violence is impossible. ${ }^{75}$ The trauma of having hair cut for the first time is revealed in this boy's story:

They went to work and cut off my braids, which according to Assiniboine custom, was a token of mourning - the closer the relative, the closer the cut. After my haircut, I wondered in silence if my mother had died, as they had cut my hair so close to the scalp. ${ }^{76}$

Hair, for Aboriginal peoples, was and continues to be sacred, and the cutting of hair was only done in most Aboriginal cultures for specific events, such as mourning. As 
one step in the larger process of 'civilizing' the Aboriginal children at the schools, the cutting of hair, viewed by Westerners as harmless, became a violent act and an assertion of control over the child. From the optic of Bourdieu's symbolic violence, such acts were part of a strategy of domination through the imposition of cultural values. They were violent because of their role in the establishment of social inequality, and 'gentle' because they were embedded in well-intentioned practices. Drawing on Foucault's discussion of power and control, the goal of the process was to convert the children from Aboriginal to Westernized individuals. These conversions most often led to a resistant acceptance and adoption of Western cultural values, behaviours, and expectations. Homi Bhabha discusses how these conversions of indigenous peoples into 'Westernized' peoples are usually connected to an ambivalent and diffused feeling of resistance to imperial power. Bhabha calls such conversions 'mimicry' that "always teeters on the edge of menace." ${ }^{, 77}$ The conversion process is presented in the photographic images of Thomas Moore (Figure 29), which were utilized by the Department of Indian Affairs in their 1897 Annual Report to show a 'before' and 'after' representation of how the Residential school system was a successful strategy for conversion. However, is young Thomas Moore truly 'converted'? Or is he a mimic of Western identity camouflaged in European dress?

In the last moments of the performance, Blondeau trades places with the woman whose hair she has been combing. As Blondeau describes, "She begins to comb and braid my hair. I am silent. When she is done braiding my hair, she cuts my braid off. I get up and walk out." In the Cree ceremony, the hair of a corpse was braided, and prior to burial the braid was cut off and then tied to the end of an upright stick at the head of the grave. 
According to David Mandelbaum, four days after burial, the braid was brought into the tipi during a feast of mourning. ${ }^{78}$ Mandelbaum recounts:

[When] none remained, except the leader and a few old people, the braid was untied from the stick, wrapped in cloth or hide, and bound with thongs. A bit of tobacco was placed next to the hair. The wrapped braid was placed in the nayahtcikan (carried on the back bundle), together with the braids of other deceased members of the family. These bundles were sacred family possessions and were carefully guarded. ${ }^{79}$

Once again, Blondeau's performative narrative tells several stories, offering complexities and the opportunity for multiple readings. The practice of braiding hair that Blondeau incorporates into her performance alludes to the personal adornment of Aboriginal women's hair. In the case of the Plains Cree, women usually wore their hair in two braids with the tips wrapped in leather or ribbon. The final act of cutting off the braid is powerful and violent. Her audience is left in the void of their storyteller's silence, and remain locked in their pen with Blondeau's braid left on the floor of the performance space. Memory, story, and ritual imbue these last moments of Blondeau's performance, intimately engaging the audience until she abruptly ends the piece by walking out.

This piece indicates shifts in the current political climate surrounding the residential school experience, exemplified by the Canadian government's acknowledgment of this once silenced history. In the summer of 1998, a number of residential school survivors gathered in Squamish, British Columbia, for what Richard Kistabish, the Chairman of the Legacy of Hope Foundation, deemed an important first step in the healing process, the creation of the Aboriginal Healing Foundation (AHF). Kistabish writes:

The Legacy of Hope Foundation was established to address the long-term implications of the damage done to Aboriginal children and their families by many of the residential schools. The psychological wounds run deep and have infected new generations. Healing is a gradual process that will demand time and patience. A primary objective of our work is to promote awareness among the Canadian public about residential schools and try to help them to understand the ripple effects those schools have had on Aboriginal life. But 
equally important, we want to bring about reconciliation between generations of Aboriginal people, and between Aboriginal people and non-Aboriginal Canadians. ${ }^{80}$

Are You My Mother? contributes to this discourse, re-addressing the story of residential schools, and acknowledging the ripple effects of this traumatic history. It is a postcolonial re-writing for a new understanding, negotiating reconciliation and empowerment.

\section{Sisters: Ritual, Repetition, and Remembrance}

Sisters (Figure 2), like all of Blondeau's work, is repetitively performed in different venues. Its first presentation was at an international exhibition, Americas Remixed, in 2002 in Milan, Italy (Figure 30). Whereas, the video recording that I have watched is from her November 2002 performance for the IndianActs: Aboriginal Performance Art symposium at The Emily Carr Institute of Fine Art organized by Grunt Gallery, and from her participation in the Shubox Theatre exhibition, University of Saskatchewan. These are merely a handful of venues where Blondeau has performed the piece. Sisters is a sequence of four scenes that lead to a double-twist ending. ${ }^{81}$ These scenes are linked to each other through the ritualization of actions. Each is a physical act connected with the concept of food as both sustenance and poison. ${ }^{82}$ In the gallery space, a hand-sized stone rests on a larger, rougher rock. To the right of the rock and stone is a fish and a neatly folded piece of red cloth. Blondeau walks in to the space wearing a simple off-white cloth dress cut above the knees. With her, she carries a basket of saskatoon berries. David Garneau's personal account of Sisters describes what the audience sees: "For the next fifteen minutes, she crushes the berries (Figure 31), guts the fish (Figure 32), and tears the cloth into strips (Figure 33). She remains straight faced and silent throughout. The unfolding events are reproduced as a video projection on a screen 
in the middle of the stage." ${ }^{, 83}$ As noted earlier, the length of Blondeau's actions depends on several variables, such as venue, audience, her own mood, and time restrictions. Blondeau observes that the live-feed projection is incorporated into her performance space to create a focus on her ritual actions, not her costume, which was intentionally made simple and plain. She writes, "They [the audience members] have the option of watching the projection, which zooms in on my hands as I crush the berries, or they can watch me as the piece unfolds-my facial expressions, body gestures, and the way I occupy space. ${ }^{, 84}$ Her first three actions in the first vignette draw her audience in. It is a beautiful performative act of ritual, ceremony, memory, and story, communicated not through words but through repetitive actions.

Blondeau acknowledges that this performance piece is informed by concepts of memory. She writes, "The piece is about my memories of watching my mother and her sisters at our house cleaning ducks. I remember the awful smell of singed feathers. Another memory is of watching my mother and all the other women in my family gut fish." ${ }^{85}$ Blondeau utilizes her memories to perform her ritual actions once part of the daily lives of Aboriginal women. By the repetition of these actions Blondeau links herself to the women of her family. The act of cleaning ducks or gutting fish allowed the women in Blondeau's family to come together; it was a time to connect and share the stories of daily life. Her performance also alludes to the relearning of Aboriginal traditions, gesturing at traditions lost because of residential schools. "One of the reasons I wanted to do this performance was to teach myself the skills that the women in my family have known for generations." 86 She is locating traces of Aboriginal history, surfacing stories once camouflaged by colonial discourse. Through the act of re-enacting ritual practices or 
skills that Aboriginal women used on a daily basis, Blondeau comments on the contemporary reality of Aboriginal peoples. In some families, these 'common practices' continue, while in others women have lost knowledge of them due to the impact of colonization. The familial stories that are the inspiration for Sisters mirror the larger Aboriginal, specifically Plains Cree, experience of colonial history. Blondeau writes:

My grandmother told me a story about the late 1930s when they had no food. They were starving, and my grandfather was too proud to hunt small game like pheasants and prairie chickens, which were traditionally the preserve of the women. So my grandmother snared all these partridges. (She claims there are no partridges on the prairies because she snared them all.) But she stopped snaring them when she cut one open to gut it and maggots came out. She read this as a sign, and that was the last partridge she snared. ${ }^{87}$

Although Blondeau does not speak throughout the performance of Sisters, her repetitive actions tell numerous stories.

The repetition of gestures opens up a space for change, enabling a deeper understanding and "shifting responses that bring the habitus into the performativity of performance." ${ }^{, 88}$ According to Pierre Bourdieu, life experiences "are internalized as second nature and so forgotten as history [that the habitus is] the active presence of the whole part of which it is a product." ${ }^{, 89}$ In other words, the subject is formed through an accumulation of tacit and conscious moments; we embody our experiences. ${ }^{90}$ Blondeau's repetitive actions stimulate recall, she writes: "After I perform Sisters, audience members often come up to me and talk about their own memories, and experiences: as if my action somehow triggers their memories."91 Some of my memories triggered by Blondeau's actions were of berry picking with my sister, and making jam with our mother and my Nana's hands working with cloth. It also made me question the lack of Aboriginal knowledge in Canadian society, and how this incorporation could lead to stronger societal frameworks. It made me wonder: Why do indigenous world views remain on the 
periphery in this current period of post-colonialism?

Blondeau's first action is crushing berries. She uses the smaller rock to render the saskatoons into a liquid soup (Figure 30). Blondeau writes, "For me this piece is visually beautiful because all you see is this red, red liquid, which runs down the stone like blood. All you hear is the hypnotic sound of rocks colliding against each other." 92 The second action is the gutting of a fish (Figure 32), which Blondeau notes as being "beautiful but unsettling at the same time. It makes me gag." ${ }^{93}$ David Garneau describes his impressions of the scene: "Initially, the activities seem authentic, a theatrical presentation of Aboriginal 'women's work' of a century or more ago. But soon, things look a little off. For example, the crushing is sloppy. The lower stone should be flatter, more like a bowl to keep in the pulp and juices." He continues, "The way the rich purple mush oozes over the rock like a messy sacrifice is evocative, but not efficient pemmican making." 94

The ripping of red cloth (Figure 33) is the third action. Blondeau incorporates Cree cultural ritual and ceremonial tradition into this part of the performance. She states that the "cloth is an offering for the fish and the berries." As noted in Koozma Tarasoff's study of Plains Cree and Saulteaux ceremonialism: "Material offerings of cloth are made whenever the Spirit Powers are asked to exert their influence toward some particular end." 95 Blondeau remarks that "the sound of ripping of cloth takes me back to being a child and going to feasts and ceremonies and watching my grandmother rip cloth for offerings. I find myself longing for a way of life that doesn't exist anymore." 96 From this statement it is clear that Sisters also acknowledges feelings of loss and displacement, emotions of longing. Blondeau's storytelling continues throughout this performance using the actions as her 'voice.' Lynne Bell observes that "Rooted in childhood 
memories and family stories, Sisters, speaks to the impact of colonialism on the traditional Plains lifestyle and food culture of Blondeau's family." 97 Blondeau says, "My great-great-grandfather lived on a diet of pemmican, wild roots, berries, and wild game. The demise of the buffalo meant that in one generation our traditional lifestyle was changed forever. Today's fast food is killing Native people with diabetes, obesity, and other diseases." 98

Many of the ritual and traditional actions of Aboriginal culture she recalls, have been displaced through the processes of colonization. S.J. Tambiah defines ritual as "a culturally constructed system of symbolic communication. It is constituted of patterned and ordered sequences of words and act, often expressed in multiple media." 99 In this respect, ritual is a performed arrangement characterized in varying degree by formality, stereotyping, fusion, and repetition. The performance practice of Blondeau can be considered a form of 'ritual action': political ritual, a rite of exchange and communication, and rites of affliction and commemoration. ${ }^{100}$ Ritualizing, in this case, means "both a social process involving an audience and an act of cultural assertion." relating the ceremony to post-Oka Aboriginal performance art, Archer Pechawis observes:
In traditional forms of ceremonial performance there is an enactment of collective unconscious, a reflection of communal dreams. Culture and community are reinforced. In contemporary First Nations performance art there is a continuation of this legacy. Artists from different nations address the concerns of equally diverse Urban Indian communities, re-inventing tradition. ${ }^{102}$

Charlotte Townsend-Gault argues that some contemporary Aboriginal art employs "efficacy of ceremony, or ritual, as a vehicle for personal and social negotiation. The meaning and values are rooted in a way of life that has been drastically modified...these ritualized markers of a recovered power, exercised in a new way draw on old sources of 
power but do not depend on them alone." ${ }^{103}$ Lori Blondeau works within the 'traditional' concepts of Aboriginal performance, while situating herself within her contemporary reality.

The next action is unexpected and diverts from Aboriginal traditions. Blondeau removes herself from the space, where 'evidence' or traces of berry crushing, fish gutting, and cloth ripping remain. (Figure 34) "I step out of the picture, so to speak, and move into a space separate from the three actions of the performance." ${ }^{104}$ In doing so, she shifts the performance in a new direction. She transcends time, space, and culture. No longer preparing fresh berries or fish, Blondeau reaches into a large lunch box or a large McDonald's paper bag and proceeds to eat as many McDonald's hamburgers as possible to the song 'Hello Dolly!' (Figure 35) She continues this action of repetitive and excessive eating, forcing hamburgers into herself for the duration of the song. During her performance at the IndianActs symposium, as the audience watched her eat, they listened to the sounds and images of rocks crushing berries, fish scales being scraped off, and cloth being ripped into pieces. (Figure 36) She went on forcing the hamburgers into her mouth until the big paper bag was empty. Each time she finished a hamburger, she would crumple the packaging and place it with the others to her right, making a pile of McDonald's food wrappings, leaving only traces of her actions. (Figure 37) Whenever Blondeau picked up another hamburger, her facial expression shared pain and nausea with her audience. Blondeau admits that, "This action makes me sick to my stomach."105 (Figure 38) Lynne Bell remarks that this vignette is a "painful, and not quite funny action...And, for the first time, Blondeau looks her audience in the eye, challenging us to meet her gaze."106 (Figure 39) 
From this act of excessive eating, many meanings unfold. This twist in the performance scene promotes a reconsidering of her previous acts of ritual food preparation and ceremonial act of offering cloth. Her previous actions seemed awkward, as if she was playing at being a traditional 'Indian' woman. Her gestures had been slow, careful, and incomplete, not the hands of a woman who is comfortable with these actions. Was Blondeau merely playing with her audience? Perhaps the scene is meant to express the disconnection and or displacement an urban Aboriginal woman has between her lived contemporary experience and the traditional daily lives of her ancestors. ${ }^{107}$ Or does it comment on the loss of Aboriginal knowledge due to colonization? Blondeau is clearly making reference to today's processed foods, symbolizing extreme diet changes in the Aboriginal community, which have led to health issues such as obesity, poor nutrition, and diabetes. ${ }^{108}$ She could also be commenting on European colonization's relationship with greed and excessive behaviours, as well as Western society's exploitation of natural resources. For example, it is well known to Canadians that McDonald's and other giant food corporations have had a large part in the destruction of rainforests in South America, promoting the clearing of forests for farming of cattle.

Multiple interpretative readings are possible in Blondeau's performative storytelling and ritualized actions. She engages with her audience, provoking them, and enticing them to recognize the histories she has offered. They participate in the reciprocal relationship between storyteller and listener. This being said, the audience is not obligated to listen to these stories. However, since they have chosen to come to watch/interpret/witness the performance, they most likely are there with some level of engagement. In the case of reception of art, and more significantly performance art, the 
artist cannot control the ways in which her audience interprets the work, or determine their level of commitment to listening to the piece. Nevertheless, she can negotiate and manipulate active and critical engagement through the power of live performance, or as Blondeau puts it:

The audience looks at me, and I return their gaze while gagging. The audience is uncomfortable because it is the first time in the work that I return their gaze. The projected traces of the performance still play on the wall, giving the audience members a place of refuge, a place to avoid my gaze. In this way, the viewer[s] become an active part of the performance, selecting and editing what she chooses to see. ${ }^{109}$

Blondeau's performance is unsettling. Sisters is a powerful piece that lures the audience to actively engage with the memories triggered by her repetitive ritual actions and also with the feelings stirred by her disturbing act of bingeing on McDonald's hamburgers. This performance participates in a larger discussion highlighting the importance of the decolonization of Aboriginal cultural, historical, and social knowledge for indigenous sovereignty.

\section{Conclusion}

Are You My Mother? and Sisters illustrate Blondeau's storytelling practice. She weaves traditions of Aboriginal oratory with performance art methods to articulate postcolonial protest and intervention within the Canadian colonial discourse. Equipped with her stories and knowledge of the legacies of colonialism, the artist negotiates new spaces for the Aboriginal community, while bringing silenced histories to light. In this sense, Blondeau's performance practice participates in a continuum of Aboriginal resistance and survivance, contributing to the discourse of indigenous sovereignty and selfdetermination. She is a high-tech storyteller. Her narratives, presented through the practice of performance art, share her perspectives and family's stories in order to take part in the palimpsest interchange to reclaim camouflaged indigenous histories. 


\section{Chapter 4 Lori Blondeau's High-Tech Storytelling for the Decolonization of Aboriginal Women's Identities}

Stories are how we explain, how we teach, how we entertain ourselves, and how we often do all three at once. They are at the juncture where facts and feelings meet. And for those reasons, they are central to civilizations - in fact, civilization takes form in our mind as a series of narratives. ${ }^{\text {I }}$ Robert Fulford

In this chapter, Lori Blondeau's performance practice will be discussed in relation to reclaiming the identities of Aboriginal women. The story will continue to be an integral part of this discussion, which will also include issues of identity politics and the body's relationship to performance. Blondeau's performances will be explored as sites of exchange, communication, recognition, and political protest. The creation of her personas will be discussed in relation to strategies of mimicry and subversion of stereotypes. Betty Daybird (Figure 5), CosmoSquaw (Figure 3), Lonely Surfer Squaw (Figure 4), and Belle Sauvage (Figure 6) will be analyzed in this chapter. Blondeau's performative articulations are armed with tools of parody, humour, and at times, the trickster. She is playing with an aesthetic practice in order to disrupt and dislodge - stripping away layers of colonial text and imagery from the surface of the Aboriginal woman's body. In this sense, Blondeau is re-writing and re-representing the identities of Aboriginal women.

The process of re-naming and re-telling histories in performance art can reconstruct and transform the representation and therefore the identity of Aboriginal women. This process breaks up colonial language. Re-appropriation and adoption of colonial language is yet another means for the dislodging of fixed signs, which is a method incorporated into Blondeau's performance practice. I propose that Blondeau's incorporation of colonial words is an act of protest and an attempt to decolonize the histories and imagery of Aboriginal peoples from the dominant discourse and archive of representation. Her appropriation of the word 'squaw' in her performance narratives and 
persona's names, CosmoSquaw and Lonely Surfer Squaw, mirrors Judith Butler's

discussion of using the "word that wounds" to subvert and as an "instrument of

resistance." Belle Sauvage (Indian Princess) is yet another of Blondeau's colonial name

appropriations, used in a humorous and parodic way for subversion. In regard to the

subversion of deprecating, harmful and, derogatory names, Butler argues:

The word that wounds becomes an instrument of resistance in the redeployment means speaking words without prior authorization and putting into risk the security of linguistic life, the sense of one's place is language as it calls into question the linguistic survival of the one addressed.

Insurrectionary speech becomes the necessary response to injurious language, a risk taken in response to being put at risk, a repetition in language that forces change. ${ }^{2}$

Lori Blondeau recounts a personal memory that became the inspiration for her subversion

of the derogatory term 'squaw':

I remember being called a squaw, and it was meant to insult, violate and degrade. One day I went home crying after being called 'a fucking ugly squaw.' I was only sixteen. My grandmother, who lived on the reserve, was visiting. She asked me what was the matter, and I told her, "I was called an ugly squaw." She looked at me and said, "You are a squaw and be proud of that." I asked her what 'squaw' meant. She said, "It means 'woman' and you are a woman. And you're beautiful." After this, anytime anyone called me a squaw, I would reply, "Yes, I am. Do you have a problem with it?" I would no longer give the person the satisfaction of seeing me hurt and embarrassed. I now had the knowledge of what the word meant and knew somehow that the person insulting me did not. All it took was this moment of doubt in the mind of the person calling me a squaw and he or she retreated with the embarrassment that was intended for me. ${ }^{3}$

\section{Storytelling and the Stereotype: A Post-colonial Re-dressing for the Decolonization of Aboriginal Women's Identities}

The issue of 'the other' is one of power, of a dynamic between those who impute otherness to some and those who are designated as other. So the questions I ask about otherness have to do with how others or the other are spoke of, who is speaking about them, and why have they chosen to speak of the other at the given historical moment. ${ }^{4}$ Coco Fusco

Lori Blondeau rejects the stereotypes of Aboriginal peoples constructed throughout the process of colonization. ${ }^{5}$ Her work plays a significant role in the repositioning of Aboriginal people in the Canadian cultural landscape. Post-colonial theorists Bill Ashcroft, Gareth Griffiths, and Helen Tiffin introduce their discussion of 
place and displacement in The Empire Writes Back. Due to the colonial sense of displacement, it is within the discourse of the post-colonial that there is acknowledgment of the crisis of identity, and fundamentally, "the concern with the development or recovery of an effective identifying relationship between self and space." ${ }^{\prime 6}$ In The White Man's Indian, from Columbus to the Present, Robert Berkhofer writes, "For most of the past five centuries, the Indian of the imagination and ideology has been as real, perhaps more real, than the Native American of actual existence and contact."7 The image, and therefore the representation, of the Aboriginal woman in particular has been saturated and defined as 'other,' from the dominant Eurocentric perspective. Blondeau's personas Betty Daybird, CosmoSquaw, Lonely Surfer Squaw, and Belle Sauvage actively play with the stereotypes of the Indian princess and squaw. The suffering and damage caused by stereotyping is discussed by Bonita Lawrence, who addresses Aboriginal identity in terms of how it has been constructed through the process of colonization. The colonial regulation of Aboriginal people has "permeated the ways in which Native peoples think of themselves." ${ }^{, 8}$ Hilary Weaver asserts that, "Today, Native people often learn about themselves and their culture within the dominant mainstream, and therefore adopt some stereotypes and distorted meanings."9 The significance of Blondeau's performance practice becomes heightened when the impact of stereotyping is discussed in relation to her performance personas.

In her article "Some Kinda Princess," Blondeau discusses her reasons for including storytelling and the creation of personas into her performance practice, along with personal stories of her lived experiences as an urban Cree/Saulteaux growing up in Saskatchewan. She recognizes the lasting wounds stereotypes trace on a person, which 
can also motivate resistance. She writes:

Today we can see the image of the Indian Princess is still alive and well in the 1995 Disney film of Pocahontas which is educating a new generation of non-Natives and Native children on how an Indian princess should look. As I am confronted with these new images of old stereotypes, I feel an urgency to document my own stories and the stories of the women in my family. This is a story of my journey through oppression, consciousness, and finally resistance. ${ }^{10}$

Blondeau clearly articulates two significant events in her life that substantiate the impact

of stereotyping on Aboriginal women. She shares her experiences with the Indian

princess:

When I was fourteen, a non-Native woman asked me if I were an Indian princess. I replied no. She went on to say, "If you were to lose some weight, you could be an Indian princess." This was the first time I had ever been asked that question, but it wasn't the first time I had been confronted with the image of the Indian Princess. Growing up in Saskatchewan as an urban Indian, I remember my mother braiding my sister's long hair and putting a beaded headband around her forehead. My mother then took a picture of her gazing off into the horizon and not into the camera. These pictures were carefully placed in our family photo album. At the time, I do not think my mother realized or even thought about where she had seen these images of a Native woman looking so romantic. But the reality was we grew up with them all around us. We saw them in Hollywood Westerns, on product packaging, on calendars, and now we were creating them for ourselves. The Indian Princess was an acceptable image; she represented something opposite to the Squaw. How could we not see her as our only positive role model? After all she was a princess. She was royalty. She represented some sort of civilized image far from the image of the Squaw, who was not as well accepted by the general public. ${ }^{11}$

Here, Blondeau's story recounts the implications of stereotypes, as discussed by Charles

Taylor, where the sign created by the dominant culture is adopted by the oppressed, consequently instilling the negative stereotype into the consciousness of the community.

This means that the stereotype is then projected as a true rendering, a true identity of self. ${ }^{12}$ Taylor writes about the significance of recognition for a subordinated and marginalized community such as the indigenous peoples of Canada:

A group of people can suffer real damage, real distortion, if the people around them mirror back to them a confining or demeaning or contemptible picture of themselves. Non-recognition or misrecognition can inflict harm, can be a form of oppression, imprisoning someone in a false, distorted, and reduced mode of being. ${ }^{13}$

This misrecognition of Aboriginals as 'Indians', according to Gerald Vizenor, is 
oppressive and constructs a prison of false identities. ${ }^{14}$ The anecdote about Blondeau's mother and the romantic photograph gives an example of this theory in practice. Until recently, Aboriginal people have been relatively powerless in terms of selfrepresentation, which as Weaver states, has allowed them to be invisible and nameless. ${ }^{15}$ As a performance artist, Lori Blondeau reclaims the identity and image of the Aboriginal woman, and by performing in 'mainstream' venues demands the positive recognition the Aboriginal community has always deserved.

The politics of identity are directly connected to this complex web of stereotypes. Blondeau's performance practice participates in the process of decolonizing the imagery of Aboriginal women as the squaw and Indian princess. These stereotypes have a long tradition of representation in Western literature and imagery. Pocahontas, the quintessential Indian princess story, has inspired countless works of art in all genres, usually idealizing the image of the Aboriginal woman to conform to Eurocentric concepts of femininity and beauty. ${ }^{16}$ In the early seventeenth century, James Nelson Barker was inspired by the narrative of John Smith, whose life was allegedly 'saved' by Pocahontas, and Barker wrote a play entitled The Indian Princess or La Belle Sauvage. ${ }^{17}$ This was the first of the Pocahontas dramas; it established the basic story, although the narrative evolved throughout colonial history to reflect the nature of the Aboriginal-nonAboriginal relationship. The Disney version of the fairy tale reveals that "Pocahontas's social imagery is monolithic, a representation rooted in ambiguous, sexualized fantasies that appropriate and reconstruct her Indian identity." ${ }^{18}$ Interestingly, Gail Guthrie Valaskakis remarks that, "Disney's historical revisionism emerged at a time of new tension between Natives and newcomers, over land and resources, sovereignty and self- 
determination, artifacts and images." ${ }^{19}$ Disney's Pocahontas tale is one of the vehicles

Blondeau uses to destabilize the archive of representations of indigenous women.

The squaw can be understood as the Indian princess', or Pocahontas', darker twin.

Calling her the 'anti-Pocahontas,' Daniel Francis specifies:

Where the princess was beautiful, the squaw was ugly, even deformed. Where the princess was virtuous, the squaw was debased, immoral, a sexual convenience. Where the princess was proud, the squaw lived a squalid life of servile toil, mistreated by her men...prostituting [herself]...a low, sexual commodity. ${ }^{20}$

In Fear and Temptation, Terry Goldie discusses the representation of Aboriginal women in literature stating that "both maiden and squaw are manifestations of the white culture's felt temptation by the indigene and by what the indigene represents in the land." ${ }^{21}$ The Indian princess, Goldie argues, stands for temptation, and the squaw, fear. He expands on this idea, stating that the maiden represents the 'optimism that the land holds, the potential of a positive indigenization,' whereas the squaw represents 'the pessimism and potential that this alien realm will be a negative indigenization, a destructive takeover of the soul. ${ }^{22}$ These descriptions shed light on the imagery incorporated into Blondeau's performances. Such depictions of Aboriginal women devalue and objectify them. Blondeau's performance personas appropriate the stereotypical representations of the Indian princess and squaw in order to make a space for representations of Aboriginal women from indigenous perspectives.

In the early twentieth century, the Indian princess continued to inundate popular culture's understanding of Aboriginal women. These narratives are a continuum of the Pocahontas story. The Indian princess was taken over by Sacajawea ${ }^{23}$ and her sisters. These maidens paddled birch bark canoes, fished, and walked in flower patches, and were posed in a picturesque landscape of mountains, waterfalls, forests, and moonlit lakes, 
wearing a red tunic, a requisite headband and feather. From 1915 to 1940, the Indian princess, or the 'lady in red,' was the dominant representation of Aboriginal women in popular culture, ${ }^{24}$ appearing on paintings, postcards, calendars, and advertisements. The images of Nanoochee (Figure 40) and Daughters of the Incas (Figure 41) exemplify the tradition of the single or twinned 'red-tunic lady' presented in the standard romanticized pose and setting. These are arguably the first North American 'pin-up girls,' featured as icons of consumer society for mass-produced goods such as Land o' Lakes butter and Mazola oil, and Buffalo Bill Cody's Wild West shows. They were also a propaganda tool, used to promote the development of the western lands of North America. Guthrie Valaskakis substantiates this claim: "These statue-like figures of the imagination marketed the North American West as alluring, unoccupied, available, and now open to railroad travel." 25 These images of Indianness are commodities for Euro-Canadian consumption, and the identities they project are not a 'true' representation of Aboriginal peoples.

Lori Blondeau uses "doubleness" to subvert these stereotypes of Indian women, thereby displacing them from their history as commodities. Her personas are not for consumer consumption; they function within the realm of intellectual consumption. Her strategic subversions are illustrated in the performance personas Betty Daybird (Figure 5), CosmoSquaw (Figure 3), and Lonely Surfer Squaw (Figure 4). Playing with stereotypes in order to subvert is arguably a dangerous act, possibly resulting in their reinforcement. However, as Coco Fusco suggests, an awareness of symbolic representation is a key site of political struggle and political irreverence. ${ }^{26}$ Blondeau's extensive knowledge of the history of representation of Aboriginal women allows her to 
utilize this archive of iconic and stereotypical imagery to intervene and disrupt these derogatory representations.

\section{Storytelling and Humour: The Use of Parody for a Post-colonial Rewriting}

"Humour is not resigned; it is rebellious." ${ }^{, 27}$ Rebelliousness is overtly evident in Blondeau's humorous personas. Her use of parody is observed in the attitudes, movement, costumes, and especially in the stories her personas share with her audience. To communicate these hard histories, Blondeau employs humour, a key element of Aboriginal culture, and also the healing and bridging capabilities of laughter. Her created personas appropriate stereotypes even as they subvert them, elucidating the absurdity of stereotyping. Blondeau's personas often spark debate about the need for positive images of Aboriginal women in popular culture. ${ }^{28}$ They challenge historical representations of Aboriginal women, asking the viewer why there are not more identified positive Aboriginal role models in popular culture. By means of self-deprecating humour, Blondeau addresses the need for society to discard stereotypical images to better understand indigenous women.

In this passage, Anishinabe storyteller Basil Johnston discusses the aspect of humour in Aboriginal storytelling:

It is precisely because our tribal stories are comical and evoke laughter that they have never been taken seriously outside of the tribe... But behind and beneath the comic characters and the comic situations exists the real meaning of the story... what the tribe understood about human growth and development. ${ }^{29}$

Each Aboriginal community has its own way of expressing humour. For example, Mirjam Hirch notes that the Iroquois and Haida are known for their aggressive humour, while in the Cree and the Anishinabe communities, humour is less aggressive but clever and cunning. ${ }^{30}$ Despite this diversity, there are two universal facets to Aboriginal 
humour: the strong tradition of teasing and the self-deprecatory joke. ${ }^{31}$ Blondeau's use of humour accords with the description Margaret Atwood gives of Thomas King's subversive style, remarking that humour can "ambush the reader. They get the knife in, not by whacking you over the head with their own moral righteousness, but by being funny." ${ }^{32}$ Lynne Bell states, "Like Luna, Blondeau uses humour and the serious as part of her critique, juxtaposing the fabulous, the political, the parodic and the philosophical to produce riveting moments of high-tech storytelling for social change." ${ }^{33}$ One of Blondeau's strengths is her insightful ability to employ humour, irony, and parody as tools to criticize historically and socially rooted misconceptions about the realities of Aboriginal existence and identity.

Linda Hutcheon's postmodern theory mediates an understanding of the function of parody in Aboriginal art. Hutcheon defines parody as "repetition with critical distance that allows ironic signalling of difference at the very heart of similarity." 34 Allan J. Ryan notes that "in this sense, irony becomes the chief rhetorical strategy of parody, and 'critical distance' becomes the critical aspect of redefinition." 35 Hutcheon observes that within the framework of postmodernism, the primary function of irony is a critical reworking of history, noting that this is most effectively accomplished through a creative relationship with parody. ${ }^{36}$ I would argue that Blondeau's work incorporates Hutcheon's definition of irony, as she employs parody for a critical reworking of history as a decolonizing strategy. Furthermore, I propose that Blondeau's strategic incorporation of parody and humour acknowledges the hostile environment in which the image of Aboriginal women exists, but it also generates the possibility for new images of a decolonized indigenous femininity to be created within the Canadian landscape. 
Jayne Wark hits the nail on the head in terms of Blondeau's use of parody; she writes, "Blondeau shows that humour can indeed repudiate reality, and thus enable the humourists to resist his or her own subjection. It is, finally, a way to "make trouble" for the status quo of hegemonic power structures." ${ }^{37}$ There is always a risk in employing defiant humour and parody strategically to establish an oppositional debate illuminating the exploitative actions of the dominant culture. However, in Blondeau's practice, defiant humour and subversive parody are used to lure in audience members, while disarming the potentially hostile. In the case of 'expert' audience members, who have become accustomed to acts of subversion of this kind, they can participate with Blondeau, generating critical interpretations and layers of meaning. Her use of humour enables her to take some of the audience by surprise with defiant words and stories, and wild acts of subversion. Jayne Wark concludes:

Using popular forms of humour and entertainment allows [the] artists to speak through the language of the common culture in order to gain critical purchase on that culture. But at the same time, in order for such art to maintain its criticality, it must be deftly poised on the razor's edge between the seductive appeal and subversive potential of popular culture. ${ }^{38}$

Blondeau's Belle Sauvage and Betty Daybird manifest elements of the trickster. The trickster is often characterized as a creative rebel whose humorous exploits may illuminate his or her didactic function. ${ }^{39}$ From this perspective, Blondeau is a creative rebel employing concepts of the trickster into her performative narratives. As Gerald Vizenor suggests, "The tribal tricksters in their stories were compassionate... and they liberated the mind." ${ }^{40}$ In Vizenor's Trickster theory, there exists a constant reference to the visual and to humour, which as he identifies as the trickster's modus operandi. ${ }^{41}$ Vizenor argues that the "oral tradition is a visual event," articulating the connection between contemporary artists and traditional storytelling. As Ryan notes, this concept of 
the trickster is a way to redirect the audience to reject the antiquated paradigm that celebrates Aboriginal art as mystical and legend bound, "in favour of recognizing the active spirit of the traditional Native trickster." ${ }^{, 42}$ Blondeau can therefore be seen as incorporating the trickster into her visual and verbal language.

To recognize the significant role of the trickster in contemporary Aboriginal performance art, we must understand that historically, North American indigenous peoples have a comic or mostly comic character as a fundamental element within their societal frameworks. The trickster can be understood as a method of serious play. For contemporary artists, the trickster is employed in an attempt to cause epistemological rupture, or as Ryan phrases it, the incorporation of the trickster reflects a desire for "a radical shift in viewer perspective and even political positioning by imagining and imaging alternative viewpoints. ${ }^{, 43}$ Locating a comic spirit at the centre of indigenous identity, ${ }^{44}$ Vizenor asserts that the trickster is an act of 'doing' not an aesthetic presence, or a museum being. From these insights into the trickster, we can recognize Lori Blondeau as a contemporary Aboriginal artist who incorporates facets of the trickster in many of her performances - as a 'Contemporary Traditionalist., 45

Blondeau explores colonial history and contemporary experience through humour, often touching on stories and events that have been forgotten by the general public, or silenced. She presents indigenous knowledge and stories, while illuminating issues of representation of which many non-Aboriginal audience members would not be aware. In this sense, her performances are potential sites of non-Aboriginal recognition for the need of healing in the Aboriginal community. Blondeau employs humour and the non-serious as part of her critique to open up the audience, allowing for reception by 
Aboriginal and non-Aboriginal alike of the uncomfortable or painful subjects she addresses. Blondeau's persona CosmoSquaw, in particular, results from the utilization of humour to address hard issues and to counter ignorance with understanding.

\section{CosmoSquaw and Lonely Surfer Squaw}

The signifiers of Indian-ness (such as coloured feather, beaded headbands and faux buckskin dress and moccasins) are not true representations of Indians. They are stereotypical representations that have been created by the dominate society to appease its way of seeing Native Americans. The stereotypes of Indian women can be traced back to first contact with Europeans through narratives, drawings, paintings, and photographs ${ }^{46}$ Lori Blondeau

Lori Blondeau elicits recognition for Aboriginal people through confrontational performance. As Peggy Phelan theorizes, performance art's confrontation is 'between the looker and the given to be seen," I perceive that the essence of Lori Blondeau's performance work is a confrontation between her audience and their expectations. In the case of audience members who have come to expect humorous deconstructions, their position as an 'expert' allows them to be even more engaged in the process of recognition. Blondeau's performance space equates with Luna's 'battlefield.' In the confrontations staged in her created environments, she often employs the weapons of humour, even absurdity, in hopes of catalyzing her audiences' consciousness.

Lonely Surfer Squaw (Figure 4) and CosmoSquaw (Figure 3) are included in my discussion of performance personas since Blondeau argues that her photo shoots constitute a performance, and that such work is "performative photography." ${ }^{\text {48 }}$ It parallels Shelley Niro's series Mohawks in Beehives (1991) (Figure 42). In this innovative series from 1991, Niro photographs her sisters. This is humorous performative photography that incorporates and plays with stereotypes. Blondeau has acknowledged the work of Niro as 
an influence, especially in her early work, such as Lonely Surfer Squaw. ${ }^{49}$ Blondeau has created these personas as part of her strategy to unsettle her audience's perceptions of the image and identity of Aboriginal women. CosmoSquaw (Figure 3), otherwise known as Betty Daybird, uses the parodic mode to re-represent the cultural stereotype of the 'squaw' ${ }^{50}$ CosmoSquaw made her debut as a magazine cover girl, forming part of a light-box image, made in collaboration with Bradlee LaRocque for a show entitled Native Love in $1996 .{ }^{51}$ Since then, CosmoSquaw has appeared in live performances, television interviews, videos, and on the internet. Her audacious persona, confident attitude, and flamboyant clothes derive from Blondeau's personal experience with popular culture. ${ }^{52}$ Her genesis dates to the time when Blondeau "started thinking about inventing a magazine like Cosmopolitan for Native women...coming up with the name CosmoSquaw."

The choice to use the word 'squaw' was difficult for Blondeau, as it is generally regarded as a derogatory and harmful term — and because she was aware that she would receive criticism from the Native community. ${ }^{54}$ However, her decision to use the term reflects her intention to reclaim the word's original meaning in Cree, woman. In this regard, Blondeau is strategically employing what Rebecca Schneider identifies as counter-mimicry, in order to re-negotiate the identities of the Aboriginal woman. ${ }^{55}$ Through her personas, Blondeau explicitly presents how identity is constructed within a colonial framework. ${ }^{56}$ Her incorporation and prominent use of the term squaw is, as she states, "about taking away the negative connotations and replacing them with something positive, ${ }^{, 57}$ and about drawing attention to the colonial stereotypes that have influenced Aboriginal women's sense of self. ${ }^{58}$ Judith Butler argues that this act of reclaiming is the 
initiating moment of a counter-mobilization. ${ }^{59}$ According to Blondeau, the decision to incorporate the prefix 'cosmo' relates to her belief that all women are cosmo-squaws, or women of the universe. One could argue that Cosmopolitan magazine equates to the artificiality of Euro-American fashion and beauty industries, and that the women represented in the pages are stereotypes. In other words, there is little 'real' in Cosmopolitan magazine. Blondeau's CosmoSquaw may thus be seen to challenge not only the representations of Aboriginal women, but the unrealistic images in the magazine.

In this work, Blondeau reinvents herself as a cover girl model, with big hair, red lipstick, and pouting lips. She is confident, sexy, and powerful. She utilizes the layout from Cosmopolitan, including the types of information on the cover. This month's CosmoSquaw cover girl is surrounded by titles of mock feature articles such as: "10 easy make-up tips for a killer bingo face,"60 and "Is your man getting tired of the same old dish? Learn How to Spoon-feed your Man!" These mock titles are rewards to the Aboriginal woman who understands the inside jokes, especially the meaning of 'the spoon,' which in many communities is a slang term for vagina. ${ }^{61}$ Both the CosmoSquaw and Lonely Surfer Squaw personas take on the idealized portrayals of feminine beauty in the media and how damaging that can be for women from minority groups who are not even represented within these marginalized depictions of the 'perfect woman.' This is articulated in Jim Logan's Venus Myth, 1993 (Figure 43). In the text incorporated into the image, Logan writes: Beauty seems to be a secret, kept by those in magazines. So powerful is beauty that my sister wishes she was white and my sons won't look at their own. Turning her focus to the harmful effects that the popular media has had on herself and on the other women in her community, Blondeau places her own body on the iconic 
image of the white pin-up girl. Blondeau draws from her own stories and experiences to generate her performance personas. Logan's statement that his sister wishes she was white is commonly heard among Aboriginal youth, especially amongst the young women. Blondeau's mock magazine addresses the need for an increase in visible, positive Aboriginal role models in the media, or at least diverse visibility to counter the negative stereotypes perpetuated on the nightly news. ${ }^{62}$ I would argue that Cosmopolitan is not the ideal venue or vehicle for this type of 'mainstream' visibility and or recognition. However, Lori Blondeau's CosmoSquaw's (Figure 3) feature on the cover of Canadian Art magazine is a site for positive public recognition.

Taking Cosmopolitan magazine's cover page as a point of departure, Lori Blondeau challenges her audience to produce new readings and recognize new decolonized identities. ${ }^{63}$ In this work, she invites her viewers, both Aboriginal and nonAboriginal, to question the fixed signs of indigenous women, exemplified by the word 'squaw.' Deploying the tactic of repetition-with-difference, she reveals through shifts in meaning, the silences and omissions of the original page. Aboriginal women are excluded from the 'original page,' based on 'mainstream' definitions of femininity, sensuality, and sexuality. Lynne Bell says that Blondeau is among the "Canadian artists who rent or poach the format of highly influential pages in everyday culture in order to, in the words of the cultural critic de Certeau, 'insinuate their countless differences into the dominant text'." ${ }^{64}$ Within the paradigm of post-colonialism, Lori Blondeau 'rents' the front cover of Cosmopolitan to insert herself as the first Aboriginal cover girl, ensuring her audience's immediate recognition of her intervention in popular culture. From its national debut on the cover of Canadian Art, it was available to a large multicultural audience, 
and now it appears on the magazine's website. This image remains accessible for further viewing, and for continued contemplation.

CosmoSquaw employs mimicry and parody in providing an alternative to Aboriginal women, while addressing the erasure of their bodies in popular culture's hegemonic model of beauty. As Blondeau explains in a conversation with Lynne Bell, "So, it's about taking away the negative connotations and replacing them with something positive." ${ }^{\text {,65 }}$ Mimicry is a key concept, which has gained a significant space within postcolonial studies, due to its possibilities to describe the ambivalent ${ }^{66}$ relationship between colonizer and colonized. In colonial discourse, the colonized are encouraged to adopt and mimic the colonizer's cultural habits, institutions, and value systems. The result of this type of mimicry is never a simple reproduction of traits, it is rather a 'blurred copy' of the colonizer, and a potential threat, due to the fact that mimicry is never far from mockery. Mimicry therefore locates cracks in the proclaimed certainty of colonial dominance, generating an uncertainty in its control over the behaviour of the colonized.

The use of costume is a major factor in the effectiveness of Blondeau's personas in terms of re-addressing and re-envisioning signs of Aboriginal women. The artist employs costume to mimic and subvert the dominant culture's image of women's beauty. As Bhabha argues, "Mimicry emerges as the representation of a difference that is itself a process of disavowel. Mimicry is thus, the sign of a double articulation; a complex strategy of reform." ${ }^{67}$ Blondeau's performance personas arguably are 'double articulations,' negotiating identities and stereotypes. In "Dressed to Thrill: Costume, Body, and Dress in Canadian Performative Art," Jayne Wark introduces the necessity to consider costume in relation to body politics, in other words, to not overlook the 
inclusion of a persona's costume as a significant facet of performance methods. She writes:

If the body is indeed the site where the particularities of identity are visibly marked, it is also indisputable that the body in performance is rarely unadorned. More often than not, the body is accompanied by various cultural artifacts, from simple street clothes to theatrical costumes to elaborate constructions that function as hybrids between prop and art. ${ }^{68}$

Kaja Silverman discusses the significance of dressing the body in "Fragments of a Fashionable Discourse," noting that without ornamentation the body is not culturally visible, furthermore, that clothing on the body enables an articulation into a "meaningful form" and to be "culturally seen." 69 Viewed in this way, clothing or dress acts as a signifier of cultural identity, allowing the body to be interpreted and recognized as belonging to a certain socio-cultural group. Blondeau's inclusion of elaborate dress for her personas provides an introduction to the problematics of stereotypes. She is not dressed in the typical 'Indian' women's dress, she wears lingerie and bikinis.

While CosmoSquaw (Figure 3) is easily recognizable as a subversive reiteration of a Cosmopolitan cover girl, Lonely Surfer Squaw (Figure 4), with her beaver skin bikini and gigantic pink surfboard, appropriates and transforms the pin-up girl of California's 1960s white surfing culture. The Lonely Surfer Squaw persona also mocks the idealized Californian beach-babes from contemporary mainstream television shows like Baywatch. In Lonely Surfer Squaw, Blondeau poses in a fur bikini and knee-high fur boots, with a surfboard carved from pink insulation foam, along the bank of the partially frozen South Saskatchewan River. ${ }^{70}$ This image and persona were originally created for an internet postcard project in 1996. Bradlee Larocque's photo shoot produced the series, titled 6 tips for prairie surfin, which included the images SurferSquaw Catch (Figure 24), Surfer Squaw Surf-Up (Figure 25), and Surfer Squaw Grease (Figure 26). In addition to the 
images on the internet, Lonely Surfer Squaw has been publicly viewed in Toronto during the IndigenUs Festival (Figure 28 \& 29) and was also included in the Canadian Art article.

Analyses of these photographs can suggest numerous readings, such as a critical play on the highly sexualized images in the Sports Illustrated bathing suit edition. In this context, Blondeau's sexy Surfer-Squaw comments on the lack of inclusion of Aboriginal women in popular culture's fashion and beauty magazines, reinforced by the inclusion of the word Lonely in the title of the piece. She may also be 'lonely' because she is attempting to surf in the middle of winter on a river in the Canadian prairies, humorously revealing that she is displaced-lost in the landscape. Blondeau states that although humour, expressed as absurdity, is a primary element, the underlying meaning to her Lonely Surfer Squaw series relates to the effects of displacement. ${ }^{71}$ In addition, Lonely Surfer Squaw overtly expresses issues of sexuality. It appears that she is flirting with the viewer, suggestively looking at and posing for the camera. Her bare skin and bikini combo feed into Blondeau's sexually vocal image. She is playing with popular culture's representations of women in lingerie, as featured in the Victoria Secret catalogue, for example. The gigantic pink surfboard could be interpreted as both a phallic and vaginal representation. The shape and colour denotes both sexes' genitalia, which is the basis for several questions. Is she longing for male or female intimacy? Or perhaps she is presenting her love of herself, making a comment on the need for women, especially Aboriginal women to love and respect themselves. Surfer Squaw is self-confident, enticing the viewer to look at her not as a victim but as an empowered individual. The setting in the snow, arguably an iconic sign of Canada, seems to hold out the promise of a 
voluptuous Canadian Aboriginal surf-babe. This image offers viewers a representation of an empowered Aboriginal woman, while also acknowledging the impact of displacement in Aboriginal communities.

Blondeau's photographs can arguably be viewed as portraits. However, are they portraits of Blondeau or of her personas? For example, the image Some Kinda Princess (Figure 44) is a photograph of Blondeau's Belle Sauvage dressed in an 'Indian Princess' mock buckskin dress made of cloth, with a holster, two toy guns in her hands, and a beehive hair do. Her costume resembles the dress of Disney's Pocahontas (Figure 45). The photograph/portrait resembles a 'Wanted' poster from the Wild West, and just such a 'Wanted' style poster appears as the backdrop for this image. What does this signify? Perhaps Blondeau is commenting on the need for imagery of Aboriginal peoples made by the Aboriginal lens. Along this line, perhaps Blondeau 'Wants' to offer herself as a possible new representation of Aboriginal women's identity. This piece draws in viewers, asking them questions such as, what is she 'Wanted' for? I argue that these performative photographs are portraits of Blondeau's personas; and because these personas are based on Blondeau's lived experiences, they also are portraits, visual representations of Blondeau's stories. Some Kinda Princess captures Belle Sauvage's confidence, power, humour, and sly sexuality. However this piece is analyzed, as a portrait of the artist or of her persona, it confronts the viewer with new imagery, new ways of viewing Aboriginal women.

This also holds true for Blondeau's other photographs, CosmoSquaw (Figure 3) and Lonely Surfer Squaw (Figure 4), which re-deploy wounding experiences and words from her own life and the lives of her mother and grandmother. These two pieces are 
intergenerational, multi-layered works that use tongue-in-cheek humour to "startlingly subversive, compulsively entertaining, and highly political ends."72 Mimicry is employed as Blondeau's post-colonial choice of agency. Blondeau's performances wield humour and memory to invite contemplation of the violence of colonization and offer the opportunity to envision a new possibility, decolonization.

\section{Betty Daybird}

Subversion through humour is a powerful cross-cultural weapon that can bridge multicultural audiences. They become connected to each other by Blondeau's storytelling. ${ }^{73}$ Blondeau has created a detailed biography for Betty Daybird, which is based on her own histories and articulated in her performances. Blondeau incorporated her great-grandfather's name, Daybird, as a method of asserting continuum, a way to foster survivance of her family's stories. Betty Daybird tells of her birth on a Cree reservation, "in a small government frame house... under the long shadow of St. Anne's church tower," and her childhood summers "spent travelling extensively with her grandmother [Belle Sauvage] in what some likened to be the only gay Wild West show on the continent." ${ }^{74}$ Although Blondeau never did travel with a Wild West show and historically there were no gay Wild West shows, she did spend her summers with her grandmother on a reservation in Saskatchewan. Blondeau writes a history for Daybird that includes her performing as the "Eskimo High Tower Diver," the "Wild Indian Wonder Girl," and her big break in Hollywood as the "Million Dollar Surfer Squaw," These roles reflect the objectification of Aboriginal people as the exotic 'other.'

Blondeau imposes her reconstructed self/identity on the dominant aesthetic system, which only accommodates the Aboriginal woman in representational 
stereotypes. ${ }^{75}$ Drawing upon Amelia Jones' notion of 'subversive narcissism,' Amy Sara Caroll suggests that Betty Daybird's parodying of the diva claims "a self-fashioned space for her identity as a Native woman, while also poking fun at the idea of the perfomer[artist]-hero[ine] by pushing the image to an extreme limit. ${ }^{76}$ I would argue that Blondeau's performance practice reflects Jones' concept of subversive narcissism, but goes beyond it to include the stories of her family and community. Blondeau uses her body as a site for decolonizing the images of Aboriginal women, subverting the stereotype as a method of post-colonial critique and intervention. As Coco Fusco suggests:

\footnotetext{
Aesthetic engagement with the historical trauma of colonialism...is simply not comparable with the insipid narcissism of talk-show.confessionals. The refusal to forget that history and the insistence on returning to it in order to perceive the parallels between old and new forms of dehumanization...the post-colonial's strategic means of debunking the triumphalist narratives of modernism and postmodernism."
}

Lori Blondeau's performance 'act' recognizes her desire to be seen. Rebecca Schneider writes, "The 'seen' takes on an agency of her own and wields the unnerving potential of a subversive reciprocity of vision, an explicit complicity, or mutual recognition between seer and seen in the scene of viewing."78 Through self-representation in performance art, Blondeau subverts the colonially framed body of the Aboriginal woman as an intervention of the 'other.' This strategy emphasizes the body as an agent of manipulation, re-signifying the Aboriginal woman's body, and therefore dislodging it from its fixed representations. Performance art is therefore about disclosure, illuminating the multi-meanings in the act of performing the body.

I see Blondeau's work as a parody of opposites. Betty Daybird is powerful and glamorous, which is in stark contrast to the stereotypes of Aboriginal squaws and Indian princesses. Here, Blondeau describes her genesis: 
For years I had been doing research into Native women. I became frustrated with the research because it was always written from a non-Native perspective. I saw, Daybird as a way to take little jabs at the western viewpoint... and I wanted to play with some of the history. For her character I also use situations that have affected and made me who I am. This meant looking at the women in my family, my mother and her sisters and my grandmother. ${ }^{79}$

Daybird is a Hollywood diva, chic and sexy in a sassy red negligee and feather boa, black boots, beehive hairdo, and an 'Indian princess' tattoo called falls to pieces (Figure 46). Typically, Blondeau performs in art venues, in a cabaret style performance/audience relationship. ${ }^{80}$ Amy Sara Caroll at Neutral Ground Gallery in Regina notes how Blondeau's Betty Daybird (Figure 47) “presides over her audience, snapping her fingers to solicit lipstick, a lit cigarette, a glass of wine...she even demands the performances second-take, yelling 'Cut'." ${ }^{\prime 81}$ (Figure $48 \& 49 \& 50$ ) Carroll observed Daybird's political agenda of self-control, confidence, and representation, stating that her sovereignty shines throughout her performance. ${ }^{82}$ From my observations, Blondeau is playing with power through her control over the space, the music, the audience. Daybird has the attention of every person in the space- they are watching her every move, drawn in by her confident, almost arrogant demeanour, waiting for her next move (Figure 51). While viewing recorded footage of one of her many Betty Daybird performances, I witnessed a woman commanding attention, wanting to be looked at (Figure 52). She presents herself as a sex symbol, parading around to a rendition of Sinatra's I Get a Kick Out of You. On numerous occasions, she pulls up her negligee, showing off her thighs (Figure 53). She also removes her red silk robe half way through the performance, moving into the realm of striptease-without revealing too much (Figure 54). As stated above, during Daybird's humorous show, images of her 'adventures' are projected on a screen behind her. The viewer gets a glimpse into the life of Betty Daybird, such as playing a game of pool at a 
bar and posing on city streets (Figure 55). Betty Daybird's character seems close to the absurd, which is clearly a calculated measure taken by Blondeau to elucidate the absurdity of stereotypes of Aboriginal women. Blondeau's choice of a red outfit recalls the representation of the Indian princess as the 'lady in red.' While historically the 'lady in red' image (Figure 40) was used as a symbol of the availability of the lands in the West, here Betty Daybird stakes a claim to her own space.

The persona of Betty Daybird is Blondeau's testimony to Aboriginal women's sexuality, femininity, autonomy, and power. Daybird also tells many stories that expand the limits of Aboriginal women's identities and subjectivity. Within this discussion, critical questions arise, such as why does Blondeau not create new 'positive' representations of Aboriginal women? Why does she superimpose the Aboriginal woman onto imagery of White women, who are arguably objectified in popular culture? Is the use of parody and humour an effective strategy? Or is she merely replacing one stereotype with another? Carroll states that Blondeau, "claims a self fashioned space for her identity as a Native woman." ${ }^{83}$ I agree with Carroll, and suggest that to re-envision the representation of Aboriginal women in popular culture, the stereotype must be explicitly exposed to show how and why these types of negative images exist. Blondeau's performance of Betty Daybird results in the illumination of the performative and constructed quality of identity. ${ }^{84}$

Blondeau's discussion of Aboriginal women's issues in her performance practice could be argued as being a feminist critique. In Aboriginal literature, many critics note that feminism is a discourse and agency that excludes and that does not represent the issues and stories of Aboriginal women. Although Blondeau's focus is to act as a catalyst 
to release the image and identity of the indigenous woman from their stereotypical past, she has stated that her relationship with feminism is an ambivalent one. The following account will show Blondeau's hesitations about adopting the feminist label, as an Aboriginal performance artist. In October of 2001 in Winnipeg, Lori Blondeau was to speak at MAWA, Women's Art Symposium, Locating Feminism. She was scheduled to present a paper entitled "Search for Feminism," however, Betty Daybird sauntered in wearing her red negligee, sun glasses, and beehive hair, and stated that Lori Blondeau "hadn't wanted to come and had sent" Daybird in her place. ${ }^{85}$ Parodying the academic lecture format, "the eccentric Daybird piled numerous stacks of blank paper (hauled in on a wagon by her assistant) onto a table, jokingly inviting anyone to read her dissertation on feminism. ${ }^{\text {86 }}$ Daybird proceeded to give a slide presentation on her search for feminism, a long journey that began in a bar by interviewing the waitresses on the subject of feminism. At the end of Daybird's account, she stated that her "search provided few answers and she concluded that feminism was inside herself." This being said, and given that Daybird's presentation was to a predominantly white and mostly academic conference on feminism, I interpret Blondeau's performance as an attempt to voice frustrations with what is arguably a largely white, middle-class, academic feminism that excludes her native identity, including only her identity of woman. Throughout this tongue-in-cheek performance, Blondeau pointedly raised her hesitance towards feminism, as a First Nations woman. ${ }^{87}$ In "Savage Hegemony: From Endangered Species to Feminist Indigenism," M.A. Jaimes Guerrero discusses:

Many Native Women have argued that the priorities and socio-political agendas of the predominantly white women's movement are not necessarily constitutive of the same liberation agenda for Native women in their indigenous struggles for decolonization. As community based women, Native women cannot afford to participate in what often appears to them to be an individually oriented Euro-American middle class women's 
sociopolitical agenda. ${ }^{88}$

Consequently, at this point in Blondeau's search for feminism, she does not label herself

a feminist artist. Therefore, her performance practice will not be explored in relation to

feminist theory. Blondeau is, however, an activist - attempting to reclaim the image of

the indigenous woman, to create new inclusive histories. ${ }^{89}$ In the persona of Betty

Daybird, she offers herself as a re-representation of Aboriginal women's identity,

controlled by the self-determined Aboriginal lens not the colonial gaze.

\section{Belle Sauvage: Post-colonial History Lesson}

The Persona of Belle Sauvage was created for a postcard I made in 1998 for the Dunlop Art Gallery. The Dunlop asked me to make a work responding to the show Indian Princesses and Cowgirls: Stereotypes from the Frontier. For me, this exhibition demonstrated once again that as a Native woman I could play only two roles in the frontier narratives: one being the Indian Princess and the other, the Squaw. I saw this as my opportunity to create an Indian cowgirl. ${ }^{90}$ Lori Blondeau

A Moment in the Life of Belle Sauvage addresses the history of colonial trauma

and the limitations of Aboriginal women's stereotypes with humour, subversion, and parody, to radically open up decolonized spaces. Belle Sauvage first appeared as a photographic image in the style of an early twentieth-century postcard (circa 1918). Lori Blondeau has a thorough understanding of the politics of representation, and attempts to subvert these images of Aboriginal women. She creates imagined spaces for Native women, negotiating identity through stories. Blondeau generates a new discourse that exposes the instability of the structures of power, thwarting them through irony. Foucault discusses the mutability of power:

Discourses are not once and for all subservient to power or raised up against it, any more than silences are. We must make allowance for the concept's complex and unstable process whereby discourse can be both an instrument and an effect of power, but also a hindrance, a stumbling block, a point of resistance and a starting point for an opposing strategy. Discourse transmits and produces power; it reinforces it, but also undermines and exposes it, renders it fragile and makes it possible to thwart it. ${ }^{91}$ 
Blondeau's performative practice, as evidenced in Belle Sauvage, makes clear how power and history can be dynamically and continuously contested, therefore, localized once the discourse in which they reside is understood.

In the post-colonial sense, Blondeau creates an intimate conversation between herself and her audience members, enticing listening, witnessing, and remembering. $A$ Moment in the Life of Belle Sauvage performance space will be explored as a site for palimpsest exchange, where Blondeau shares stories as an agency of testimony. Lewis Hyde writes that a work of art is a gift, consequently, from this perspective the narrative and knowledge illustrated in art can also be understood as part of what is given, not solely the aesthetic value. ${ }^{92}$ Blondeau's performativity theoretically acts as the gift; this gift is new knowledge or the recognition of old and new stories.

The stage is set, Blondeau transforms the gallery space to transport her audience and herself back in time, to the Wild West of the nineteenth century. The back of the gallery is draped in luminous brown velvet curtains and filled with hay bales, a cow skull, and shadowy black and white images of an Indian Cowboy and an Indian Princess. These images are of her grandparents, underscoring the use of her family's stories as a point of departure. ${ }^{93}$ The multicultural and multi-generational audience sits or stands facing Blondeau's staged Wild West arena. As the curtains part and the crowd applauds, Belle Sauvage (Figure 6) makes her memorable entrance to the Doris Day song The Black Hills of Dakota (from the film Calamity Jane, 1953). Belle Sauvage is dressed in a cowboy hat, western style vest, fringed suede pants, and cowboy boots with metal spurs. Her gun holster, presumably purchased at a souvenir shop, bears an image of the 'Indian Brave.' The smoke from her cigarette spirals up, while the audience follows the star of the show 
into the intimate atmosphere of a dusty rodeo arena. ${ }^{94}$ Throughout Belle Sauvage's storytelling, she drinks out of a whiskey bottle, pulls and shoots her guns, and practises her roping skills.

Belle Sauvage is an imagined persona (Figure 56). However, woven into the imagined are personal memories, factual stories, and historical events. Blondeau states that through the project at the Dunlop Gallery, she was able to "create my own fictional history. If western history could do it why couldn't I?"95 There is a large body of literature and visual imagery that represents the Western Frontier from the European lens. Gerald McMaster writes, "It makes little sense for Indigenous people to respond to the outrageous historical fictions of the West. On the contrary, we must focus on our own perspectives. ${ }^{96}$ McMaster's argument is significant, but it optimistically overlooks current reality and the impact of colonial histories on Aboriginal identity. These historical representations, no matter how outrageous or ridiculous, continue to circulate within popular culture and consequently shape the identities of all North Americans. Consequently, artists such as Lori Blondeau respond to these colonial narratives and representations, because if they are left untouched by critical investigation, unfortunately, they will remain the imagery representing Aboriginal peoples. Blondeau also creates imagined spaces of the Wild West, where colonial history and indigenous perspectives intertwine. Her Aboriginal stories challenge the West's fictitious narratives. Belle Sauvage (Figures $6 \& 57$ ) is a mean trick roper, capable of drinking most men under the table. She is also a notorious outlaw with a large appetite for adventure. During the performance she turns on her legendary charm for the cameras, posing with guns twirling. ${ }^{97}$ Lynne Bell remarks that "this seductive cowgirl's props are a long cigarette 
holder, a trick rope and a bottle of whiskey."98 This Aboriginal cowgirl is exemplified in Blondeau's “Some Kinda Princess” (Figure 44 \& 56).

Lori Blondeau draws from her family history in the scripting and design of her campy, satirical performance, A Moment in the Life of Belle Sauvage. Blondeau's stage persona is loosely based on indigenous women who performed in Wild West shows and Vaudeville acts in the early twentieth century, and spoofs the 1950s film Calamity Jane, in which Doris Day appeared as a cross-dressing, gender-bending white cowgirl (Figure 57). Blondeau's performance art remix of the Wild West presents a post-colonial reading of the narratives of Hollywood pop culture. Her work speaks to the importance of maintaining one's identity and beliefs as a First Nations person while living and working in 'mainstream' society. In her pointed and disarmingly humorous take on contemporary art and society, Blondeau confronts and co-opts conventional stereotypes.

In yet another creative twist, A Moment in the Life of Belle Sauvage is set in the only gay Wild West show that toured Europe and North America. Blondeau notes that she imagined Belle Sauvage as being "bigger than life and bigger than Calamity Jane or Belle Star." 99 This persona arose out of Blondeau's awareness of the absence of First Nations women in North American history, which made an impression on her when researching Pocahontas. She recalls another impetus:
I became frustrated with the conflicting stories surrounding her life. Belle Sauvage gave me the opportunity to develop a fictional persona using my own, my mother's and my grandmother's stories. Building on these stories I developed a persona that is part fiction and part non-fiction. Belle Sauvage is both believable and absurd at the same time. Her persona plays with the notion of history and its authority. ${ }^{100}$

The decision to name her persona Belle Sauvage suggests a parodic commentary on the history of the Indian princess and of Pocahontas. ${ }^{101}$

The performance A Moment in the Life of Belle Sauvage is, as Lynne Bell states, 
rich in comic exaggerations, taking the audience on a roller-coaster ride through laughter and painful testimony. ${ }^{102}$ In one of Blondeau's performances of Belle Sauvage the performance starts with Sauvage entering the gallery, whose walls are draped in white curtains and lit with red lights, to Doris Day's song “The Black Hills of Dakota.” There are life-sized photographic cut-outs mounted on foam core, and a hay bale with a plastic bull's head in the middle of the gallery for Belle Sauvage's roping practice. ${ }^{103}$ As Day's song plays, Belle Sauvage saunters around with a bottle of whiskey in hand, captivating her audience with her life's testimony. Blondeau writes:

She tells us about some of the men she has known and the women that didn't want to know her and how her life has always been lived on the fringe. She tells us that she rode with the gay Wild West show because it was the only show in town that would take her seriously as a cowgirl and not just stereotype her as an Indian Princess. ${ }^{104}$

Blondeau succeeds in sharing some of her painful stories through humour. In one segment, Sauvage gestures towards the life-sized black-and-white photograph of an Indian cowboy, and declares, "He was a bronco rider who kept horses in the 1920s on the Gordon Reserve in the Touchwood Hills, Saskatchewan. ${ }^{105}$ It's a pity that he couldn't leave the reserve without a pass." 106 This image is of her grandfather as a young cowboy in 1927, he has a six-shooter in one hand and a shotgun in the other. He is wearing a beaded cowboy vest, gloves, and jeans tucked into his cowboy boots. In the performance, the Touchwood Hills of Saskatchewan are identified as a place occupied by colonial systems of oppression, by the "Gordon Reserve." The 'pass' Sauvage mentions, refers to the 'pass and permit system,' a component of a larger system to 'control' the movement of Aboriginal peoples from their reservation lands. Passes had to be applied for, and were granted by an Indian Agent. These Department of Indian Affairs positions held great power and authority over First Nations communities, as they controlled the economic, 
agricultural, educational, medical, political, and cultural aspects of reserve life. ${ }^{107} \mathrm{Her}$ grandfather's personal story is associated with the larger reality of the Indian Act. ${ }^{108}$ The words "pass' and 'permit" introduce into Blondeau's performance space the politics of the so-called 'Indian problem,' and the Canadian government's 'civilizing' and 'assimilating' interventions.

Belle Sauvage's storytelling forces the audience to take part in a post-colonial history lesson. She lures them into questioning their understanding of 'Indian Agents,' the Indian Act, and other hegemonic policies. In A Moment in the Life of Belle Sauvage, her stories also act as evidence of the failure of the Canadian government's attempts at cultural genocide. Blondeau writes:

The first time I saw this photograph of my grandfather I thought, wow! He was a cowboy and a bronco rider. But he was an Indian cowboy with these beautiful beaded garments. He couldn't leave the reserve because it was still under the pass-permit-system. But he owned his own horses and that's how he learnt how to break horses. I wish I could talk to him. Where did he first see the cowboy image? Why did he want to become a cowboy? Maybe he was a performance artist? My grandfather comes from one of the original ten families of Gordon's First Nations located in the Touchwood Hills. His grandfather was Daybird, who in his time was a very powerful medicine man. My grandfather was also a strong man when it came to his culture and identity as a Native person. This was something that not even colonialism could take away from him. He was a traditional dancer, and when we were children, he would take us around the powwow trail in the 1960s and 1970s. Maybe he showed us that you could live in both worlds and still maintain your identity and your beliefs as a First Nation person. ${ }^{109}$

These stories of Blondeau's grandfather, incorporated into the life and narrative of Belle Sauvage, emphasize cultural survivance and resistance. This performance can therefore be understood within the discourse of Gerald Vizernor's theory of Survivance, which he defines as more than merely indigenous cultural survival or endurance. He claims, "the stories of survivance are an active presence...[and] are the creases of sovereignty." 110 Blondeau continues the lifeline of her family's stories into the present by telling and re- 
telling them; thus, her storytelling actively contributes to their survivance. Her storytelling actively shares the history of her family, placing their experiences into the present, and presenting them under the lens of sovereignty.

The following passage by Lynne Bell is a personal account of her experience of this performance, which informs us of the intensity of Blondeau's practice and methods and reminds us of her intentions as a performance artist/activist. Blondeau deliberately creates this environment and space: for the purpose of education. Blondeau's statement that her Grandfather was restricted from leaving the reserve, Bell states:

hangs in the air, its sense suspended, a reminder of the prisons of colonial space and the public secret of the pass and permit systems that restricted the movement and business transactions of First Nations people in Saskatchewan from the late $19^{\text {th }}$ through the mid $20^{\text {th }}$ centuries. ${ }^{111}$

I would agree with this statement, and offer this reading of Blondeau's work. Even if the viewer is not aware of colonial histories, the concept of confinement and displacement connected with the words reserve and pass registers. I suggest that Belle Sauvage not only offers a re-dressing of colonial histories but offers her histories as a reciprocal gift to her audiences through the inclusion of humour. Although these histories are hard and traumatic to remember, her listener of Aboriginal or non-Aboriginal descent can take in the story Blondeau tells in order to participate in her post-colonial re-writing.

Blondeau's performance points to the historical climate of an earlier era. The current discourse of antimodernism investigates 'primitivism,' and subsequently the romanticization of all things 'primitive.' The desire for the return to nature that prevailed in what is termed the 'modern era,' is marked by significant ironies and complexities. One example of this is the period of extensive 'salvaging' by museums, occurring at the same time as the development of the legislative ceremonial bans. These bans either 
forced Canada's Aboriginal peoples to go underground to perform cultural rituals and stories, and to produce material culture, or to abolish them completely. The Belle Sauvage persona plays with 'history and its authority' in the 'development' of the West. The land that now makes up Canada was viewed by Euro-Canadians as open and free for the taking. Blondeau's choice of a Wild West setting recalls this history of Aboriginal land loss. Using parody and humour, the artist creates a counterpoint to Canada's iconic Old West, with its celebration of white cowboy culture and its erasures of Aboriginal histories and voices. ${ }^{112}$ This brings us back to the concept of performance as storytelling, as a way to disrupt national patterns of remembering and forgetting, and in this case, to educate and start a new pattern of cultural understanding and empowerment. Blondeau states that "parody can be a powerful force for challenging and disempowering the inherited violence embedded in Western ways of knowing the world." ${ }^{113}$ This performance is Blondeau's version of the old west, populated by First Nations cowboys and cowgirls. Through Belle Sauvage, a voluptuous, worldly, and gay First Nations cowgirl, Blondeau writes yet another layer of meaning over the history of Aboriginal representation in popular culture. Her 'imagined' Wild West reflects a closer reading of the period than that projected by Hollywood westerns.

The concluding section of Belle Sauvage's performance is her exit to the lyrics of Tom Petty's song "Swingin":

Well, she was standing by the highway in her boots and silver spurs Gonna hitchhike to the yellow moon when a Cadillac stopped for her And she said, "Hey, nice to meet you, are you goin' my way?" Yeah, that's when it happened. The world caught fire that day And she went down swingin.' Yeah she went down swingin' Well, she was over twenty-one in trouble with the law And it didn't faze her none. She called her mother-in-law And said I need a little money. I knew I could count on you After that night in Vegas and the hell that we went through 
We went down swingin.' Like Benny Goodman. Yeah we went down swingin'

Moonlight on the interstate. She was 'cross the Georgia line

Looked out the window feeling great. Yeah, it had to come in time

And she said I'm never going back. She said at last I'm free

I wish ma could see me now, she'd be so proud of me

She went down swingin.' Like Tommy Dorsey. Yeah she went swingin.' Like Sammy Davis

She went down swingin.' Like Sonny Liston

The words of the song fill the room, bearing witness to the names of individuals such as

Sammy Davis and Sonny Liston, who had to fight and challenge societal 'norms' to achieve their life goals. If the audience is aware of this song and the histories of these individuals they may make connections between the histories of Belle Sauvage and Blondeau's grandfather therefore recognizing and bearing witness to colonial histories. ${ }^{114}$ The chorus 'She went down swingin' arguably alludes to a fundamental meaning of this performance, which is Aboriginal resistance and survivance. Belle Sauvage's persona is a fighter, too. Her 'opponents' are stereotypes and the colonial discourse; her altercations provide an opportunity for disruption for the purpose of social change. The songs used in this performance are meant to trigger memories for the audience, and to leave traces of the experience in their minds.

Blondeau's multifaceted performance practices invite critical listening and engagement with her audience. In A Moment in the Life of Belle Sauvage, not only does she test the audience's knowledge of Canadian and Aboriginal history, she knowingly tells stories that are unknown to most in the room. I found that her methods of engagement lured me in, acting as catalysts for my own self-questioning. Blondeau's inclusion of harsh historical testimony also reminds the audience of the "power, unpredictability and rawness of live art." "115 Her intentions are clear, to educate through storytelling. She also assumes the role of meaning maker: her performative storytelling draws upon memory and inserts it into the official narrative, thus participating in the 
process of decolonization.

\section{Conclusion}

Blondeau's high-tech storytelling decolonizes the identities and histories camouflaged in the colonial discourse. Paradoxically, she dresses up, in order to strip away the colonial 'clothing' from the Aboriginal woman's body. Blondeau employs her body as agency for removing layers of colonial text and representations, to re-envision post-colonial possibilities. She creates performance personas in order to use the body as a battleground for indigenous decolonization and empowerment. Lori Blondeau uses strategies of humour, irony, and parody for her 'battle' with stereotypes, subverting them in order to use art as political activism. The strategic use of her body as an instrument for social change, to re-member identities inscribed by colonial discourse, bears witness and gives testimony to the 'traces' of Aboriginal stories present on Canada's historical palimpsest. 


\section{Conclusion}

Lori Blondeau is a high-tech storyteller, a trickster, a post-colonial Aboriginal image consultant, a history re-writer, a transcultural negotiator, and a political activist. Her artistic practice combines performance with video and photography to articulate her own story and the issues faced by Aboriginal women in the twenty-first century. In this thesis, Lori Blondeau's performances were explored through the trope of the palimpsest metaphor, as removing the layers of the colonial text from Aboriginal bodies, minds, and spaces. Her performance practice illuminates multiple histories, while telling her own stories.

I have discussed the practice of high-tech storytelling, defining and setting the parameters of this contemporary practice. I have explored and contextualized the performance practice of Blondeau by discussing the links between Aboriginal storytelling and performance art. Initially, I discussed Pauline Johnson in order to introduce the beginnings of Aboriginal performative storytelling in the dominant society, or mainstream. Johnson was argued to have used the tradition of oratory to make interventions and acts of cultural resistance. The role of storytelling in Aboriginal culture was then explored, and argued as a vehicle for resistance. I drew on the writings of Aboriginal scholars and storytellers, such as Thomas King, Simon Ortiz, and N. Scott Momaday to substantiate my findings that the story has a history of staging cultural survival and resistance. The fusion between storytelling and performance art was investigated as a fundamental element of Aboriginal performance. I argued that the result of this fusion was a politically vocal, culturally diverse artistic medium employed by many artists, including Blondeau. James Luna and Rebecca Belmore were introduced as 
high-tech storytellers to create a context of Aboriginal performance art and situate the work of Lori Blondeau. My findings were that Aboriginal performance art can be used to confront dominant representations of Aboriginal peoples, to create interventions within the colonial discourse, and to share indigenous perspectives. My research of Blondeau's performances supported my argument that Aboriginal performance art can act as sites for public questioning and social change, based on the stories that she shares.

Blondeau's CosmoSquaw, Betty Daybird, Belle Sauvage, and Lonely Surfer Squaw performance personas were discussed in relation to their reclaiming and revisioning of Aboriginal women's identities. Drawing on Stuart Hall and Charles Taylor's discussion of the construction and impact of stereotypes, the significance of tackling these erroneous representations was increased, and subsequently places value on the performance practice of Blondeau. Blondeau's employment of the tools of humour, parody, trickster, and costume were explored to illuminate how she successfully synthesizes these methods into her performance personas, transforming herself into characters, or alter egos, who possess a myriad of signifiers representing numerous stereotypes. Her work was explored to elucidate how she actively negotiates the archive of representation of Aboriginal women, which is saturated in Eurocentric imagery. Lori Blondeau generates conversations of a decolonizing dialogue with the representations of Aboriginal women from mainstream popular culture. Her performances are testimony to the ridiculous nature of stereotypes, while offering new perspectives and voicing resistance. Due to the transcultural aspect of Blondeau's costumes, spaces, and stories, her personas do not fit cleanly into the categories popular culture and colonial process have generated for Aboriginal women. I argued that this is her objective. Her personas 
problematize the sign of the Aboriginal women, generating a questioning of the inflexibility of cultural coding. Blondeau's performances use the body to question issues of representation, interpretation, and identity. Blondeau's body negotiates histories while transcending time.

Many questions were raised in relation to Blondeau's performance personas, such as, why is there a lack of positive representation of Aboriginal women in popular culture? Blondeau's performances subvert stereotypes in order to disclose their absurdity and the fact that identity is a construct, thereby exposing the dominant Euro-Canadian constructions of the 'Indian.' From her humorous subversions, Blondeau re-claims the position of the colonized Aboriginal woman, the so-called victim, and re-positions her into a new indigenized space of empowerment, self-determination, and sovereignty. Blondeau's personas act as a decolonizing agent, challenging established socio-cultural signifiers of identity. Her personas do not necessarily offer 'positive' role models for Aboriginal women, as Betty Daybird and Belle Sauvage are known for their drinking, but they demand recognition of socio-political issues, such as alcohol abuse, plaguing Canada's Aboriginal communities. The personas are not meant to be role models; the role model is Lori Blondeau.

Blondeau's performances Are You My Mother, Sisters, and Belle Sauvage were discussed and argued as having used live art to clear a space for the enunciation of difficult knowledge. ${ }^{1}$ In addition, Blondeau's use of visual storytelling was argued as being unsettling and de-stabilizing, and a politicized force that reclaimed Aboriginal stories/histories entrenched in the colonial discourse. Blondeau's work was discussed as contributing to the decolonization of Canadian indigenous stories, while gifting 
knowledge to her audiences, with the resultant creation of reciprocal relationships within her performance spaces. The work of Homi Bhabha and Edward Said substantiated my claim that Blondeau's performance participates in the process of decolonization. The role of re-membering for radical social change by means of recognizing colonial atrocities as well as indigenous knowledge systems was argued as being a key tool for decolonization. Through the lens of Aboriginal sovereignty, the significance of Blondeau's exchange of histories and stories is increased, emphasizing her role as a self-determined political activist generating interventions and sites for indigenous empowerment in the gallery space.

Storytelling is a performative act of exchange. The audience gives Blondeau the opportunity to share her stories and the possibility for the stories' continuum. In other words, some audience members take the stories with them, perhaps sharing their new knowledge and/or empowerment with others from both the Aboriginal and nonAboriginal community. The community created through Blondeau's performances generates and participates in the larger process of decolonization; their act of bearing witness acknowledges Blondeau's family's stories and their relationship to the colonial discourse. The audience, therefore, is an integral element in Blondeau's performance practice. They bear witness to Blondeau's acts of intervention, contributing to the sovereignty and decolonization of indigenous knowledge, landscapes, and bodies.

Blondeau's performance art incorporates post-colonial methodological approaches such as the voicing of silenced colonial histories, challenging the mainstream to recognize her performance's positions as agents of decolonization. She, along with her audience, negotiates a space for a post-colonial re-writing, and provokes political protest 
through performance art. Blondeau's subversive relationship to popular culture and her inclusion of politically vocal storytelling pushes the boundaries established through colonialism in order to ask her audiences to step into her performance field to mediate a new understanding. The high-tech storytelling performance practice of Lori Blondeau reclaims Aboriginal stories, histories, and identities once controlled by colonization and its legacies. She negotiates space for the discussion of indigenous knowledge, while contributing to the processes of Aboriginal decolonization. 


\title{
Endnotes
}

\author{
Preface \\ ${ }^{1}$ Jeanette C. Armstrong, 'I am Indian Woman,' in An Anthology of Canadian Native Literature in English, \\ eds., Daniel David Moses and Terry Goldie (Don Mills ON: Oxford University Press, 1998), 229-230. \\ 2 The terms Aboriginal and indigenous will be used to include First Nations, Inuit, Metis, and non-status \\ Canadian indigenous peoples. \\ ${ }^{3}$ The term Indian will be used in this thesis in its historical context. \\ ${ }^{4}$ David Barsamian and Edward W. Said, Culture and Resistance: Conversations with Edward W. Said \\ (Cambridge: South End Press, 2003).187.
}

\section{Chapter 1}

${ }^{5}$ Lee Maracle, I am Woman (North Vancouver: Write-On Press, 1988), xi. Dennis Maracle's powerful remarks in Lee Maracles's introduction to I am Woman, talks about the positive contributions the creation of artistic expressions can have on Aboriginal women's identities.

${ }^{6}$ This is a Maori Proverb, found in Jonathan Mane-Wheoki, "The Resurgence of Maori Art: Conflicts and Continuities in the Eighties," The Contemporary Pacific vol. 9. no.1 (Spring 1995): 1.

${ }^{7}$ Lynne Bell and Lori Blondeau interviewed Rebecca Belmore, exploring her participation in the HighTech Storyteller conference. Lori Blondeau and Lynne Bell, "On the Fightin Side of Me: In Conversation with Rebecca Belmore," Fuse vol. 28 no. 1 (February 2005): 25-33.

${ }^{8}$ Lori Blondeau, "Professional Statement," Department of Art History Website. http://www.arts.usask.ca/art/faculty/pages/l blondeau.html

${ }^{9}$ The term 'high-tech storytellers' comes from James Luna, who is a self-defined high-tech storyteller. In 2000, there was the High-Tech Storytellers Festival organized by Lori Blondeau. Lori Blondeau and Lynne Bell are jointly involved in the High-Tech Storytellers: An Interdisciplinary Aboriginal Art Project.

${ }^{10}$ Gerald McMaster, "Our (Inter) Related History," in On Aboriginal Representation in the Gallery, edited by Lynda Jessup (Ottawa: Canadian Museum of Civilization, 2002), 3.

${ }^{11}$ Gerald McMaster, "Our (Inter) Related History," 7.

${ }^{12}$ Steve Loft, "Aboriginal Media Art and the Postmodern Conundrum: A Coyote Perspective," in Transference, Tradition, and Technology (Banff: Walter Phillips Gallery, 2005), 93.

${ }^{13}$ Jean Fisher, "The Health of the People is the Highest Law" in Revisions: Third Text no. 2 (Winter 1987/88): 63-75.

${ }^{14}$ Lynne Bell and Janet Williamson, "High Tech Storytelling: A Conversation with Performance Artist Lori Blondeau," FUSE vol. 24 no. 4 (2001): 27.

${ }^{15}$ Della Pollack, "Oral Traditions in Performance," Oral Tradition vol. 18 no. 2 (2003): 263.

${ }^{16}$ Della Pollack, "Oral Traditions in Performance," 263.

${ }^{17}$ Aiyanna Maracle, "Performance Art and The Native Artists: an rEvolutionary Mix?" in Live at the End of the Century: Aspects of Performance Art in Vancouver, edited by Brice Canyon (Vancouver: Grunt Gallery, 2000), 100.

${ }^{18}$ Aiyanna Maracle, "Performance Art and the Native Artists," 99.

${ }^{19}$ Lori Blondeau is known for arriving in persona to academic conferences. CosmoSquaw arrived in style, as a famous diva, by limousine to the IndianActs: Aboriginal Performance Art conference held at Emily Carr organized by the Grunt Gallery in November of 2002. http://www.grunt.bc.ca

${ }^{20}$ Aiyyana Maracle, 106.

${ }^{21}$ Lynne Bell and Janice Williamson, "High Tech Storyteller: A Conversation with Performance Artist Lori Blondeau," 33.

${ }^{22}$ Aiyanna Maracle, 100-102.

23 Ibid., 100.

${ }^{24}$ Lynne Bell and Janice Williamson, "High Tech Storyteller," 29.

${ }^{25}$ Lucy Lippard, "Independent Identities," in Native American Art in the Twentieth Century, edited by Jackson Rushing (London, New York: Routledge, 1999), 135.

${ }^{26}$ Lori Blondeau "Some Kinda Princess," in Mentoring Artists For Women's Art: Culture of Community, 
edited by Vera Lemecha (Winnipeg, MAWA, 2004), 23.

${ }^{27}$ Gerald Vizenor, "Four Skin," Tamaqua: Native American Issue vol.2 no.2 (Winter/Spring 1991): 92.

${ }^{28}$ Gail Guthrie Valaskakis, Indian Country Essays on Contemporary Native Culture (Waterloo, ON:

Wilfred Laurier University Press, 2005), 3-5.

${ }^{29}$ Stuart Hall, "Spectacle of the Other," in Representation: Cultural Representation and Signifying

Practices (London: Open University, 1999), 223-290. This is also discussed in Stuart Hall, "Signification, Representation, Ideology: Althusser and the Poststructuralist Debates," Critical Studies in Mass

Communication vol. 2 no. 2 (1985): 91-114.

${ }^{30}$ Gail Guthrie Valaskakis, "Parallel Voices: Indians and Others-Narratives of Cultural Struggle,"

Canadian Journal of Communication vol. 18 no. 3 (1995): 283-4.

${ }^{31}$ James Clifford, The Predicament of Culture: Twentieth Century Ethnography, Literature and Art

(Cambridge: Harvard University Press, 1988): 289.

${ }^{32}$ Bonita Lawrence, "Gender, Race, and the Regulation of Native Identity in Canada and the United States," Hypatia: Native American Issue vol. 18 no. 2 (2003): 3.

This concept defines the Canadian Indian Act as a body of laws which have controlled every aspect of Indian life. Lawrence argues, "As a regulatory regime, the Indian Act provides ways of understanding Native identity, organizing a conceptual framework that has shaped contemporary Native life in ways that are now so familiar as to almost seem 'natural'." Bonita Lawrence, "Gender, Race, and the Regulation of Native Identity in Canada and United States," 3.

${ }^{33}$ Bonita Lawrence, "Gender, Race and the Regulation of Native Identity," 4.

${ }^{34}$ Ian Chambers, Border Dialogues: Journeys in Postmodernity (London and New York: Routledge, 1990), 26.

${ }^{35}$ Homi K. Bhabha, The Location of Culture (London and New York: Routledge, 2004), 100.

${ }^{36}$ Homi K. Bhabha, The Location of Culture, 100.

${ }^{37}$ Homi K. Bhabha, "Democracy De-realized," in Democracy Unrealized: Documenta, edited by Okwui Enwezor, Carlos Basualdo et al. (Kassel : Hatje Cantz Publishers, 2002), 357.

${ }^{38}$ Lynne Bell argues that Blondeau's 'Artist Page' is a space for decolonizing pedagogy, and incorporates Bhabha's concept of 'aesthetic unsettlement." I argue that Blondeau's decolonizing tactics in 'Writing Spaces' parallel her visual/oral performance practice. See Lynne Bell, "Artist's Pages: Decolonizing Tactics in 'Writing Spaces,' in The Future of the Page, edited by Peter Stoicheff and Andrew Taylor (Toronto: University of Toronto Press, 2004), 255-70.

${ }^{39}$ Marie Battiste, ed., Reclaiming Indigenous Voice and Vision (Vancouver: University of British Columbia, 2000), xxi.

${ }^{40}$ Poka Laenui, "Process of Decolonization," in Reclaiming Indigenous Voice and Vision, edited by Marie Battiste (Vancouver: Talonbooks, 2000), 155.

${ }^{41}$ Poka Laenui, "Process of Decolonization," 152-53. His discussion of decolonization is based on the late Virgilio Enriques arguments of the process of colonization. His steps are the following: denial and withdrawal, destruction and eradication, denigration and belittlement, tokenism and transformation/ exploitation.

${ }^{42}$ Ibid., $154-55$

${ }^{43}$ Ibid., $155-57$.

${ }^{44}$ Buffy Ste. Marie, "Victims No More," Akwasasne Notes (Early Winter 1976): 29. Cited in Devon Abbott Mihesuah, Indigenous American Women: Decolonization, Empowerment, Activism (Lincoln: University of Nebraska Press, 2003).

${ }^{45}$ Poka Laenui, 158-159.

${ }^{46}$ Susan Berry Brill de Ramirez, Contemporary American Indian Literature ad Oral Traditions (Tucson, Arizona, University of Arizona Press, 1999), 12.

${ }^{47}$ Lee Maracle, "Oratory: Coming to Theory," Essays on Canadian Writing: The Gender Issue vol. 54 (Winter 1994): 10.

${ }^{48}$ Thomas King, The Truth about Stories: A Native Narrative (Toronto: House of Anansi Press, 2003), 2.

${ }^{49}$ Laura Coltelli, Winged Words: American Indian Writers Speak (Lincoln: University of Nebraska Press, 1990), 156.

${ }^{50}$ Leroy Little Bear, "Jagged Worldviews Colliding," in Reclaiming Indigenous Voice and Vision, edited by Marie Battiste (Vancouver: Talonbooks, 2000), 81.

${ }^{51}$ Steven Loft, "Aboriginal Media Art and the Postmodern Conundrum: A Coyote Perspective," in 
Transference, Tradition and Technology (Banff, Alberta: Walter Phillips Gallery Editions, 2005 ), 93.

${ }^{52}$ Gail Guthrie Valaskakis, Indian Country Essays on Contemporary Native Culture, 3. From Beverly Slapin and Doris Steale, eds., Through Indian Eyes: The Native Experience in Stories for Children (Gabriola Island, BC: New Society, 1992), 985-99.

${ }^{53}$ Kateri Akiwenzie-Damm, "Says Who: Colonialism, Identity and Defining Indigenous Literature" in Looking at the Words of Our People: First Nations Analysis of Literature, edited by Jeanette Armstrong (Penticton: Theytus Books, 1993), 24.

${ }^{54}$ Svend Dhal. History of the Book (Metuchen, NJ: The Scarecrow Press, 1968), 24. A Palimpsest is a manuscript, typically of papyrus, parchment or vellum that has been written on more than once. Its earlier writings are incompletely erased and are often legible. The motives behind the re-using of papyrus, parchment, or vellum sheets were economically based, and more significantly were based on the directions and the desire of Church officials to 'convert' pagan Greek script by overlaying it with the word of God.

${ }^{55}$ The palimpsest is a trope that has permeated theoretical discourse over the past centuries. Josephine McDonagh notes that "the palimpsest became a recurrent metaphor in the nineteenth century for the human psyche and for history," such as Matthew Arnold's History of Rome (1838) and Elizabeth Barrett-

Browning's Aurora Leigh (1856) (McDonagh 208; OED). In McDonaugh's essay "Writings on the Mind," she notes Thomas De Quincey's ambivalence towards the figuration of the palimpsest in relation to history: "Built on a contradiction, a mode that both erases and retains the past, the palimpsest disrupts a sense of temporality; and the kind of history facilitated by its retentive function is at once restorative and violating" Josephine McDonagh, 214.

${ }^{56}$ Bill Ashcroft, Gareth Griffiths, and Helen Tiffin, Postcolonial Studies: The Key Concepts (London and New York: Routledge, 1998), 174.

${ }^{57}$ Paul Carter, The Road to Botany Bay (London: Faber and Faber, 1987), 23.

${ }^{58}$ Gillian Cowlishaw, Rednecks, Eggheads and Blackfellas: A Study of Racial Power and Intimacy (Ann Arbour: University of Michigan Press, 1999), 294.

${ }^{59}$ In the first chapter of The Gift: Imagination and the Erotic Life of Property discusses the beginnings of Western scholarship's curiosity with Aboriginal acts of 'gifting'. He writes: When the Puritans first landed in Massachusetts, they discovered a thing so curious about Indians' feelings for property that they felt called upon to give it a name. In 1764, when Thomas Hutchinson wrote his history of the colony, the term was already an old saying: "An Indian Gift," he told his readers, "is a proverbial expression signifying a present for which an equivalent return is expected." Lewis Hyde, The Gift: The Imagination and Erotic Life of Property (New York: Vintage Book, 1983), 3.

${ }^{60}$ Marcel Mauss argued that in 'primitive' societies, tribal based cultures the exchange of goods were not the same as the market exchanges of capitalist, and usually Western societies. He argued that in capitalist societies goods were produced to further economic and accumulative gains, whereas, the social function of exchange, meaning reciprocity was secondary. Mauss' starting point for his argument was that so-called 'primitive' societies were composed of 'segmented social units', meaning tribes and clans, he contested that exchange of goods established a system which unified these social units erecting broader social solidarity. Andrew Nurse, Tradition and Modernity: The Cultural Work of Marius Barbeau (PhD Dissertation: Queen's University, 1998), 105.

${ }^{61}$ This concept was presented in the work of Homi K. Bhabha, The Location of Culture (London and New York: Routledge, 1994).

${ }^{62}$ Edward Said, "In Conversation with Neeladri Bhattacharya, Suvir Kaul, and Ania Loombia," in Relocating Postcolonialism, edited by David Theo Goldberg and Ato Quayson (Oxford: Blackwell, 2002), 3.

${ }^{63}$ Karen Sykes, Arguing with Anthropology: An Introduction to Critical Theories of the Gift (London and New York: Routledge, 2005). 1-4. Analysis of Mauss is most useful to understand his contribution to the discipline of Anthropology. She writes "Mauss' work is monumental in anthropology because he chose to describe gift exchange, as it constitutes social life or 'society' most generally and philosophically... Mauss also poses a central question in what it means to be human by asking why a person should feel obligated to give back what he or she had received from another. The problem of the 'gift' comprises two kinds of questions: how people keep their social life at the centre of consciousness, and why it should seem meaningful for them to do so." Karen Sykes, Arguing with Anthropology: An Introduction to Critical Theories of the Gift, 4. Stephen Gudeman's The Anthropology of Economy introduces the history of the gift's discourse. He also includes a discussion of the 'gifts' shared interest in economic and anthropological 
scholarship. See Stephen Gudeman, The Anthropology of Economy (Oxford, Blackwell Publishers, 2001), 80-93. See also Mark Osteen, ed., The Question of the Gift: Essays Across Disciplines (London and New York: Routledge, 2002). Aeftke E Komter, ed., The Gift: An Interdisciplinary Perspective (Amsterdam: Amsterdam University Press, 1996).

${ }^{64}$ Amelia Jones and Andrew Stephenson, Performing The Body: Performing the Text (London, New York: Routledge, 1999), 1.

${ }^{65}$ Jackson Rushing III, ed., Native American Art in the Twentieth Century ( New York: Routledge, 1999), 75.

${ }^{66}$ Charlotte Townsend-Gault, "If Art is the Answer, What is the Question? Some Questions Raised by First Nations' Visual Culture in Vancouver," RACAR vol. 21 (1994): 101.

${ }^{67}$ Charlotte Townsend-Gault, "If Art is the Answer, What is the Question?" 101.

${ }^{68}$ Fundamental questions of definition continue to hamper our understanding of the 'modern' and the 'contemporary' in Native art...To be judged 'modern', must a work be produced in Western art media and formats, or should all forms of art made by Native people during the past century be included, whether in 'craft' or 'fine art' media? If expressed in Western media, must the works deal with 'contemporary' issues or should art about traditional heritage and belief be included? Is professional art school training and familiarity with current idioms of modernism or postmodernism a necessity, or are apprenticeship and the use of historicist styles acceptable?

Janet Berlo and Ruth Phillips Native North American Art (Oxford: Oxford University Press, 1998), 209.

\section{Chapter 2}

${ }^{1}$ Leroy Little Bear, "Jagged World Views," edited by Marie Battiste Reclaiming Indigenous Voice and Vision (Vancouver: Talonbooks, 2000), 77-78.

${ }^{2}$ Leroy Little Bear, Jagged World View, 78.

3 Jolene Rickard, "Sovereignty: A Line in the Sand," Aperture 139 (Summer 1995): 207.

${ }^{4}$ Robert Houle, "The Emergence of a New Aesthetic Tradition," New Work by A New Generation [exhibition catalogue] (Regina: McKenzie Art Gallery, 1982), 5.

${ }^{5}$ Ruth Phillips, "Performing the Native Woman: Primitivism and Mimicry in Early Twentieth-Century Visual Culture," in Antimodernism and Artistic Experience: Policing the Boundaries of Modernity edited by Lynda Jessup (Toronto: University of Toronto Press, 2001), 27.

${ }^{6}$ In Maria Tippett, "Review of Veronica Strong-Boag and Carole Gerson Paddling Her Own Canoe: The Times and Texts of E. Pauline Johnson," Canadian Historical Review vol. 83 no. 1 (March 2002): 140. Tippett agrees with Strong-Boag and Gerson's use of Johnson's poetry as evidence to prove her position as a social-activist. It was from my own reading of Johnson's poetry that I began to consider her as part of the history of performative storytelling. It was her words that made me explore further her role as storyteller.

${ }^{7}$ Veronica Strong-Boag and Carole Gerson discuss Pauline Johnson's work from a Euro-Canadian feminist perspective in Paddling Her Own Canoe: The Times and Texts of E. Pauline Johnson and as Tippett argues in her review of their publication on Johnson the poems act as evidence for their claims of her being an advocate for socio-political and cultural rights of both Aboriginal peoples and women living in Canada. Ibid., 140.

${ }^{8}$ Carole Gerson and Veronica Strong-Boag, eds., E. Pauline Johnson Tekahionwake: Collected Poems and Selected Prose (Toronto: University of Toronto Press, 2002), xiii. Johnson was a born in the 1861 on the Six Nations Reserve. Her father, a chief, was the son of a high ranking Mohawk family, which had resisted European sovereignty. Johnson's mother was non-Aboriginal English-born who raised her children by English middle-class culture's standards of manners and behaviour. Concurrently, Johnson and her three siblings were raised with their Mohawk heritage, learning from their father and grandfather, chief Sakayenwaraton (John Smoke Johnson). Carole Gerson and Veronica Strong-Boag, eds., E. Pauline Johnson Tekahionwake, xiv

${ }^{9}$ Pauline E. Johnson, "The Song My Paddle Sings," in Carole Gerson and Veronica Strong-Boag, eds., E. Pauline Johnson Tekahionwake, 81-83.

${ }^{10}$ Prior to Pauline Johnson's performance debut in 1892, she had become a familiar name in local press and national magazine, publishing in Canadian Magazine and Dominion Illustrated. Her first publication was in 1889. Two of her love poems were included in W. D. Lighthall's Songs of the Great Dominion.

" Frank Yeigh "Off to a Good Start," in Sheila Johnston, Bucksin and Broadcloth: A Celebration of E. 
Pauline Johnson Tekahionwake (Toronto: Natural Heritage/Natural History, 1997), 104. Other poems celebrated the glamour of war due to the social climate of the era. Their authors, for the majority men, wrote from a Eurocentric position in which legitimated warfare. Throughout the world the second half of the nineteenth century saw great conflict, from the Northwest Rebellion in the Canadian prairies (1885),the Crimean War 1853-56, the Civil War (1861-65) and Indian Wars (1700-1890's) in the United States, to the Boers War in South Africa (1880-1900). Generally speaking poetry was arguably a way to capture the events and glory of war, presenting to the public the successes of their military and creating heroes of their army. For example, Robert W. Service's poem The March of the Dead shows the brutalities of war, but also the glory:

The Cruel war was over-oh, the triumph was so sweet!

We watched the troops returning, through our tears;

There was triumph, triumph, triumph down the scarlet glittering street,

And you scarce could hear the music for the cheers

And you scarce could see the house-tops for the flags that flew between;

The bells were pealing madly to the sky,

And everyone was shouting for the Soldiers of the Queen,

And the glory of an age was passing by-

(Excerpt from "March of the Dead")

${ }^{12}$ E. Pauline Johnson, "A Cry From An Indian Wife," Flint and Feather (Toronto: Musson Books, 1914), 17-18.

${ }^{13}$ Frank Yeigh was a close friend of Johnson's and was her first professional manager. He invited her to the 1892 'Canadian Literary Evening' at the Young Liberal Club of Toronto in 1892, which was the debut of her 'professional' performance career.

${ }^{14}$ Carole Gerson and Veronica Strong-Boag, xvi

${ }^{15}$ Interview with Charlotte Grey about Flint and Feathers: The Life and Times of E. Pauline Johnson Tekahionwake" HarperCollins Publishing Review (Fall 2002), 8.

${ }^{16}$ Ruth Phillips, "Performing the Native Woman," 31.

${ }^{17}$ Ibid., 31 .

${ }^{18}$ Pauline E. Johnson, "The Cattle Thief," Flint and Feather, 14-16.

${ }^{19}$ Sheila Johnston, Buckskin and Broadcloth A Celebration of E. Pauline Johnson Tekahionwake (Toronto: Natural Heritage/Natural History, 1997), 110. From The Toronto Star ( 22 May 1892).

${ }^{20} \mathrm{Ibid}$. 110. From The Toronto Star ( 22 May 1892).

${ }^{21}$ Art Solomon Song for The People: Teachings on the Natural Way (Toronto: NC Press 1990), 14.

${ }^{22}$ Gail Guthrie Valaskakis, "Parallel Voices: Indian and Others-Narratives of Cultural Struggle," Canadian Journal of Communication vol. 18 no. 2 (1993): 286.

${ }^{23}$ Thomas A. McKean, "Tradition as Communication" Oral Tradition vol. 18 no. 1 (2003): 49.

${ }^{24}$ N. Scott Momaday, "Man Made of Words," Assembly Presentation at the First Convocation of American Indian Scholars, in Indian Voices, edited by Rupert Costo (San Francisco: The Indian Historian Press, 1970), 49-84.

${ }^{25}$ Lois J. Einhorn, The Native American Oral Tradition: Voices of the Spirit and Soul (Westport: Connecticut, Greenwood, 2000), 3.

${ }^{26}$ The practice of storytelling in the Aboriginal community reflects a sense of 'recording' of histories, however, as Vine Deloria notes there is less emphasis in indigenous stories with specifics, especially in relation to time. He states that "lacking a sense of rigid chronology, most tribal religions did not base their validity on any specific incident dividing man's time experience into a before and after." Vine Deloria Jr., God is Red (New York: Delta Book, 1973), 113. In God is Red, Deloria maps out the differences in Western and Aboriginal concepts of history, creation and religion.

${ }^{27}$ Simon Ortiz, Fightin': New and Collected Stories (New York: Thunder's Mouth Press, 1983), 57.

${ }^{28}$ Bo Scholer, ed., Coyote was Here: Essays On Contemporary Native American Literary and Political Mobilizations (Arhus, Denmark: Selkos, 1983), 136.

${ }^{29}$ In her book Yearning: race, gender, and cultural politics (1990) bell hooks explores the idea of history in storytelling. Specifically, hooks develops the notion of quilting being a form of storytelling, connecting generations of women to generations of history. She writes "Baba (her grandmother) believed that each quilt had its own narrative-a story that began from the moment she considered making a particular quilt. The story was rooted in the quilt's history, why it was made, why a particular pattern was chosen...Baba 
would show her quilts and tell their stories, giving the history (the concept behind the quilts) and the relation of chosen fabrics to individual lives... Together we would examine this work and she would tell me about the particulars, about what my mother and her sisters were doing when they wore a particular dress. To her mind these quilts were maps charting the course of our lives. They were history of life lived." bell hooks, Yearning: race, gender, and cultural politics (Boston: South End Press, 1990), 120-121.

${ }^{30}$ Emerance Baker, "Loving Indianness: Native Women's Storytellng as Survivance," Atlantis vol. 29 no. 2 (Spring 2005):112.

${ }^{31}$ Mary Leen, "An Art of Saying: Joy Harjo's Poetry and the Survival of Storytelling," Indian Art Quarterly vol.19 no.1 (Winter 1995): 3.

${ }^{32}$ Gerald Vizenor, The People Named the Chippewa: Narrative Histories (University of Minnesota Press, 1984), 7.

${ }^{33}$ In Joseph Bruchac, ed., Survival This Way (Tucson: Sun Tracks and University of Arizona Press, 1987), 9.

${ }^{34}$ Thomas A. McKean, "Tradition as Communication," 50.

${ }^{35}$ Simon Ortiz, Woven Stone (Tuscon, AR: University of Arizona Press, 1992), 7.

${ }^{36}$ This is an excerpt from Jeanette C. Armstrong's poem "Threads of Old Memory". This poem/story discusses the significance of storytelling and how stories are histories linked from one generation to the next through the act of storytelling. They are presented through dance, song, oratory, and visual material. Daniel David Moses and Terry Goldie, eds., An Anthology of Canadian Native Literature in English (Don Mills ON: Oxford University Press, 2005), 235.

${ }^{37}$ Homi K. Bhabha, The Location of Culture (London: Routledge, 1994), 251-52.

${ }^{38}$ Peggy Phelan, Unmarked: The Politics of Performance (London and New York: Routledge, 1993), 3.

${ }^{39}$ Jessica Bradley, "Rebecca Belmore: Art and Object of Performance," in Caught in the Act: An Anthology of Performance art by Canadian Women, edited by Tanya Mars and Johanna Householder (Toronto: YYZ Books, 2004), 121.

40 Jessica Bradley, "Rebecca Belmore: Art and the Object of Performance," 121.

${ }^{41}$ Phellan states in her first chapter that "Unmarked attempts to find a theory of value for that which is not 'really' there, that which cannot be surveyed within the boundaries of the putative real. Unmarked examines the implicit assumptions about the connections between representational visibility and political power which have been a dominant force in cultural theory in the last ten years. Among the challenges this poses is how to retain the power of the unmarked by surveying it within a theoretical frame." Peggy

Phellan, Unmarked: The Politics of Performance (London and New York: Routledge, 1993) 1-2.

${ }^{42}$ Gerald Vizenor, Manifest Manners: Post-Indian Warriors of Survivance (Middleton, CT: Wesleyan University Press, 1994), 53.

${ }^{43}$ Lois J. Einhorn, The Native American Oral Tradition: Voices of the Spirit and Soul (Westport: Connecticut, Greenwood, 2000), 104.

${ }^{44}$ Craig Womack, Red on Red: Native American Literary Separatism (Minneapolis: University of Minnesota Press, 1999), 11-12.

${ }^{45}$ Kim Anderson, A Recognition of Being: Reconstructing Native Womanhood (Toronto: Sumach Press, 2000), 131.

${ }^{46}$ Lois Einhorn, The Native American Oral Tradition: Voices of the Spirit and Soul, 117.

${ }^{47}$ Anna Lee Walter, Talking Indian: Reflections on Survival and Writing (Ithaca, NY: Greenfield Review Press, 1979), 11-13.

${ }^{48}$ Charles Taylor, "Politics of Recognition," in Multiculturalism: A Critical Reader, edited by D.T Goldberg (Oxford: Blackwell Publishing, 1994).

"Politics of Recognition,"

${ }^{49}$ Homi K. Bhabha, The Location of Culture, 246.

${ }^{50}$ Jeanette Armstrong, "Threads of Old Memory" in An Anthology of Canadian Native Literature in English, edited by Daniel David Moses and Terry Goldie (Don Mills ON: Oxford University Press, 2005) 236.

${ }^{51}$ Paula Gunn Allen, The Sacred Hoop: Recovering the Feminine in American Indian Tradition (Boston, Beacon Press: 1986), 45.

${ }^{52}$ Elin Diamond, Performance and Cultural Politics (London, New York: Routledge, 1996), 5.

${ }^{53}$ RoseLee Goldberg, Performance: From Futurism to the Present (London: Thames \& Hudson Ltd. 2001),

7. These artistic movements include Futurism, Constructivism, Dadaism, Surrealism, Minimalism, and 
conceptual art.

${ }^{54}$ Charles Garoian, Toward an Art of Politics (New York: State University of New York Press, 1999$), 18$.

${ }^{55}$ Elin Diamond, ed., Performance and Cultural Politics, 2.

${ }^{56}$ Charles Garoian, Toward an Art of Politics, 19.

${ }^{57}$ Allan Kaprow, "Nontheatrical Performance," in Essays on the Blurring of Art and Life, ed., J. Kelley (Berkeley: University of California Press, 1993), 177.

${ }^{58}$ RoseLee Goldberg, Performance: From Futurism to the Present, 7.

${ }^{59}$ Henry Giroux, Disturbing Pleasures: Learning Popular Culture, (New York: Routledge, 1994), 135.

60. Ibid., 135 .

${ }^{61}$ Homi K. Bhabha, The Location of Culture, 247.

${ }^{62}$ Currently, Canadian Aboriginal communities continue to fight for land and resource rights, and in BC for Treaty settlements. The Caledonia protest has recently erupted into a conflict between the Iroquois Confederacy, fighting for land rights in Caledonia, Ontario with the local non-Aboriginal residents. Reservations are still challenged with the lack of adequate housing, in some cases, without drinking water. Drug abuse and alcoholism continue to spread in both on-reserve and urban communities reflecting the need and furthermore the necessity of education and empowerment for the indigenous peoples of Canada.

${ }^{63}$ Tagny Duff, "FFWD, RWD, and PLAY: Performance Art, Video, and Reflections on Second-Wave Feminism in Vancouver 1973-1983," in Caught in the Act: An Anthology of Performance art by Canadian Women, eds., Tanya Mars and Johanna Householder (Toronto: YYZ Books, 2004), 50.

${ }^{64}$ Tagny Duff, "FFWD, RWD, and PLAY: Performance Art, Video, and Reflections on Second-Wave Feminism in Vancouver 1973-1983," 50-51.

${ }^{65}$ For more information on this project go to www.grunt.bc.ca/fnp/ There is an extensive archive on their website. This archive holds video recordings, and photographs of performances. It also has essays and other texts.

${ }^{66}$ Edward Poitras was the first Aboriginal artist to be selected to represent Canada at the Venice Biennale. He exhibited in the 1995 Biennale.

${ }^{67}$ Blake Gopnik, "Indian Artist in Venice: Off the Traditional Path," Washington Post Sunday July 24, 2005: NO1. A real watershed moment for the United States would be to select Luna or any other Native American as its representative.

${ }^{68}$ Lee-Ann Martin, "The Waters of Venice: Rebecca Belmore at the $51{ }^{\text {st }}$ Biennale," Canadian Art vol. 22 no. 2 (Summer 2005): 50. Belmore's performance was documented in the Globe and Mail July $16^{\text {th }} 1987$. This performance is among the very first Aboriginal performances to receive national attention, and is included in Alain-Martin Richard and Clive Robertson, Performance in Canada 1970-90 (Quebec: Editions Intervention, 1991).

${ }^{69}$ Lee-Ann Martin writes in her recent article "The Waters of Venice: Rebecca Belmore at the $51^{\text {st }}$ Biennale," that The Spirit Sings exhibition was highly criticized, publicly boycotted, and angrily condemned due to perpetuation of the romanticized image of Aboriginal culture while denying the complex contemporary issues faced by Aboriginal communities.

${ }^{70}$ In the January $13^{\text {th, }} 1988$, issue of Northwest Times News Ross Longbottom wrote: "Protest to coincide with the arrival of the Olympic torch in Thunder Bay and the Shell sponsorship of the native culture exhibit, the Spirit Sings (followed a call by Alberta's Lubicon Indian Band for a boycott of the Olympics and the exhibit). Shell Canada is one of several oil companies extracting oil from their land." Longbottom includes a description of the performance by Belmore: "In a display case set up by the roadside I sat with a Shell logo pinned to my chest, and a Canadian flag pinned to my back. Above my head is a sign: "The Glenbow Museum presents" and leaning against my display is another sign which reads "The Spirit Sings" Directly in front of me is a number which discreetly labels this exhibit: Artifact \#671b." A side note of interest, is that the number $671 \mathrm{~b}$ is an inside joke incorporated by Belmore. The number is the Ontario Liquor Control Board's number for a favourite local brand of cheap wine. Charlotte Townsend-Gault, "Rebecca Belmore," Land, Spirit, Power (Ottawa: National Gallery of Canada, 1992), 117

${ }^{71}$ Lynn Hill discusses the arrival of contemporary Aboriginal art in her AlterNative: Contemporary Photo Compositions. Hill comments on the fact that the 1970's and 1980's were a time of political awareness for First Nations people across the United States and Canada. During this time broken treaties, land claims and social injustices were being addressed through Indigenous organizations and political groups. This period of Aboriginal North American history raised the resources, and consequently strengthened the political voice of the First Nations in North America. At the same time, came the arrival of a second generation of 
contemporary artists. Among them were: Gerald McMaster, Robert Houle, Carl Beam, Jane Ash Poitras, and Joane Cardinal Schubert, artists who moved away from the more traditional or legend-based works. These artists started creating innovative Indigenous aesthetic expressions therefore constructing a new visual language. Charged with political and social influences, these artists used the power of their visual vision and voice to protest and question the insurmountable injustices endured by the Aboriginal community throughout colonial history. Lynn Hill, AlterNative: Contemporary Photo Compositions [exhibition catalogue] (Kleinburg ON: McMichael Canadian Art Collection, 1995), 11.

${ }^{72} \mathrm{My}$ use of this term is not meant to re-inscribe categories created by a patriarchal, Euro-American centrism which excluded those artists of non-European cultural ancestry, women and/or gay and lesbian. My use of mainstream is to establish the fact that Aboriginal performance art and contemporary indigenous arts for that matter, unfortunately are not included in most discussions of contemporary art. There are token inclusions, such as brief acknowledgements of Spider Women, a Native North American women's performance collective into introductory texts on performance art. There is also debate within the Aboriginal community and art historical discourse whether Aboriginal art should be included into the larger Canadian and Global art context or if it should be a separate discourse all together. In his recent article, Gerald McMaster "Our (Inter)Related History," In On Aboriginal Representation in the Gallery, eds., Lynda Jessup (Ottawa: Canadian Museum of Civilization, 2002). McMaster argues for an interconnected discussion of Aboriginal and other Canadian art. Inclusions represent problematic results, such as homogeneous representations. Nevertheless, the inclusion of Aboriginal art into 'mainstream' art discourse should not mean that it be discussed from a euro-centric world view but be recognized as being a part of a larger discourse of contemporary art.

${ }^{73}$ Coco Fusco, The Bodies That Were Not Ours: and Other Writings (London and New York: Routledge, 2001), xiv.

${ }^{74}$ Coco Fusco, The Bodies That Were Not Ours, xv.

${ }^{75}$ Marvin Carlson, Performance: A Critical Introduction, $2^{\text {nd }}$ Edition (New York: Routledge, 2004$), 179$.

${ }^{76}$ Aiyyana Maracle, "Performance Art and the Native Artist: an rEvolutionary Mix?" in Live At the End of the Century: Aspects of Performance Art in Vancouver ed., Brice Canyon, (Vancouver: Grunt Gallery, 2000), 100.

${ }^{77}$ Phillip Zarilli, "For Whom is the King a King? Issues of Intercultural Production, Perception, and Reception in a Kathikali King Lear," in in Critical Theory and Performance, eds., Joseph Roach and Janelle Reinelt, (Ann Arbor, Mich: University of Michigan Press, 1992), 16.

${ }^{78}$ Archer Pechawis, "New Traditions: Post-Oka Aboriginal Performance Art in Vancouver," in Live At the End of the Century: Aspects of Performance Art in Vancouver, ed., Brice Canyon (Vancouver: Grunt Gallery, 2000), 137.

${ }^{79}$ Lynne Bell and Janice Williamson, "High Tech Storyteller: A Conversation with Performance Artist Lori Blondeau," FUSE vol. 24 no. 4 (2001):34.

80 'The high-tech peace pipe' is comprised of a red touch tone phone and peace pipe as the hand receiver, 'the wet-dream catcher' is made out of a tennis racket with condoms attached to the netting, and the ' 2 worlds war dance technology' is a converse shoe decorated with beads and feathers attached to two large springs. Images available at www.jamesluna.com

${ }^{81}$ Charlotte Townsend-Gault, "Hot Dogs, A Ball Gown, Adobe, and Words," in Native American Art in the Twentieth Century, ed., Jackson Rushing III (London and New York: Routledge, 1999), 123.

${ }^{82}$ INDIAN ACTS? Aboriginal Performance Art (Vancouver: Emily Carr Institute of Art and Design, 2002). www.grunt.bc.ca/IndianAct/ or www.mailman.smufsa.nu/pipermail/apao/2002-November.html

${ }^{83}$ INDIAN ACTS? Aboriginal Performance Art.

${ }^{84}$ Townsend-Gault, "Hot Dogs, A Ball Gown, Adobe, and Words," 123.

${ }^{85}$ INDIAN ACTS? Aboriginal Performance Art.

${ }^{86}$ Canadian Oxford Dictionary (Don Mills, ON: Oxford University Press, 1998), 456.

${ }^{87}$ News Bulletin, “Artist James Luna Selected by the Smithsonian's' National Museum of the American Indian for the 2005 Venice Biennale," Smithsonian National Museum of the American Indian: Office of Public Affairs May 2005.

${ }^{88}$ Blake Gopnik, "Indian Artist in Venice: Off the Traditional Path," NO1.

${ }^{89}$ Marvin Carlson suggests that this performance by Gomez-Pena and Fusco is probably the best known performance of the 1990's. Marvin writes, “because it touched upon so many of the central concerns of performance in that decade-including spectatorship and display, the touristic gaze and cultural 
appropriation, colonialism, racism, and the dynamics of cultural interaction." This performance draws upon the practice of exhibiting indigenous peoples from Africa, Asia, and the Americas in fairs, and exhibitions. Gomez-Pena and Fusco displayed themselves for 3 days in a cage as recently discovered Aboriginal peoples from an island in the Gulf of Mexico. They performed 'traditional tasks' of sewing voodoo dolls, lifting weights, watching TV. They ate 'traditional foods' of sandwiches and fruit and were taken to the bathroom on leashes. Information panels were provided with mock scientific and anthropological details on their 'cultural heritage' and 'native culture'. This was an ironic commentary on the colonial discourse and its appropriations and representations of indigenous peoples. However, to the surprise of both performers, many viewers took their exhibition seriously. This outrageous misinterpretation raises many questions regarding performance arts subversion of stereotypes and use of parody to generate political slippages. It also raises the significance and importance that these types of performances continue to be viewed by mainstream society to foster education and greater understanding of our colonial histories. Marvin Carlson , Performance: A Critical Introduction, 200-202.

${ }^{90}$ Blake Gopnik, "Indian Artist in Venice: Off the Traditional Path," NO1.

${ }^{91}$ Justin Clark, "A Native American in Venice," L.A Weekly (Thursday June 23, 2005).

${ }^{92}$ Ellen Fernandez-Sacco, "Check Your Baggage: Resisting Whiteness in Art History," Art Journal, vol. 60, no.4 (Winter 2001): 59.

${ }^{93}$ Charlotte Townsend-Gault, "Ritualizing Ritual's Ritual," Art Journal, vol. 51 no. 3 (Fall 1992): 55.

${ }^{94}$ José Torres Tama, "Healing with Humor: New American Perspectives from James Luna and Dan Kwong," Art Papers vol. 25 no. 5 (September/October 2001): 17.

${ }^{95}$ Torres Tama, Healing with Humor: New American Perspectives from James Luna and Dan Kwong," 17.

${ }^{96}$ Jann L.M. Bailey and Scott Watson, "Introduction," Rebecca Belmore: Fountain (Kamloops Art Gallery and The Morris and Helen Belkin Art Gallery, 2005), 8.

${ }^{97}$ Lee-Ann Martin, "The Waters of Venice: Rebecca Belmore at the $51^{\text {st }}$ Biennale," Canadian Art vol. 22 no. 2 (Summer 2005):50.

${ }_{98}$ Ibid., 50 .

${ }^{99}$ Ibid.,52.

${ }^{100}$ In 1996 it was included as part of the formal Aboriginal People's Protest held in Ottawa due to the exclusion of their representatives from the First Ministers Conference. Noted by Townsend-Gault, Belmore's megaphone enabled the members of the Assembly of First Nations "to voice their anger... outside the Prime Minster's official residence during the conference dinner." In regards to the inclusion of her art at an official political protest, Belmore comments, "Perhaps I have moved this artwork into a different place by allowing it to enter into an official political realm. Hopefully, it insists and continues to echo: we are of this land." Charlotte Townsend-Gault, "Rebecca Belmore," Land, Spirit, Power, 118.

${ }^{101}$ It was first shown just outside the Banff Centre of Fine Arts. She invited thirteen Aboriginal people to address the earth directly. Lubicon Cree Chief Bernard Ominayak's powerful call to Mother-earth set the stage. He said "with a call for support and unity, an invitation to 'join the circle' in the political struggle of the First Nations to prevent the expropriation and destruction of the land." Charlotte Townsend-Gault, "Rebecca Belmore," Land, Spirit, Power, 118.

${ }^{102}$ Ibid., 118.

${ }^{103}$ Janet Berlo and Ruth Phillips, Native North American Art. (Oxford: Oxford University Press, 1998), 236.

${ }^{104}$ Janet Berlo and Ruth Phillips, Native North American Art, 237.

${ }^{105}$ Charlotte Townsend-Gault, "Rebecca Belmore," Land, Spirit, Power, 118. Blondeau shares this familial connection with Belmore, but in her case, her mother's and grandmother's stories act as primary inspirations for her performances, such as in Are You My Mother? In this performance, the artist recounts the impact of residential schools on five generations of women from Blondeau's family. Blondeau tells this silenced colonial history, which continues to affect today's generation of Aboriginal peoples.

${ }^{106}$ Charlotte Townsend-Gault, The Named and the UnNamed [exhibition catalogue] (Vancouver: Morris and Helen Belkin Art Gallery, 2002), 18.

${ }^{107}$ Charlotte Townsend-Gault, Named and the UnNamed, 19.

${ }^{108}$ The artists named here are part of a larger community of Aboriginal performance/installation and video artists. There inclusion is a sampling of a much larger discourse. Other artists include: Cheryl

L'Hirondelle, Dana Claxton, Reona Brass, Thirza Cuthand, Shelley Niro, Ahasiw Maskegon-Iskwew, 
Skawennati Tricia Fragnito, and Greg Hill.

\section{Chapter 3}

${ }^{\mathrm{I}}$ Trinh T. Minh-ha, Woman, Native, Other: Writing Postcoloniality and Feminism (Indianapolis: Indiana University Press, 1989), 2.

${ }^{2}$ S. Berry Brill de Ramirez, Contemporary American Indian and Oral Traditions (Tucson: University of Arizona Press, 1999), 4.

${ }^{3}$ S, Berry Brill de Ramirez, Contemporary American Indian and Oral Traditions, 6.

${ }^{4}$ Ibid.,6.

${ }^{5}$ Lori Blondeau, "Some Kinda Princess," in Mentoring Artists For Women's Art: Culture of Community, edited by Vera Lemecha (Winnipeg, MAWA, 2004), 25.

${ }^{6}$ Lori Blondeau, "Some Kinda Princess,"25.

${ }^{7}$ Amelia Jones and Andrew Stephenson, Performing the Body: Performing the Text (London/New York:Routledge, 1999), 2.

${ }^{8}$ Amelia Jones and Andre Stephenson, Performing the Body: Performing the Text, 2.

${ }^{9}$ Lori Blondeau, 25.

${ }^{10}$ Edward Said, "In Conversation with Neeladri Bhattacharya, Suvir Kaul, and Ania Lommbia," in Relocating Postcolonialism, edited by David Theo Goldbert and Ato Quayson (Oxford: Blackwell, 2002), 13.

${ }^{11}$ Homi K. Bhabha, The Location of Culture, (London and New York: Routledge, 2004), 90.

${ }^{12}$ Lynne Bell and Janice Williamson, "High Tech Storyteller: A Conversation with Performance Artist Lori Blondeau," 33.

${ }^{13}$ Cyber Powwow is a website that is Aboriginal designed and controlled. It offers a so-called 'decolonized' space for indigenous artists to exhibit their work. This introduces the concept of digital storytelling, which fits within the discussion of high-tech storytelling. This however, does not fit within the scope of my thesis. www.cyberpowwow.com

${ }^{14}$ Peggy Phelan, Unmarked: the politics of performance (New York and London: Routledge, 1993), 3. For further discussion see Peggy Phelan chapter "Broken symmetries: memory, sight, love" 1-33. The ideology of the visible participates in the discourse of the politics of visibility - which is linked to identity politics. Phelan brings up a significant point in relation to visibility and the unmarked body of marginalized subject, she suggests that through recognition of the unmarked body, problematics arise. Phelan states, "I am not suggesting that continued invisibility is the 'proper' political agenda for the disenfranchised, but rather that the binary between the power of visibility and the impotency of invisibility is falsifying. There is real power in remaining unmarked; and there are serious limitations to visual representation as a political goal. Visibility is a trap ('In this matter of the visible, everything is a trap' Lacan) it summons surveillance and the law; it provokes voyeurism, fetishism, the colonist/imperial appetite for possession. Yet it retains a certain political appeal. " Peggy Phelan, Unmarked, the politics of performance, 6 .

${ }^{15}$ Ann Dumonceaux, "Accomplished Art Grad Student First to be Admitted under PLAR Program," On Campus News, vol. 8 no. 9 (January 19 2001): 3.

${ }^{16}$ Lynne Bell and Janice Williamson, 32.

17 Ann Dumonceaux, "Accomplished Art Grad Student," 3.

${ }^{18}$ Pierre Bourdieu, Outline of a Theory of Practice (Cambridge: Cambridge University Press, 1977), 165.

${ }^{19}$ See Charles Garoian, Performing Pedagogy: Towards an Art of Politics (New York: State University of New York Press, 1999), 1-16. Amelia Jones, Body Art: Performing the Subject (Minneapolis: University of Minnesota Press, 1998), 1-20.

For a general overview, including discussions of avant-garde performance art, see Rose-Lee Golberg, Performance Art: From Futurism to the Present (London: Thames \& Hudson Ltd., 2001).

${ }^{20}$ David Barsamian and Edward W. Said, Culture and Resistance: Conversations with Edward W. Said (Cambridge: South End Press, 2003), 18.

${ }^{21}$ Judith Butler, /Excitable Speech/ A Politics of the Performative (New York: Routledge, 1997), 8.

${ }^{22}$ Annie Coombes, "Inventing the 'Postcolonial': Hybridity and Constituency in Contemporary Curating" in The Art in Art History: A Critical Anthology, edited by Donald Preziosi (Oxford, New York: Oxford 
University Press, 1998), 489.

${ }^{23}$ Moira G. Simpson, Making Representations: Museums in the Post-Colonial Era (London: Routledge, 2001), 1 .

${ }^{24}$ See Moria G. Simpson, Making Representations: Museums in the Post-Colonial Era, and Laura Pearce and Alison K. Brown, Museums and Source Communities (London: Routledge, 2003). The inclusion of community collaboration and consultation reflects a shift in authorship, meaning in the inclusion of Native voices in the Gallery and Museum space.

${ }^{25}$ Moira G. Simpson, Making Representation: Museums in the Post-Colonial Era, 1-2. It is significant to note, although, not directly linked to this conversation of storytelling how, in colonialism, the stories have been documented by the colonizer, and that today through progressive and assertive actions, material, visual and ceremonial culture of Aboriginal peoples are being in some cases being treated as pertaining to specific cultural customs, and other repatriated to the original communities. Laura Pearce and Alison Brown comment in their Introduction to Museums and Source Communities that the radical shift that Simpson discusses is in many cases responds to conflicts generated by museum exhibition. Pearce and Brown argue "Responses to such conflicts have led to the creation of working groups in several countries which have made recommendations for change in museum practice designed to meet the needs of source communities and to encourage better working relations with them." Laura Pearce and Alison K.Brown, Museums and Source Communities, 12.

Within the Canadian context, a joint meeting between Canadian Museum Association and the Assembly of First Nations resulted in the creation of the 1992 Task Force Report on Museums and First Peoples. This meeting was instigated by its catalyst, The Spirit Sings exhibition held during the 1988 Winter Olympic Games in Calgary Alberta. The controversy resulted in a meeting between museum representatives and First Nations communities to "develop an ethical framework and strategies for Aboriginal Nations to represent their history and culture in concert with cultural institutions." (Task Force 1992). Trudi Nicks states that the report results in suggesting to make museums more accountable to Aboriginal communities, in relation to access of collections, the repatriation of human remains, and increased opportunities for training of Aboriginals. Trudi Nicks, "Partnerships in developing cultural resources: lessons from the Task Force on Museums and First Peoples," Culture vol. 12 no. 1 (1992): 8793.

For specific Canadian discussion of the politics of representation of Aboriginal histories and material and visual culture see Lynda Jessup's On Aboriginal Representation in the Gallery. This anthology includes diverse discussion of the issues of representing Aboriginal stories in the museum and gallery space.

${ }^{26}$ Whereas, several recordings of James Luna's performances are available for purchase from his website. www.jamesluna.com

${ }^{27}$ Lori Blondeau, "Professional Profile" Art History website, University of Saskatchewan www.arts.usask.ca/art/faculty/pages/l blondeau.html/

${ }^{28}$ This organization's mission statement is the following: "TRIBE is dedicated to the development of independent venues where Aboriginal media, visual and performing artists can develop, create and present a variety of art forms on a consistent and scheduled program."28 Saskatchewan Arts Board website: http://www.artsboard.sk.ca/story/story links.shtml

${ }^{29}$ The concept of Aboriginal cultural 'survivance' was introduced by Gerald Vizenor. Gerald Vizenor, Manifest Manners: Post-Indian Warriors of Survivance (Middleton, CT: Wesleyan University Press, 1994), 53. Also defined in Gerald Vizenor, Fugitive Poses: Native American Indian Scenes of Absence and Presence (Lincoln: University of Nebraska, 1998), 15.

${ }^{30}$ Augusto Boal, Games for Actors and Non-Actors (London and New York: Routledge, 1992). This book is related to his 1979 publication of The Theatre of the Oppressed. Games for Actors gives a thorough introduction of the TO and gives specific theatrical methods and games for participants in TO.

${ }^{31}$ Laura Coltelli, Winged Words (Lincoln: University of Nebraska Press, 1990), 57.

${ }^{32}$ Lynne Bell, "Scandalous Personas, Difficult Knowledge, Restless Images," Canadian Art. vol.21 no. (4 Winter 2004): 49.

${ }^{33}$ This performance was first performed as Minding the Motherload in 1997 at Emily's, a small café in Saskatoon. The piece was a part of a festival organized by "Women in the Arts" associated with the University of Saskatchewan. The thematic focus of this festival was on artists and mothering. Lynne Bell and Janice Williamson, "High-Tech Storyteller," 31.

${ }^{34}$ Walter Benjamin, "The Storyteller," in Illuminations: Essays and Reflections, trans. Harry Zohn (New 
York: Schocken Books, 1969), 97-98.

${ }^{35}$ Walter Benjamin, "The Storyteller," in Illuminations: Essays and Reflections, 83-84.

${ }^{36}$ Jean Fisher, "Witness for the Prosecution: The Writings of Coco Fusco," in The Bodies That Where Not

Ours, and Other Writings, ed., Coco Fusco (London and New York: Routledge, 2001), 228.

${ }^{37}$ Coco Fusco draws upon Foucault's concept of heterotopias which are sites that relate to more stable sites, "in such a way as to suspect, neutralize, or invert the set of relations that they happen to designate, mirror of reflect." Michel Foucault, “Of Other Spaces," Diacritics (Spring 1986), 24. Fusco defines heterotopias as "physical spaces that are symbolically charged, where social and political relations can be reconfigured." Coco Fusco, Corpus Delecti: Performance Art of the Americas (London and New York: Routledge, 2000), 10. From Fusco's point of view, the spaces created through the performativity of Blondeau storytelling are heterotopias. Blondeau's practice challenges and mirrors colonial landscapes to reclaim, revision, and reconfigure a post-colonial Aboriginal landscape.

${ }^{38}$ Jean Fisher, "Witness for the Prosecution: The Writings of Coco Fusco," 228.

${ }^{39}$ Lori Blondeau, "Some Kinda Princess," in Mentoring Artists For Women's Art, 26.

${ }^{40}$ Lori Blondeau, "Some Kinda Princess," 26.

${ }^{41}$ Ibid., 26.

${ }^{42}$ Ibid., 26.

${ }^{43}$ A. E. Forget, Sessional Report from the Indian Commissioner, (Ottawa, Government of Canada, 1897), Section: Education, 291. The following passage was included in the joint exhibition project catalogue of The Aboriginal Healing Foundation, Legacy of Hope Foundation and National Archives of Canada Where are the Children published in 2003. This passage is found under the subject heading "The Purpose Behind the Residential Schools," 16-17.

${ }^{44}$ Jeff Thomas, Where Are the Children?: Healing The Legacy of the Residential Schools (Ottawa: Legacy of Hope Foundation, Library and Archives Canada, 2003), 17-18. Ethnocide is defined as a deliberate attempt to eradicate socio-cultural frameworks of a people, and depends heavily on the dominant society's strategic manipulation of its political power. Thomas Barfield ed., The Dictionary of Anthropology (Malden, MA: Blackwell Publishing Ltd., 1997), 156.

${ }^{45}$ J.R Ponting, Arduous Journey: Canadian Indians and Decolonization (Toronto: McClelland and Stuart, 1989), 26.

${ }^{46}$ For a review of Canadian policy, see John L. Tobias, "Protection, Civilization, Assimilation: An Outline History of Canada's Indian Policy", in As Long as the Sun Shines and Water Flows, ed. Ian A.L. Getty and Antoine S. Lussier (Vancouver: University of British Columbia Press, 1983); J.R. Miller, Skyscrapers Hide the Heavens: A History of Indian-White Relations in Canada, revised edition (Toronto: University of Toronto Press, 1989); and Olive P. Dickason, Canada's First Nations: A History of Founding Peoples (Toronto: McClelland \& Stewart Inc., 1992).

47 "Residential Schools" Report Royal Commission on Aboriginal Peoples, volume 1: Looking Forward Looking Back Part 2: False Assumptions and a Failed Relationship, Chapter 10.

${ }^{48}$ Aboriginal Healing Foundation. Aboriginal Healing Foundation Program Handbook, 2nd Edition. Ottawa: Aboriginal Healing Foundation (1999), A5. The following statement that $I$ included does not mean that all children who attending residential schools endured abuse or that all survivors then abused their children. However, my intention in this inclusion is to acknowledge the significant trauma still faced in Aboriginal communities due to experiences in Residential schools. Other legacies, recognized by the AHF of the residential school experience persistently present in Aboriginal families are: dysfunctional families and interpersonal relationships, parenting issues such as emotional coldness, rigidity, neglect, poor communications and abandonment, low self-esteem, educational blocks - aversions to formal learning programs that seem 'too much like school', psychologically-based learning disabilities, alcohol and drug abuse; chronic, widespread depression, rage and anger. This list is only a handful of the prevalent consequences endured on a daily bases by intergenerational survivors. See http://www. wherearethechildren.ca/en/impacts.html for a more complete list of impacts of residential schools. Also see: the Aboriginal Healing Foundation Reclaiming Connections: Understanding Residential School Trauma Among Aboriginal People (Ottawa: Aboriginal Healing Foundation, 2005). Specifically see Section II "Impacts of 'Aggressive Assimilation' and Traumatic Disconnection" 43-48. ${ }^{49}$ Basil Johnston, Indian School Days (Oklahoma: University of Oklahoma Press, 1989). Celia Haig Brown, Resistance and Renewal: Surviving Indian Residential Schools (Vancouver BC: Arsenal Press, 1988). These two publications provide examples of the Aboriginal struggle against these institutions and 
the resistance negotiated by its students. For example, some children were able to maintain their knowledge of Aboriginal culture and language.

${ }^{50}$ Lori Blondeau "Some Kinda Princess," 27.

51 Ibid., 26-27.

${ }^{52}$ Ibid., 27.

${ }^{53}$ I discovered the use of Julien's term in relation to the Canadian contemporary Aboriginal context in reading Dr. Lynne Bell's abstract "The Post/Colonial Photographic Archive and the Performance as Testimony" where she discusses the work of Lori Blondeau, Edward Poitras and Dana Claxton. Bell states "All three artists are actively engaged in a mode of decolonizing visual work that has been called 'the undoing of the colonial archive.' This lecture was given at the Australian National University Testimony and Witness: From the Local to the Transnational Conference February 14-16 2006. http://www.anu.edu.au/HRC/conferences/conferences 2006/Testimony Abstracts.pdf Also see Isaac Julien's professional website: http://www.isaacjulien.com/home

${ }^{54}$ Jean Fraser, "Witness for the Prosecution: The Writings of Coco Fusco," 227. Fraser discusses Coco Fusco's use of narrative as means to disrupt the problematics of aesthetic and political agency.

${ }^{55}$ Shoshana Felman and Dori Laub, Testimony: Crises of Witnessing in Literature, Psychoanalysis, and History (London and New York: Routledge, 1992), 5.

${ }^{56}$ Michel Foucault, "The Subject and Power," in The Essential Foucault, eds., Paul Rabinow and Nikolas Rose (New York: The New Press, 2003),130.

${ }^{57}$ Lori Blondeau, "Some Kinda Princess," 27.

${ }^{58}$ Homi K. Bhabha, The Location of Culture, 100-101.

${ }^{59}$ Bill Ashcroft, Gareth Griffiths and Helen Tiffin, Post-Colonial Studies: The Key Concepts, 226.

${ }^{60}$ Lori Blondeau, "Some Kinda Princess," 27.

${ }^{61}$ Ibid.,27.

${ }^{62}$ Ibid.,27.

${ }^{63}$ Ibid.,27.

${ }^{64}$ Peggy Phelan, Unmarked: The Politics of Performance (London, New York: Routledge, 1993), 174.

${ }^{65}$ Ibid., 174.

${ }^{66}$ Lori Blondeau, "Some Kinda Princess" 27.

${ }^{67}$ In was not until 1951 that the Indian Act policy towards Aboriginal education was changed. Prior to this time, children were consistently removed from their learning to do chores around the school and also some had 'vocational' jobs in the surrounding areas. Prior to this era, little time was spent on learning, on average two hours of instruction per day on academic subjects and the rest of the day was spent working, cleaning and farming. Non-Aboriginal children spent five hours a day in public school learning. See Where Are the Children? Healing the Legacy of the Residential Schools, 54-55.

${ }^{68}$ The process of skinning logs is a laborious task, which involves removing the tree's bark, along with the branches, until all that's left is a long thick pole. The process of skinning logs transcends cultures. Aboriginal peoples, specifically the Plains Cree, removed bark from lodge wood pines which were used as the poles for their tipi lodges, while the European settlers skinned logs for creation the log cabins. While the log cabin participates in the representation of Canada's western development, presented as an icon of Euro-Canadian settlement of 'wild and vacant' lands, the tipi lodge participates in the iconic narrative of the Wild West and the warrior plains peoples presented in literary fiction and Hollywood films.

${ }^{69}$ Lori Blondeau, 27.

${ }^{70}$ Ibid., 27.

${ }^{71}$ Ibid., 28.

${ }^{72}$ Ibid., 28 .

${ }^{73}$ Ibid.,28.

${ }^{74}$ Roberta Greyeyes, St Michael's Indian Residential School 1894-1926; a study within a broader historical and ideological (MA Thesis Carleton University, 1995). Jack Funk elaborates on this dehumanizing process. His account is specific to the Delmas Boarding School in Saskatchewan. He states: "Each student was given a number which they retained during their years at Delmas. Their number determined the order in which they line up for anything, and they lined up for everything: classes, prayers, food, dismissal, bedtime, toilets, and washing in the mornings, noon, and night. Often the students were called by their number rather than by name." Jack Funk, "Une Main Criminelle," in 
Residential Schools: The Stolen Years, edited by Linda Jaine (Saskatoon: University of Saskatchewan, 1993), 72.

${ }^{75}$ Pierre Bourdieu, Outline of a Theory of Practice Translated by Richard Nice, (Cambridge: Cambridge University Press, 1977), 196.

${ }^{76}$ Jacqueline Gresko, "White Rites and Indian Rites: Indian Education and Native Responses in the West, 1870-1910," in Shaping the Schools of the Canadian West, edited by D.C Jones, N.M Sheehan and R.M. Stamp (Calgary: Detselig Enterprises, 1979), 89.

${ }^{77}$ Homi K. Bhabha, The Location of Culture, 123.

${ }^{78}$ David Mandelbaum, The Plains Cree: An Ethnographic, Historical and Comparative Study Canadian Plains Studies \#9 (Regina, Canadian Plains Research Center University of Regina, 1979), 154.

${ }^{79}$ David Mandelbaum, The Plains Cree: An Ethnographic, Historical and Comparative Study, 155.

${ }^{80}$ Richard Kistabish, in Where are the Children? Healing the Legacy of the Residential Schools (Ottawa: Legacy of Hope Foundation, 2003), 4. It is estimated there are 80,000 people alive today who attended Indian residential schools, according to Statistics Canada. Of the 16,751 Indian residential school claims filed against the Government of Canada by former students, 3,940 have been resolved. http://www.irsrrqpi.gc.ca/english/statistics.html\#a Indian Residential Schools Resolution Canada.

${ }^{81}$ David Garneau, "Lori Blondeau: ShuBox Theatre, University of Regina," Vie Des Art vol. 48 no. 190 (Spring 2003): 86.

${ }^{82}$ Lynne Bell, "Scandalous Personas, Difficult Knowledge, and Restless Images," 52.

${ }^{83}$ David Garneau, "Lori Blondeau: ShuBox Theatre," 86

${ }^{84}$ Lori Blondeau, "Some Kinda Princess," 26.

85 Ibid., 25.

${ }^{86}$ Ibid.,25.

${ }^{87}$ Ibid.,25.

${ }^{88}$ Andrea Breen "Between the Covers, Feminist, Antiracist and Queer Performance Art in Australia," in . Feminism and Antiracism: International Struggles for Justice, edited by France Winddance Twine and Kathleen M. Blee (New York: New York University Press, 2001), 164.

${ }^{89}$ Pierre Bourdieu, The Field of Cultural Production: Essays on Art and Literature (Cambridge: Polity Press/Basil Blackwell, 1993).

${ }^{90}$ Pierre Bourdieu, The Field of Cultural Production: Essays on Art and Literature.

${ }^{91}$ Lori Blondeau, 25.

92 Ibid., 25-26.

${ }^{93}$ Ibid., 26.

${ }^{94}$ David Garneau, 86.

${ }^{95}$ Koozma J. Tarasoff, "Persistent Ceremonialism: The Plains Cree and Saulteaux," National Museum of Man Mercury Series Canadian Ethnology Service, Paper no. 69 (Ottawa 1980): 23.

${ }^{96}$ Lori Blondeau, 26.

${ }^{97}$ Lynne Bell, "Scandalous Personas," 52-53.

${ }^{98}$ Ibid., 52-53.

${ }^{99}$ S. J. Tambiah, A Performative Approach to Ritual (London: The British Academy and Oxford University Press, 1979), 119.

${ }^{100}$ Catherine Bell identifies six categories of ritual action: rites of passage or life crisis rituals, calendrical and commemorative rites, rites of exchange and communion, rites of affliction, rites of feasting, fasting, and festival, and political rituals. Catherine Bell, Ritual Perspectives and Dimensions (Oxford and New York: Oxford University Press, 1997), 94

${ }^{101}$ Charlotte Townsend-Gault, “Ritualizing Ritual's Ritual," Art Journal, vol. 51 no. 3 (Fall 1992):53.

${ }^{102}$ Archer Pechawis, "New Traditions: Post-Oka Aboriginal Performance Art in Vancouver," 137.

${ }^{103}$ Charlotte Townsend-Gault, "Ritualizing Ritual's Ritual," 51.

${ }^{104}$ Lori Blondeau, 26.

${ }^{105}$ Ibid., 26.

${ }^{106}$ Lynne Bell, “Scandalous Personas, Difficult Knowledge, and Restless Images," 52.

${ }^{107}$ David Garneau, 86.

${ }^{108}$ Ibid., 86

${ }^{109}$ Lori Blondeau, 26 


\section{Chapter 4}

'Robert Fulford, "The Triumph of Narrative," in Story Works. How Teachers Can Use Shared Stories in the New Curriculum, edited by David Booth and Bob Barton (Markham: Pembroke Publishers, 2000).

${ }^{2}$ Judith Butler, /Excitable Speech/ A Politics of the Performative (New York: Routledge, 1997), 162.

${ }^{3}$ Lori Blondeau, "Some Kinda Princess," in Mentoring Artists For Women's Art: Culture of Community, edited by Vera Lemecha (Winnipeg, MAWA, 2004), 24.

${ }^{4}$ Coco Fusco, "Managing the Other," Lusitania vol. 1 no. 2 (1990): 77.

${ }^{5}$ Many contemporary Aboriginal artist have negotiated new readings of the images represented in the photographic record. See the work of David Neel, Shelly Niro, George Littlechild, and Joane Cardinal-Schubert.

${ }^{6}$ Bill Ashcroft, Gareth Griffiths, Helen Tiffin, Empire Writes Back (London, Routledge: 1989), 8-9.

${ }^{7}$ Robert F. Berkholfer, The White Man's Indian: Images of the American Indian, From Columbus to the Present (New York and Toronto: Random House, 1979), 72.

${ }^{8}$ Bonita Lawrence, "Gender, Race, and the Regulation of Native Identity in Canada and the United States," Hypatia: Native American Issue. vol. 18 no. 2 (2003): 4.

${ }^{9}$ Hilary Weaver, "Indigenous Identity: What Is It, and Who Really Has It?" American Indian Quarterly. vol. 25 (2001): 242.

${ }^{10}$ Lori Blondeau, "Some Kinda Princess," 23-24.

${ }^{11}$ Ibid., 28.

${ }^{12}$ See Charles Taylor "Politics of Recognition," in Multiculturalism: A Critical Reader, edited by D.T. Goldberg (Oxford: Blackwell Publishing, 1994). Bonita Lawrence, "Gender, Race, and the Regulation of Native Identity in Canada and the United States," Hypatia: Native American Issue. vol. 18 no. 2 (2003): 3-31.

${ }^{13}$ Charles Taylor, "Politics of Recognition," 75.

${ }^{14}$ Gerald Vizenor, Fugitive Poses: Native American Indian Scenes of Absence and Presence (Lincoln: University of Nebraska Press, 1988), 22.

${ }^{15}$ Bonita Weaver, "Indigenous Identity: What Is It, and Who Really Has It?" 243.

${ }^{16}$ Robert F. Berkhofer Jr. The White Man's Indian: Images of the American Indian from Columbus to the Present, 121.

${ }^{17}$ This play was performed in Philadelphia in 1808. Robert Tilton, 26. The American fairy-tale version of Pocahontas' life did not appear in John Smith's memoirs of his life written in 1608, but he did include some information is in General History of Virginia published in 1624, a narrative of harmonic friendship and co-operation during the process of early colonial expansion.

${ }^{18}$ Gail Guthrie Valaskakis, Indian Country: Essays on Contemporary Native Culture (Waterloo, ON: Wilfred Laurier University Press, 2005), 133.

${ }^{19}$ Gail Guthrie Valaskakis, Indian Country, 133.

${ }^{20}$ Daniel Francis, The Imaginary Indian: the Image of the Indian in Canadian Culture (Vancouver: Arsenal Pulp Press, 1992), 121-122

${ }^{21}$ Terry Goldie, Fear and Temptation: The Image of the Indigene in Canadian, Australian, and New Zealand Literature (Montreal: McGill-Queen's University Press, 1989) 72.

${ }^{22}$ Terry Goldie, Fear and Temptation, 72.

${ }^{23}$ Sacajawea was a real person. Gail Guthrie Valaskakis, "Sacajawea and Her Sisters: Images and Indians," Indian Princesses and Cowgirls: Stereotypes from the Frontier (Montreal: Oboro, 1992), 11-40.

${ }^{24}$ See Gail Guthrie Valaskakis Indian Princesses and Cowgirls: Stereotypes from the Frontier and Indian Country 135-143.

${ }^{25}$ Gail Guthrie Valaskakis, Indian Country.136. See a more thorough investigation in Gail Guthrie Valaskakis, Indian Princesses and Cowgirls: Stereotypes from the Frontier (Montreal: Oboro, 1992).

${ }^{26}$ Coco Fusco, The Bodies that were not ours and other writings, (London: Routledge, 2001) xvi.

${ }^{27}$ Sigmund Freud, "Humor," in the Collected Papers, vol. 5, 217 quoted in Cynthia Morrill,

"Revamping the Gay Sensibility: Queer Camp and Dyke noir," in Politics and Poetics of Camp, ed., Moe Meyer (London and New York: Routledge, 1994), 122. 
${ }^{28}$ Lynne Bell, "Scandalous Personas, Difficult Knowledge, and Restless Images," Canadian Art vol. 21 no. 3 (Winter 2004): 53.

${ }^{29}$ Basil Johnston, "How Do We Learn Language?" in Talking on the Page: Editing Aboriginal Oral Texts, eds., Laura Murray and Keren Rice (Toronto: University of Toronto Press: 1999),14.

${ }^{30}$ Mirjam Hirch, "Subversive Humour: Canadian Native Playwrights' Winning Weapon of

Resistance," in Me Funny, ed., Drew Hayden Taylor (Vancouver: Douglas and McIntyre, 2005), 106.

${ }^{31}$ Mirjam Hirch, "Subversive Humour: Canadian Native Playwrights," 106.

${ }^{32}$ Margaret Atwood, "A Double-Bladed Knife: Subversive Laughter in Two Stories by Thomas King," Canadian Literature 124-125 (March 1990): 244.

${ }^{33}$ Lynne Bell, "Scandalous Personas,"52.

${ }^{34}$ Linda Hutcheon, A Poetics of Postmodernism: History, Theory, Fiction (New York and London: Routledge,1988), 26. Cited in Allan J. Ryan, The Trickster Shift Humour and Irony in Contemporary Native Art (Vancouver: UBC Press, 1999), 23.

${ }^{35}$ Allan J. Ryan, Trickster Shift, 23.

${ }^{36}$ Linda Hutcheon, A Poetics of Postmodernism: History, Theory, Fiction, 4.

${ }^{37}$ Jayne Wark, "Dressed to Thrill: Costume, Body, and Dress in Canadian Performative Art," in Caught in the Act: An Anthology of Performance Art by Canadian Women, edited by Tanya Mars and Johanna Householder (YYZ Books, Toronto: 2004), 99.

${ }^{38}$ Jayne Wark, "Dressed to Thrill: Costume, Body, and Dress in Canadian Performative Art," $100-101$.

${ }^{39}$ Allan J. Ryan, The cowboy/Indian Show: Recent Work by Gerald McMaster (Kleinburg ON: McMichael Canadian Art Collection, 1991), 65.

${ }^{40}$ A. Robert Lee, Loosening the Seams: Interpretations of Gerald Vizenor (Bowling Green: Bowling Green State University Popular Press, 2000),1. Vizenor is acclaimed to be one of the most significant First Nations writers of twentieth and twenty-first centuries. He has produced over 25 books in a variety of genres, from poetry, fiction, journalism and literary theory. Gerald Vizenor, Interior Landscapes: Autobiographical Myths and Metaphors (Minneapolis: University of Minnesota, 1990).

${ }^{41}$ Elaine Jahner, "Trickster Discourse and Postmodern Strategies," Loosening the Seams (Bowling Green Ohio: Bowling State University Press, 2000), 43.

${ }^{42}$ Allan J. Ryan, "Postmodern Parody: A Political Strategy in Contemporary Canadian Native Art," Art Journal vol. 51 no. 3 (Fall 1992):59.

${ }^{43}$ Allan J. Ryan, The Trickster Shift, 5.

${ }^{44}$ Ibid., 4.

${ }^{45}$ James Luna arrived at this term "Contemporary Traditionalist". He defines "Contemporary

Traditionalists" as trained artists of all genres "who bridge the gaps within our culture in possession of Indian Knowledge." From Jean Fisher, "In Search of the "Inauthentic": Disturbing Signs in

Contemporary Native American Art," Art Journal vol. 51. no. 3 (Fall 1992): 44.

${ }^{46}$ Lori Blondeau "Some Kinda Princess," 23

${ }^{47}$ Peggy Phelan, Unmarked: The Politics of Performance, 3.

${ }^{48}$ Ibid., 30.

${ }^{49}$ Lynne Bell, "Scandalous Personas, Difficult Knowledge, Restless Images," 51.

${ }^{50}$ Lynne Bell and Janice Williamson, "High Tech Storyteller,"28.

${ }^{51}$ Lynne Bell and Janice Williamson, 29.

${ }^{52}$ In an interview with Lynne Bell, Blondeau explains the CosmoSquaw performance persona and how she came to be. Blondeau states "In Montreal, I worked in a Native women's shelter where all the counselors were single women. One of the women used to bring in Cosmopolitan magazine every week and all the counselors and clients got involved with the quizzes. I just thought: How can you read this? The magazine targets white middle class women. How do you think you're going to find a man using the tips it gives? But at the same time, I was tempted to read it because I was a single woman looking for a man." Lynne Bell and Janice Williamson, 28.

${ }^{53}$ Ibid., 28.

${ }^{54}$ Heather Marie Anderson, Masters Thesis, Contemporary Canadian Women's Performance Art: Reading Postfeminism and Third-Wave Feminism (Master Thesis: Dalhousie University, 2003),81.

${ }^{55}$ Rebecca Schneider, The Explicit Body in Performance, (London, New York: Routledge, 1997), 134.

${ }^{56}$ Rebecca Schneider, The Explicit Body in Performance 134.

${ }^{57}$ Lynn Bell and Janice Williamson, "High Tech Storyteller," 28. 
${ }^{58}$ Heather Marie Anderson, Contemporary Canadian Women's Performance Art, 81.

${ }^{59}$ Judith Butler, "The Force of Fantasy: Feminism, Mapplethorpe and Discursive Excess," Differences vol. 2 no.2 (Summer 1990): 115.

${ }^{60}$ This title makes reference to how bingo is widely popular in Aboriginal communities throughout Canada and also is a play on the term, 'poker face'.

${ }^{61}$ Lynne Bell and Janet Williamson, "High Tech Storytelling: A Conversation with Performance Artist Lori Blondeau," FUSE vol. 24 no. 4 (2001): 28.

${ }^{62}$ In recent years, with the development of APTN more young Aboriginal women are seen daily on television as journalists, news commentators, and entertainment talk show. In addition to more visibility on television, Aboriginal magazines such as Spirit, increases the positive representation of Aboriginal women in popular culture.

${ }^{63}$ Lynne Bell discusses Blondeau's use of Cosmopolitan's cover page as a point of departure for the production of new readings. Lynne Bell "Artists Pages: Decolonizing Tactics in 'Writing Space," in The Future of the Page, edited by Peter Stoicheff and Andrew Taylor (Toronto, University of Toronto Press: 2004), 265.

${ }^{64}$ Lynne Bell “Artists Pages: Decolonizing Tactics in 'Writing Space,"”263.

${ }^{65}$ Ibid., 265

${ }^{66}$ The use of the term ambivalent is meant to suggest Homi Bhabha's understanding of it, which is meant to describe the complex relationship, or mixture rather of attraction and repulsion between the colonizer and colonized. This complicated relationship is ambivalent because the colonized subject is never simply and completely opposed to the colonizer. This means that complicity and resistance exist at the same time, in constant fluctuation. Most importantly, Bhabha's theory of ambivalence disrupts the simple relationship between the colonizer and the colonized, therefore, it is an unwelcomed aspect of colonial discourse for the colonizer. Bill Ashcroft, Gareth Griffiths, and Helen Tiffin, Post-Colonial Studies: The Key Concepts (New York: Routledge, 2000),12-14. Homi K. Bhabha, The Location of Culture, 121-31 and 145-74.

${ }^{67}$ Homi K. Bhabha, The Location of Culture (London: Routledge, 1994), 122.

${ }^{68}$ Jayne Wark, "Dressed to Thrill: Costume, Body, and Dress in Canadian Performative Art," 86.

${ }^{69}$ Kaja Silverman, "Fragments of a Fashionable Discourse," in Studies in Entertainment: Critical Approaches to Mass Culture, ed., Tania Modleski (Bloomington: Indiana University Press, 1986), 145. Jayne Wark includes Silverman's discussion of clothing as a cultural signifier, as means for a body to be cultural identified. See Jayne Wark, 87.

${ }^{70}$ Heather Marie Anderson, Contemporary Canadian Women's Performance Art: Reading

Postfeminism and Third-Wave Feminism, 81.

${ }^{71}$ Lynne Bell and Janet Williamson, 31.

${ }^{72}$ Ibid., 53.

${ }^{73}$ Mirjam Hirch, “Subversive Humour: Canadian Native Playwrights,' 116.

${ }^{74}$ Heather Marie Anderson, 82.

${ }^{75}$ Amy Sara Carroll, 44-46. Amelia Jones, Body Art: Performing the Subject (Minneapolis: University of Minnesota Press, 1998), 217.

${ }^{76}$ Amy Sara Carroll, 44.

${ }^{77}$ Coco Fusco, The Bodies that were not ours and other writings, xvi

${ }^{78}$ Rebecca Schneider, "After us the Savage Goddess: Feminist performance art of the explicit body staged, uneasily, across modernist dreamscapes," in Performance and Cultural Politics edited by Elin Diamond (London and New York: Routledge, 1996), 172.

${ }^{79}$ Heather Marie Anderson, Contemporary Canadian Women's Performance Art: Reading Postfeminism and Third-Wave Feminism, 82.

${ }^{80}$ lbid., 82.

${ }^{81}$ Amy Sara Carroll, Performing Body Politics: Bell Rogue's Collection's Runway Interventions (Regina: Neutral Ground Gallery, 2000), 44.

${ }^{82}$ Amy Sara Carroll, Performing Body Politics: Bell Rogue's Collection's Runway Intervention, 44.

${ }^{83}$ Ibid., 44.

${ }^{84}$ Ibid., 44.

${ }^{85}$ Heather Marie Anderson, Contemporary Canadian Women's Performance Art: Reading Postfeminism and Third-Wave Feminism, 83. 
${ }^{86}$ Ibid., 83 .

${ }^{87}$ This being said I am aware of Cherrie Moraga and Gloria Anzaldua's This bridge called my back and Ella Shohat's Talking Visions: Multicultural Feminism in a Transnational Age - which address alternatives and ways in which feminism exceeds narrow boundaries.

${ }^{88}$ M.A. Jaimes-Guerrero, "Savage Hegemony: From 'Endangered Species' to Feminist Indigenism," in Talking Visions: Multicultural Feminism in a Transnational Age, edited by Ella Shohat (New York: The New Museum of Contemporary Art, 1998), 432.

${ }^{89}$ In an interview with Blondeau, when asked what her relationship was with feminism, she answered: "I understand how my work is put into the category, but I don't think of myself as a feminist. This doesn't mean I don't support feminism, but I would like to ask you a question, where is feminism these days?" From this statement, Blondeau's ambivalent relationship with feminism becomes even clearer. E-mail Interview with Lori Blondeau: April 4, 2005.

${ }^{90}$ Lori Blondeau, "Some Kinda Princess," 28.

${ }^{91}$ Michel Foucault, Power/Knowledge: Selected Interviews \& Other Writings 1972-1977, edited by Colin Gordon (New York: Pantheon Books, 1980).

${ }^{92}$ Lewis Hyde, The Gift: The Imagination and Erotic Life of Property (New York: Vintage Book, $1983), 4$

${ }^{93}$ Ibid., 49.

${ }^{94}$ Ibid., 48.

${ }^{95}$ Lori Blondeau, "Some Kinda Princess," 29.

${ }^{96}$ Allan J. Ryan, The cowboy/Indian Show: Recent Work by Gerald McMaster, 21.

${ }^{97}$ Lynne Bell, "Scandalous Personas, Difficult Knowledge, Restless Images," 48.

${ }^{98}$ Ibid., 48.

${ }^{99}$ Lori Blondeau, 28.

${ }^{100}$ Ibid., 29.

${ }^{101}$ As previously mentioned, the first play written about the legend of Pocahontas was titled Belle Sauvage.

${ }^{102}$ Lynne Bell, "Scandalous Personas," 48.

${ }^{103}$ Lori Blondeau, 29.

${ }^{104}$ Ibid., 29.

${ }^{105}$ This is where Blondeau spent her summers at her grandparents, again referencing personal stories within her performance.

${ }^{106}$ Lynne Bell, "Scandalous Personas," 50.

${ }^{107}$ In a 1958 study the duties of superintendents (agents) were noted as the following: "[T]he superintendent deals with property and with records, or with the recording of property. He registers births, deaths and marriages. He administers the band's funds. He supervises business dealings with regard to band property. He holds band elections and records the results. He interviews people who want irrigation systems, who complain about land encroachments, who are applicants for loans. He suggests to others that, if they are in a common-law relationship, they should get married, for, among other reasons, this simplifies the records. He obtains information about persons applying for enfranchisement. He adjusts the property of bands when members transfer. He deals with the estates of deceased Indians. He obtains the advice of the engineering officers on irrigation systems, and the building of schools. He negotiates the surrender of lands for highways and other public purposes. He applies for funds to re-house the needy and provide relief for the indigent. He draws the attention of magistrates to factors which bear upon Indians standing trial on criminal charges." H.B. Hawthorn, C.S. Belshaw, and S.M. Jamieson, The Indians of British Columbia: A Study of Contemporary Social Adjustment (Vancouver: University of British Columbia Press, 1958), 486. See Peter Carstens, The Queen's People: A Study of Hegemony, Coercion, and Accommodation among the Okanagan of Canada (Toronto: University of Toronto Press, 1991), 88.

From reading the Indian and Northern Affairs Canada's Report of the Royal Commission on Aboriginal Peoples, several other duties must also be included, such as the justice of the peace duties and powers described earlier: the power of inspecting schools and health conditions on reserves, presiding over band council meetings and, later, voting to break a tie. The agents were also responsible for encouraging Indians to enlist in the armed forces during the wars and for keeping lists of those enlisted for purposes of administering veterans' benefits after the wars. It is clear from this extensive 
list of duties, that the Indian Agent's powers and influence were formidable. See the Royal Commission on Aboriginal Peoples for a discussion of specific Agents role in communities. Within this report abuses of power are highlighted, exemplified, by deputy superintendents general Hayter Reed and Duncan Campbell Scott. Both of these Indian Agents exuded in their behaviour strict morality associated with social Darwinism. These men were feared and did not treat their constituencies with mutual respect. However, following WWII, with the returns of Aboriginal veterans, who had been treated and recognized as Canadian citizens during their tour of duty abroad, the Indian Agents authority was increasingly confronted and challenged. The position was removed from reserves all across Canada during the 1960's. See "False Assumptions and a Failed Relationship: The Indian Act" Chapter 9 Section 11 "Indian Agents".

${ }^{108}$ In the Report of the Royal Commission on Aboriginal People the pass system is discusses in relation to the Indian Act:

It began as a result of informal discussions among government officials in the early 1880's in response to the threat that prairie Indians might forge a pan-Indian alliance against Canadian authorities.

Designed to prevent Indians on the prairies from leaving their reserves, its immediate goal was to inhibit their mobility. Under the system, Indians were permitted to leave their reserves only if they had a written pass from the local Indian agent...The pass system should be read against the backdrop of other attempts to interfere with Indian cultural life, as it was intended not only to prevent Indian leaders and potential militants from conspiring with each other, but also to discourage parents from visiting their children in off-reserve residential schools and to give agents greater authority to prevent Indians from participating in banned ceremonies and dances on distant reserves. ${ }^{108 . ~ " F a l s e ~ A s s u m p t i o n s ~}$ and a Failed Relationship: The Pass System" Chapter 9 section 10, Report of the Royal Commission on Aboriginal Peoples (Ottawa, Canada: Canádian Government, 1996).

${ }^{109}$ Lori Blondeau, 29.

${ }^{110}$ Gerald Vizenor, Fugitive Poses: Native American Indian Scenes of Absence and Presence (Lincoln, Nebraska: First Bison Book, 2000), 15.

111 Lynne Bell, "Scandalous Personas,"50.

112. Ibid., 50.

113 Ibid., 52.

${ }^{114}$ In Blondeau's concluding sentence of her article "Some Kinda Princess" she writes: When they hear this song, will people remember my performance? If they know the song, what memories will it trigger?

${ }^{115}$ Lynne Bell, 50.

\section{Conclusion}

1 Lynne Bell, "Scandalous Personas, Difficult Knowledge, and Restless Images," Canadian Art vol. 21 no. 3 (Winter 2004): 51. 


\section{Bibliography}

Aboriginal Healing Foundation. Reclaiming Connections: Understanding Residential School Trauma Among Aboriginal People. Section II "Impacts of 'Aggressive Assimilation' and Traumatic Disconnection." Ottawa: Aboriginal Healing Foundation, 2005.

Aboriginal Healing Foundation. Aboriginal Healing Foundation Program Handbook. 2nd Edition. Ottawa: Aboriginal Healing Foundation (1999), A5.

Aboriginal Healing Foundation. Where Are the Children? Impacts of Residential Schools. http://www.wherearethechildren.ca/en/impacts.html

Acland, Joan Reid. "First Nations Art in Canada-1960-1999: A Pivotal Juncture." First Nations Artists in Canada: A Biographical Guide, 1960-1999. Montreal: The Gail and Stephen A. Jarislowsky Institute for Studies in Canadian Art, 1999.

Akiwenzie-Damm, Kateri. "Says Who, Colonialism, Identity, and Defining Indigenous Literature." In Looking at the Words of Our People: First Nations Analysis of Literature. Edited by Jeanette Armstrong. Penticton: Theytus Books, 1993.

Allen, Paula Gunn. The Sacred Hoop: Recovering the Feminine in American Indian Tradition. Boston, Beacon Press: 1986.

Anderson, Heather M. Contemporary Canadian Women's Performance Art: Reading Postfeminism and Third-Wave Feminism. Masters Thesis. Halifax: Dalhousie University, 2003.

Anderson, Kim. A Recognition of Being: Reconstructing Native Womenhood. Toronto: Sumach Press, 2000.

Ashcroft, Bill, Gareth Griffiths, and Helen Tiffin. Postcolonial Studies: The Key Concepts. London and New York: Routledge, 1998.

Ashcroft, Bill, Gareth Griffiths, and Helen Tiffin. The Empire Writes Back. London, Routledge: 1989.

Atwood, Margaret “A Double-Bladed Knife: Subversive Laughter in Two Stories by Thomas King." Canadian Literature. 124-125 (March 1990).

Bailey, Jann LM, and Scott Watson. Rebecca Belmore: Fountain. [exhibition catalogue] Kamloops Art Gallery and The Morris and Helen Belkin Art Gallery. Canadian Pavilion, Venice Biennale, 2005.

Baker, Emerance. "Loving Indianess: Native Women's Storytelling as Survivance." Atlantis. vol. 29 no. 2 (Spring 2005): 111-118. 
Barajas, Anne. "Native American Artists Challenge Stereotypes In MabeeGerrer" Press Release (September 7, 2000) St Gregory's University. http://www.stgregorys.edu/prrelease interface/article.asp?prkey $=42$

Barfield, Thomas, ed. The Dictionary of Anthropology. Malden, MA: Blackwell Publishing Ltd., 1997.

Barsamian, David, and Edward W. Said. Culture and Resistance: Conversations with Edward W. Said. Cambridge: South End Press, 2003.

Battiste, Marie, ed. Reclaiming Indigenous Voice and Vision. Vancouver: UBC Press, 2000 .

Bell, Catherine. Ritual Perspectives and Dimensions. Oxford and New York: Oxford University Press, 1997.

Bell, Lynne. "The Post/Colonial Photographic Archive and the Performance as Testimony." Presentation Abstract. Australian National University Testimony and Witness: From the Local to the Transnational. Conference February 14-16 2006. http://www.anu.edu.au/HRC/conferences/conferences 2006/Testimony Abstracts .pdf

Bell, Lynne. “Artist's Pages: Decolonizing Tactics in 'Writing Spaces,' In The Future of the Page. Edited by Peter Stoicheff and Andrew Taylor. Toronto:University of Toronto Press, 2004.

Bell, Lynne. “Scandalous Personas, Difficult Knowledge, Restless Images.” Canadian Art. vol.21 no. (4 Winter 2004): 48-53.

Bell, Lynne, and Janice Williamson. "High Tech Storyteller: A Conversation with Performance Artist Lori Blondeau." FUSE vol. 24 no. 4 (2001):27-34.

Benjamin, Walter. “The Storyteller.” In Illuminations: Essays and Reflections. trans. Zohn, Harry. New York: Schocken Books, 1969.

Boal, Augusto. Games for Actors and Non-Actors (London and New York: Routledge, 1992).

Berkhofer, Robert F. Jr. The White Man's Indian: Images of the American Indian from Columbus to the Present. New York: Alfred A. Knopf Inc, 1978.

Berlo, Janet C, and Ruth B. Phillips. Native North American Art. Oxford: Oxford University Press, 1998.

Berry Brill de Ramirez, Susan. Contemporary American Indian and Oral Traditions. Tucson: University of Arizona Press, 1999. 
Bhabha, Homi K. "Democracy De-realized." In Democracy Unrealized:Documenta. Edited by Okwui Enwezor and Carlos Basualdo. Kassel :Hatje Cantz Publishers, 2002.

Bhabha, Homi K. The Location of Culture. London and New York: Routledge, 2004.

Blondeau, Lori. "Some Kinda Princess." In Mentoring Artists for Women's Art: Culture of Community. Edited by Vera Lemecha. Winnipeg: MAWA, 2004.

Blondeau, Lori, and Carla Taunton. Ongoing Interview with the Artist (Blondeau) via Email: commenced April 4 2005-August 2006.

Blondeau, Lori. "Professional Profile." Art History website, University of Saskatchewan www.arts.usask.ca/art/faculty/pages/l blondeau.html/

Blondeau, Lori. Published Artists Statement. Postcolonial University: Lori Blondeau: http://www/usask.ca/education/postcolonial/blondeau/bios.html

Boal, Augusto. Games for Actors and Non-Actors. London and New York: Routledge, 1992.

Bourdieu, Pierre. Outline of a Theory of Practice. Translated by Nice, Richard.

Cambridge: Cambridge University Press, 1977.

Bourdieu, Pierre. The Field of Cultural Production: essays on Art and Literature. Cambridge: Polity Press/Basil Blackwell, 1993

Bowie, Fiona. The Anthropology of Religion. Oxford: Blackwell Publishing, 2000.

Bradley, Jessica. "Rebecca Belmore: Art and Object of Performance." In Caught in the Act: An Anthology of Performance art by Canadian Women. Edited by Tanya Mars and Johanna Householder. Toronto: YYZ Books, 2004.

Breen, Andrea. "Between the Covers, Feminist, Antiracist and Queer Performance Art in Australia." In Feminism and Antiracism: International Struggles for Justice. Edited by France Winddance Twine and Kathleen M. Blee. New York: New York University Press, 2001. 150-169.

Brown, Celia Haig. Resistance and Renewal: Surviving Indian Residential Schools. Vancouver BC: Arsenal Press, 1988.

Bruchac, Joseph, ed. Survival This Way. Tucson: Sun Tracks and University of Arizona Press, 1987. 
Burgess, Marilyn, and Valaskakis, Gail Guthrie. Indian Princesses and Cowgirls: Stereotypes from the Frontier. Montreal: Gallery Oboro, 1995.

Butler, Judith. /Excitable Speech/ A Politics of the Performative. New York: Routledge, 1997.

Butler, Judith. "The Force of Fantasy: Feminism, Mapplethorpe and Discursive Excess." Differences. vol. 2 no. 2 (Summer 1990): 105-125.

Canyon, Brice, ed. Live at the End of the Century: Aspects of Performance Art in Vancouver. Vancouver: Grunt Gallery, 2000.

Carlson, Marvin. Performance: A Critical Introduction. London: New York,1996.

Carroll, Amy Sara. Performing Body-Politics: Belle Rogue's Collection's Runway Interventions. [exhibition catalogue] Regina: Neutral Ground Gallery, 2000.

Carstens, Peter. The Queen's People: A Study of Hegemony, Coercion, and Accommodation among the Okanogan of Canada. Toronto: University of Toronto Press, 1991.

Carter, Paul. The Road to Botany Bay. London: Faber and Faber, 1987.

Chambers, Ian. Border Dialogues: Journeys in Postmodernity. London and New York: Routledge, 1990.

Clark, Justin.“A Native American in Venice.” L.A Weekly. (Thursday June 23, 2005).

Clifford, James. The Predicament of Culture: Twentieth Century Ethnography, Literature and Art. Cambridge: Harvard University Press, 1988.

Clifford, James, ed. Writing Culture: The Poetics and Politics of Ethnography. Berkeley: University of California Press, 1986.

Coltelli, Laura. Winged Words: American Indian Writers Speak. Lincoln: University of Nebraska Press, 1990.

Coombes, Annie. Inventing the 'Postcolonial': Hybridity and Constituency in Contemporary Curating. In The Art in Art History: A Critical Anthology. Edited by Donald Preziosi. Oxford, New York: Oxford University Press, 1998.

Cowlishaw, Gillian. Rednecks, Eggheads and Blackfellas: A Study of Racial Power and Intimacy. Ann Arbour: University of Michigan Press, 1999. 
Crosby, Marcia. "Construction of the Imaginary Indian." In Vancouver Anthology: The Institutional Politics of Art. Edited by Stan Douglas. Vancouver: Talonbooks, 1991.

Cyberpowwow. www.cyberpowwow.com

Dahl, Svend. History of the Book. Metuchen, NJ: The Scarecrow Press, 1968.

Deloria, Vine Jr. God Is Red. New York: Delta Book, 1973.

Diamond, Elin, ed. Performance and Cultural Politics. London, New York: Routledge, 1996.

Dickason, Olive P. Canada's First Nations: A History of Founding Peoples. Toronto: McClelland \& Stewart Inc., 1992

Duff, Tagny. "FFWD, RWD, and PLAY: Performance art, Video, and Reflections on Second-Wave Feminism in Vancouver 1873-1983." In Caught in the Act: An Anthology of Performance art by Canadian Women. Edited by Tanya Mars and Johanna Householder. Toronto: YYZ Books, 2004.

Dumonceaux, Ann. "Accomplished Art Grad Student First to be Admitted under PLAR Program." On Campus News, vol. 8 no. 9 (January 19 2001): 3.

Einhorn, Lois J. The Native American Oral Tradition: Voices of the Spirit and Soul. Westport: Connecticut, Greenwood, 2000.

"False Assumptions and a Failed Relationship: The Pass System." Chapter 9 section 10 Report of the Royal Commission on Aboriginal Peoples. Ottawa, Canada: Canadian Government, 1996.

Farmer, Gary. "The Shameman: Going Beyond Indian-the Performance Art of James Luna." Aboriginal Voices. vol. 1 no. 4 (Fall 1994):19-24.

Felman, Shoshana, and Dori Laub. Testimony: Crises of Witnessing in Literature, Psychoanalysis, and History. London and New York: Routledge, 1992.

Ferfuson, Russell, Martha Gever, Trinh T. Minha-ha, and Cornel West, eds. Out There: Marginalized and Contemporary Cultures. Cambridge, Massachusetts: MIT Press, 1990.

Fernandez-Sacco, Ellen. "Check Your Baggage: Resisting Whiteness in Art History." Art Journal. no. 60 vol. 4 (Winter 2001):59-61.

First Nations Performance Series. Vancouver: Grunt Gallery, 1989-2004. www.grunt.bc.ca/fnp/ 
Fisher, Jean. "Witness for the Prosecution: The Writings of Coco Fusco." In The Bodies That Where Not Ours, and Other Writings. Edited by Coco Fusco. London and New York: Routledge, 2001.

Fisher, Jean. "In Search of the "Inauthentic": Disturbing Signs in Contemporary Native American Art." Art Journal. vol.51. no. 3 (Fall 1992): 44-50.

Fisher, Jean. "The Health of the People is the Highest Law." In Revisions: Third Text. no.2 (Winter 1987/88): 63-75.

Forget, A. E. Sessional Report from the Indian Commissioner. Ottawa, Government of Canada, 1897. Section: Education, 291.

Foster, Hal. Recodings: Art, Spectacle, Cultural Politics. Port Townsend: Bay Press, 1985.

Foucault, Michel. "The Subject and Power." In The Essential Foucault.

Edited by Paul Rabinow and Nikolas Rose. New York: The New Press, 2003.

Foucault, Michel. Power/Knowledge: Selected Interviews \& Other Writings 1972-197. Edited by Colin Gordon. New York: Pantheon Books, 1980.

Foucault, Michel. The Archaeology of Knowledge. Translated by Smith A.M Sheridan. London: Tavostock, 1972.

Francis, Daniel. The Imaginary Indian: the Image of the Indian in Canadian Culture. Vancouver: Arsenal Pulp Press, 1992.

Freud, Sigmund. "Humor." Collected Papers, vol. 5, 217. Quoted In Morrill, Cynthia. "Revamping the Gay Sensibility: Queer Camp and Dyke noir." In Politics and Poetics of Camp. ed. Meyer, Moe. London and New York: Routledge, 1994. 122.

Fulford, Robert. "The Triumph of Narrative." In Story Works: How Teachers Can Use Shared Stories in the New Curriculum. edited by Booth and Barton. Markham: Pembroke Publishers, 2000.

Funk, Jack. “Une Main Criminelle.” In Residential Schools: The Stolen Years. Edited Linda Jaine. Saskatoon: University of Saskatchewan, 1993.

Fusco, Coco. The Bodies That Were Not Ours: and Other Writings. London and New York: Routledge, 2001.

Fusco, Coco. Corpus Delecti: Performance Art of the Americas. London and New York: Routledge, 2000. 
Garneau, David. "Lori Blondeau: ShuBox Theatre, University of Regina." Vie Des Art. vol. 48 no. 190 (Spring 2003):86.

Garoian, Charles R. Performing Pedagogy: Toward an Art of Politics. New York: State University of New York Press, 1999.

Gerson, Carole, and Veronica Strong-Boag, eds. E. Pauline Johnson Tekahionwake: Collected Poems and Selected Prose. Toronto: University of Toronto, 2002.

Giroux, Henry. Disturbing Pleasures: Learning Popular Culture. New York: Routledge, 1994.

Golberg, RoseLee, Performance Art: From Futurism to the Present. London: Thames \& Hudson Ltd., 2001.

Goldie, Terry. Fear and Temptation: The Image of the Indigene in Canadian, Australian, and New Zealand Literature. Montreal: McGill-Queen's University Press, 1989.

Gopnik, Blake. "Indian Artist in Venice: Off the Traditional Path." Washington Post (Sunday July 24, 2005): NO1.

Gray, Charlotte. Flint and Feather Toronto: HarperCollins Publishers, 2002.

Gresko, Jacqueline. "White Rites and Indian Rites: Indian Education and Native Responses in the West, 1870-1910." In Shaping the Schools of the Canadian West. Edited by D.C., Jones, N.M. Sheehan, and R.M. Stamp.Calgary: Detselig Enterprises, 1979.

Greyeyes, Roberta. St Michael's Indian Residential School 1894-1926; a study within a broader historical and ideological. MA Thesis Carleton University, 1995.

Gudeman, Stephen, The Anthropology of Economy Malden, MA: Blackwell Publishers, 2001.

Hall, Stuart. Representation: Cultural Representation and Signifying Practices. London: Open University, 1999.

Hall, Stuart. "Cultural Identity and Cinematic Representation.” Framework. vol. 36 (1989):68-81.

Hall, Stuart. "Signification, Representation, Ideology: Althusser and the Poststructuralist Debates." Critical Studies in Mass Communication. vol. 2. no. 2 (1985): 91-114.

Hayden-Taylor, Drew, ed. Me Funny. Vancouver: Douglas and McIntyre, 2005. 
Hawthorn, H.B., C.S. Belshaw and S.M. Jamieson. The Indians of British Columbia: A Study of Contemporary Social Adjustment. Vancouver: University of British Columbia Press, 1958.

Hill, Lynn. AlterNative: Contemporary Photo Compositions. [exhibition catalogue] Kleinburg ON: McMichael Canadian Art Collection, 1995.

Hirch, Mirjam. “Subversive Humour: Canadian Native Playwrights' Winning Weapon of Resistance." In Me Funny. Edited by Drew Hayden Taylor. Vancouver: Douglas and McIntyre, 2005.

hooks, bell. Yearning: Race, Gender, and Cultural Politics. Boston: South End Press, 1990.

Houle, Robert, Diana Nemiroff and Charlotte Townsend-Gault. eds. Land, Spirit, Power: First Nations at the National Gallery of Canada. [exhibition catalogue] Ottawa: National Gallery of Canada, 1992.

Houle, Robert. "The Emergence of a New Aesthetic Tradition." New Work by a New Generation. [exhibition catalogue] Regina: McKenzie Art Gallery, 1982.

Hultkrantz, Ake. Belief and Worship in Native North America. Syracuse: Syracuse University Press, 1981.

Hutcheon, Linda. A Poetics of Postmodernism: History, Theory, Fiction. New York, London: Routledge, 1988.

INDIAN ACTS? Aboriginal Performance Art,(Vancouver: Grunt Gallery, 2002). www.grunt.bc.ca/IndianAct/ or www.mailman.smufsa.nu/pipermail/apao/2002November.html

Indian Residential Schools Resolution Canada. Ottawa, Canadian Government. http://www.irsr-rqpi.gc.ca/english/statistics.html\#a

Jahner, Elaine A. "Trickster Discourse and Postmodern Strategies." In Loosening the Seams: Interpretations of Gerald Vizenor. Edited by Robert A. Lee. Bowling Green: Bowling Green State University Press, 2000.

Jaimes-Guerrero, M.A. “Savage Hegemony: From 'Endangered Species' to Feminist Indigenism." In Talking Visions: Multicultural Feminism in a Transnational Age. Edited by Ella Shohat. New York: The New Museum of Contemporary Art, 1998.

Jenness, Diamond, The Indians of Canada. Toronto: University of Toronto Press, 1977.

Jessup, Lynda, ed. On Aboriginal Representation in the Gallery. Ottawa: Canadian Museum of Civilization, 2002.

Johnson, Pauline E. Flint and Feather. Toronto: Musson Books, 1914. 
Johnston, Basil. "How Do We Learn Language?" In Talking on the Page: Editing Aboriginal Oral Texts. Edited by Laura Murray and Keren Rice. Toronto: University of Toronto Press: 1999.

Johnston, Basil. Indian School Days. Oklahoma: University of Oklahoma Press, 1989.

Johnston, Sheila. Buckskin and Broadcloth A Celebration of E. Pauline Johnson Tekahionwake. Toronto: Natural Heritage/Natural History, 1997.

Jones, Amelia. Body Art: Performing the Subject. Minneapolis: University of Minnesota Press, 1998.

Jones, Amelia, and Andrew Stephenson. Performing The Body: Performing the Text. London, New York: Routledge, 1999.

Kaprow, Allan. "Nontheatrical Performance." In Essays on the Blurring of Art and Life. Edited by J. Kelley. Berkeley: University of California Press, 1993.

King, Thomas. The Truth About Stories: A Native Narrative. Toronto: House of Anansi Press, 2003.

Kirby, Vicki. Telling Flesh: The Substance of the Corporeal. London and New York: Routledge, 1997.

Komter, Aeftke E., ed. The Gift: An Interdisciplinary Perspective. Amsterdam: Amsterdam University Press, 1996.

Kroeber, Karl. Retelling/Rereading: The Fate of Storytelling in Modern Times. New Brunswick, New Jersey: Rutgers University Press, 1992.

Kruput, Arnold. The Turn to the Native: Studies Criticism and Culture. Lincoln: University of Nebraska Press,1996.

Laenui, Poka. "Process of Decolonization." In Reclaiming Indigenous Voice and Vision. Edited by Marie Battiste. Vancouver: Talonbooks, 2000.

Lawrence, Bonita. "Gender, Race, and the Regulation of Native Identity in Canada and the United States." Hypatia: Native American Issue. vol. 18 no. 2 (2003):3-31.

Lee, Maracle. I am Woman. North Vancouver: Write-On Press, 1988.

Lee, Robert A., ed. Loosening the Seams: Interpretations of Gerald Vizenor. Bowling Green: Bowling Green State University Press, 2000.

Leen, Mary. "An Art of Saying: Joy Harjo's Poetry and the Survival of Storytelling." 
Indian Art Quarterly vol.19 no.1 (Winter 1995): 1-16.

Lewis, Hyde. The Gift: The Imagination and Erotic Life of Property. New York: Vintage Book, 1983.

Lippard, Lucy. "Independent Identities." In Native American Art in the Twentieth

Century. Edited by Jackson Rushing III. London, New York: Routledge, 1999.

Little Bear, Leroy "Jagged Worldviews Colliding." In Reclaiming Indigenous Voice and Vision. Edited by Marie Battiste. Vancouver: Talonbooks, 2000.

Loft, Steven. "Aboriginal Media Art and the Postmodern Conundrum: A Coyote Perspective." In Transference, Tradition and Technology. Banff, Alberta: Walter Phillips Gallery Editions, 2005.

Luna, James. Professional/archival website. www.jamesluna.com

MacClancy, Jeremy, ed. Contesting Art: Art, Politics and Identity in the Modern World New York: Berg Publishing, 1997.

McKean, Thomas A. "Tradition as Communication," Oral Tradition vol. 18 no. 1 (2003): 49-50.

McMaster, Gerald. "Our (Inter) Related History." In On Aboriginal Representation in the Gallery. Edited by Lynda Jessup. Ottawa: Canadian Museum of Civilization, 2002.

McMaster, Gerald. "Towards an Aboriginal Art History." In Native American Art in the Twentieth Century. Edited by Jackson Rushing III. London, New York: Routledge, 1999.

McMaster, Gerald. "Foreword." First Nations Artists in Canada: A Biographical Guide, 1960-1999. Montreal: The Gail and Stephen A. Jarislowsky Institute for Studies in Canadian Art, 1999

McMaster, Gerald and Lee-Ann Martin. Indigena: Contemporary Native Perspectives. [exhibition catalogue] Ottawa: Museum of Civilization, 1992.

Mandelbaum, David. The Plains Cree: An Ethnographic, Historical and Comparative Study. Canadian Plains Studies. \#9 Regina, Canadian Plains Research Center University of Regina, 1979.

Mane-Wheoki, Jonathan. "The Resurgence of Maori Art: Conflicts and Continuities in the Eighties." The Contemporary Pacific. vol. 9. no.1 (Spring 1995): 1-

Maracle, Aayanna. "Performance Art and The Native Aritist: a rEvolutionary Mix?" In 
Live at the End of the Century: Aspects of Performance Art in Vancouver. Edited by Bryce Canyan.Vancouver: Grunt Gallery, 2000.

Maracle, Lee. "Oratory: Coming to Theory." Essays on Canadian Writing: The Gender Issue. vol. 54 (Winter 1994):7-11.

Mars, Tanya, and Johanna Householder, eds. Caught in the Act: An Anthology of Performance art by Canadian Women. Toronto: YYZ Books, 2004.

Martin, Lee-Ann. "The Waters of Venice: Rebecca Belmore at the $51^{\text {st }}$ Biennale." Canadian Art. vol. 22 no. 2 (Summer 2005):48-53.

Martin, Linda R. “James Luna.” Native Peoples. vol. 10 (Spring 1997):96.

Mihesuah, Devon Abbott. Indigenous American Women: Decolonization, Empowerment, Activism. (Lincoln: University of Nebraska, 2003).

Miller, J.R. Skyscrapers Hide the Heavens: A History of Indian-White Relations in Canada. Revised Edition. Toronto: University of Toronto Press, 1989.

Minh-ha, Trinh T. Woman, Native, Other: Writing Postcoloniality and Feminism. Indianapolis: Indiana University Press, 1989.

Momaday, N. Scott. "Man Made of Words.” In Indian Voices. Edited by Rupert Costo. San Francisco: The Indian Historian Press, 1970.

Moses, Daniel David., and Terry Goldie, eds. An Anthology of Canadian Native Literature in English. Don Mills ON: Oxford University Press, 2005.

Moses, Daniel David., and Terry Goldie, eds. An Anthology of Canadian Native Literature in English. Don Mills ON: Oxford University Press, 1998.

"Native Arts on View During Tozzer Library's 25"."Harvard Gazette (October 14, 1999): http://www.news.harvard.edu/gazette/1999/10.14/tozzer.html

Nemiroff, Diana. "Modernism, Nationalism, and Beyond: A Critical History of Exhibitions of First Nations Art." In Land, Spirit, Power: First Nations at the National Gallery of Canada. Edited by R. Houle, D. Nemiroff and C. TownsendGault. [exhibition catalogue] Ottawa: National Gallery of Canada, 1992.

Nicks, Trudi. "Partnerships in developing cultural resources: lessons from the Task Force on Museums and First Peoples." Culture. vol. 12 no. 1 (1992): 87-93.

Nurse, Andrew. Tradition and Modernity: The Cultural Work of Marius Barbeau. PHD Dissertation: Queen's University, 1998.

Ortiz, Simon. Woven Stone. Tucson, AR: University of Arizona Press, 1992. 
Ortiz, Simon. Fightin': New and Collected Stories. New York: Thunder's Mouth Press, 1983.

Osteen, Mark, ed. The Question of the Gift: Essays Across Disciplines. London and New York: Routledge, 2002.

Pearce, Laura, and Alison K. Brown. Museums and Source Communities. London: Routledge, 2003.

Pechawis, Archer. "New Traditions: Post-Oka Aboriginal Performance Art in Vancouver." In Live At the End of the Century: Aspects of Performance Art in Vancouver. Edited by Brice Canyon. Vancouver: Grunt Gallery, 2000.

Phelan, Peggy. Unmarked: The politics of Performance. London, New York: Routledge, 1993.

Phillips, Ruth B. "Performing the Native Woman: Primitivism and Mimicry in Early Twentieth-Century Visual Culture." In Antimodernism and Artistic Experience: Policing the Boundaries of Modernity. Edited by Lynda Jessup. Toronto: University of Toronto Press, 2001.

Phillips, Ruth B. "Art History and the Native-made Object: New Discourses, Old Differences?" In Native American Art in the Twentieth Century. Edited by Jackson Rushing III. London, New York: Routledge, 1999.

Podedworny, Carole. Stay Here With Us. [exhibition catalogue] Thunder Bay, ON: Thunder Bay Art Gallery, 1986.

Pollack, Della. “Oral Traditions in Performance.” Oral Tradition. vol. 18 no. 2 (2003): 263-265.

Ponting, J.R. Arduous Journey: Canadian Indians and Decolonization. Toronto: McClelland and Stuart, 1989), 26.

Preston, Richard J. Cree Narrative: Expressing the Personal Meanings of Events. Canadian Ethnology Service. Paper no. 30 National Museum of Man, Mercury Series 1975.

Rabinow, Paul, and Nikolas Rose, eds. The Essential Foucault. New York: The New Press, 2003.

"Residential Schools." Report Royal Commission on Aboriginal Peoples. volume 1: Looking Forward Looking Back. Part 2: False Assumptions and a Failed Relationship, Chapter 10. Ottawa: Canadian Government, 1996.

Richard, Alain-Martin, and Clive Robertson. Performance In Canada 1970-1990. 
Quebec: Editions Intervention, 1990.

Rickard, Jolene. "Sovereignty: A Line in the Sand." Aperture 139 (Summer 1995): 51-9.

Ryan, Allan. The Trickster Shift: Humour and Irony in Contemporary Native Art. Vancouver: UBC Press, 1999.

Ryan, Allan. "Postmodern Parody: A Political Strategy in Contemporary Canadian Native Art.” Art Journal. vol. 51 no. 3 (Fall 1992): 59-65.

Ryan, Allan. The cowboy/Indian Show: Recent Work by Gerald McMaster. [exhibition catalogue] Kleinburg ON: McMichael Canadian Art Collection, 1991.

Said, Edward. "In Conversation with Neeladri Bhattacharya, Suvir Kaul, and Ania Loombia." In Relocating Postcolonialism. Edited by David Theo Goldberg and Ato Quayson. Oxford: Blackwell, 2002.

Saskatchewan Arts Board website: http://www.artsboard.sk.ca/story/story links.shtml

Schneider, Rebecca. "After us the Savage Goddess: Feminist performance art of the explicit body staged, uneasily, across modernist dreamscapes." In Performance and Cultural Politics. Edited by Elin Diamond. London and New York: Routledge, 1996.

Schneider, Rebecca. The Explicit Body in Performance. London, New York: Routledge, 1997.

Scholer, Bo, ed. Coyote was Here: Essays On Contemporary Native American Literary and Political Mobilizations. Arhus, Denmark: Selkos, 1983.

Shapiro, Michael J. Methods and Nations: Cultural Governance and the Indigenous Subject. London and New York: Routledge, 2004.

Silverman, Kaja. "Fragments of a Fashionable Discourse" In Studies in Entertainment: Critical Approaches to Mass Culture. Edited by Tania Modleski. Bloomington: Indiana University Press: 1986.

Simpson, Moira G. Making Representations: Museums in the Post-Colonial Era. London: Routledge, 2001.

Slapin, Beverly, and Doris Steale, eds. Through Indian Eyes: The Native Experience in Stories for Children. Gabriola Island, BC: New Society, 1992.

Smith, Sidonie, and Julia Watson, eds. Interfaces: Women/Autobriography/Image/ Performance. Ann Arbor, Michigan: The University of Michigan Press, 2005.

Smithsonian National Museum of the American. "Indian Artist James Luna Selected by 
the Smithsonian's' National Museum of the American Indian for the 2005 Venice Biennale." News Bulletin. Office of Public Affairs. February 7, 2005.

http://www.newsdesk.si.edu/releases/nmai venice.pdf

Solomon, Art. Song for The People: Teachings on the Natural Way. Toronto: NC Press 1990.

Strong-Boag, Veronica, and Carole Gerson. Paddling Her Own Canoe: Time and Texts of E. Pauline Johnson. Toronto: University of Toronto, 2000.

Sykes, Karen. Arguing with Anthropology: An Introduction to Critical Theories of the Gift. London and New York: Routledge, 2005.

Tambiah, S. J. A Performative Approach to Ritual. London: The British Academy and Oxford University Press, 1979.

Tarasoff, Koozma J. Persistent Ceremonialism: The Plains Cree and Saulteaux. National Museum of Man Mercury Series. Paper no. 69 Ottawa: Canadian Ethnology Service, 1980.

Taylor, Charles. "Politics of Recognition." In Multiculturalism: A Critical Reader. Edited by T.D. Goldberg. Oxford: Blackwell Publishing, 1994.

Thomas, Jeff. Where Are the Children?: Healing The Legacy of the Residential Schools Ottawa: Legacy of Hope Foundation, Library and Archives Canada, 2003.

Tilton, Robert, S. Pocahontas: The Evolution of an American Narrative. Cambridge: Cambridge University Press, 1994.

Tippett, Maria. "Review of Carole Gerson and Veronica Strong-Boag Paddling her Own Canoe." Canadian Historical Review. vol. 83 no, 1 (March 2002):140.

Tobias, John L. "Protection, Civilization, Assimilation: An Outline History of Canada's Indian Policy." In As Long as the Sun Shines and Water Flows. Edited by Ian A.L. Getty. Lussier, Antoine S. Vancouver: University of British Columbia Press, 1983.

Torres-Tama, Jose. "Healing with Humor: New American Perspectives from James Luna and Dan Kwong." Art Papers. vol. 25 no. 5 (September/October 2001): 17

Townsend-Gault, Charlotte. The Named and the UnNamed [exhibition catalogue] Vancouver: Morris and Helen Belkin Art Gallery, 2002.

Townsend-Gault, Charlotte. "Hot dogs, A Ball Gown, Abode, and Words." In Native American Art in the Twentieth Century. Edited by Jackson Rushing III. London, New York: Routledge, 1999.

Townsend-Gault, Charlotte. "Art, Argument and Anger on the Northwest Coast." In 
Contesting Art: Art, Politics and Identity in the Modern World. Edited by Jeremy MacClancy. New York: Berg Publishing, 1997.

Townsend-Gault, Charlotte. "If Art is the Answer, What is the Question? Some Questions Raised by First Nations' Visual Culture in Vancouver." RACAR. vol. 21 (1994): 100-101.

Townsend-Gault, Charlotte. "Having Voices and Using Them: First Nations Artists and 'Native Art'." Arts Magazine. vol. 65 (February 1991):65-70.

Townsend-Gault, Charlotte. "Rebecca Belmore." In Land, Spirit, Power. Edited by R. Houle, D. Nemiroff, and C. Townsend-Gault. [exhibition catalogue] Ottawa: National Gallery of Canada, 1992.

Tuhiwai Smith, Linda. Decolonizing Methodologies: Research and Indigenous Peoples. Dunedin: University of Otago Press, 1999.

Valaskakis, Gail Guthrie. Indian Country Essays on Contemporary Native Culture. Waterloo, ON: Wilfred Laurier University Press, 2005.

Valaskakis, Gail Guthrie. "Parallel Voices: Indians and Others-Narratives of Cultural Struggle." Canadian Journal of Communication. vol. 18 no. 3 (1993). 283-296.

Velie, Alan, ed. Native American Perspectives on Literature and History. Norman: University of Oklahoma Press, 1994.

Vizenor, Gerald. Manifest Manners: Post-Indian Warriors of Survivance. Middleton, CT: Wesleyan University Press, 1994.

Vizenor, Gerald. "Four Skin.” Tamaqua: Native American Issue. vol.2 no.2 (Winter/Spring 1991).

Vizenor, Gerald. Interior Landscapes: Autobiographical Myths and Metaphors. Minneapolis: University of Minnesota, 1990.

Vizenor, Gerald, ed. Narrative Chance: Postmodern Discourse on Native American Indian Literatures. Albuquerque: University of New Mexico Press, 1989.

Vizenor, Gerald. Fugitive Poses: Native American Indian Scenes of Absence and Presence. Lincoln: University of Nebraska Press, 1988.

Vizenor, Gerald. The People Named the Chippewa: Narrative Histories.University of Minnesota Press, 1984.

Walter, Anna Lee. Talking Indian: Reflections on Survival and Writing. Ithaca, NY: 
Greenfield Review Press, 1979.

Wark, Jayne. "Dressed to Thrill: Costume, Body, and Dress in Canadian Performative Art." In Caught in the Act: An Anthology of Performance Art by Canadian Women. Edited by Tanya Mars and Johanna Householder. YYZ Books, Toronto: 2004.

Weaver, Hilary. "Indigenous Identity: What Is It, and Who Really Has It?" American Indian Quarterly. vol. 25 (2001):240-255.

Wheale, Nigel, ed. Postmodern Arts. London, New York: Routledge, 1995.

Womack, Craig. Red on Red: Native American Literary Separatism. Minneapolis: University of Minnesota Press, 1999.

Zarilli, Phillip. "For Whom is the King a King? Issues of Intercultural Production, Perception, and Reception in a Kathikali King Lear," In Critical Theory and Performance. Edited by Joseph Roach and Janelle Reinelt. Ann Arbor: University of Michigan Press, 1992. 


\section{Illustrations}

(Figure 1) Lori Blondeau, Are You My Mother? Performance still, 2000; rpt. in Lynne Bell, "Scandalous Personas, Difficult Knowledge, Restless Images," Canadian Art vol. 21 no. 4 (Winter 2004): 51.

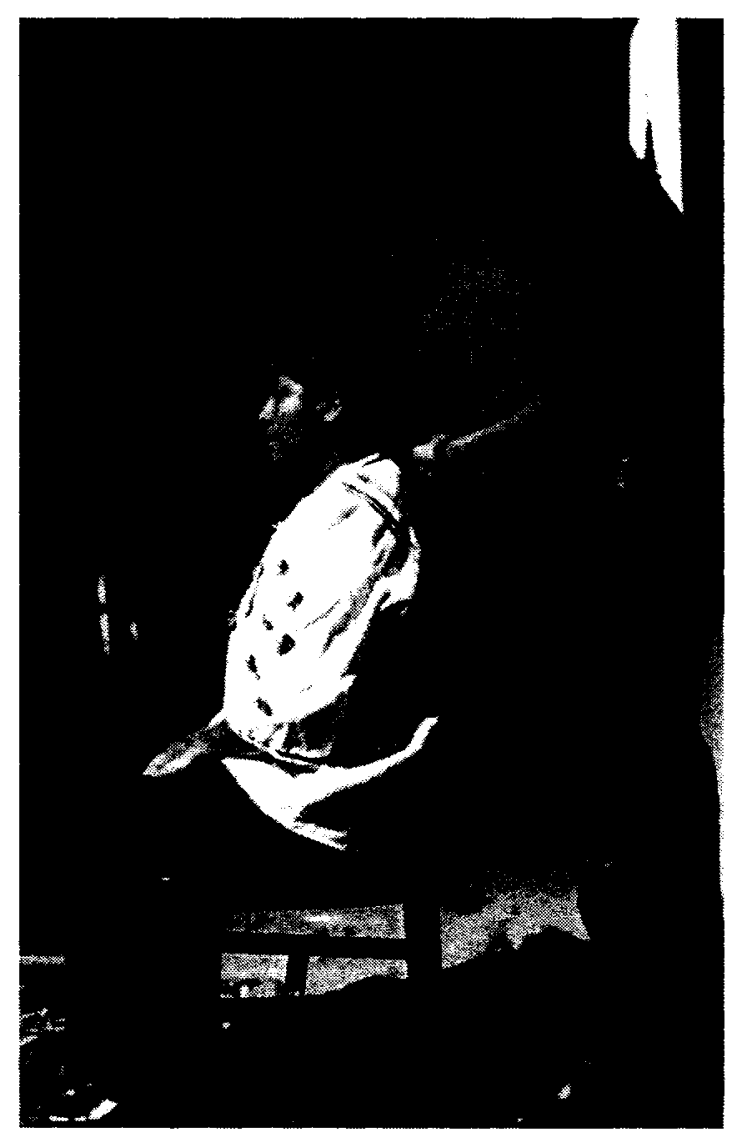


(Figure 2) Lori Blondeau, Sisters. Performance still, 2000; rpt. in Lynne Bell, "Scandalous Personas, Difficult Knowledge, Restless Images." Canadian Art vol.21 no. 4 (Winter 2004): 52.

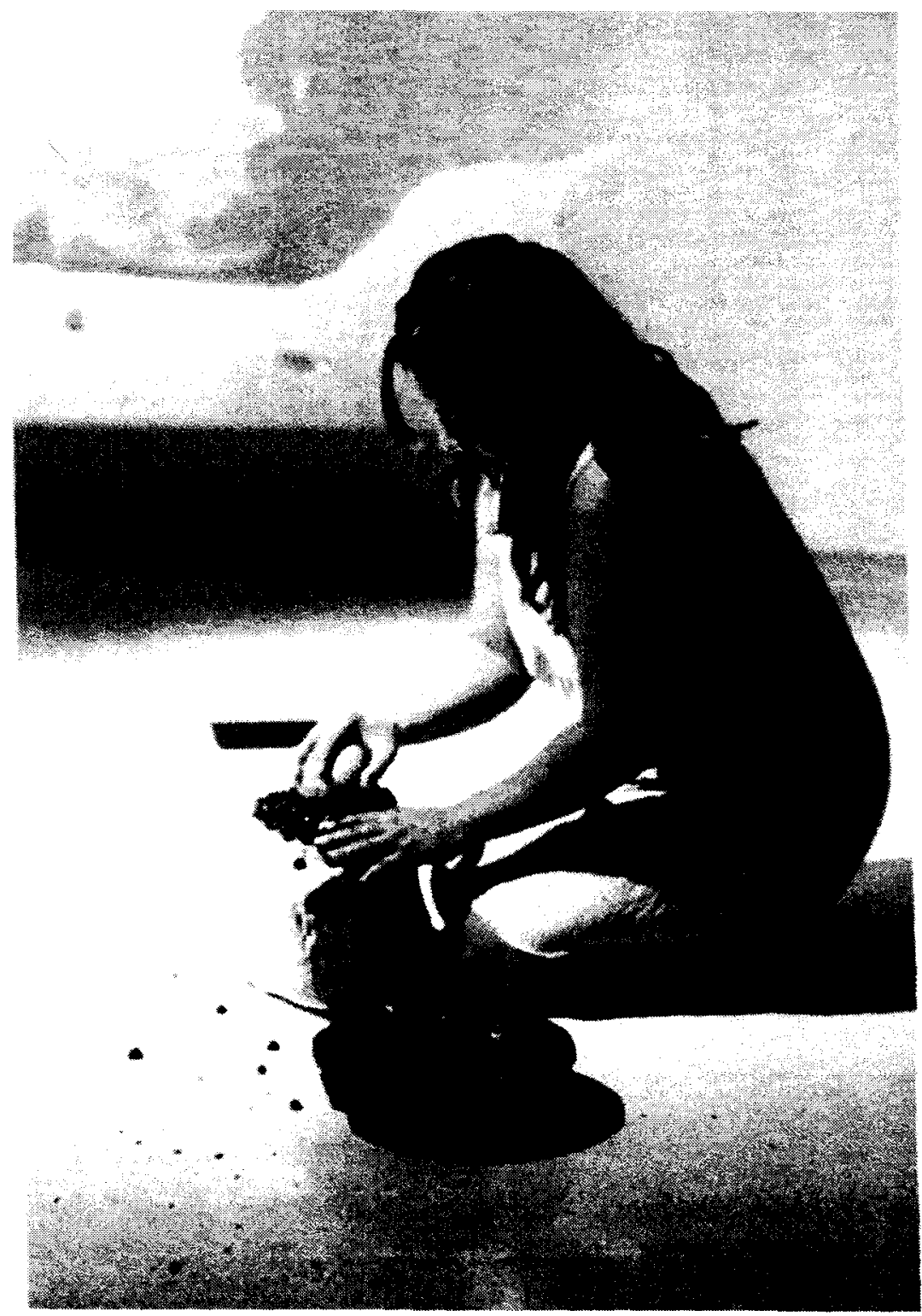


(Figure 3) Lori Blondeau, CosmoSquaw, 1996; rpt. in Lynne Bell, "Scandalous Personas, Difficult Knowledge, Restless Images." Canadian Art vol.21 no. 4 (Winter 2004): 50 .

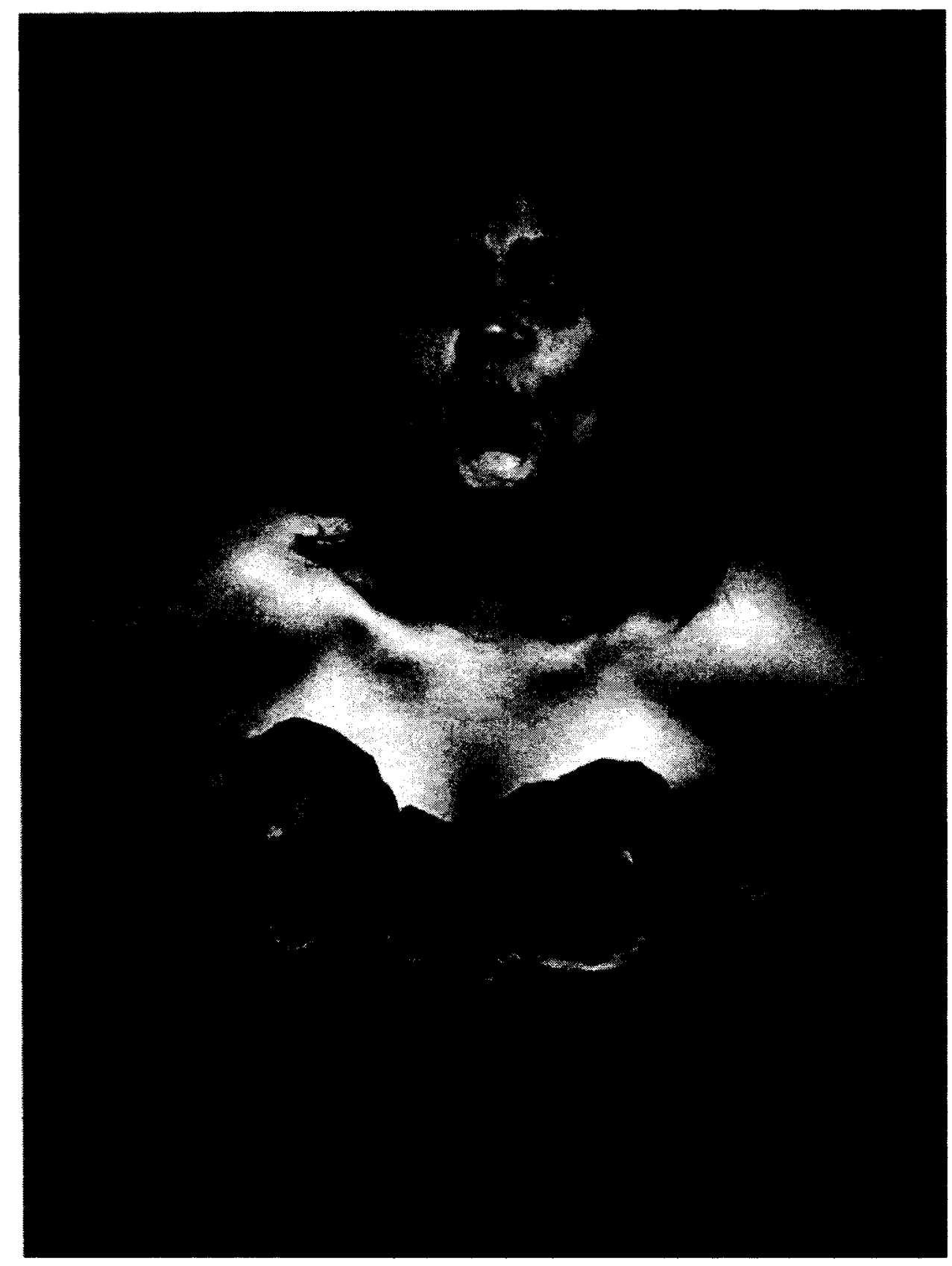


(Figure 4) Lori Blondeau, Lonely Surfer Squaw. photograph, 1996; rpt. in Lynne Bell, "Scandalous Personas, Difficult Knowledge, Restless Images." Canadian Art vol.21 no. 4 (Winter 2004): 53.
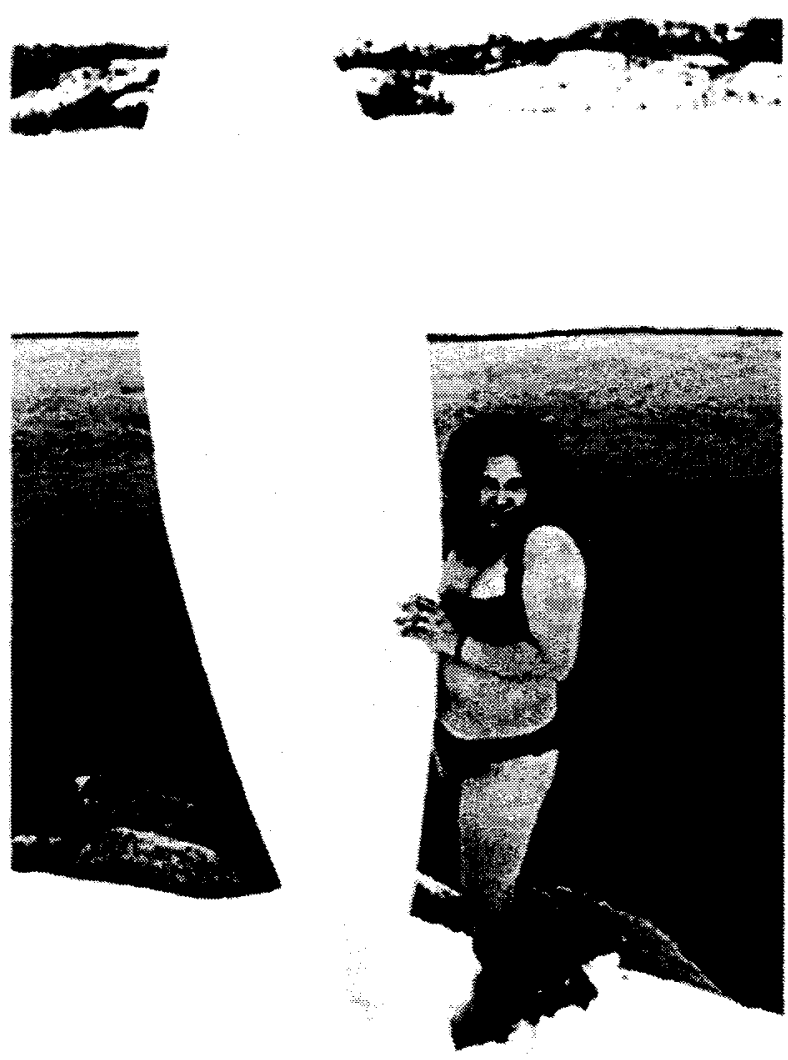
(Figure 5) Lori Blondeau, Betty Daybird. Performance still, 2000; in Amy Sara Carroll, Performing Body-Politics: Belle Rogue's Collection's Runway Interventions (Regina: Neutral Ground Gallery, 2000), 44.

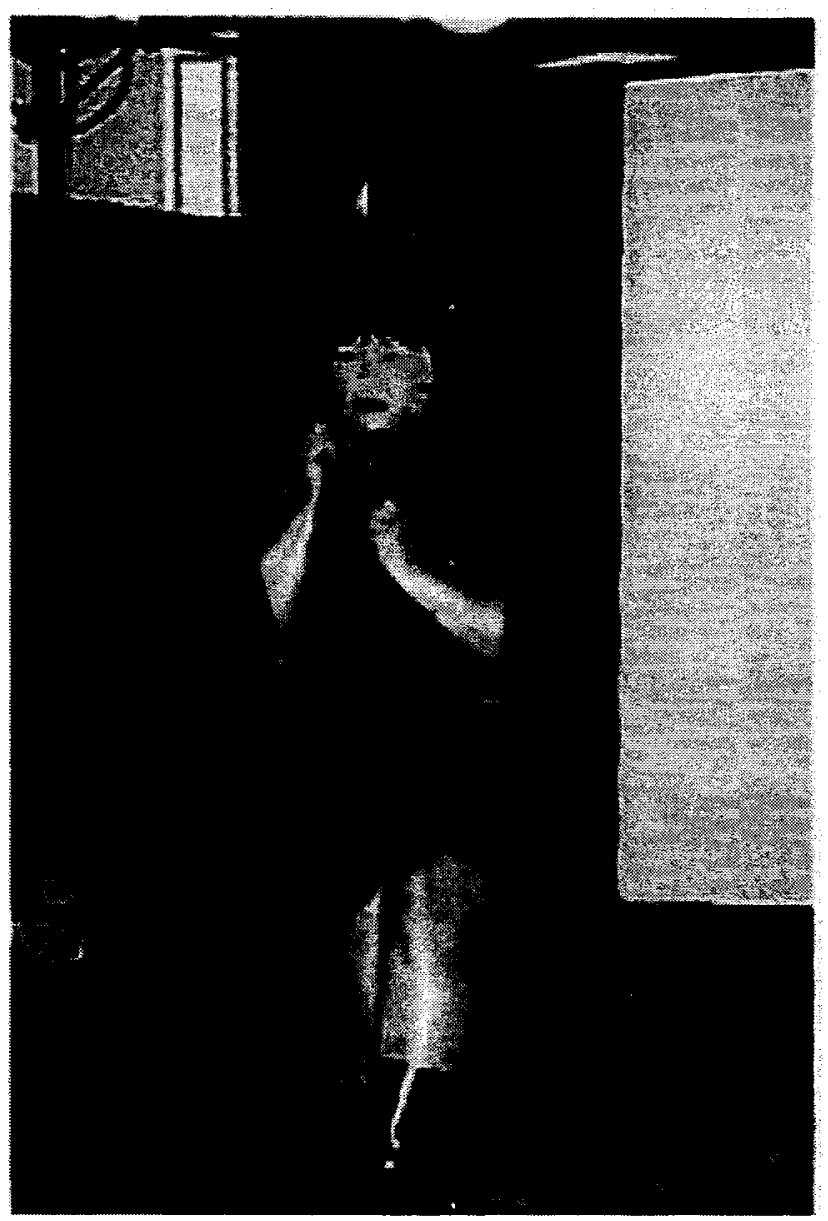


(Figure 6) Lori Blondeau, Belle Sauvage, Performance still, 2002; in Gordon Shelgrove Gallery Archive, University of Saskatchewan:

http://www.usask.ca/snelgrove/mfa/02 LB/08.html

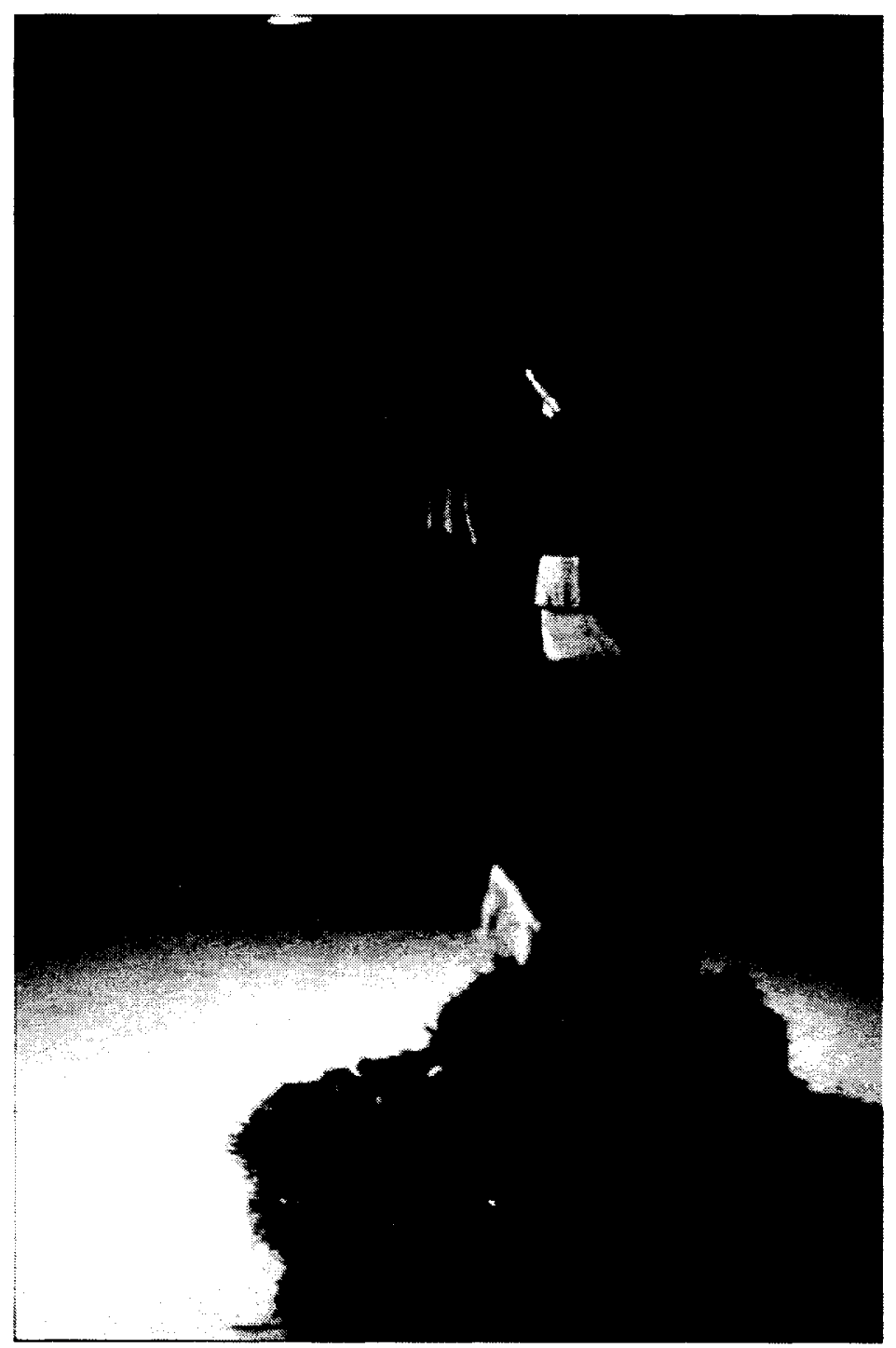


(Figure 7) Pauline Johnson (1861-1913), "Mohawk poet and performer" photograph c.1904; Provincial Archives of British A-09684.

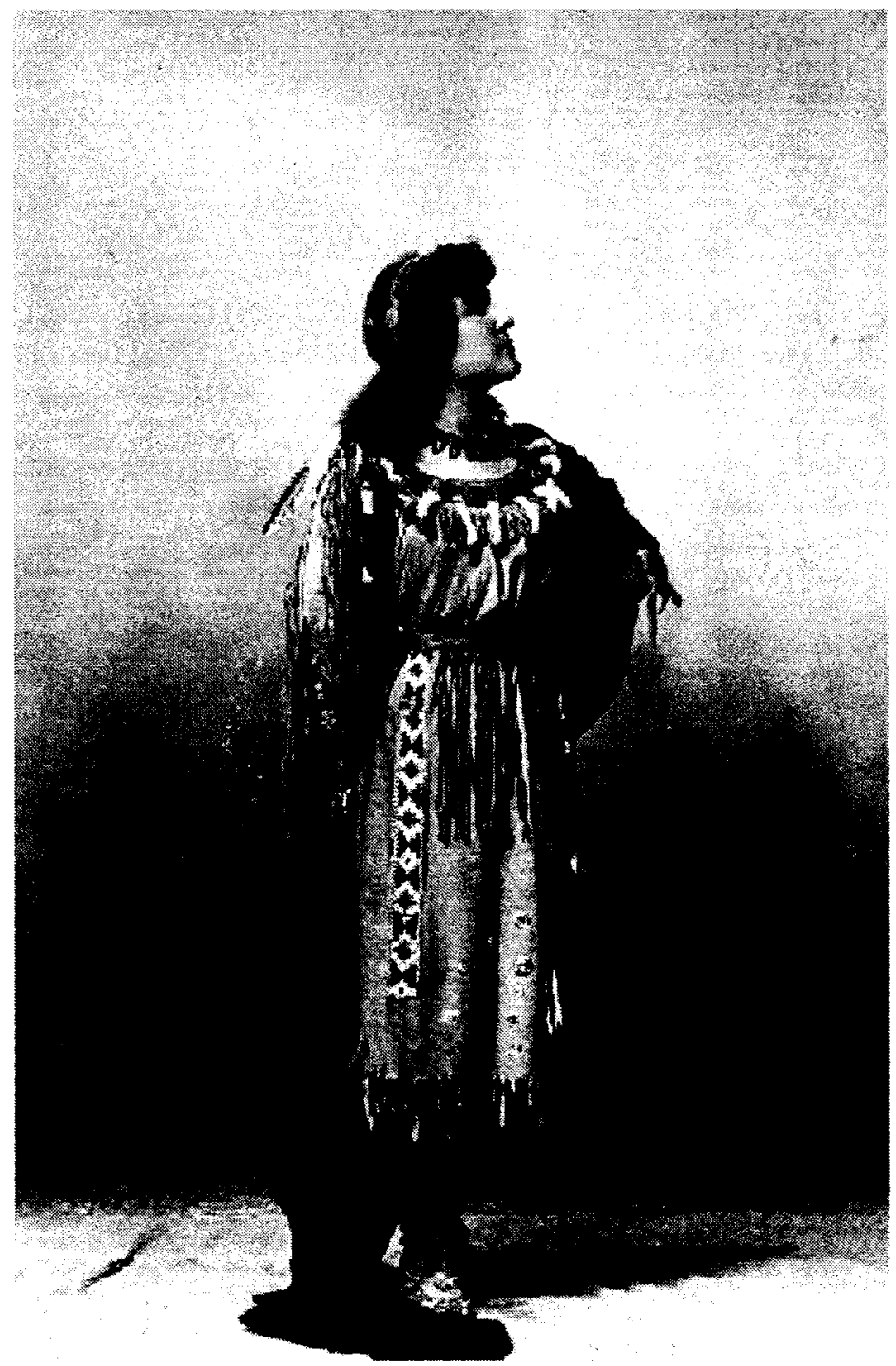


(Figure 8) Amelia Productions, 100 Aboriginal Women at DIA Vancouver, Video still, 1981; rpt. in Tagny Duff, "FFWD, RWD, and PLAY: Performance Art, Video, and Reflections on Second-Wave Feminism in Vancouver 1973-1983," in Caught in the Act: An Anthology of Performance art by Canadian Women, edited by Tanya Mars and Johanna Householder (Toronto: YYZ Books, 2004), 51.

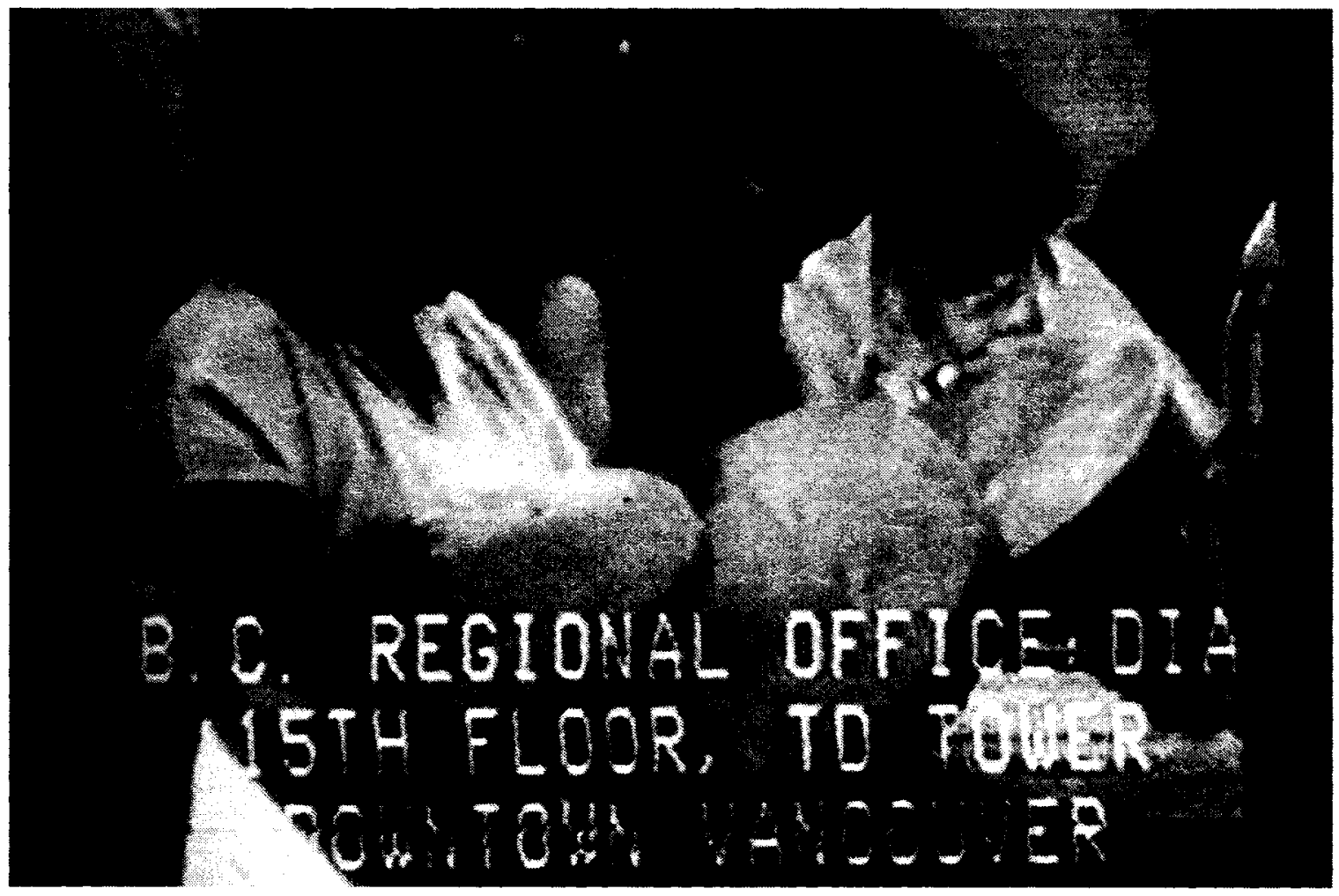


(Figure 9) Rebecca Belmore Fountain, video still, 2005. Cover of Catalogue, in Jann LM Bailey and Scott Watson, "Introduction," Rebecca Belmore: Fountain (Kamloops Art Gallery and The Morris and Helen Belkin Art Gallery) Canadian Pavilion, Venice Biennale, 2005.

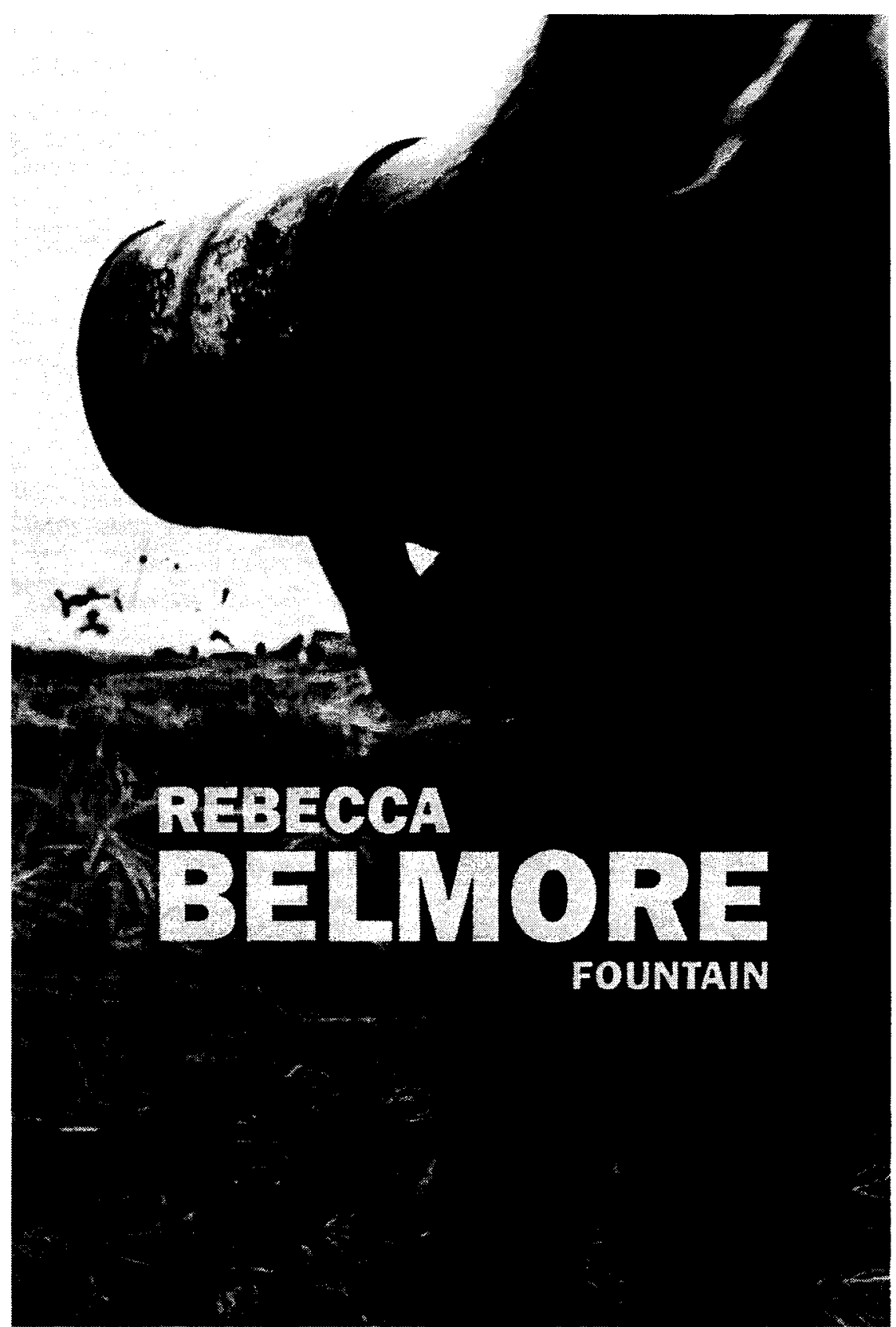


(Figure 10) "Rebecca Belmore's Fountain" Cover page in Canadian Art Magazine vol. 22 no. 2 (Summer 2005).

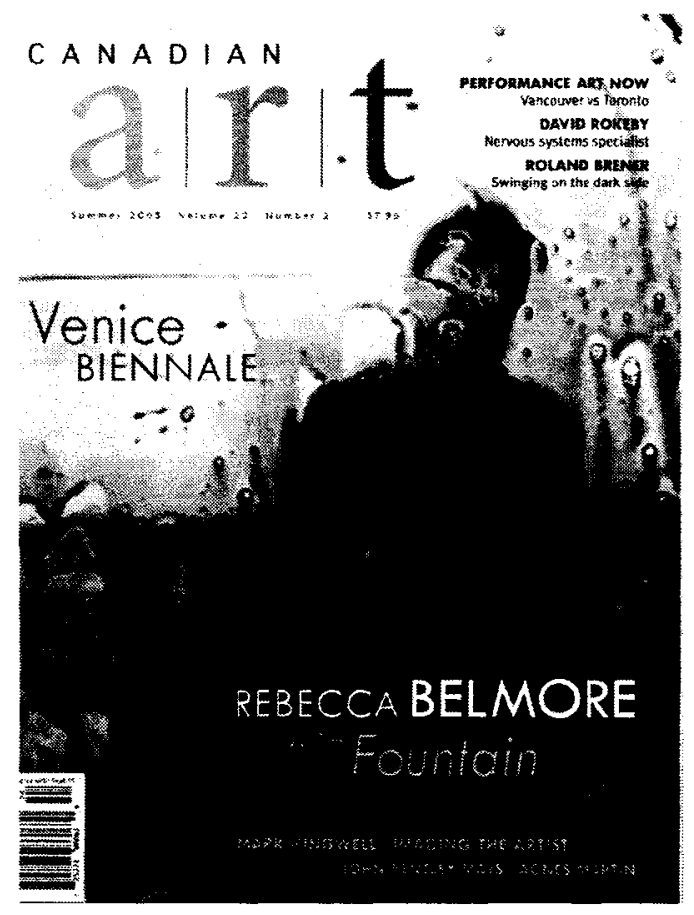

(Figure 11) "Lori Blondeau as Belle Sauvage" Cover page in Canadian Art Magazine vol. 21 no. 4 (Winter 2004).

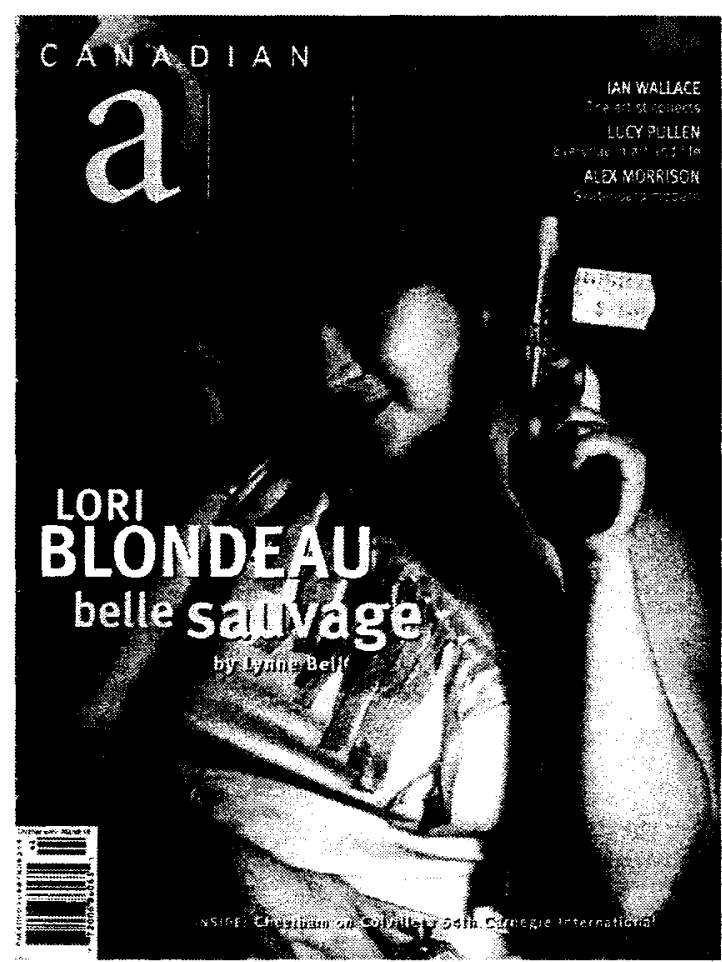


(Figure 12)Rebecca Belmore Exhibit 671b, Performance still, January 12 1988, Thunder Bay Art Gallery; rpt. in Charlotte Townsend-Gault, "Having Voices and Using Them: First Nations Artists and 'Native Art'," Arts Magazine vol. 65 (February 1991):65.

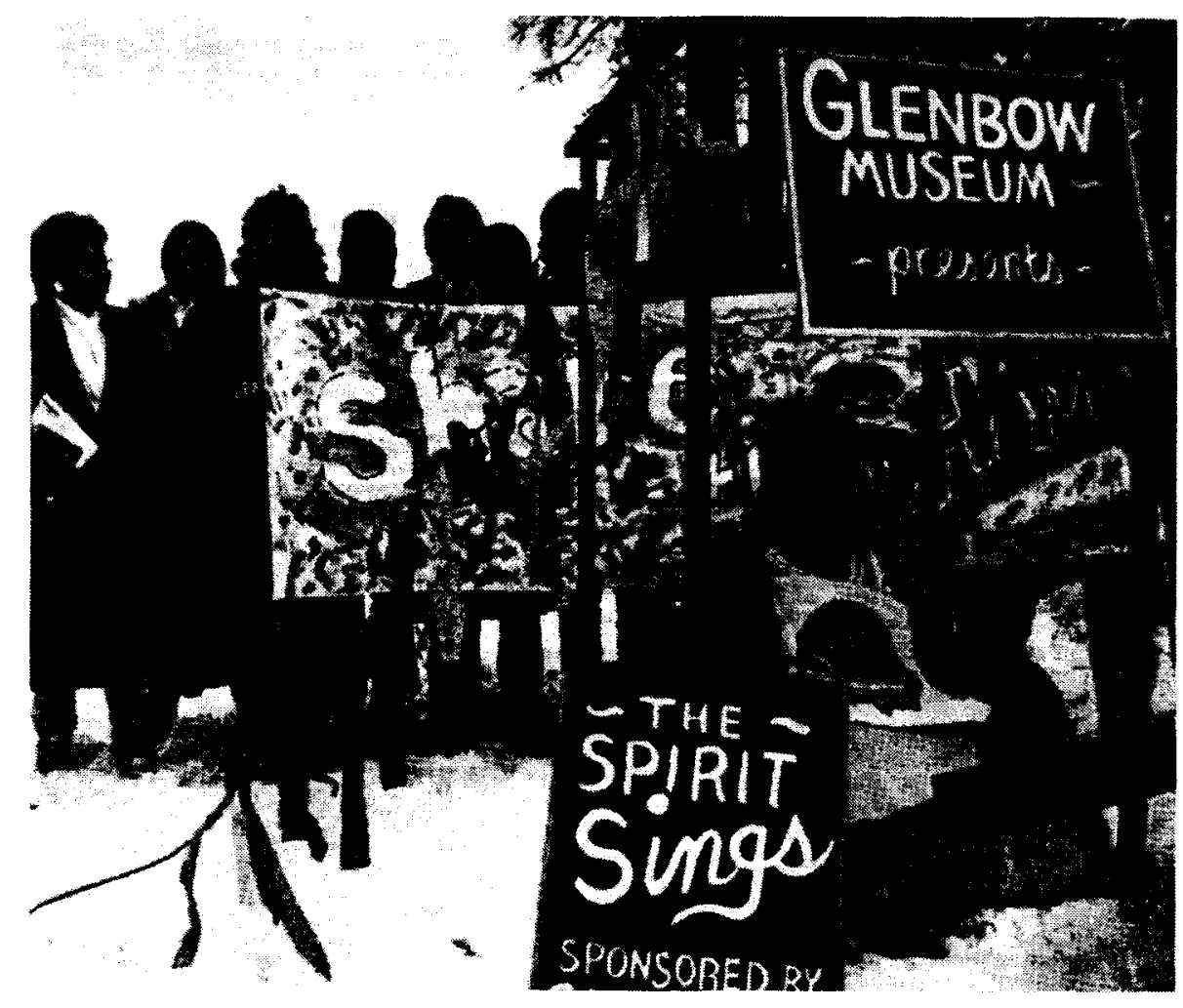


(Figure 13) James Luna, Emandatio, Performance still, Venice Biennale Performance, 2005; rpt. in http://www.artnet.com/magazine/reviews/walrobinson/robinson6-10-05.asp

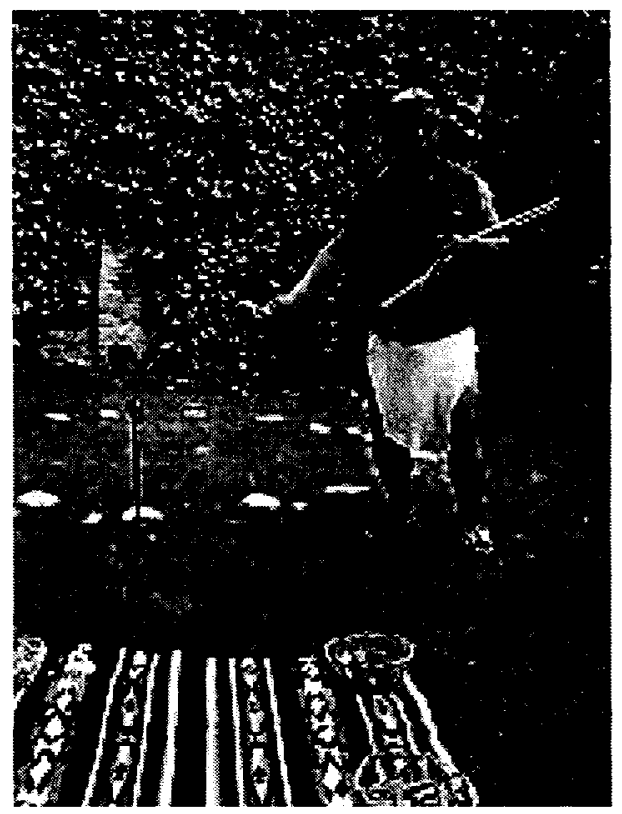

(Figure 14) Coco Fusco and Guillermo Gomez-Pena, Two Amerindians, Performance still, 1992; rpt. in Marvin Carlson, Performance: A Critical Introduction (London and New York: Routledge, 2004), 201.

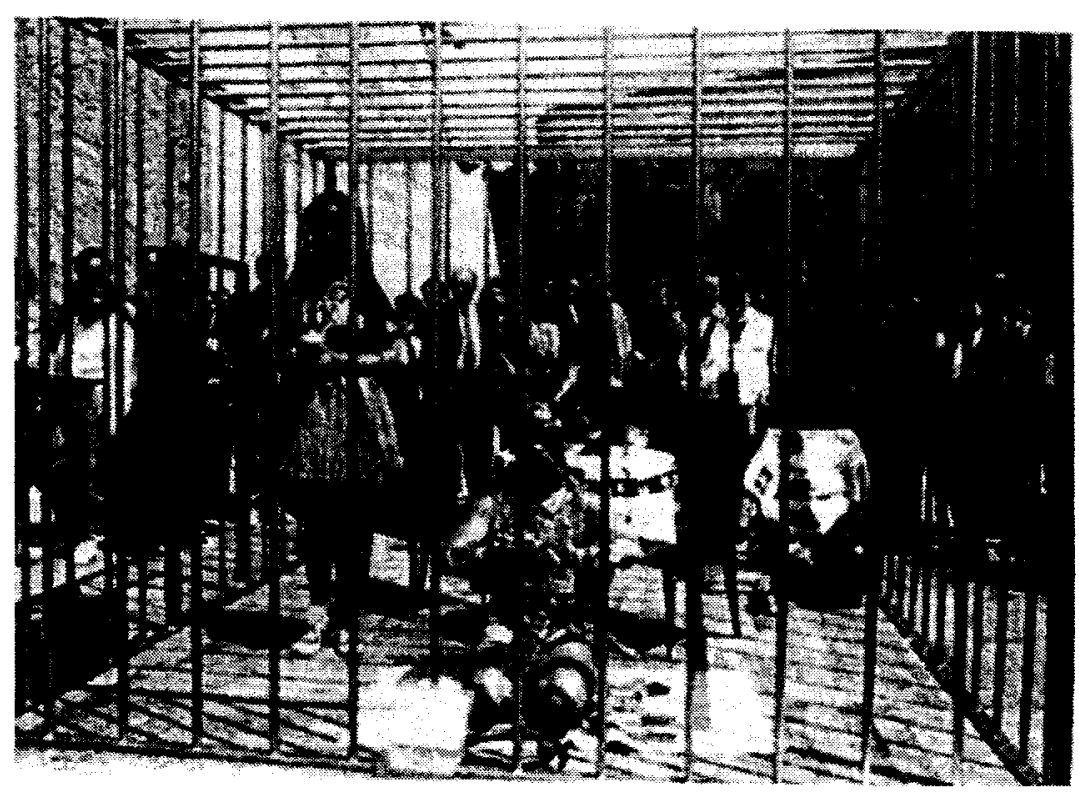


(Figure 15) James Luna, Shameman, Performance still, 2000; rpt. in www.collections.ic.gc.ca/artists/luna img.html

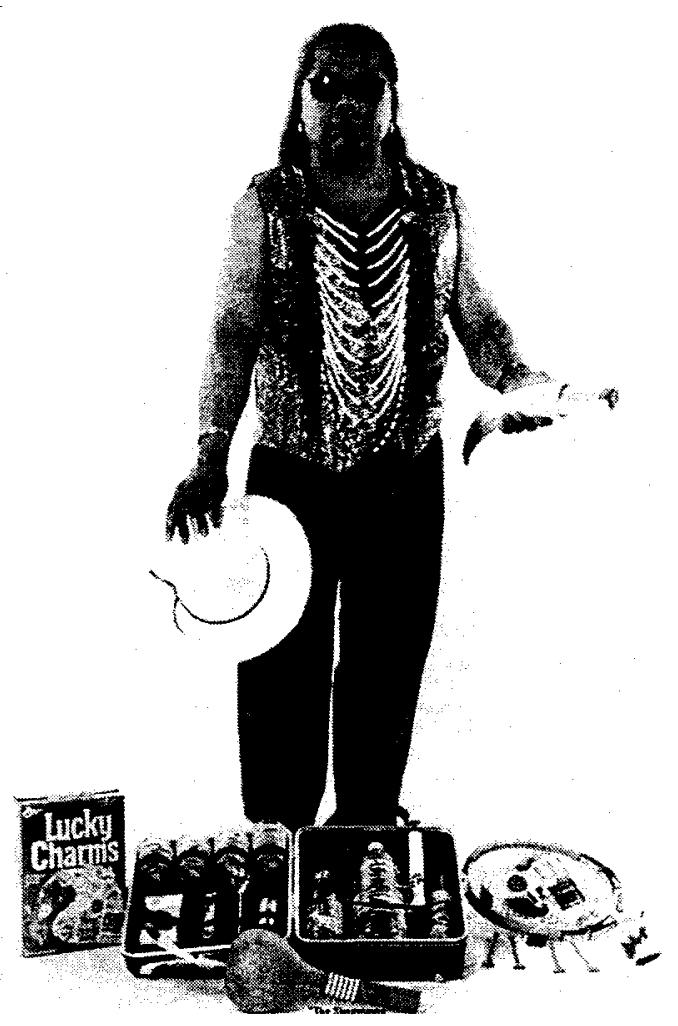


(Figure 16) Rebecca Belmore, Fountain, Performance still, 2005; rpt. in Bailey, Jann L.M., and Scott Watson. Rebecca Belmore: Fountain. [exhibition catalogue] Kamloops Art Gallery and The Morris and Helen Belkin Art Gallery, 2005. Canadian Pavilion, Venice Biennale.
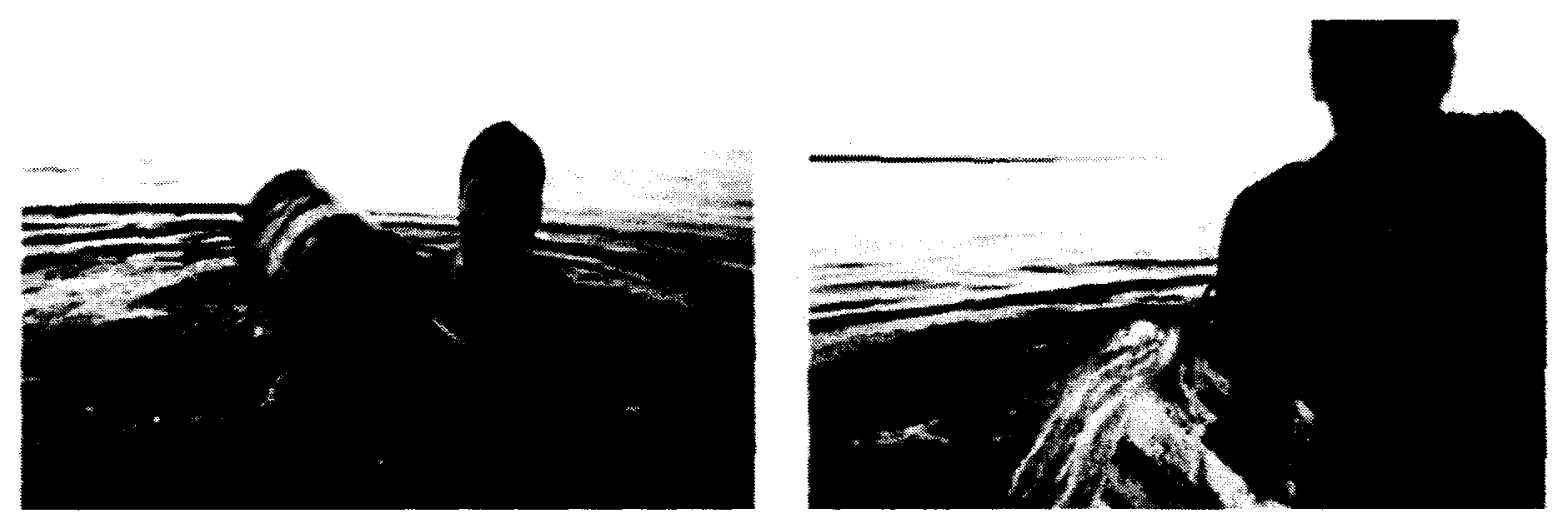

(Figure 17) Rebecca Belmore, Fountain. Performance still, 2005; rpt in Bailey, Jann L.M. and Scott Watson. Rebecca Belmore: Fountain. [exhibition catalogue] Kamloops Art Gallery and The Morris and Helen Belkin Art Gallery, 2005. Canadian Pavilion, Venice Biennale.
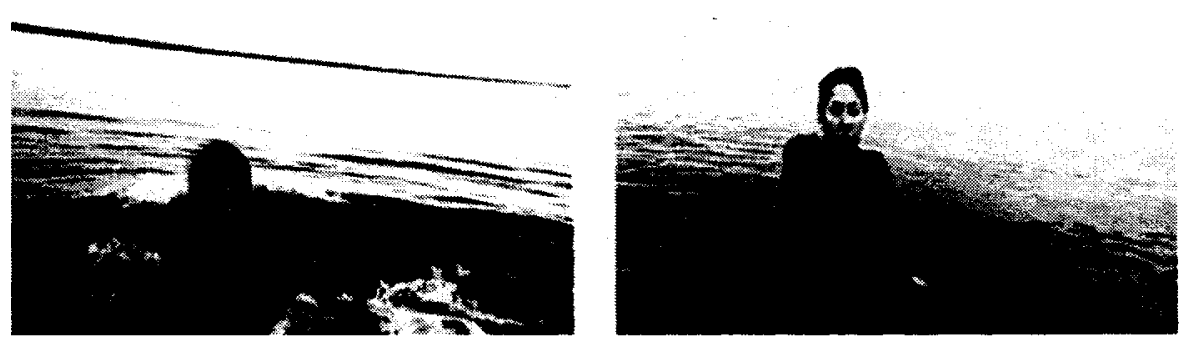
(Figure 18) Rebecca Belmore, Fountain. Performance still, 2005; rpt. in Bailey, Jann L.M., and Scott Watson. Rebecca Belmore: Fountain. [exhibition catalogue] Kamloops Art Gallery and The Morris and Helen Belkin Art Gallery, 2005. Canadian Pavilion, Venice Biennale.
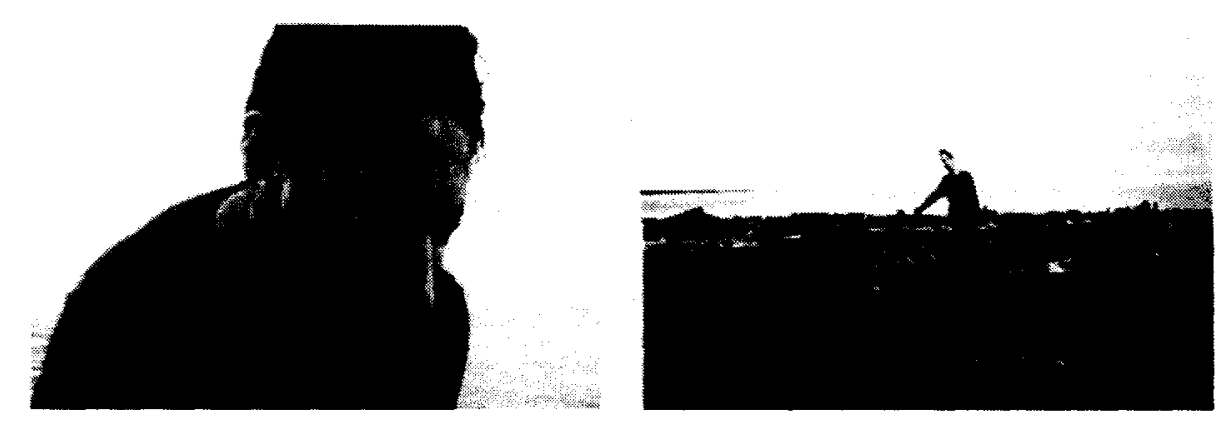

(Figure 19) Rebecca Belmore, Fountain. Performance still, 2005; rpt. in Bailey, Jann L.M., and Scott Watson. Rebecca Belmore: Fountain. [exhibition catalogue] Kamloops Art Gallery and The Morris and Helen Belkin Art Gallery, 2005. Canadian Pavilion, Venice Biennale.
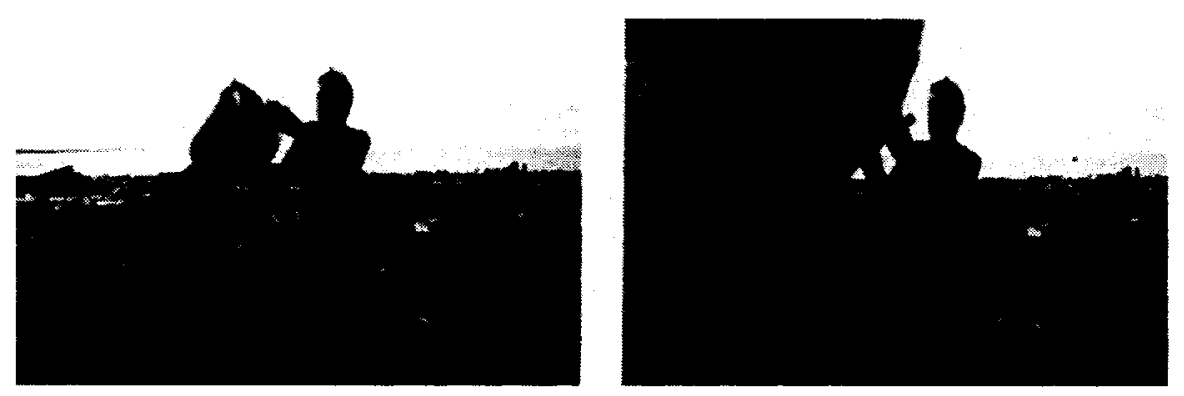

(Figure 20) Rebecca Belmore, Fountain. Performance still, 2005; rpt. in Bailey, Jann L.M., and Scott Watson. Rebecca Belmore: Fountain. [exhibition catalogue] Kamloops Art Gallery and The Morris and Helen Belkin Art Gallery, 2005. Canadian Pavilion, Venice Biennale.
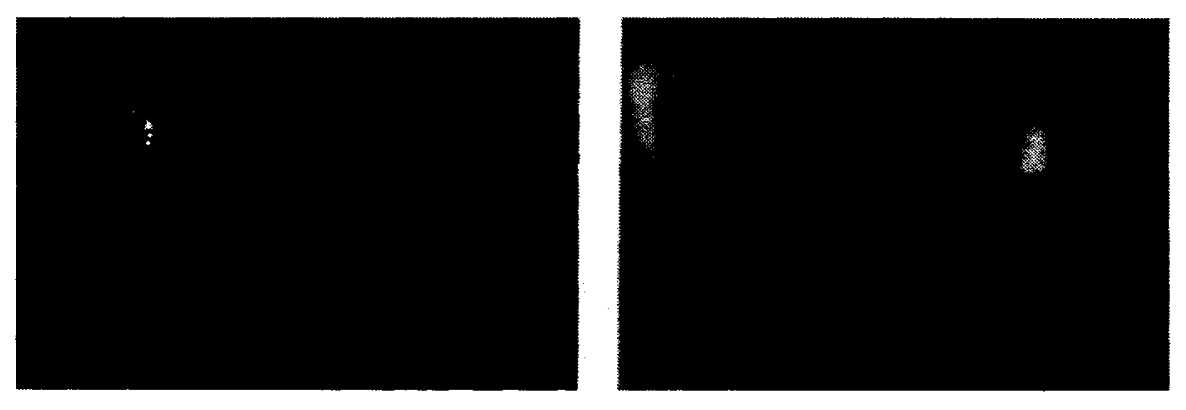
(Figure 21) Rebecca Belmore, Ayumee-aawach Oomama-mowan: Speaking to Their Mother, Performance still, 1991; rpt. in Lee-Ann Martin, "The Waters of Venice:

Rebecca Belmore at the 51 ${ }^{\text {st }}$ Biennale," Canadian Art vol. 22 no. 2 (Summer 2005): 53.

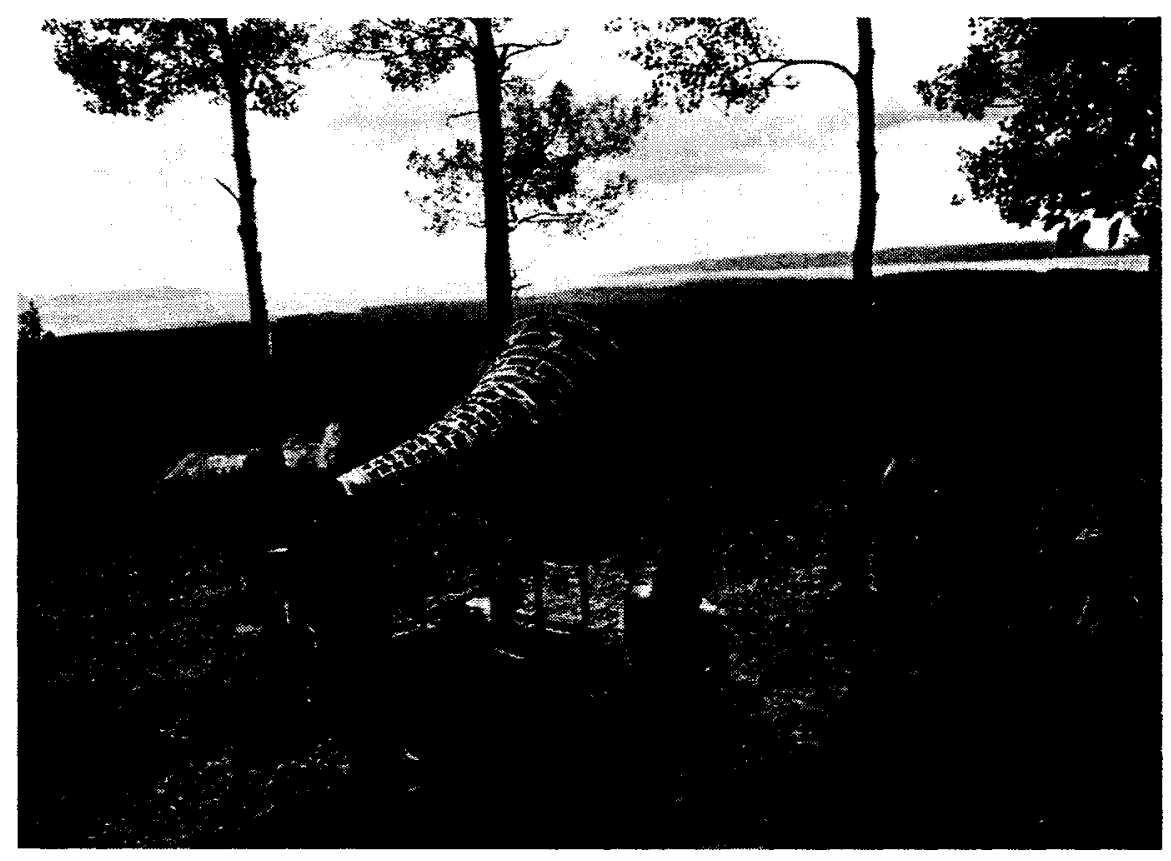

(Figure 22) Rebecca Belmore, Mawa-che-hitoowin: A Gathering of People for Any Purpose, installation, mixed media, 1992; rpt. in Janet Berlo and Ruth Phillips, Native North American Art (Oxford: Oxford University Press, 1998), 237.

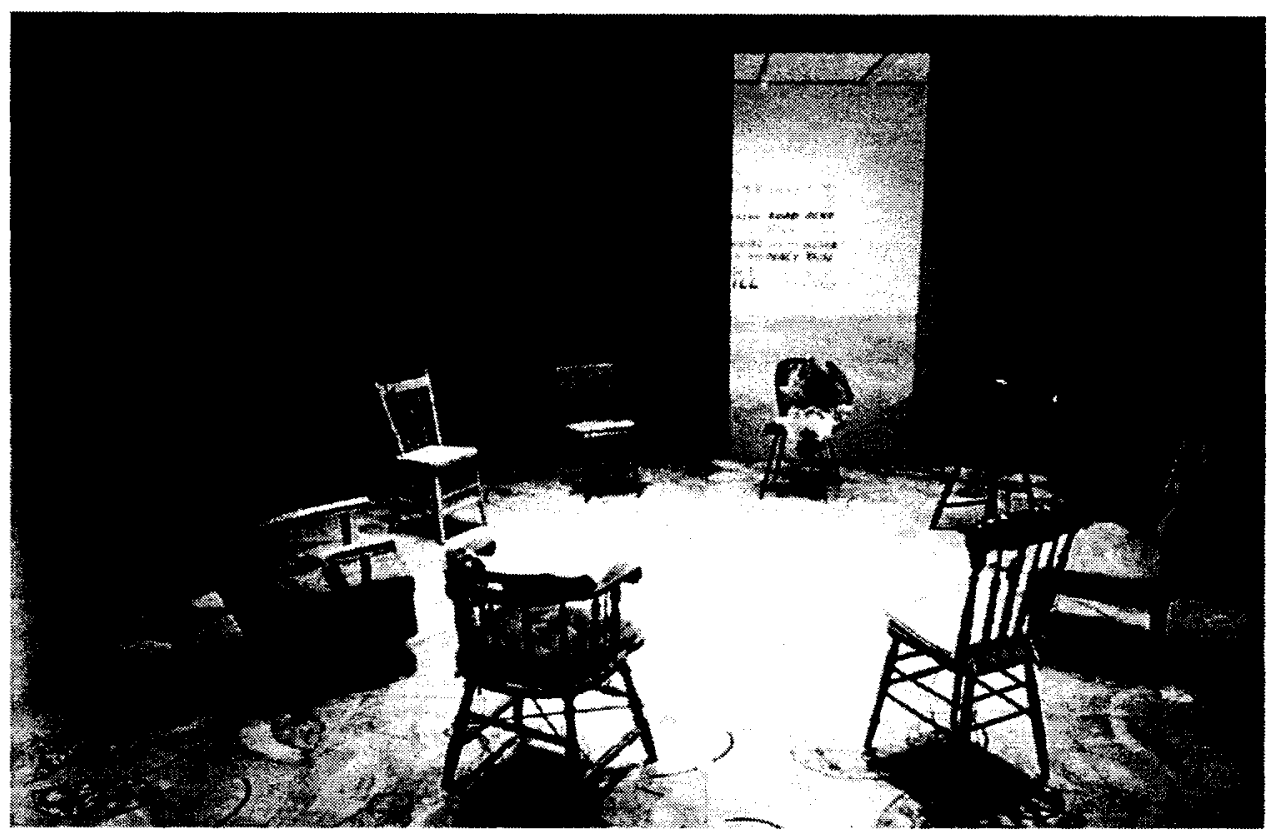


(Figure 23) Rebecca Belmore, Named and UnNamed: Vigil Performance, performance still; in Charlotte Townsend-Gault, The Named and the UnNamed [exhibition catalogue] (Vancouver: Morris and Helen Belkin Art Gallery, 2002), 20.

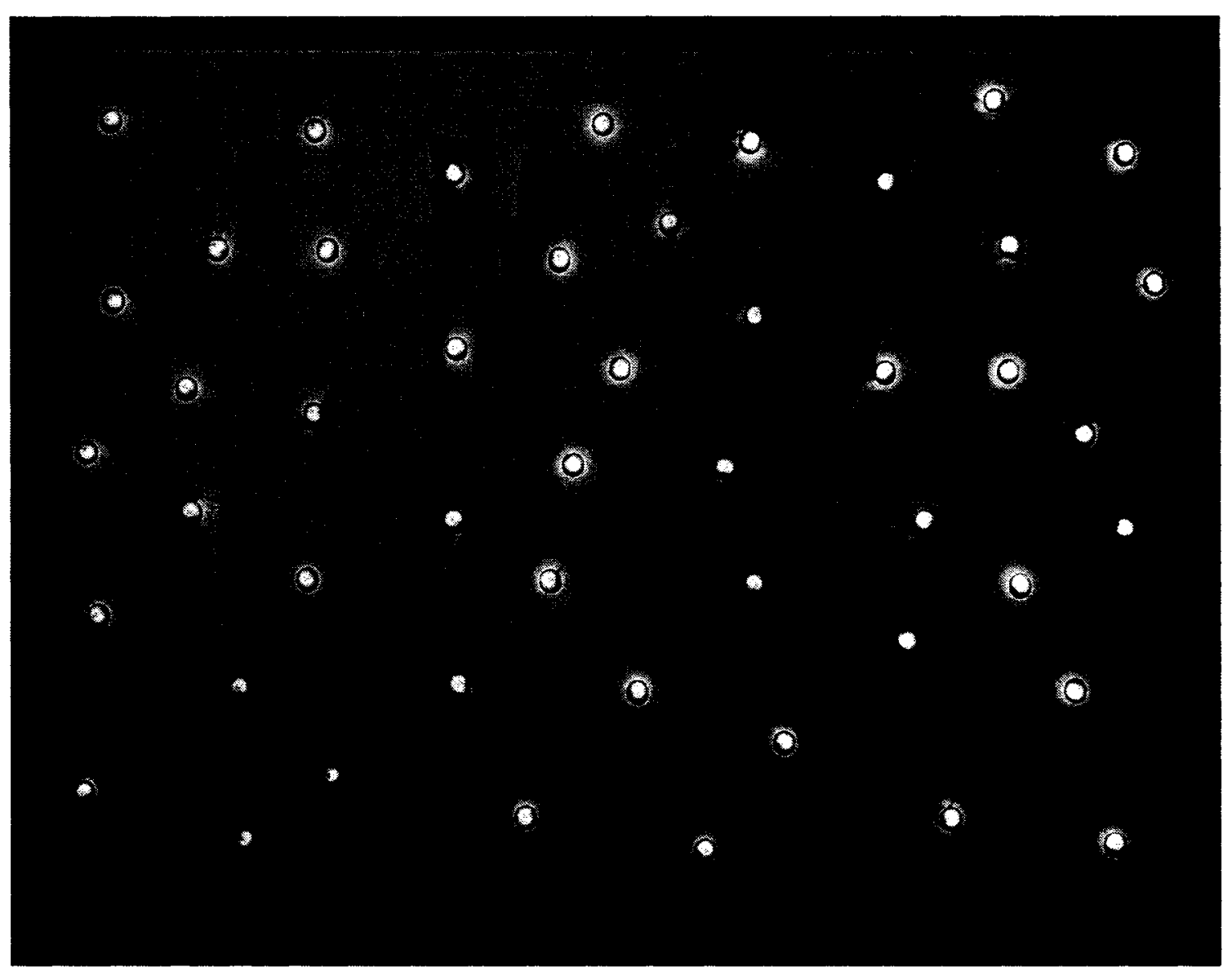


(Figure 24) Lori Blondeau, SurferSquaw Catch, Photograph, 1996; in http://www.mawa.ca/archives/postcards/lorib/lb5.html

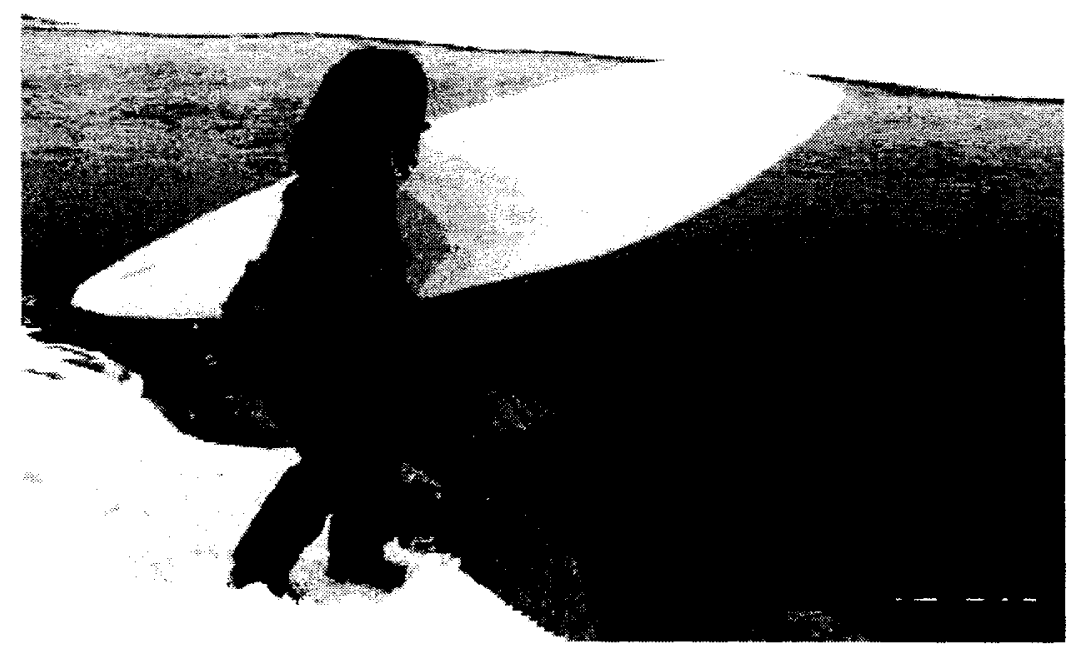

(Figure-25) Lori Blondeau, Surfer Squaw Surf-Up, Photograph, 1996; in http://www.mawa.ca/archives/postcards/lorib/lb5.html

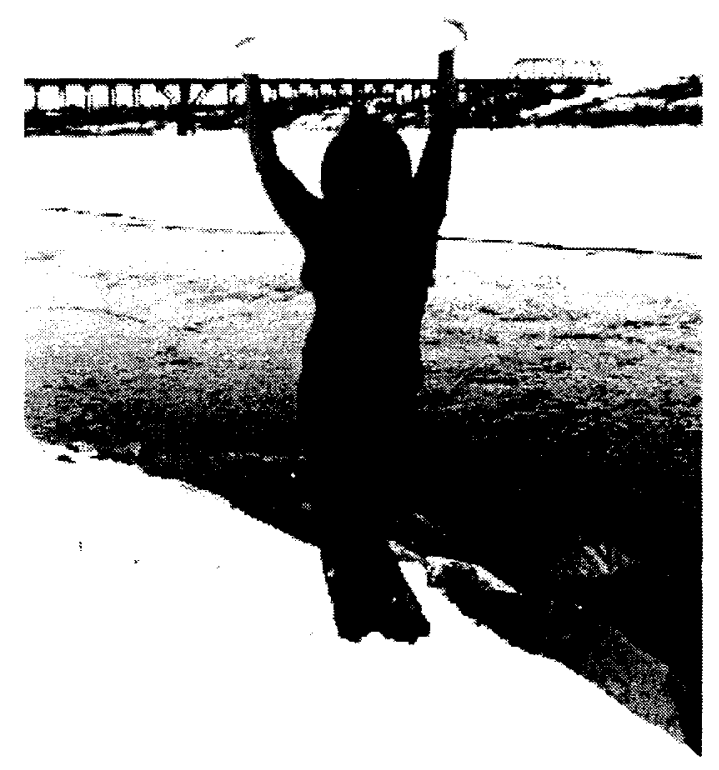


(Figure 26) Lori Blondeau, Surfer Squaw Grease, Photograph, 1996; in http://www.mawa.ca/archives/postcards/lorib/lb5.html

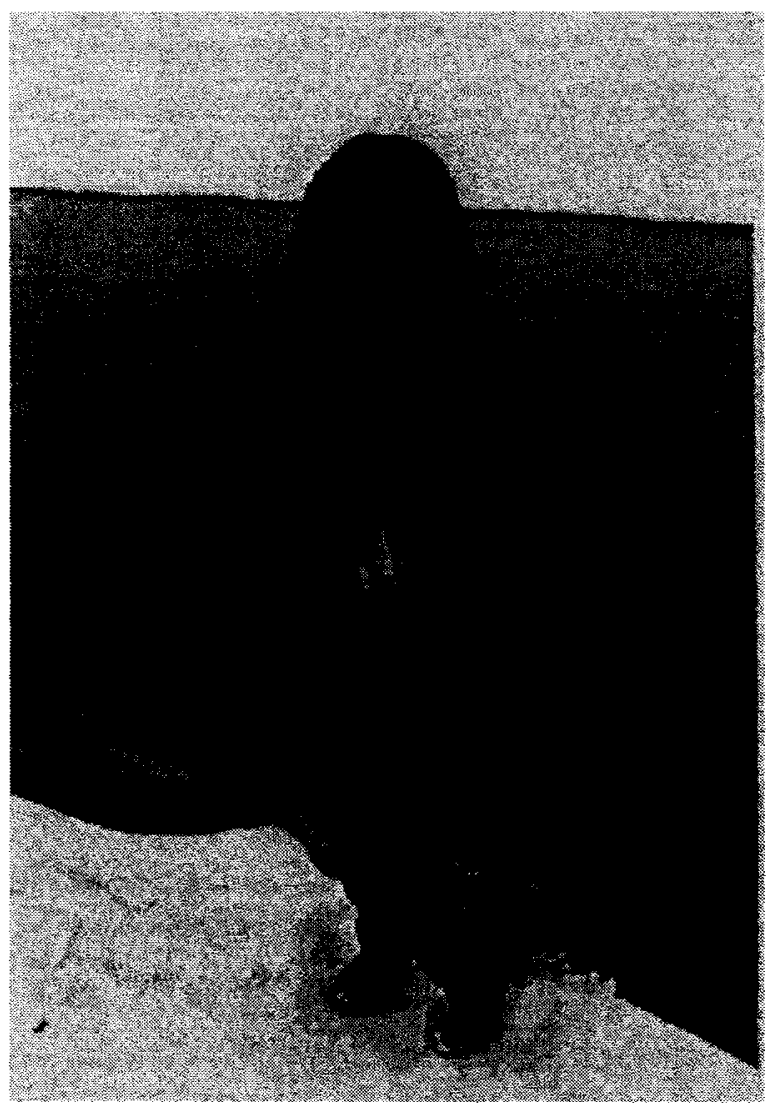


(Figure 27) Lori Blondeau and $7^{\text {th }}$ Generation of Image Makers, Streetwise Poster Campaign, Poster Reproduction, 2004; in

http://www.photobasedart.ca/html/publications/essays/ESY0406.html

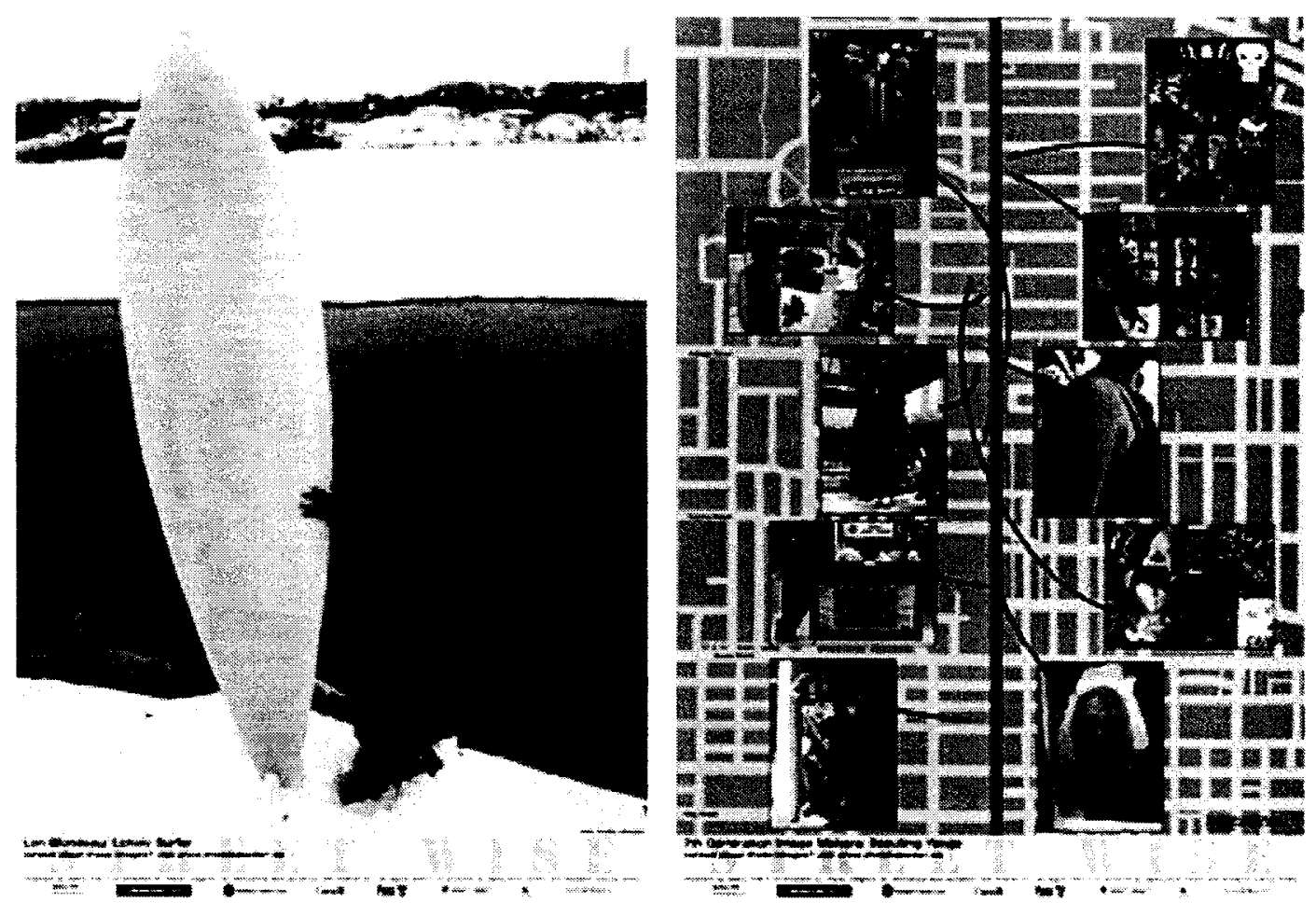

(Figure 28) Lori Blondeau and $7^{\text {th }}$ Generation of Image Makers, Streetwise Poster Campaign, Toronto part of Planet Indigenous Festival, 2004. http://www.photobasedart.ca/html/publications/essays/ESY0406.html

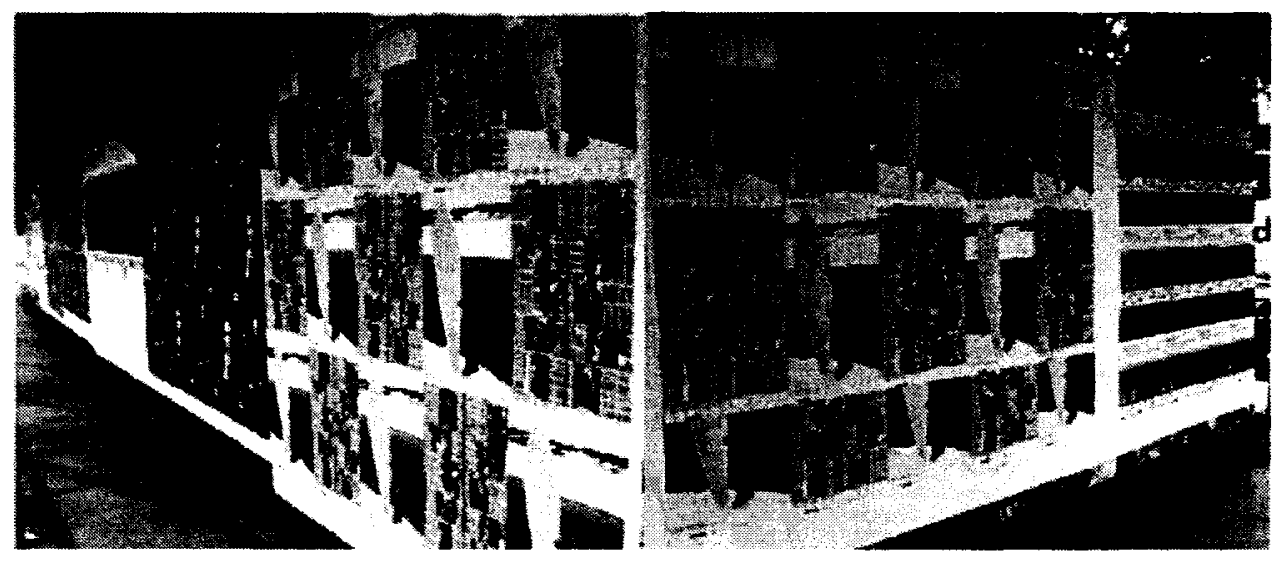


(Figure 29) Thomas Moore, before and after his entrance into the Regina Indian Residential School in Saskatchewan, photograph, 1874; Library and Archives Canada NL-022474
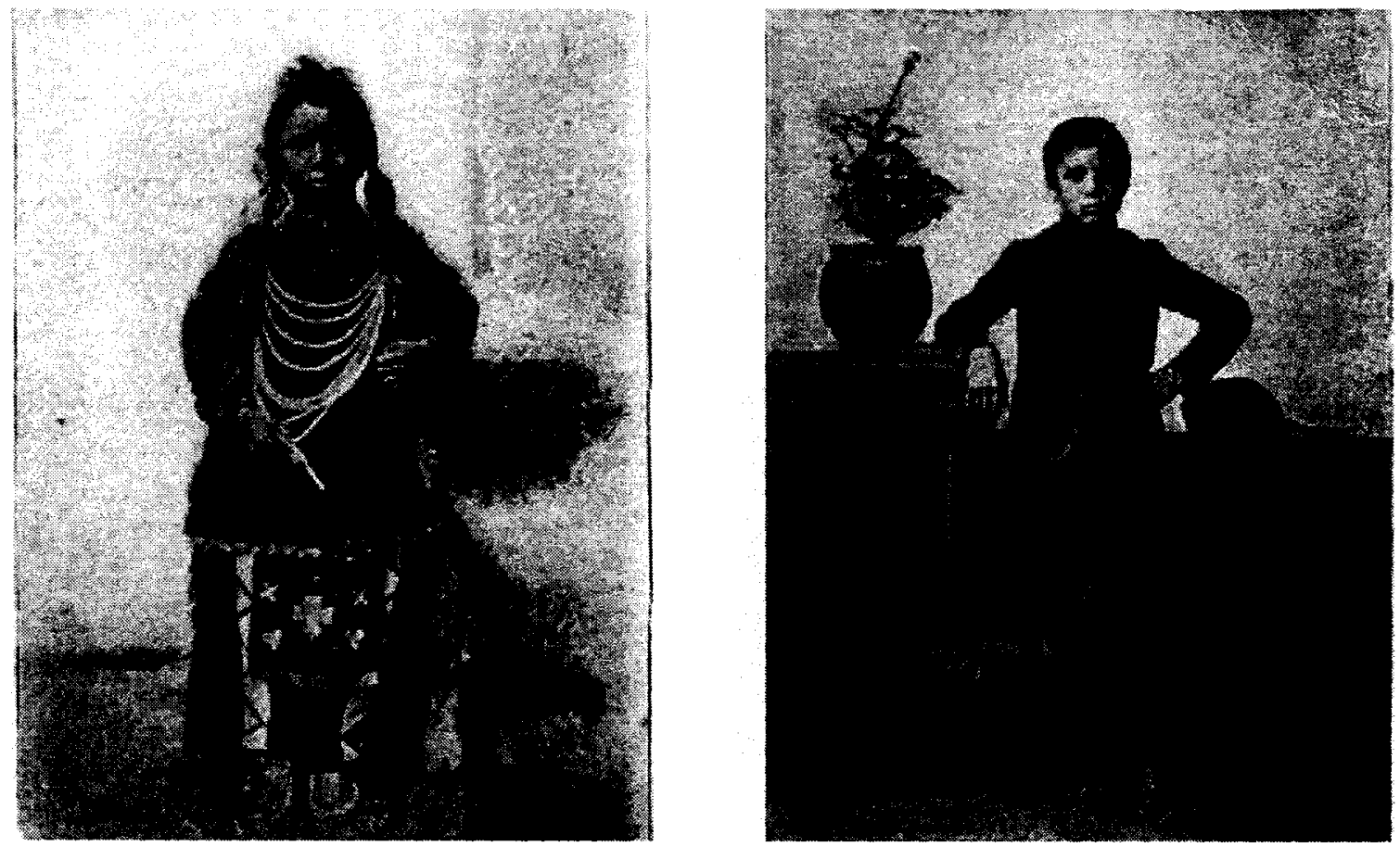
(Figure 30) Lori Blondeau, Sisters, Performance still, 26 September, 2002.

America Remixed Exhibition, Milan Italy; in City of Milan Archive La Fabbrica del

Vapora www.fabbricadelvapore.org/it/foto.show.php2?k=75

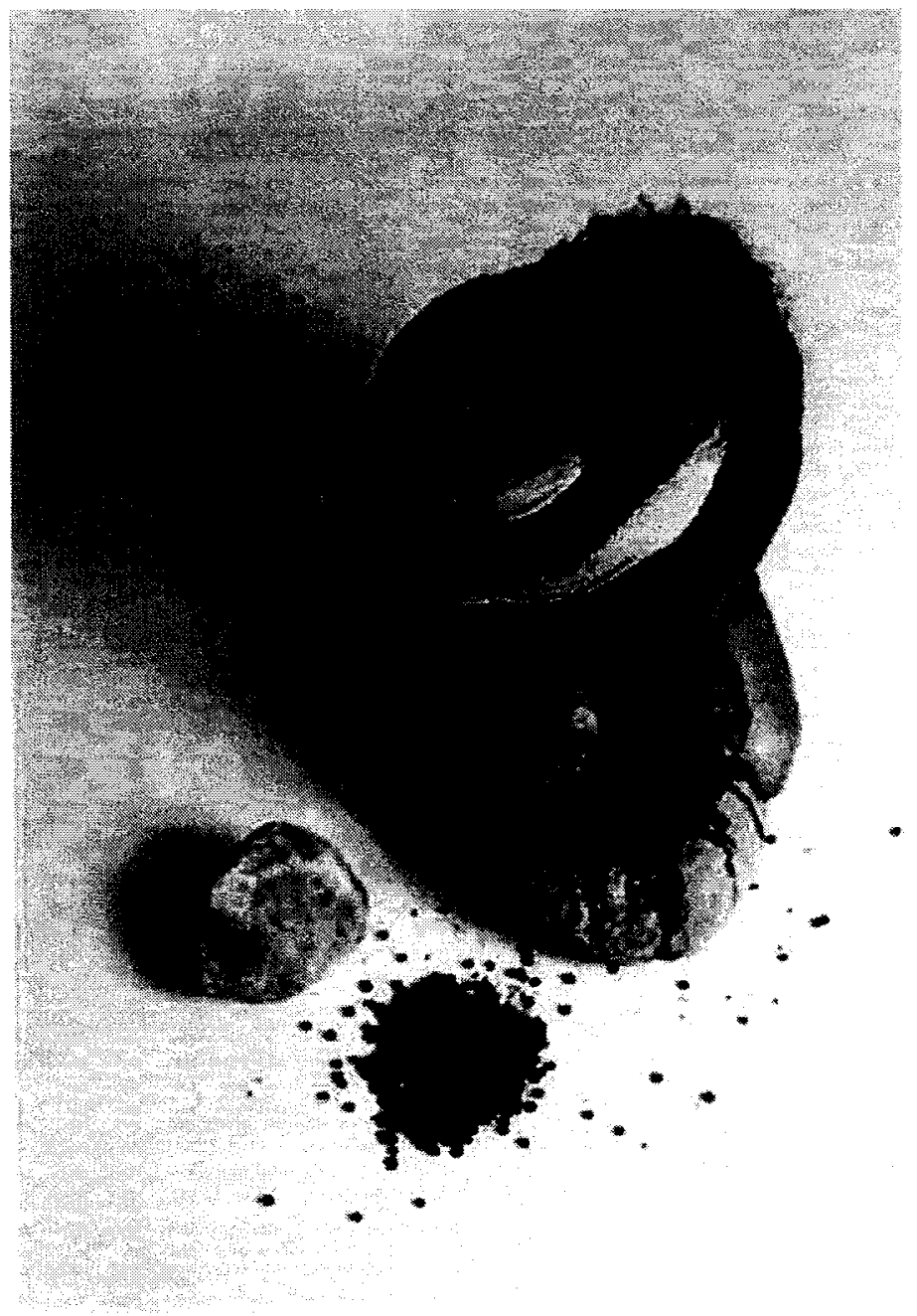


(Figure 31) Lori Blondeau, Sisters. Performance still, 2002; in Gordon Shelgrove Gallery Archive, University of Saskatchewan:

http://www.usask.ca/snelgrove/mfa/02 LB/08.html

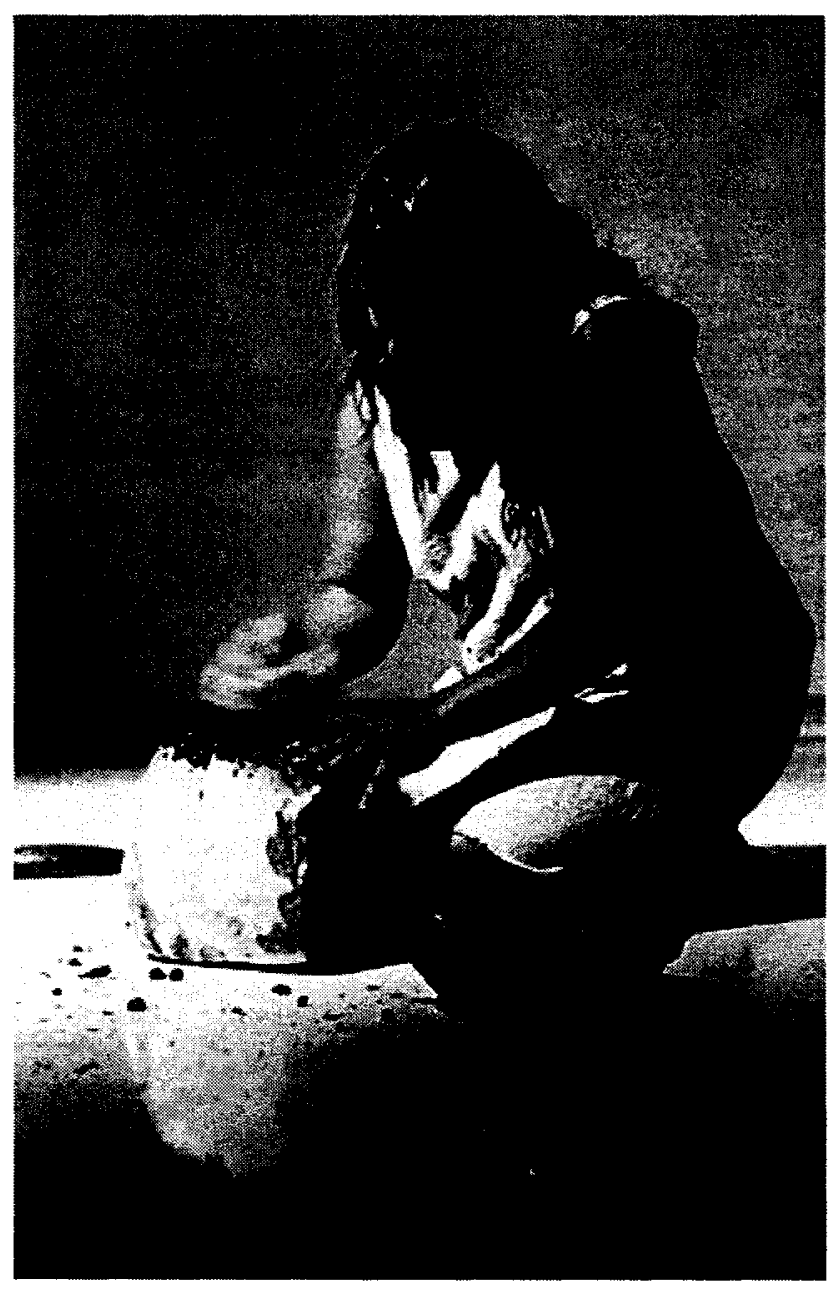


(Figure 32) Lori Blondeau, Sisters. Performance still, 2002; in Gordon Shelgrove Gallery Archive, University of Saskatchewan:

http://www.usask.ca/snelgrove/mfa/02_LB/08.htm1

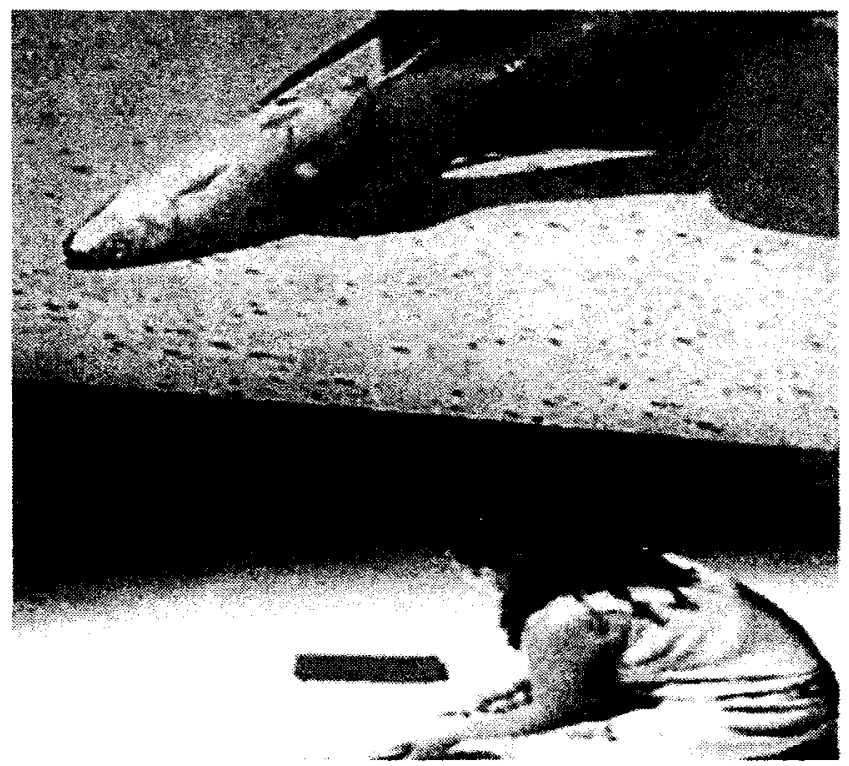


(Figure 33) Lori Blondeau, Sisters, Performance still, 2002; in Gordon Shelgrove Gallery Archive, University of Saskatchewan:

http://www.usask.ca/snelgrove/mfa/02 LB/08.html

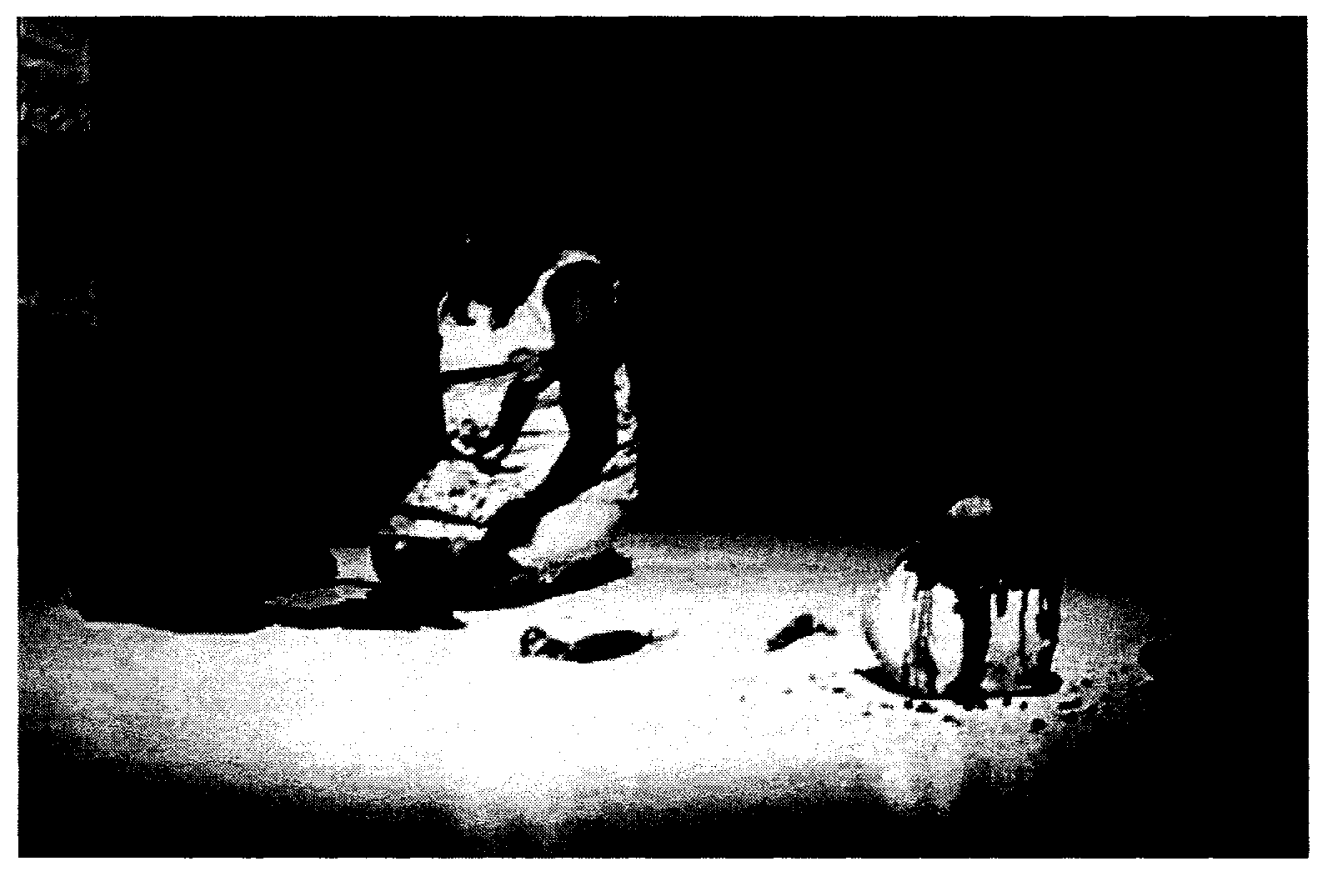

(Figure 34) Lori Blondeau, Materials used in Sisters, Digital photograph, March 22, 2002 at Gallery One One One: Wintercount walkabout Winnipeg; in Gallery One One One Exhibition Archive: http://www.umanitoba.ca/schools/art/galleryoneoneone/winter.html

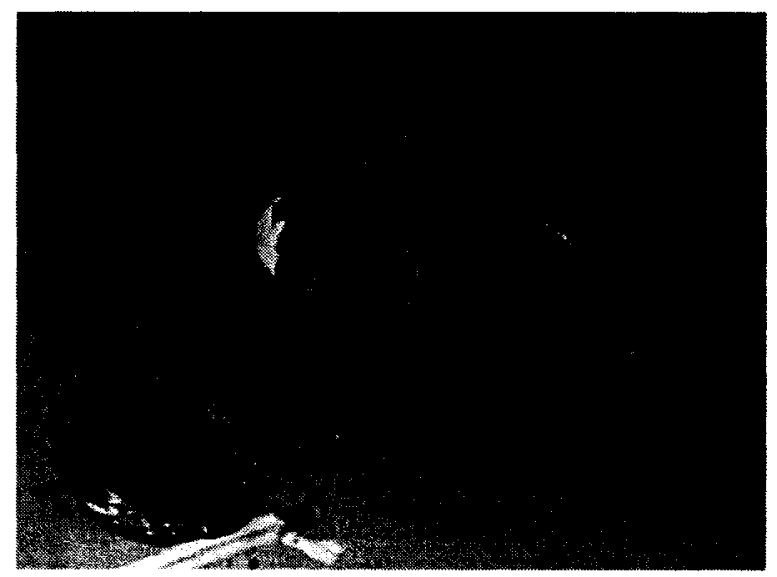


(Figure 35) Lori Blondeau, Sisters, Performance still, November 29, 2002. Grunt Gallery, Vancouver: First Nations Performance Archive. www.grunt.bc.ca/fnp/ or www.grunt.bc.ca/IndianAct/

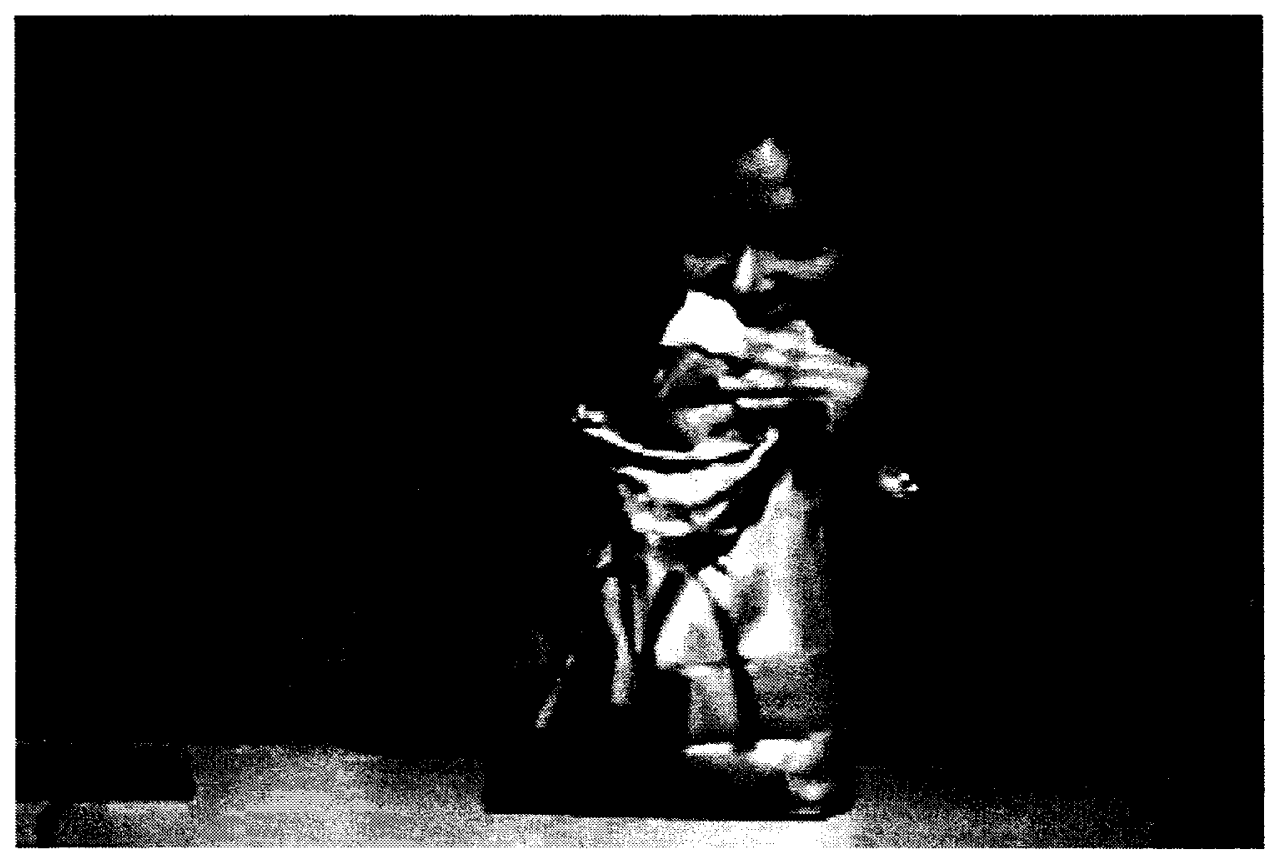

(Figure 36) Lori Blondeau, Sisters, Performance still, November 29, 2002.Grunt Gallery, Vancouver: First Nations Performance Archive. www.grunt.bc.ca/fnp/ or www.grunt.bc.ca/IndianAct//

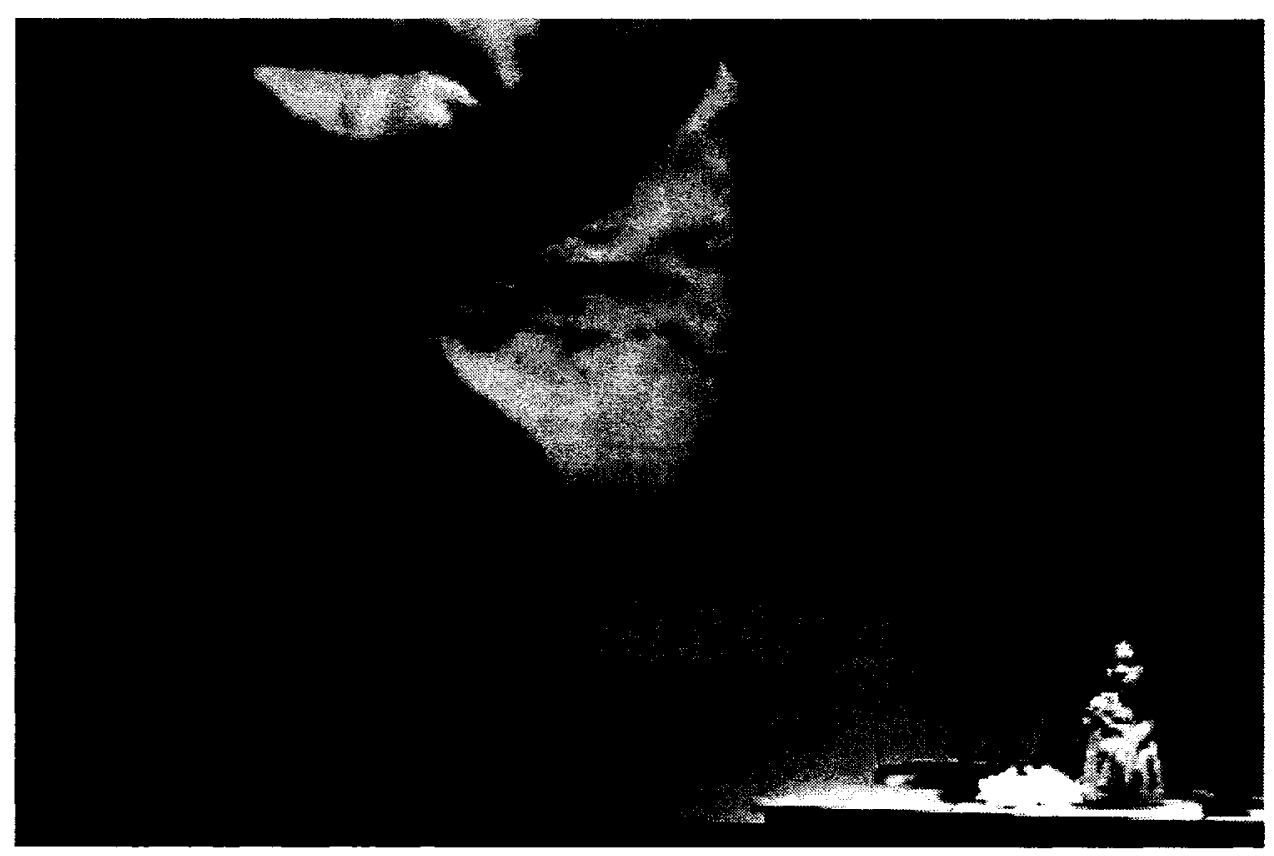


(Figure 37) Lori Blondeau, Sisters, Performance sill, November 29, 2002. Grunt Gallery, Vancouver: First Nations Performance Archive. www.grunt.bc.ca/fnp $/$ or www.grunt.bc.ca/IndianAct/

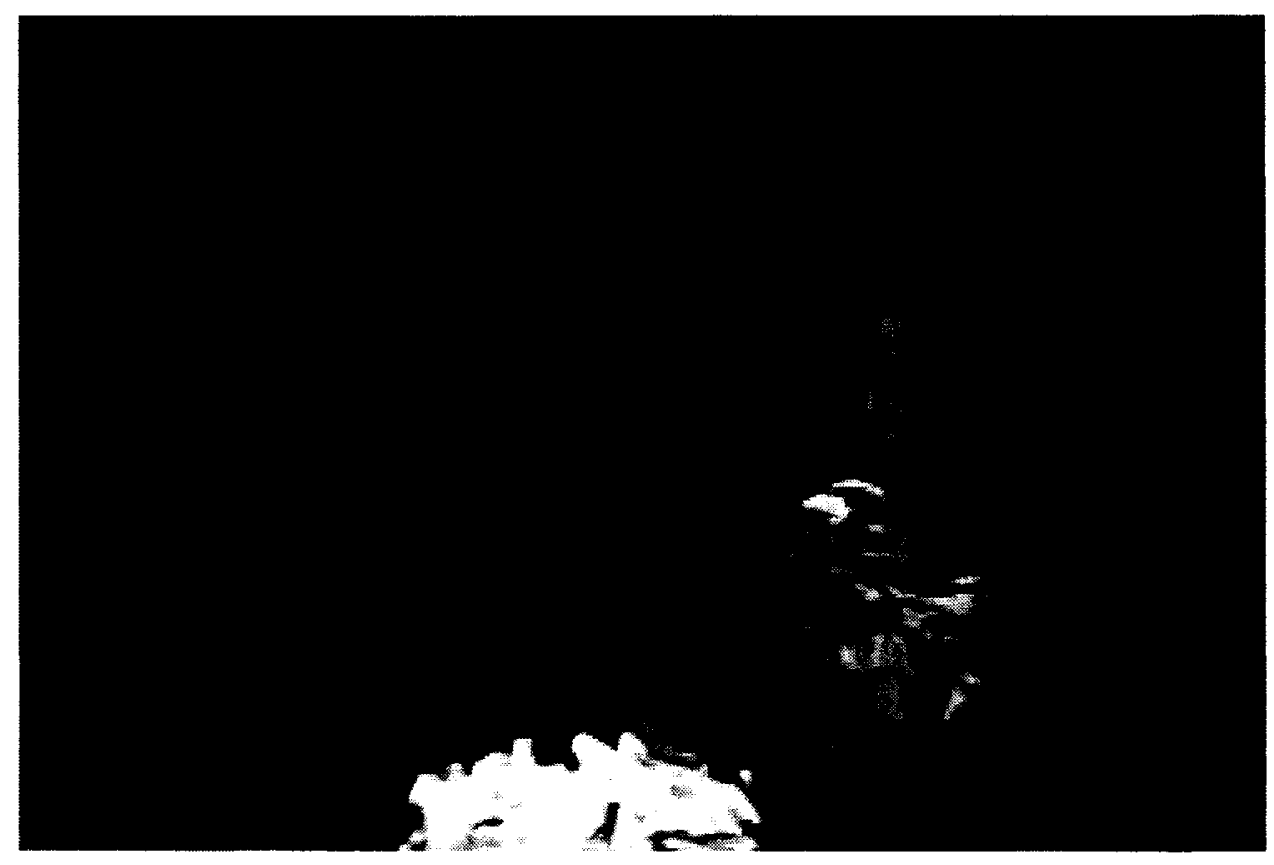

(Figure 38) Lori Blondeau, Sisters, Performance sill, November 29, 2002. Grunt Gallery, Vancouver: First Nations Performance Archive. www.grunt.bc.ca/fnp/ or www.grunt.bc.ca/IndianAct

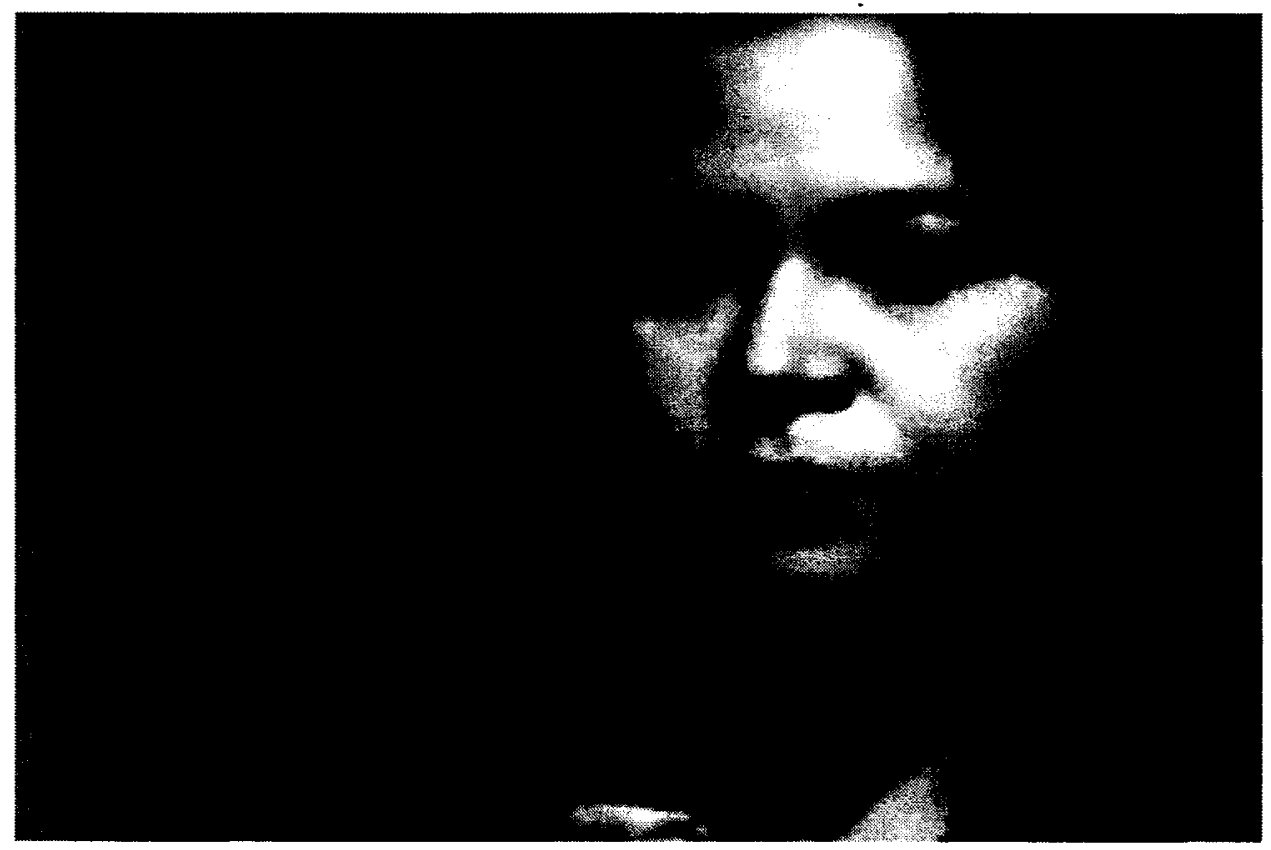


(Figure 39) Lori Blondeau, Sisters, Performance sill, November 29, 2002. Grunt Gallery,Vancouver: First Nations Performance Archive. www.grunt.bc.ca/fnp/ or www.grunt.bc.ca/IndianAct/

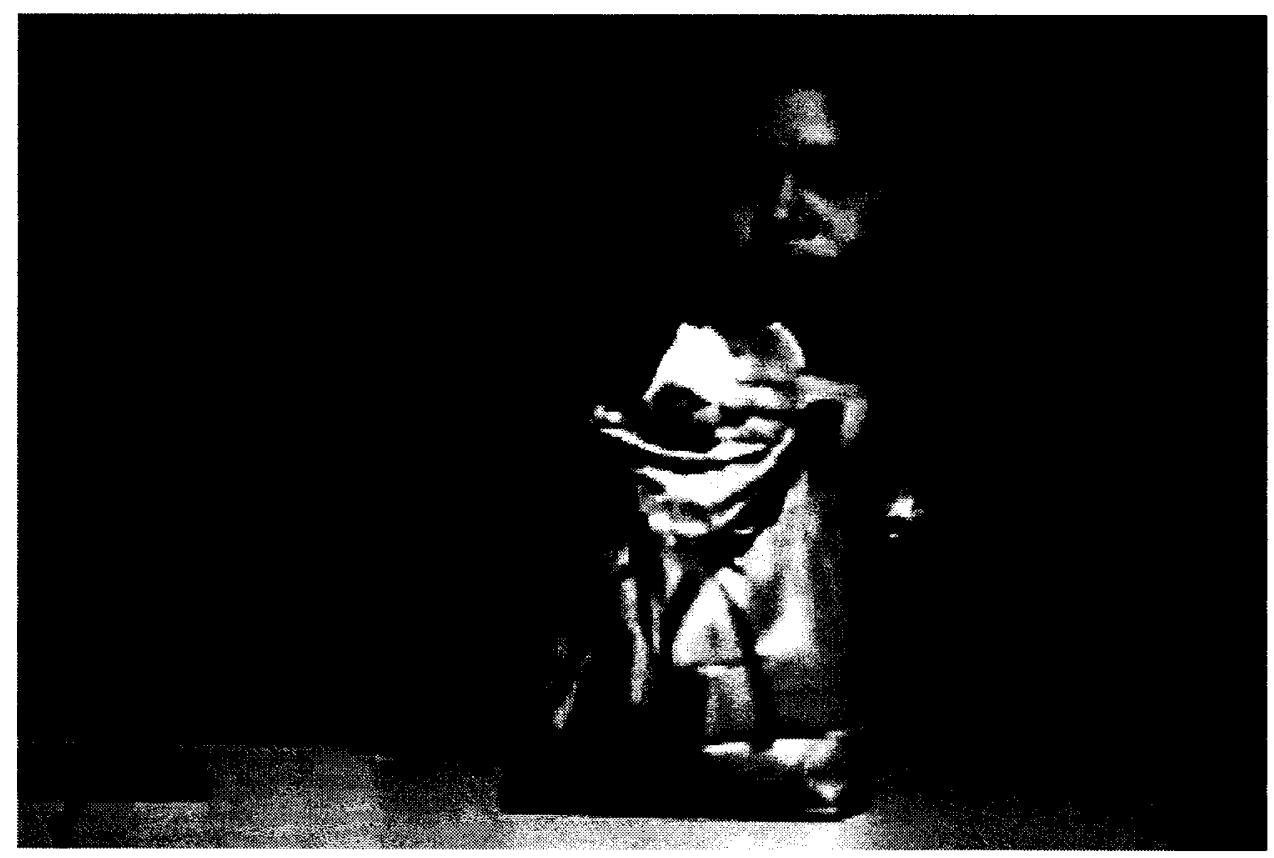


(Figure 40) Nanoochee, colour print; rpt. in Gail Guthrie Valaskakis, Indian Princesses and Cowgirls: Stereotypes from the Frontier (Montreal: Oboro, 1992), 13.

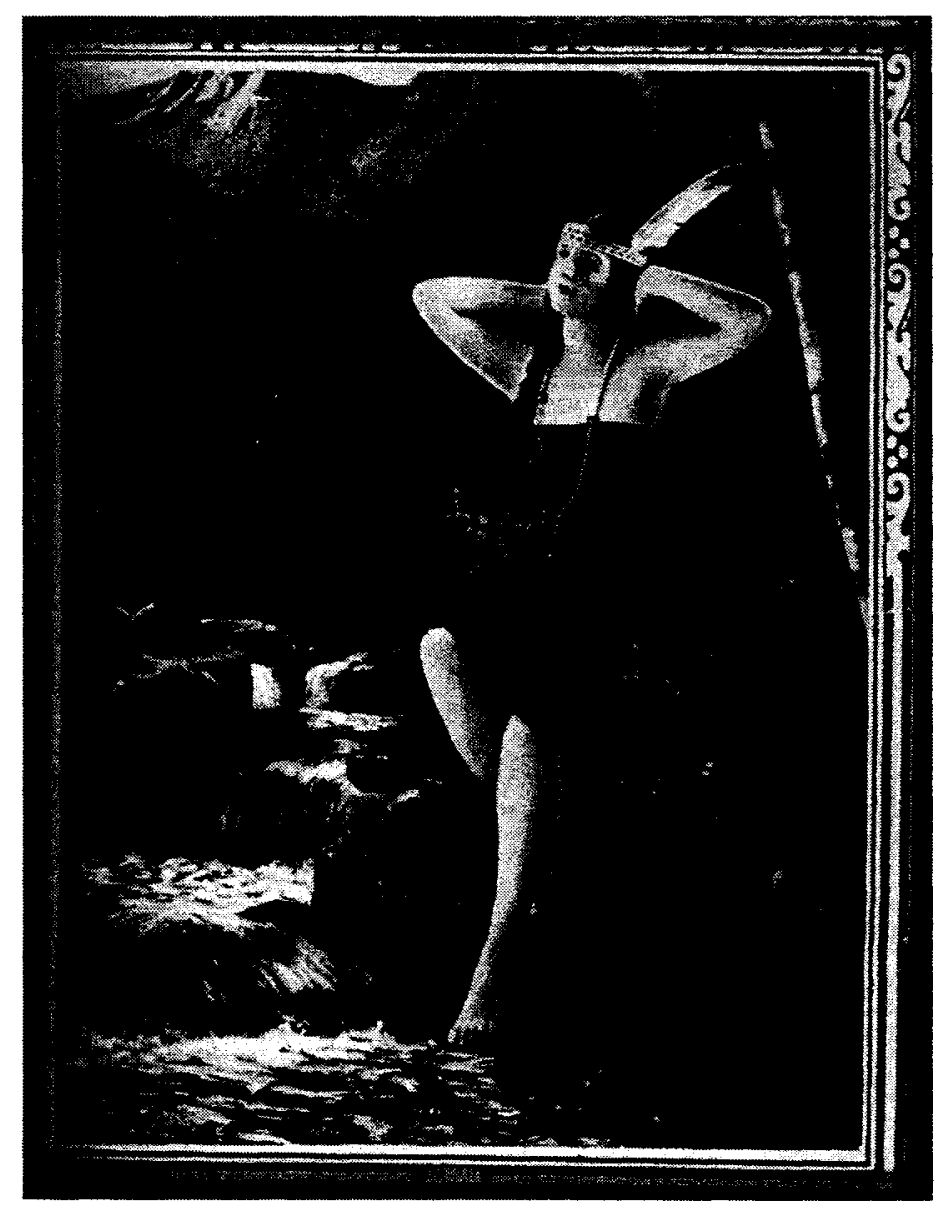

(Figure 41) Daughters of the Incas, Printed by Bwon and Bigelow, St. Paul, Minnesota, 1929; rpt. in Gail Guthrie Valaskakis, Indian Princesses and Cowgirls:

Stereotypes from the Frontier (Montreal: Oboro,1992), 24.

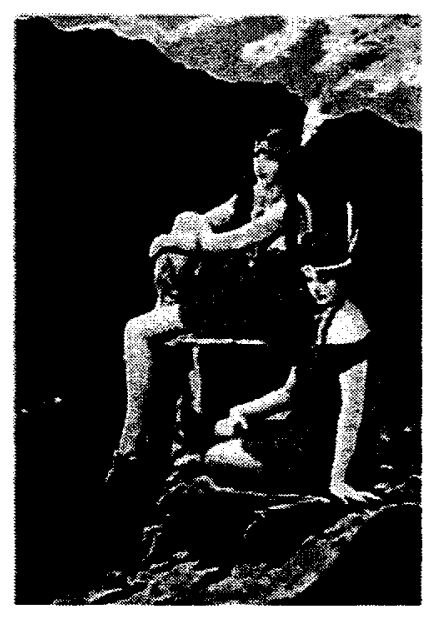


(Figure 42) Shelley Niro, Mohawks in Beehives 1,black and white hand tinted photograph, $20 \times 25 \mathrm{~cm}, 1991$; rpt. in Allan J. Ryan, The Trickster Shift: Humour and Irony in Contemporary Native Art (Vancouver: UBC Press, 1999),70.

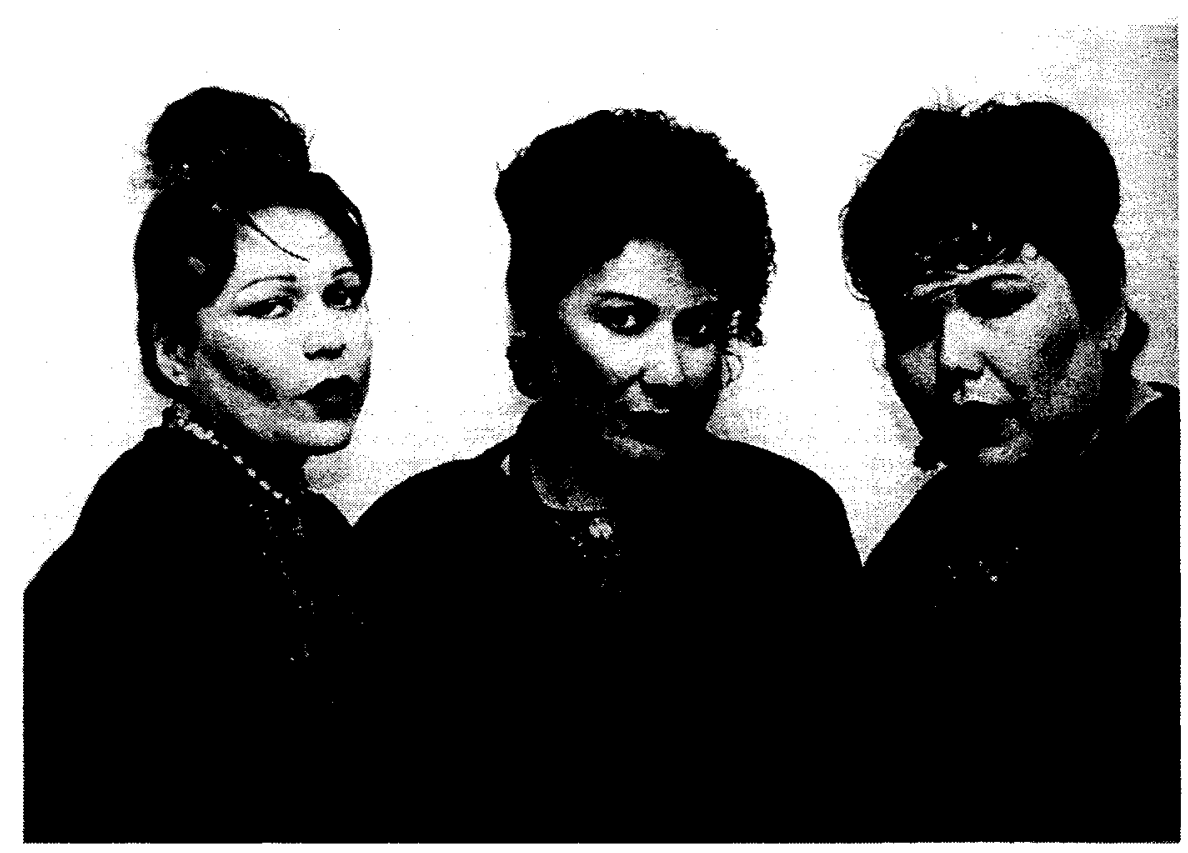

(Figure 43) Jim Logan, Venus Myth, multi-media, 1993; rpt. in Allan J. Ryan, The Trickster Shift Humour and Irony in Contemporary Native Art (Vancouver: UBC Press, 1999), 81.

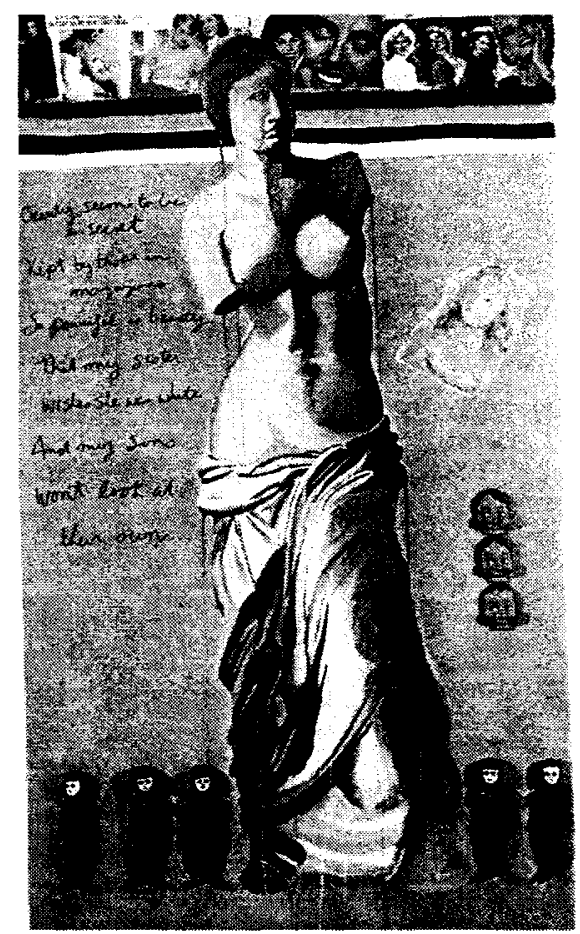


(Figure 44) Lori Blondeau, Some Kinda Princess. Photograph, 1999; rpt. in Lynne Bell, "Scandalous Personas, Difficult Knowledge, Restless Images." Canadian Art vol. 21 no. 4 (Winter 2004): 48.
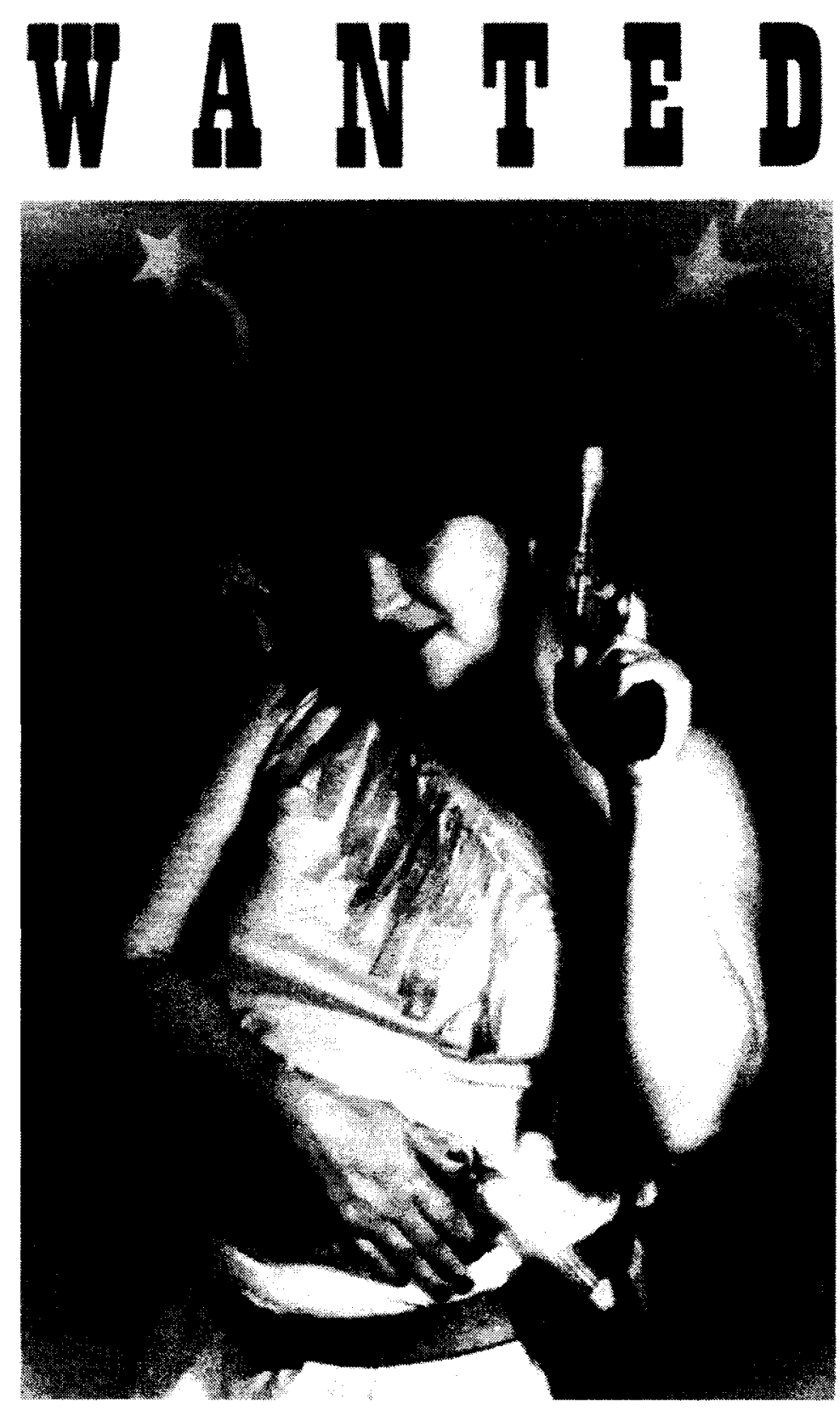
(Figure 45) Image of Walt Disney's 1995 Pocahontas

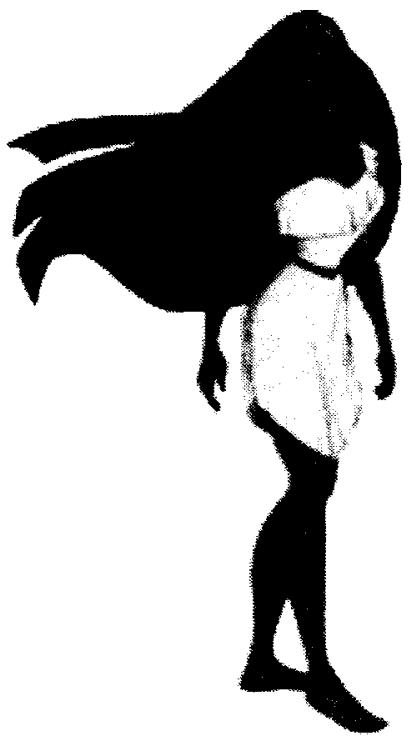

(Figure 46) Lori Blondeau, Betty Daybird: Belle Rogue's Collection's Runway Interventions, Performance still, 2000. Regina: Neutral Ground Gallery; in http://www.neutralground.sk.ca//assets2004/movies/br excerpt 4.mov.

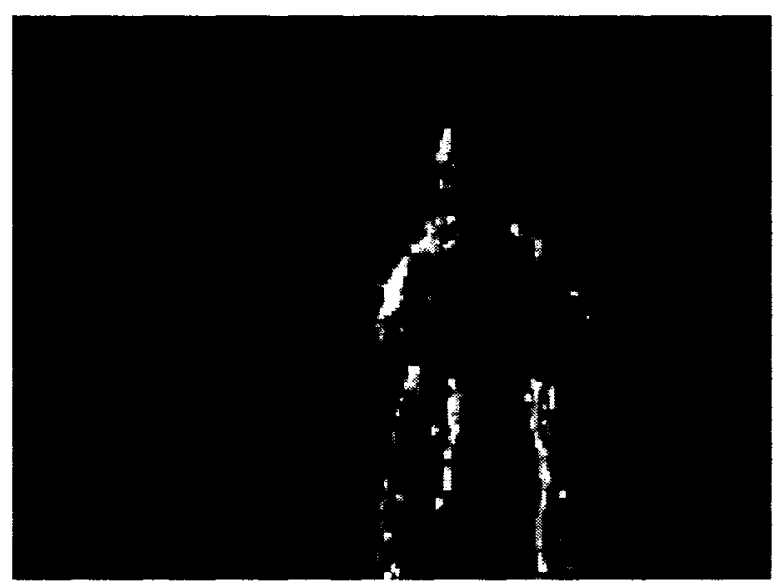


(Figure 47) Lori Blondeau, Betty Daybird, Performance still, 2000; rpt. in Amy Sara. Performing Body Politics: Belle Rogue's Collection's Runway Interventions (Regina: Neutral Ground Gallery, 2000), 45.

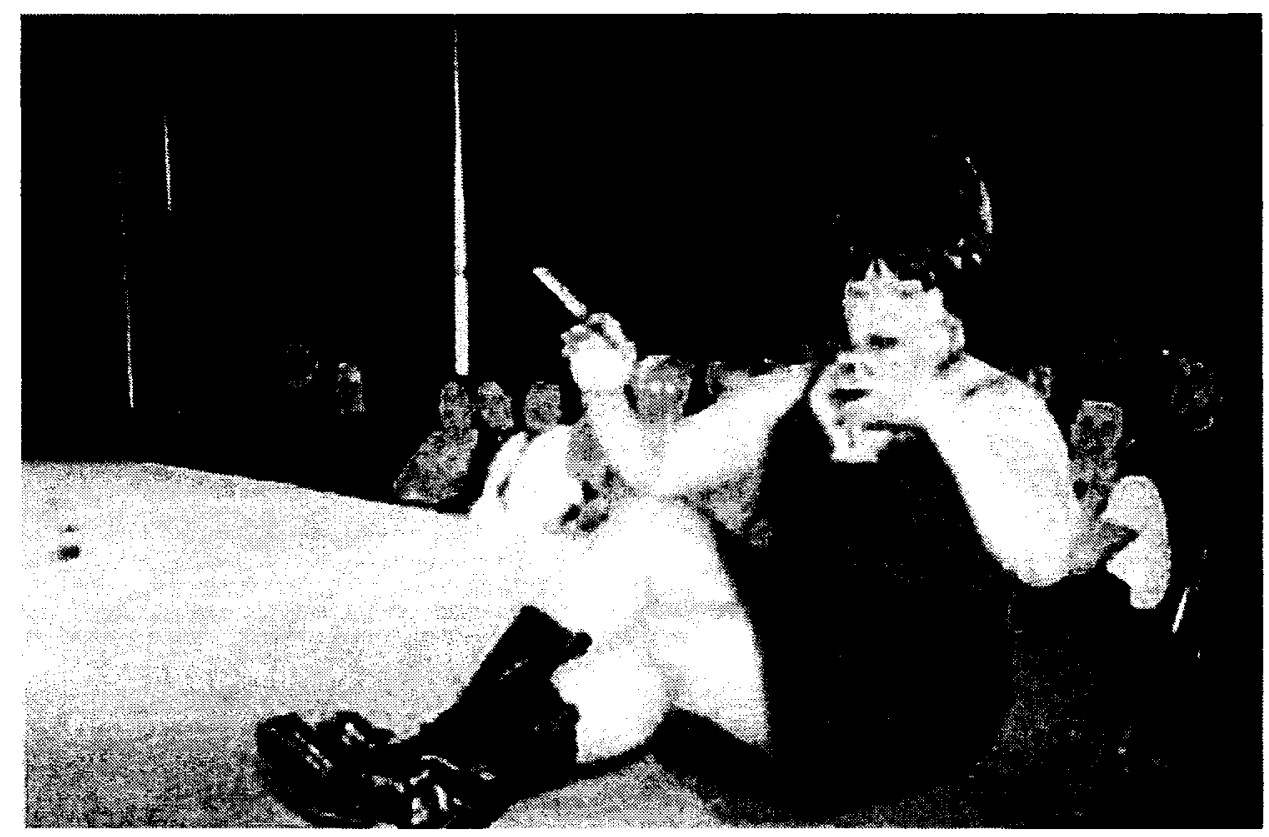

(Figure 48) Lori Blondeau, Betty Daybird: Belle Rogue's Collection's Runway Interventions, Performance still, 2000. Regina: Neutral Ground Gallery; in http://www.neutralground.sk.ca//assets2004/movies/br excerpt 4.mov

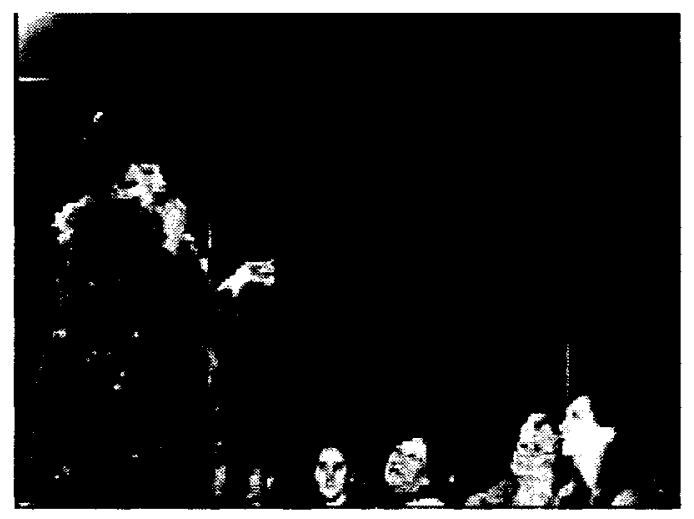


(Figure 49) Lori Blondeau, Betty Daybird: Belle Rogue's Collection's Runway Interventions, Performance still, 2000. Regina: Neutral Ground Gallery; in http://www.neutralground.sk.ca//assets2004/movies/br excerpt 4.mov

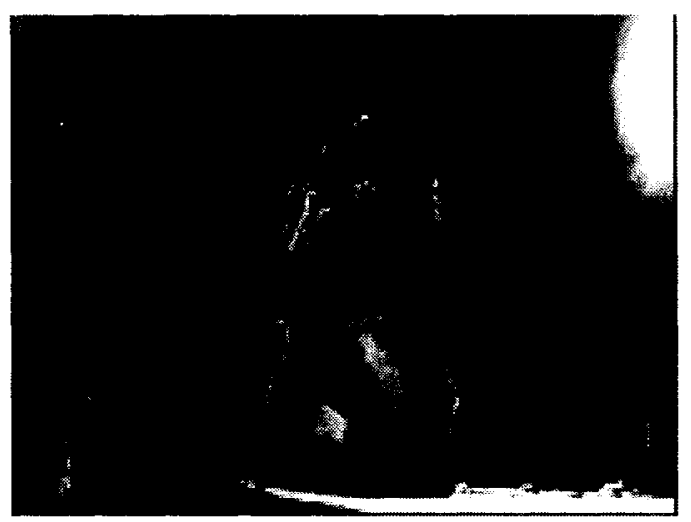

(Figure 50) Lori Blondeau, Betty Daybird: Belle Rogue's Collection's Runaway Interventions, Performance still, 2000. Regina: Neutral Ground Gallery; in http://www.neutralground.sk.ca//assets2004/movies/br excerpt 4.mov

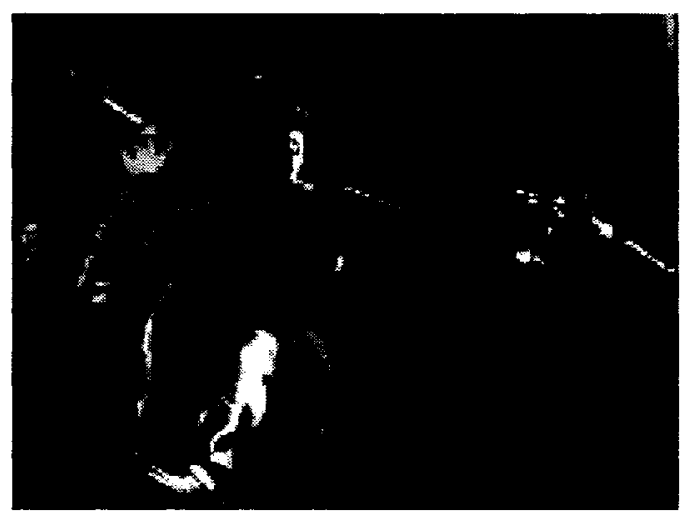


(Figure 51) Lori Blondeau, Betty Daybird: Belle Rogue's Collection's Runway Interventions, Performance still, 2000. Regina: Neutral Ground Gallery; in http://www.neutralground.sk.ca//assets2004/movies/br excerpt 4.mov

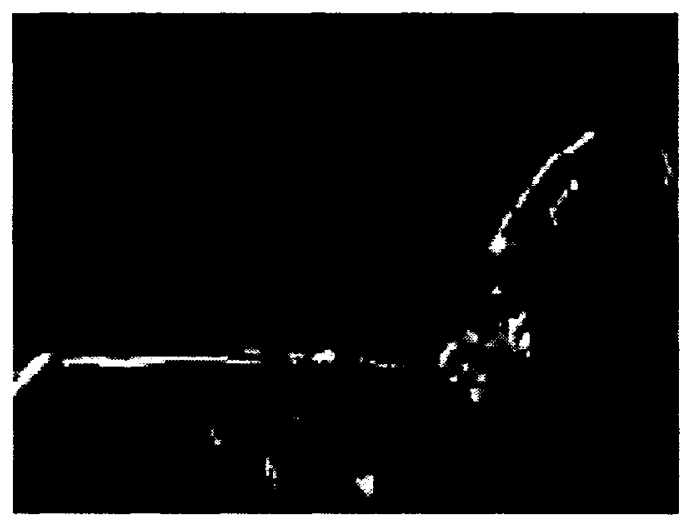

(Figure 52) Lori Blondeau, Betty Daybird: Belle Rogue's Collection's Runway Interventions, Performance still, 2000. Regina: Neutral Ground Gallery; in http://www.neutralground.sk.ca//assets2004/movies/br excerpt 4.mov

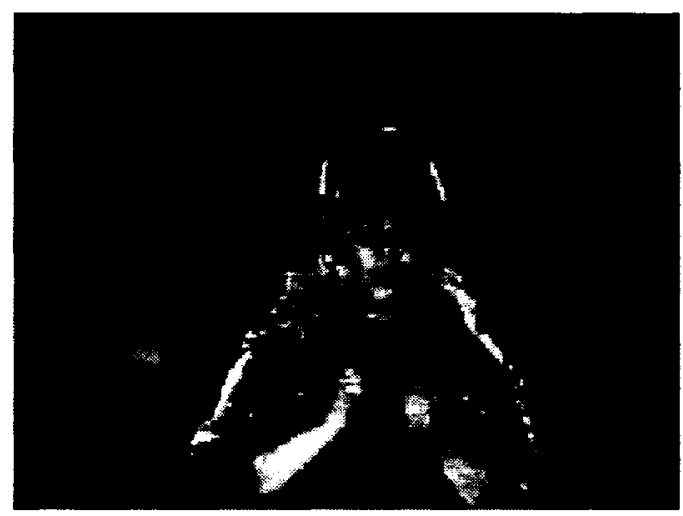


(Figure 53) Lori Blondeau, Betty Daybird: Belle Rogue's Collection's Runway Interventions, Performance still, 2000. Regina: Neutral Ground Gallery; in http://www.neutralground.sk.ca//assets2004/movies/br_excerpt 4.mov

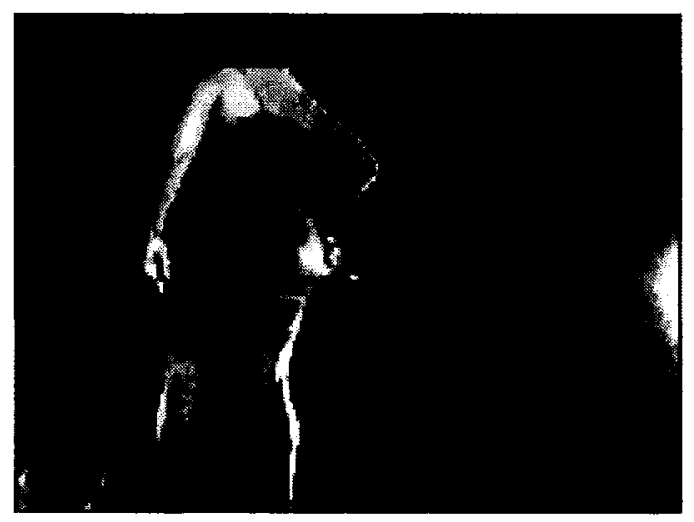

(Figure 54) Lori Blondeau, Betty Daybird: Belle Rogue's Collection's Runway Interventions, Performance still, 2000. Regina: Neutral Ground Gallery; in http://www.neutralground.sk.ca//assets $2004 /$ movies/br excerpt 4.mov

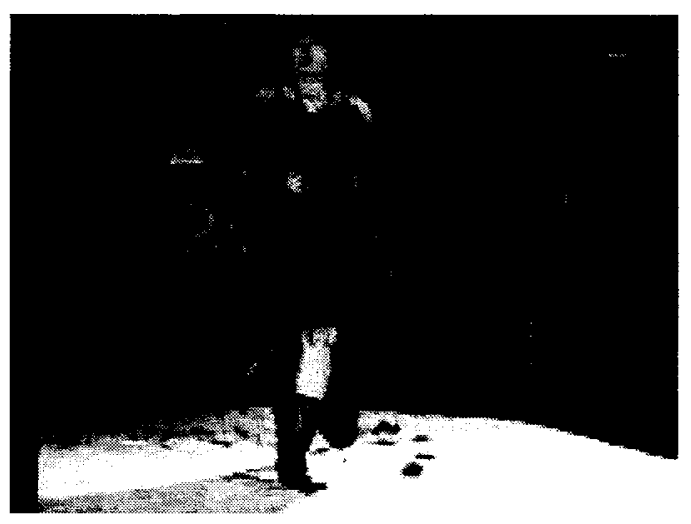


(Figure 55) Lori Blondeau, Betty Daybird. Photograph. In Belle Rogue Fashion Show performance; rpt. in Amy Sara Carroll, Performing Body Politics: Bell Rogue's Collection's Runway Interventions, (Regina: Neutral Ground Gallery, 2000), 44.

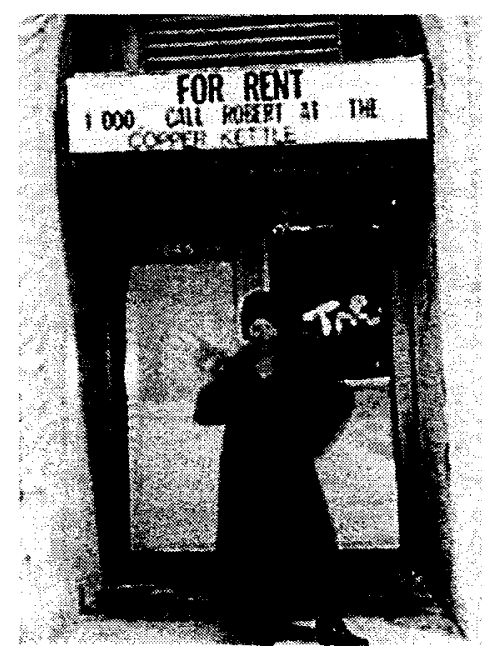

(Figure 56) Lori Blondeau, Belle Sauvage, Six Colour Silkscreen print. 22" x 30". 2002; in http://www.banffcentre.ca/va/art editions/blondeau l.asp

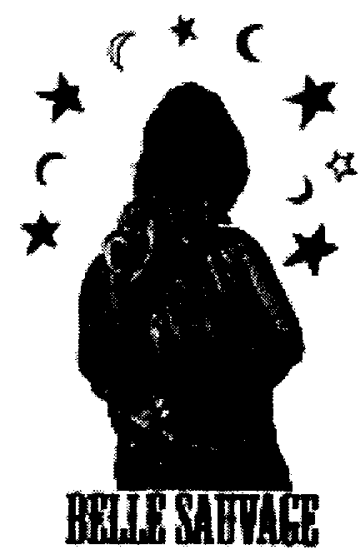


(Figure 57)Lori Blondeau. Belle Sauvage. Performance still; rpt. in Lynne Bell, "Scandalous Personas, Difficult Knowledge, Restless Images," Canadian Art vol. 21 no. 4 (Winter 2004): 51.

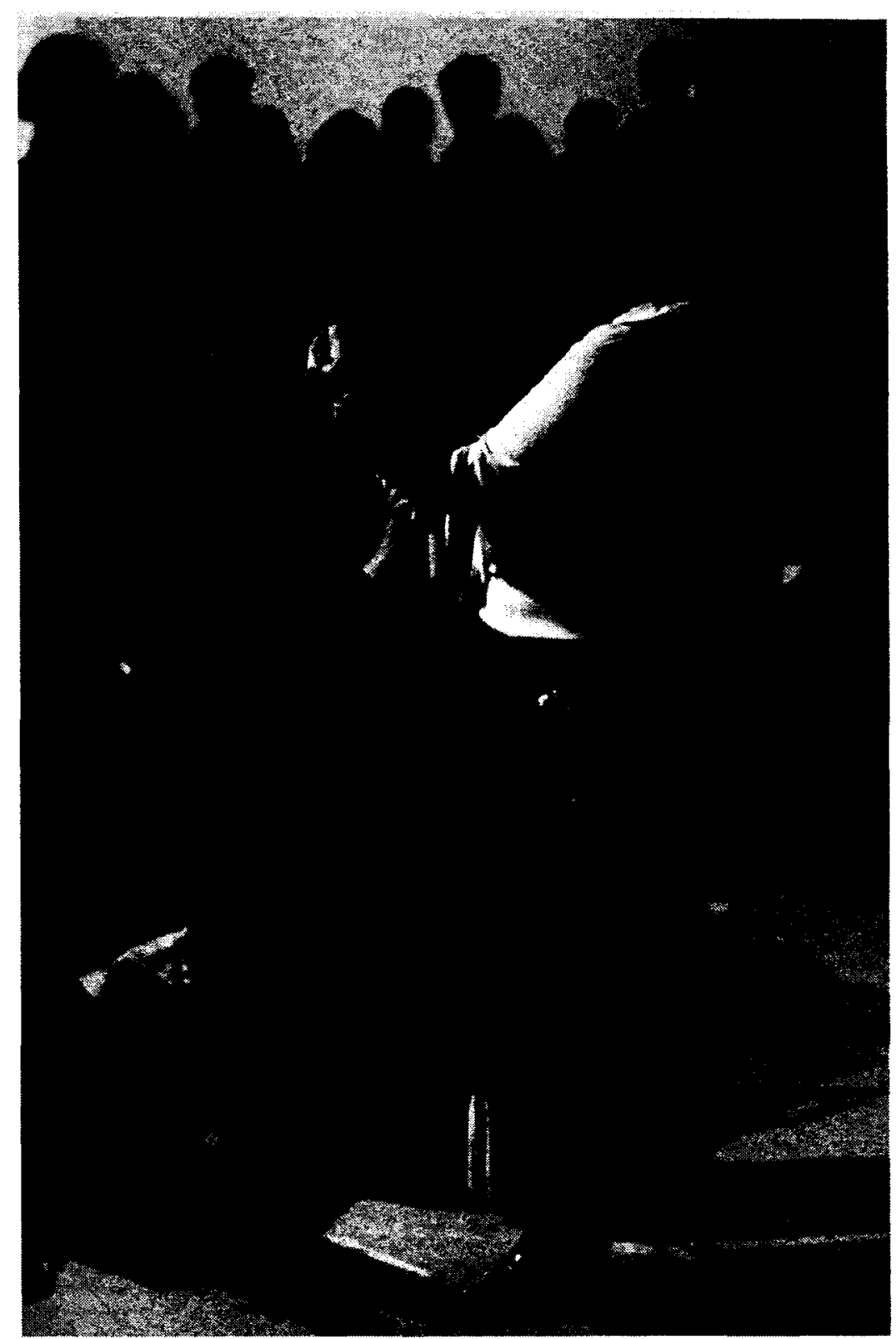


(Figure 58) Lori Blondeau, Belle Sauvage, Photograph,1999; rpt in Lynne Bell, "Scandalous Personas, Difficult Knowledge, Restless Images." Canadian Art. vol. 21 no. 4 (Winter 2004): 48. (Left Image)

(Figure 59) Doris Day, Calamity Jane, 1953 Warner Brothers Film Production; rpt. in http://www.dorisdaytribute.com/movies-calamityjane.htm (Right Image)
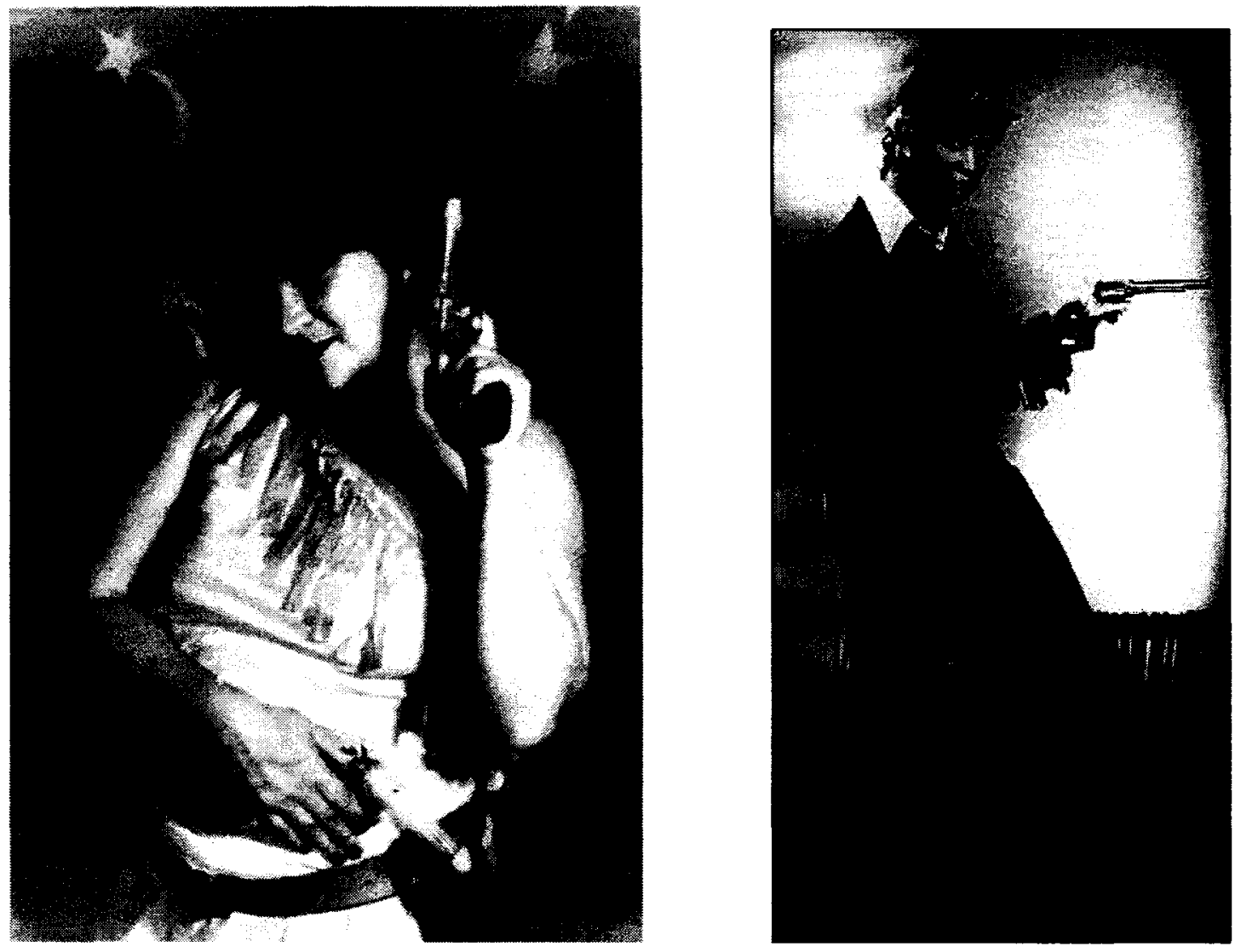
